Patricia Gon Corradini

\title{
Investigação de nanocatalisadores de platina-terras raras suportados em carbono para células a combustível de etanol direto
}

\section{Exemplar revisado}

O exemplar original encontra-se em acervo reservado na Biblioteca do IQSC-USP

Tese apresentada ao Instituto de Química de São Carlos da Universidade de São Paulo como parte dos requisitos para a obtenção do título de doutor em ciências.

Área de concentração: Físico-química

Orientadora: Prof. ․ㅡ Dr. ․ Joelma Perez

São Carlos, 
Autorizo a reprodução e divulgação total ou parcial deste trabalho, por qualquer meio convencional ou eletrônico, para fins de estudo e pesquisa, desde que citada a fonte.

\author{
Catalogação na publicação \\ Serviço de Biblioteca e Documentação \\ Instituto de Química de São Carlos
}


Gostaria de dedicar esse trabalho ao meu marido, Felipe de Almeida Silva Corradini e à minha mãe Sandra Maria Gon Corradini, que me incentivaram nessa trajetória e acreditaram mais em mim do que eu mesma. 


\section{AGRADECIMENTOS}

A Jeová Deus, pois "[...] fizeste os céus, sim, o céu dos céus e todo o seu exército, a terra e tudo o que nela há, os mares e tudo o que há neles" (Neemias 9:6). "Agradeçam a Jeová, pois Ele é bom; O seu amor leal dura para sempre" Salmo 136:1.

Ao meu amado marido Felipe de Almeida Silva Corradini, por todo carinho, compreensão, paciência e por sempre me motivar a prosseguir, apesar das dificuldades.

Aos meus pais, Sandra Maria Gon Corradini e Edmar Gatti Corradini, e à minha irmã, Larissa Gon Corradini, que mesmo com a distância, se fizeram presentes, por me incentivar e apoiar nas escolhas que fiz.

À Professora Dr. a Joelma Perez, pela confiança, pela enorme compreensão e paciência durante os últimos 6 anos, pela disposição em ajudar e pela orientação nesse trabalho.

Aos Professores Dr. Boniface Kokoh e Dr. Têko W. Napporn, pela supervisão no estágio no Institut de Chimie des Milieux et Matériaux de Poitiers, Université de Poitiers na França.

Aos membros da banca examinadora, Dr. Denis Ricardo Martins de Godoi, Dr. a Lúcia Helena Mascaro Sales, Dr. Marcos Lanza e Dr. ${ }^{\text {a }}$ Margarida Juri Saeki, por aceitarem o convite de participar na comissão avaliadora deste trabalho.

Ao Valdecir Paganni, pela paciência, disposição em ensinar, por toda a colaboração no grupo de eletroquímica e na realização deste trabalho.

À Nathalia Abe Santos, pela grande colaboração nesse trabalho, pela paciência e por todo o suporte, pela companhia nas viagens a congressos e especialmente nas "aventuras gastronômicas" em São Carlos.

À minha grande amiga-irmã Milena Helmer Lauer, pelo carinho e agradável amizade.

À querida Melissa Cristina Espírito Santo, pela amizade e pela enorme disposição em ajudar em todos os momentos.

Às amigas incríveis de longa data: Bruna Gomes, Fabíola Wantil e Kizye Tavares, que moram no meu coração e contribuíram em muito no que sou.

A todos os colegas do laboratório de eletroquímica, tanto pelas discussões e incentivo, em especial: Adriana Queiroz, Bruno Alarcon, Elenice Araújo, Graziela Ferreira, Guilherme Saglietti, Jéssica Nogueira, Luiza Nunes, Martin Hernandez, Nickson Perini, Otávio Beruski, Rapher Santos, Seiti Venturini, Thairo Araújo, Thiago Mariano e Wanderson Silva. 
Ao Instituto de Química de São Carlos (IQSC), pelo espaço físico e auxílios fornecidos.

Aos técnicos do IQSC, em especial: Gabriel Christiano da Silva, Jonas Ferreira e Mauro Fernandes, do grupo de Eletroquímica; Márcio de Paula, pelas medidas de espectroscopia de raios X por energia dispersiva; Marcelo Calegaro, pela realização das medidas de difração de raios X; e ao Douglas Waichi Miwa pelas microscopias eletrônicas de transmissão.

Ao Laboratório Nacional de Luz Síncrotron (LNLS), pela realização das medidas de espectroscopia de absorção de raios X (Projeto XAFS1-18790, XAFS2-15144).

Ao Laboratório Nacional de Nanotecnologia (LNNano) pela realização das medidas de espectroscopia de fotoelétrons excitados por raios X (Projeto XPS-18223, XPS-20257).

Às agências de fomento CAPES e CNPq, pelos financiamentos ao laboratório.

À Fundação de Amparo à Pesquisa do Estado de São Paulo (FAPESP), por financiar minha bolsa de estudos no Brasil (Projeto 2012/12189-8) e no exterior (Projeto BEPE 2015/13218-0). 
"Tudo isso eu examinei com sabedoria, e eu disse: "Vou me tornar sábio." [....] Eu voltei meu coração para conhecer, investigar e procurar a sabedoria e a razão por trás das coisas [....] "Veja, isto é o que eu descobri", diz o congregante. "Investiguei uma coisa após outra para tirar uma conclusão, mas, o que busquei continuamente, não encontrei..."

- Eclesiastes 7: 23-25, 27-28. 


\section{RESUMO}

Sistemas de células a combustível alimentadas por etanol (DEFC - Direct Ethanol Fuel Cell) são vistos como candidatos para ajudar preencher a lacuna entre a demanda e oferta de energia elétrica. Entretanto, as DEFC ainda não apresentam desempenho tão elevado, que incentivem a comercialização. Um dos principais esforços para elevar o desempenho é obter catalisadores anódicos mais eletroativos e estáveis para reação de oxidação de etanol (ROE). Neste trabalho, visou-se obter e avaliar catalisadores Pt-Sn-Terras raras ( $\mathrm{La}, \mathrm{Ce}, \operatorname{Pr}$ e Eu) para ROE. Os catalisadores foram sintetizados a partir de algumas modificações do método do poliol; caracterizados fisicamente, por técnicas de EDX, ICP, ATG, DRX, TEM, XPS e XAS; e caracterizados eletroquimicamente em células de três eletrodos e em células unitárias. O método de síntese promoveu tamanhos médios de partícula entre 3,0 a 4,5 nm para catalisadores PtSnTR/C (TR: La, Ce, Pr e Eu), um dos menores valores reportados para esse tipo de material. Por DRX, foi possível verificar que a síntese promoveu incorporação de estanho na platina em forma de liga, entre 1 a $27 \%$, dependendo da composição do catalisador. Por XPS, confirmouse a presença de Pt e Sn metálicos, óxidos de estanho e de platina, e terras raras em forma de óxidos mistos. Por XAS, observou-se que os metais adicionados promoveram um preenchimento da banda $5 d$ da Pt. As densidades de corrente obtidas por cronoamperometrias na ROE dos materiais ternários PtSnTR/C (TR: La, Ce e Eu) 75:20:05 são 20-24 vezes maiores do que apresentada pela $\mathrm{Pt} / \mathrm{C}$, e 8 -40\% maiores do que $\mathrm{PtSn} / \mathrm{C}$ 60:40. Os testes de envelhecimento acelerado indicaram que, mesmo com a alteração dos perfis voltamétricos, os catalisadores ternários apresentaram menores perdas na atividade que os catalisadores $\mathrm{Pt} / \mathrm{C}$ e PtSn/C. Ao caracterizar os produtos da oxidação dos catalisadores por FTIR e HPLC, observouse que os produtos majoritários foram acetaldeído e ácido acético; e apenas uma pequena formação de $\mathrm{CO}_{2}$ foi detectada. A adição de terras raras, até 10 at\%, aumentou a atividade eletrocatalítica dos catalisadores $\mathrm{Pt} / \mathrm{C}$ e $\mathrm{PtSn} / \mathrm{C}$ provavelmente por disponibilizar espécies oxidadas a baixos potenciais, favorecendo a oxidação de intermediários da ROE, e contribuiu para a estabilidade dos catalisadores PtSn/C.

Palavras chaves: célula a combustível, oxidação de etanol, platina, estanho, terras raras. 
ABSTRACT

Direct ethanol fuel cell (DEFC) systems are seen as candidates to fill the gap between demand and supply of electric electricity. However, the DEFC's performance does not encourage its large commercialization yet. One of the main efforts to increase the performance is obtaining more electroactive and stable anodic catalysts for the ethanol oxidation reaction (EOR). In this work, Pt-Sn-Rare Earth catalysts ( $\mathrm{La}, \mathrm{Ce}, \mathrm{Pr}$, and Eu) were obtained and evaluated for EOR. The catalysts were synthesized using polyol method with some modifications; physically characterized by XDS, ICP, TGA, XRD, TEM, XPS, and XAS techniques; the electrochemical characterization involved tests on three electrodes cell and on unit cell systems. The synthesis method promoted mean particle sizes between 3.0 and $4.5 \mathrm{~nm}$ for PtSnRE/C catalysts (RE: La, Ce, Pr, and Eu), one of the smallest values reported for this type of material. By XRD, it was observed some degree of Pt-Sn alloy, between 1-27\%, depending on the catalyst composition. The presence of $\mathrm{Pt}$ and $\mathrm{Sn}$ metallic, tin and platinum oxides, and rare earths in the form of mixed oxides were confirmed by XPS. The added metals promoted a fill of the Pt $5 d$ band, as observed by XAS. The current densities at EOR chronoamperometry measures of the 75:20:05 PtSnRE/C (RE: La, Ce, and Eu) materials are 20-24 times than $\mathrm{Pt} / \mathrm{C}$, and $8 \%-40 \%$ higher than $\mathrm{PtSn} / \mathrm{C} 60: 40$. The accelerated aging tests indicated that, even with voltammetric profiles changes, the ternary catalysts had lower losses in the activity than the Pt/C and PtSn/C catalysts. By FTIR and HPLC, it was observed that the main products were acetaldehyde and acetic acid; and small concentration of $\mathrm{CO}_{2}$ was detected. The low addition of rare earths (until 10 at\%) increased the electrocatalytic activity of $\mathrm{Pt} / \mathrm{C}$ and $\mathrm{PtSn} / \mathrm{C}$ catalysts probably because they promoted more oxidized species at low potentials, favoring the intermediates oxidation of the EOR, and contributed to $\mathrm{PtSn} / \mathrm{C}$ catalysts stability.

Keywords: fuel cell, ethanol oxidation, platinum, tin, rare earths. 


\section{LISTA DE FIGURAS}

Figura 2.1 - Representação esquemática da reação de oxidação de etanol em meio ácido.25

Figura 4.1 - Esquematização do procedimento de envelhecimento acelerado.

Figura 4.2 - Representação da célula eletroquímica utilizada para medidas de FTIR in situ.40

Figura 4.3 - Aparato experimental para coletar os produtos da reação de oxidação de etanol na saída da célula unitária, para análise em HPLC.

Figura 5.1 - Representação esquemática da formação de nanopartículas de Pt-Sn-TR, da redução de precursores de acetilacetonado de Pt e Terras Raras (TR) e acetato de Sn.

Figura 5.2-(a) Decomposição térmica e (b) diferencial das curvas térmicas dos catalisadores $\mathrm{Pt} / \mathrm{C}, \mathrm{PtSn} / \mathrm{C}$ e PtSnEu/C sintetizados por poliol. $\Delta \mathrm{T}=5{ }^{\circ} \mathrm{C} \mathrm{min}^{-1}$; fluxo de gás de $100 \mathrm{~mL} \mathrm{~min}^{-1}$

Figura 5.3 - Difratogramas dos eletrocatalisadores de $\mathrm{Pt} / \mathrm{C}, \mathrm{PtSn} / \mathrm{C}$ 60:40 e PtSnEu/C sintetizados pelo método do poliol. No destaque, a linha tracejada refere-se ao plano Pt (220) em estrutura cfc.

Figura 5.4 - Espectros amplos de XPS dos catalisadores $\mathrm{Pt} / \mathrm{C}, \mathrm{PtSn} / \mathrm{C}$ e $\mathrm{PtSnEu} / \mathrm{C}$ sintetizados por poliol.

Figura 5.5 - Espectros de XPS para Pt 4f, Sn 3de Eu $3 d$ para os catalisadores $\mathrm{Pt} / \mathrm{C}, \mathrm{PtSn} / \mathrm{C}$ 60:40 e PtSnEu/C sintetizados por poliol.

Figura 5.6 - Espectros de XANES in situ na borda $L_{3}$ da Pt para os catalisadores Pt/C Etek, $\mathrm{PtSn} / \mathrm{C}$ Etek 75:25 e PtSnEu/C, em (a) $500 \mathrm{mV}$ e (b) $900 \mathrm{mV}$.

Figura 5.7 - Voltamogramas dos catalisadores $\mathrm{Pt} / \mathrm{C}, \mathrm{PtSn} / \mathrm{C}$ e trimetálicos $\mathrm{PtSnEu} / \mathrm{C}$ sintetizados por poliol em $0,5 \mathrm{~mol} \mathrm{~L}^{-1} \mathrm{de}_{2} \mathrm{SO}_{4}$ a $20 \mathrm{mV} \mathrm{s}^{-1}$, em atmosfera de argônio.

Figura 5.8 - (a) Curvas obtidas da subtração do $1^{\circ}$ ciclo de stripping de CO por uma linha de base para os catalisadores de Pt/C, PtSn/C 60:40 e PtSnEu/C sintetizados por poliol. v: $5 \mathrm{mV} \mathrm{s}^{-1}$, atmosfera de argônio. (a') Ampliação da figura (a) em menores correntes, sem a curva da Pt/C.

Figura 5.9 - (a) Voltamogramas lineares dos catalisadores de $\mathrm{Pt} / \mathrm{C}, \mathrm{PtSn} / \mathrm{C}$ e $\mathrm{PtSnEu} / \mathrm{C}$ sintetizados por poliol e (b) as derivadas da corrente em função do potencial em $0,5 \mathrm{~mol} \mathrm{~L}^{-1}$ de $\mathrm{H}_{2} \mathrm{SO}_{4}$ e $1,0 \mathrm{~mol} \mathrm{~L}^{-1}$ de $\mathrm{C}_{2} \mathrm{H}_{5} \mathrm{OH}$ a $1 \mathrm{mV} \mathrm{s}^{-1}$ em atmosfera de argônio. Normalização por área ativa.

Figura 5.10 - (a) Cronoamperogramas dos catalisadores Pt/C, PtSn/C 60:40 e PtSnEu/C em $0,5 \mathrm{~mol} \mathrm{~L}^{-1}$ de $\mathrm{H}_{2} \mathrm{SO}_{4}$ e $1,0 \mathrm{~mol} \mathrm{~L}^{-1}$ de $\mathrm{C}_{2} \mathrm{H}_{5} \mathrm{OH}$ a $0,600 \mathrm{~V}$, em atmosfera de argônio. Representação com normalização pela área ativa. (b) Densidade de corrente em 2800 segundos obtidas da cronoamperometria em $0,600 \mathrm{~V}$, normalizado por área ativa e por massa de platina.

Figura 5.11 - Representação esquemática de alguns processos relacionados a mecanismos de degradação de catalisadores nanoparticulados de $\mathrm{Pt}$ suportados em carbono. 
Figura 5.12 - Diagrama de Pourbaix do európio.

Figura 5.13 - Comparação dos voltamogramas antes (linha tracejada) e após (linha cheia) os testes de envelhecimento entre (a) 0,3-0,8 V e (b) 0,5-1,0 V dos catalisadores $\mathrm{Pt} / \mathrm{C}, \mathrm{PtSn} / \mathrm{C}$ e PtSnEu/C sintetizados por poliol. v: $20 \mathrm{mV} \mathrm{s}^{-1}$, atmosfera de argônio, em $0,5 \mathrm{~mol} \mathrm{~L}^{-1}$ de $\mathrm{H}_{2} \mathrm{SO}_{4}$. 66

Figura 5.14 - Variação da área ativa determinada por hidrogênio pelo número de ciclos dos catalisadores $\mathrm{Pt} / \mathrm{C}, \mathrm{PtSn} / \mathrm{C}$ e $\mathrm{PtSnEu} / \mathrm{C}$ sintetizados por poliol: envelhecimento entre (a) 0,3-0,8 $\mathrm{V}$ e (b) 0,5-1,0 V.

Figura 5.15 - Curvas obtidas da subtração do $1^{\circ}$ ciclo do stripping de CO por uma linha de base para os catalisadores $\mathrm{Pt} / \mathrm{C}, \mathrm{PtSn} / \mathrm{C}$ 60:40 e $\mathrm{PtSnEu} / \mathrm{C}$ sintetizados por poliol (a) antes do envelhecimento, (b) após ciclagem entre 0,3-0,8 $\mathrm{V}$ e (c) após ciclagem entre 0,5-1,0 V. v: $5 \mathrm{mV} \mathrm{s}^{-1}$, atmosfera de argônio. Linhas tracejadas representam curvas do respectivo material não envelhecido.

Figura 5.16 - Voltamogramas lineares dos catalisadores $\mathrm{Pt} / \mathrm{C}, \mathrm{PtSn} / \mathrm{C}$ e $\mathrm{PtSnEu} / \mathrm{C}$ em $0,5 \mathrm{~mol} \mathrm{~L}^{-1}$ de $\mathrm{H}_{2} \mathrm{SO}_{4}$ e $1,0 \mathrm{~mol} \mathrm{~L}^{-1}$ de $\mathrm{C}_{2} \mathrm{H}_{5} \mathrm{OH}$ a $1 \mathrm{mV} \mathrm{s}^{-1}$ após teste de estabilidade, envelhecidos entre (a) 0,3-0,8 V e entre (b) 0,5-1,0 V. Curvas das densidades de corrente derivadas em função do potencial, envelhecidos entre (c) 0,3-0,8 V e (d) 0,5-1,0 V. Normalização por área ativa. Linhas tracejadas representam curvas do respectivo material não envelhecido. 70

Figura 5.17 - Cronoamperogramas dos catalisadores Pt/C, PtSn/C 60:40 e PtSnEu/C sintetizados por poliol, em $0,5 \mathrm{~mol} \mathrm{~L}^{-1}$ de $\mathrm{H}_{2} \mathrm{SO}_{4}$ e $1,0 \mathrm{~mol} \mathrm{~L}^{-1}$ de $\mathrm{C}_{2} \mathrm{H}_{5} \mathrm{OH}$ em 0,600 V, após teste de envelhecimento, entre (a) 0,3-0,8 V e (b) 0,5-1,0 V em atmosfera de argônio. Normalização pela área ativa. 71

Figura 5.18 - Densidades de correntes no tempo de 2800 segundos nas medidas de cronoamperometria para os materiais de $\mathrm{Pt} / \mathrm{C}, \mathrm{PtSn} / \mathrm{C}$ e $\mathrm{PtSnEu} / \mathrm{C}$ antes do envelhecimento (azul), após ciclagem 0,3-0,8 V (laranja) e após 0,5-1,0 V. (cinza). Normalização por área ativa. 72

Figura 5.19 - Espectros de FTIR obtidos de eletrodos (a) Pt/C; (b) PtSn/C 60:40; (c) PtSnEu/C 75:20:05; (d) PtSnEu/C 65:25:10; e (e) PtSnEu/C 50:30:20 obtidos em $0,5 \mathrm{~mol} \mathrm{~L}^{-1}$ de $\mathrm{H}_{2} \mathrm{SO}_{4}$ e $0,5 \mathrm{~mol} \mathrm{~L}^{-1}$ de etanol. A janela utilizada foi $\mathrm{ZnSe}$. $\mathrm{O}$ espectro de referência foi coletado em $0,05 \mathrm{~V}$ vs. ERH e os espectros das amostras foram coletados após aplicação dos potenciais em sentido positivo (variação de 0,1 V entre espectros), com o início em 0,2 V. O potencial de 0,6 V está destacado em azul. 74

Figura 5.20 - Ilustração esquemática da eletro-oxidação de etanol na superfície bimetálica de catalisadores $\mathrm{PtSn} / \mathrm{C}$. 77

Figura 5.21 - (a) Voltamogramas a $1 \mathrm{mV} \mathrm{s}^{-1}$ e (b) cronoamperogramas em 0,600V para ROE dos catalisadores $\mathrm{Pt} / \mathrm{C}, \mathrm{PtSn} / \mathrm{C} 60: 40$ e $\mathrm{PtSnEu} / \mathrm{C}$ a $90^{\circ} \mathrm{C}$, solução de etanol $1 \mathrm{~mol} \mathrm{~L}^{-1}$. Densidades de corrente normalizadas pela área geométrica. Ânodo: $1 \mathrm{mg}_{\mathrm{Pt}} \mathrm{cm}^{-2}$. Cátodo: $30 \% \mathrm{Pt} / \mathrm{C}, 1 \mathrm{mg}_{\mathrm{Pt}} \mathrm{cm}^{-2}$. 79

Figura 5.22 - Voltamogramas lineares em PEMFC de etanol direto para os catalisadores $\mathrm{Pt} / \mathrm{C}, \mathrm{PtSn} / \mathrm{C}$ 60:40 e $\mathrm{PtSnEu} / \mathrm{C}$ a $90{ }^{\circ} \mathrm{C}$ e pressão 3 atm $\mathrm{O}_{2}$, solução de etanol $1 \mathrm{~mol} \mathrm{~L}^{-1}$. Ânodo: $1 \mathrm{mg}_{\mathrm{Pt}} \mathrm{cm}^{-2}$. Cátodo: $30 \% \mathrm{Pt} / \mathrm{C}, 1 \mathrm{mg}_{\mathrm{Pt}} \mathrm{cm}^{-2}$. 80 
Figura 5.23 - Curvas de densidade de potência e potencial em função da densidade de corrente em PEMFC de etanol direto dos catalisadores Pt/C, PtSn/C 60:40 e $\mathrm{PtSnEu} / \mathrm{C}$ a $90^{\circ} \mathrm{C}$ e pressão $3 \mathrm{~atm} \mathrm{O}_{2}$, solução de etanol $1 \mathrm{~mol} \mathrm{~L}^{-1}$. Ânodo: $1 \mathrm{mg}_{\mathrm{Pt}} \mathrm{cm}^{-2}$. Cátodo: $30 \% \mathrm{Pt} / \mathrm{C}, 1 \mathrm{mg}_{\mathrm{Pt}} \mathrm{cm}^{-2}$.

Figura 5.24 - Distribuição dos produtos quantificados por HPLC dos catalisadores de (a) $\mathrm{Pt} / \mathrm{C}$; (b) PtSn/C 60:40; (c) PtSnEu/C 75:20:05; (d) PtSnEu/C 65:25:10; e (e) PtSnEu/C 50:30:20 em $8 \mathrm{~mA} \mathrm{~cm}{ }^{-2}, 16 \mathrm{~mA} \mathrm{~cm}^{-2}$ e $30 \mathrm{~mA} \mathrm{~cm}^{-2}$ na configuração de célula completa; e em $0,5 \mathrm{~V}$ e $0,6 \mathrm{~V}$ na configuração de meia célula. 86

Figura 5.25 - Distribuição dos produtos quantificados por HPLC dos catalisadores de Pt/C, $\mathrm{PtSn} / \mathrm{C}$ 60:40 e PtSnEu/C na configuração de célula completa em (a) $8 \mathrm{~mA} \mathrm{~cm}^{-2}$, (b) $16 \mathrm{~mA} \mathrm{~cm}^{-2}$, (c) $30 \mathrm{~mA} \mathrm{~cm}^{-2}$ e em meia célula a (d) $0,5 \mathrm{~V}$ e (e) $0,6 \mathrm{~V}$.

Figura 6.1 - Representação esquemática da formas possíveis dos catalisadores de $\mathrm{PtSnTR/C}$, a partir do método do poliol. 90

Figura 6.2 - Decomposição térmica (a) e diferencial das curvas térmicas (b) dos catalisadores Pt/C, PtSn/C e PtSnTR/C (TR=La, Ce, Pr e Eu) sintetizados por poliol. $\Delta \mathrm{T}=5^{\circ} \mathrm{C} \mathrm{min}^{-1}$; fluxo de gás de $100 \mathrm{~mL} \mathrm{~min}^{-1}$.

Figura 6.3 - Micrografia eletrônica de transmissão dos catalisadores (a) Pt/C; (b) PtSn/C 60:40; (c) PtSnLa/C 75:20:05; (d) PtSnCe/C 75:20:05; (e) PtSnPr 75:20:05 e (f) PtSnEu/C 75:20:05 e respectivos histogramas de distribuição de tamanho das partículas.

Figura 6.4 - Difratogramas dos materiais PtSnTR/C (TR=La, Ce, Pr) 75:20:05 sintetizados pelo método poliol. Os dados de $\mathrm{Pt} / \mathrm{C}$, PtSn/C 60:40 e PtSnEu/C 75:20:05 foram acrescentados para comparação. Detalhe na região próxima ao plano $\mathrm{Pt}$ (220) em estrutura cfc.

Figura 6.5 - Espectros de XPS dos catalisadores PtSnTR/C (TR: La, Ce, Pr) sintetizados por poliol. Os dados de $\mathrm{Pt} / \mathrm{C}$ e $\mathrm{PtSn} / \mathrm{C}$ 60:40 foram reapresentados para comparação.

Figura 6.6 - Espectros de XPS para Pt 4f, Sn 3d, La 3d, Ce 3d e Pr 3d para os catalisadores $\mathrm{Pt} / \mathrm{C}, \mathrm{PtSn} / \mathrm{C}$ 60:40 e PtSnTR/C (TR: La,Ce e Pr) 75:20:05 sintetizados por poliol. 100

Figura 6.7 - Espectros de XANES in situ na borda $L_{3}$ da Pt para os catalisadores Pt/C Etek, $\mathrm{PtSn} / \mathrm{C}$ Etek 75:25 e PtSnTR/C (TR:La, Ce, Pr e Eu) 75:20:05, em (a) 500 mV e (b) $900 \mathrm{mV}$. 104

Figura 6.8 - Voltametria cíclica dos catalisadores Pt/C, PtSn/C 60:40 e PtSnTR/C (TR: La, $\mathrm{Ce}, \operatorname{Pr}$ e Eu) 75:20:05 em meio ácido $\left(0,5 \mathrm{~mol} \mathrm{~L}^{-1} \mathrm{H}_{2} \mathrm{SO}_{4}\right)$. Atmosfera de argônio, v: $20 \mathrm{mV} \mathrm{s}^{-1}$. 105

Figura 6.9 - (a) Primeiro ciclo obtido por stripping de CO, subtraído por uma linha de base, dos catalisadores $\mathrm{Pt} / \mathrm{C}$, PtSn e PtSnTR/C (TR= La, Ce, Pr e Eu) sintetizados por poliol em $0,5 \mathrm{~mol} \mathrm{~L}^{-1}$ de $\mathrm{H}_{2} \mathrm{SO}_{4}$ a $20 \mathrm{mV} \mathrm{s}^{-1}$, em atmosfera de argônio, $\mathrm{v}=5$ $\mathrm{mV} \mathrm{s}^{-1}$. (a') Ampliação em menores correntes, sem a curva da $\mathrm{Pt} / \mathrm{C}$ 107 
Figura 6.10 - (a) Voltamogramas lineares dos catalisadores de Pt/C, PtSn/C 60:40 e dos catalisadores PtSnTR/C (TR: La, Ce, Pr e Eu) 75:20:05 sintetizados por poliol. (b) Derivadas da corrente em função do potencial. Meio: $0,5 \mathrm{~mol} \mathrm{~L}^{-1}$ de $\mathrm{H}_{2} \mathrm{SO}_{4}$ e $1,0 \mathrm{~mol} \mathrm{~L}^{-1}$ de $\mathrm{C}_{2} \mathrm{H}_{5} \mathrm{OH} ; \mathrm{v}=1 \mathrm{mV} \mathrm{s}^{-1}$, atmosfera de argônio. Normalização pela área ativa. 108

Figura 6.11 - (a) Cronoamperogramas dos catalisadores Pt/C, PtSn/C 60:40 e PtSnTR/C (TR: La, Ce, $\mathrm{Pr}$ e Eu) 75:20:05 em 0,5 $\mathrm{mol} \mathrm{L}^{-1}$ de $\mathrm{H}_{2} \mathrm{SO}_{4}$ e $1,0 \mathrm{~mol} \mathrm{~L}^{-1}$ de $\mathrm{C}_{2} \mathrm{H}_{5} \mathrm{OH}$ a $0,600 \mathrm{~V}$, em atmosfera de argônio. Representação com normalização pela área ativa.(b) Densidade de corrente em 2800 segundos obtidas da cronoamperometria em $0,600 \mathrm{~V}$, normalizada por área ativa e por massa de platina. 110

Figura 6.12 - Diagramas do Pourbaix para os metais terras (a) lantânio, (b) cério e (c) praseodímio. 111

Figura 6.13 - Comparação dos voltamogramas antes (linha tracejada) e após (linha cheia) os testes de envelhecimento entre (a) 0,3-0,8 V e (b) 0,5-1,0 V dos catalisadores $\mathrm{Pt} / \mathrm{C}, \mathrm{PtSn} / \mathrm{C}$ e PtSnTR/C (TR: La, Ce, Pr e Eu) 75:20:05 sintetizados por poliol. v: $20 \mathrm{mV} \mathrm{s}^{-1}$, atmosfera de argônio, em $0,5 \mathrm{~mol} \mathrm{~L}^{-1} \mathrm{de}$ $\mathrm{H}_{2} \mathrm{SO}_{4}$. 112

Figura 6.14 - Variação da área determinada por hidrogênio dos catalisadores $\mathrm{Pt} / \mathrm{C}, \mathrm{PtSn} / \mathrm{C}$ e PtSnTR/C (TR: La, Ce, Pr e Eu) sintetizados por poliol: envelhecimento entre (a) $0,3-0,8 \mathrm{~V}$ e (b) $0,5-1,0 \mathrm{~V}$. 113

Figura 6.15 - Curvas obtidas da subtração do $1^{\circ}$ ciclo do stripping de CO por uma linha de base para os catalisadores Pt/C, PtSn/C 60:40, PtSnTR/C (La, Ce, Pr e Eu) 75:25:05 (a) antes do envelhecimento, (b) após ciclagem entre 0,3-0,8 V e (c) após ciclagem entre 0,5-1,0 V. v: $5 \mathrm{mV} \mathrm{s}^{-1}$, atmosfera de argônio. Linhas tracejadas representam curvas do respectivo material não envelhecido. ..... 114

Figura 6.16 - Voltamogramas lineares dos catalisadores Pt/C, PtSn/C e PtSnTR/C (TR: La, Ce, $\operatorname{Pr}$ e Eu) 75:20:05 em 0,5 $\mathrm{mol} \mathrm{L}^{-1}$ de $\mathrm{H}_{2} \mathrm{SO}_{4}$ e 1,0 mol L-1 de etanol a $1 \mathrm{mV} \mathrm{s}^{-1}$ após teste de envelhecimento acelerado, ciclados entre (a) 0,3-0,8 V e (b) 0,5-1,0 V. Curvas das densidades de corrente derivadas em função do potencial, ciclados entre (c) 0,3-0,8 V e (d) 0,5-1,0 V. Normalização por área ativa. Linhas tracejadas representam curvas do respectivo material não envelhecido. 116

Figura 6.17 - Cronoamperogramas dos catalisadores Pt/C, PtSn/C 60:40 e PtSnTR/C (TR: $\mathrm{La}, \mathrm{Ce}$, Pr e Eu) 75:20:05 em 0,5 $\mathrm{mol} \mathrm{L}^{-1}$ de $\mathrm{H}_{2} \mathrm{SO}_{4}$ e $1,0 \mathrm{~mol} \mathrm{~L}^{-1}$ de $\mathrm{C}_{2} \mathrm{H}_{5} \mathrm{OH}$ em 0,600 V, após teste de envelhecimento, entre (a) 0,3-0,8 V e (b) 0,5-1,0 V. Atmosfera de argônio, normalização por área ativa. 117

Figura 6.18-Densidades de correntes no tempo de 2800 segundos nas medidas de cronoamperometria para os materiais de $\mathrm{Pt} / \mathrm{C}, \mathrm{PtSn} / \mathrm{C}$ 60:40 e PtSnTR/C (TR: $\mathrm{La}, \mathrm{Ce}, \mathrm{Pr}$ e Eu) 75:20:05 antes do envelhecimento (cinza escuro), após ciclagem 0,3-0,8 (cinza claro) e após 0,5 a 1,0 V. (laranja). Normalização por área ativa. 118

Figura 6.19 - Comparação das composições atômicas determinadas por EDX dos catalisadores (a) $\mathrm{PtSn} / \mathrm{C}$; (b) $\mathrm{PtSnCe} / \mathrm{C}$ e (c) $\mathrm{PtSnPr} / \mathrm{C}$, antes e após envelhecimento eletroquímico até $0,8 \mathrm{~V}$. 119 
Figura 6.20 - Espectros de FTIR obtidos para os catalisadores (a) Pt/C; (b) PtSn/C 60:40; (c) PtSnLa/C 75:20:05; (d) PtSnCe/C 75:20:05; (e) PtSnPr/C 75:20:05; e (f) PtSnEu/C 75:20:05 obtidos em 0,5 $\mathrm{mol} \mathrm{L}^{-1}$ de $\mathrm{H}_{2} \mathrm{SO}_{4}$ e $0,5 \mathrm{~mol} \mathrm{~L}^{-1}$ de etanol. A janela utilizada foi ZnSe. O espectro de referência foi coletado em 0,05 V vs $\mathrm{ERH}$ e os espectros das amostras foram coletados após aplicação dos potenciais em sentido positivo (variação de $0,1 \mathrm{~V}$ entre espectros), com 0 início em $0,2 \mathrm{~V}$. O potencial de $0,6 \mathrm{~V}$ está destacado em azul. 121

Figura 6.21 - (a) Voltamogramas a $1 \mathrm{mV} \mathrm{s}^{-1}$ e (b) cronoamperogramas em 0,600V para ROE dos catalisadores Pt/C, PtSn/C 60:40 e PtSnTR/C (TR:La, Ce, Pr e Eu) 75:20:05 a $90{ }^{\circ} \mathrm{C}$, solução de etanol $1 \mathrm{~mol} \mathrm{~L}^{-1}$. Densidades de corrente normalizadas pela área geométrica. Ânodo: $1 \mathrm{mg}_{\mathrm{Pt}} \mathrm{cm}^{-2}$. Cátodo: $30 \% \mathrm{Pt} / \mathrm{C}$, $1 \mathrm{mg}_{\mathrm{Pt}} \mathrm{cm}^{-2}$. 123

Figura 6.22 - Voltamogramas lineares em PEMFC de etanol direto para os catalisadores $\mathrm{Pt} / \mathrm{C}, \mathrm{PtSn} / \mathrm{C}$ 60:40 e PtSnTR/C (TR: La, Ce, Pr e Eu) sintetizados por poliol a $90 \stackrel{\circ}{\circ}$ e pressão 3 atm $\mathrm{O}_{2}$, solução de etanol $1 \mathrm{~mol} \mathrm{~L}^{-1}$. Ânodo: $1 \mathrm{mg}_{\mathrm{Pt}} \mathrm{cm}^{-2}$. Cátodo: $30 \% \mathrm{Pt} / \mathrm{C}, 1 \mathrm{mg}_{\mathrm{Pt}} \mathrm{cm}^{-2}$ 124

Figura 6.23 - Curvas de densidade de potência e potencial em função da densidade de corrente em PEMFC de etanol direto dos catalisadores Pt/C, PtSn/C 60:40 e $\mathrm{PtSnTR/C} \mathrm{(TR:} \mathrm{La,} \mathrm{Ce,} \mathrm{Pr} \mathrm{e} \mathrm{Eu)} \mathrm{75:20:05} \mathrm{a} 90{ }^{\circ} \mathrm{C}$ e pressão $3 \mathrm{~atm} \mathrm{O}_{2}$, solução de etanol $1 \mathrm{~mol} \mathrm{~L}^{-1}$. Ânodo: $1 \mathrm{mg}_{\mathrm{Pt}} \mathrm{cm}^{-2}$. Cátodo: $30 \% \mathrm{Pt} / \mathrm{C}, 1 \mathrm{mg}_{\mathrm{Pt}} \mathrm{cm}^{-2} \ldots . .125$

Figura 6.24 - Distribuição dos produtos quantificados por HPLC dos catalisadores de (a) $\mathrm{Pt} / \mathrm{C}$; (b) PtSn/C 60:40; (c) PtSnLa/C 75:20:05; (d) PtSnCe/C 75:20:05; (e) $\mathrm{PtSnPr} / \mathrm{C}$ 75:20:05 (e) PtSnEu/C 75:20:05 em $8 \mathrm{~mA} \mathrm{~cm}^{-2}, 16 \mathrm{~mA} \mathrm{~cm}^{-2} \mathrm{e}$ $30 \mathrm{~mA} \mathrm{~cm}^{-2}$ na configuração de célula completa; e em $0,5 \mathrm{~V}$ e $0,6 \mathrm{~V}$ na configuração de meia célula 128

Figura 6.25 - Distribuição dos produtos quantificados por HPLC dos catalisadores de Pt/C, $\mathrm{PtSn} / \mathrm{C}$ 60:40 e PtSnTR/C (TR: La, Ce, Pr e Eu) na configuração de célula completa em (a) $8 \mathrm{~mA} \mathrm{~cm}^{-2}$, (b) $16 \mathrm{~mA} \mathrm{~cm}^{-2}$, (c) $30 \mathrm{~mA} \mathrm{~cm}^{-2}$ e em meia célula a (d) $0,5 \mathrm{~V}$ e (e) $0,6 \mathrm{~V}$. 129

Figura 6.26 - Esquema geral da oxidação do etanol em eletrocatalisadores Pt/C, PtSn/C e PtSnTR/C (TR: La, Ce, Pr e Eu) 130

Figura 8.1 - Comparação das composições atômicas determinadas por EDX do catalisador $\mathrm{PtSnCe} / \mathrm{C}$ obtido pelo método $\mathrm{BAE}$, antes e após envelhecimento eletroquímico até $0,8 \mathrm{~V}$. . 134 


\section{LISTA DE TABELAS}

Tabela 5.1 - Composição atômica dos materiais Pt/C, PtSn/C e ternários PtSnEu/C sintetizados pelo método do poliol.

Tabela 5.2 - Carga metálica obtida por análise termogravimétrica dos catalisadores Pt/C, $\mathrm{PtSn} / \mathrm{C}$ e PtSnEu/C, obtidos por poliol.

Tabela 5.3 - Tamanho médio de cristalito $(d)$, parâmetro de rede $\left(a_{\text {exp }}\right)$ e a distância interatômica $\left(d_{c f c}\right)$ e grau de estanho na forma de liga $\left(f_{S n}\right)$ para os catalisadores $\mathrm{Pt} / \mathrm{C}$ e PtSn/C 60:40 e PtSnEu/C obtidos por poliol.

Tabela 5.4 - Energia de ligação, em eV, dos Pt $4 f_{7 / 2}$, Sn $3 d_{5 / 2}$ e Eu $3 d_{5 / 2}$ para os catalisadores $\mathrm{Pt} / \mathrm{C}, \mathrm{PtSn} / \mathrm{C}$ 60:40 e PtSnEu/C sintetizados por poliol; as porcentagens atômicas para cada sinal; e a composição atômica superficial, calculada por XPS.

Tabela 5.5 - Áreas ativas obtida por stripping de CO para os catalisadores $\mathrm{Pt} / \mathrm{C}, \mathrm{PtSn} / \mathrm{C}$ e PtSnEu/C obtidos por poliol.

Tabela 5.6 - Áreas ativas obtidas por stripping de CO, após teste de envelhecimento e a variação da área dos catalisadores $\mathrm{Pt} / \mathrm{C}, \mathrm{PtSn} / \mathrm{C}$ e $\mathrm{PtSnEu} / \mathrm{C}$ sintetizados por poliol.

Tabela 5.7 - Atribuições das bandas observadas em FTIR. Adaptado de Shao e Adzic $(2005)^{102}$, Wang et al. (2007) ${ }^{103}$ e Delpeuch et al. (2016). ${ }^{104}$

Tabela 5.8 - Características elétricas e as concentrações de acetaldeído ( $A L)$, ácido acético (AA) e $\mathrm{CO}_{2}$ formado durante a aplicação de 20 minutos em diferentes densidades de corrente, ou aplicação de um potencial fixo por 1 hora, em uma célula de $5 \mathrm{~cm}^{2}$, com cátodo de Pt/C Etek $30 \%$ e ânodo com $1 \mathrm{mg}_{\mathrm{Pt}} \mathrm{cm}^{-2} \ldots . .84$

Tabela 6.1 - Composição atômica, determinada por EDX e por ICP; e porcentagem metálica, determinada por ICP, dos catalisadores PtSnTR/C (TR=La, Ce, Pr) sintetizados por poliol.

Tabela 6.2 - Porcentagem metálica determinada por análise termogravimétrica dos catalisadores PtSnTR/C (TR= La, Ce e Pr) 75:20:05 obtidos por poliol.

Tabela 6.3 - Tamanho médio de cristalito $(d)$, parâmetro de rede $\left(a_{\text {exp }}\right)$ e a distância interatômica $\left(d_{c f c}\right)$, e grau de estanho na forma de liga $\left(f_{S n}\right)$ e tamanhos médios de partículas obtidos por TEM $\left(d_{T E M}\right)$ para os catalisadores PtSnTR/C 75:20:05 obtidos por poliol. 98

Tabela 6.4 - Energia de ligação, em eV, dos Pt $4 f_{7 / 2}$, Sn $3 d_{5 / 2}$ e TR $3 d_{5 / 2}$ para os PtSnTR/C (TR: La, Ce e Pr), as porcentagens atômicas para cada sinal e a composição atômica superficial, calculada por XPS. 101

Tabela 6.5 - Área ativa obtida do stripping de CO para os materiais $\mathrm{PtSnLa} / \mathrm{C}, \mathrm{PtSnCe} / \mathrm{C}$ e PtSnPr/C 75:20:05, obtidos por poliol. 107

Tabela 6.6 - Áreas ativas obtidas por stripping de CO, após teste de envelhecimento e a variação da área dos catalisadores Pt/C, PtSn/C e PtSnTR/C (TR:La, Ce, Pr e Eu) 75:20:05 sintetizados por poliol. 


\section{Lista de Tabelas}

Tabela 6.7 - Características elétricas e as concentrações de acetaldeído ( $A L)$, ácido acético (AA) e $\mathrm{CO}_{2}$ formado durante a aplicação de 20 minutos em diferentes densidades de corrente, ou aplicação de um potencial fixo por 1 hora, em uma célula de $5 \mathrm{~cm}^{2}$, com cátodo de Pt/C Etek 30\% e ânodo PtSnTR (TR: La, Ce e $\operatorname{Pr}$ ) com $1 \mathrm{mg}_{\mathrm{Pt}} \mathrm{cm}^{-2}$. 


\section{LISTA DE ABREVIAÇÕES}

$\varepsilon_{\mathrm{d}}$ - Centro da banda $d$

AA - Ácido Acético

AL - Acetaldeído

ATG - Análise termogravimétrica

ATW - Atmosphere Thin Window

BAE - Bromide Anion Exchange

CAQI - Central de Análises Químicas Instrumentais

cfc - Cúbica de face centrada

DAFC - Direct Alcohol Fuel Cell - Células a combustível de álcool direto

DEFC - Direct Ethanol Fuel Cell - Células a combustível de etanol direto

DRX - Difração de Raios X

EDX - Energy dispersive $X$-ray spectroscopy - Espectroscopia de raios X por energia dispersiva

EDH - Eletrodo dinâmico de hidrogênio

EPH - Eletrodo padrão de hidrogênio

$\mathrm{ERH}$ - Eletrodo reversível de hidrogênio

FTIR-Fourier transform infrared-Espectroscopia de Infravermelho com Transformada de Fourier

HPLC - High perfomance liquid chromatography - Cromatografia Líquida de Alta

Eficiência

ICM2P - Institut de Chimie des Milieux et Matériaux de Poitiers

ICP-OES-Inductively Coupled Plasma-Optical Emission Spectroscopy -

Espectrometria de Emissão Óptica por Plasma Acoplado Indutivamente

IQSC - Instituto de Química de São Carlos

IUPAC - International Union of Pure and Applied Chemistry

LNLS - Laboratório Nacional de Luz Síncronton

LNNano - Laboratório Nacional de Nanotecnologia

MAF - Método do ácido fórmico

MCFC- Molten Carbonate Fuel Cells

MEA - Membrane electrode assembly - Conjunto membrana-eletrodos

PEMFC - Proton exchange membrane fuel cell - Células a combustível de membrana de troca protônica 


\section{Apresentação}

RID - Refractive index detector - Detector de índice de refração

ROE - Reação de oxidação de etanol

SOFC - Solid Oxide Fuel Cells

TEM - Transmission electron microscopy - Microscopia eletrônica de transmissão

TR - Metais Terras Raras

USGS - United States Geological Survey

$v$ - Velocidade de varredura

XANES - X-ray absorption near edge structure

XAS - X-ray absorption spectroscopy - Espectroscopia de absorção de raios $\mathrm{X}$

XPS - X-ray photoelectron spectroscopy - Espectroscopia de fotoelétrons excitados por raios $\mathrm{X}$ 


\section{APRESENTAÇÃO}

O desenvolvimento do projeto de doutorado intitulado "Investigação de nanocatalisadores de platina-terras raras suportados em carbono para células a combustível de etanol direto" foi dividido em duas etapas. A primeira foi avaliar os catalisadores binários Pt-TR (TR: La, Ce, $\operatorname{Pr}$ e Eu) frente à reação de oxidação de etanol (ROE). Os catalisadores binários foram sintetizados por duas rotas diferentes: método do ácido fórmico e por poliol. Apesar dos catalisadores sintetizados pelo método do ácido fórmico demonstrarem maior densidade de corrente nas ROE, os materiais sintetizados por poliol apresentaram maior área ativa, similiar a $\mathrm{Pt}$ comercial. * A segunda etapa foi sintetizar materiais ternários platina-estanho-terras raras. O terra-rara escolhido para um estudo de melhor composição atômica foi o európio, e o método para síntese utilizado foi poliol. Encontrada a composição de $\mathrm{PtSnEu} / \mathrm{C}$ com maior atividade frente à ROE, foram sintizados PtSnTR/C (TR: La, Ce e Pr) na mesma proporção. A tese reporta os dados obtidos para os catalisadores trimetálicos PtSnTR/C sintetizados pelo método do poliol.

Para uma melhor apresentação dos dados, o texto foi divido em capítulos. $O$ Capítulo I engloba a introdução, uma revisão bibliográfica breve e os objetivos do trabalho. O Capítulo II descreve a metodologia experimental usada para obtenção, caracterização física e eletroquímica dos catalisadores Pt-Sn-Terras raras. O Capítulo III apresenta e discute os resultados obtidos para os catalisadores Pt/C, $\mathrm{PtSn} / \mathrm{C}$ e PtSnEu/C e o Capítulo IV, analisa os resultados obtidos para os catalisadores PtSnTR/C (TR: La, Ce, Pr e Eu). O Capítulo V encerra o texto com a conclusão e algumas perspectivas para continuação do trabalho.

Durante o doutoramento, um trabalho paralelo foi desenvolvido no Institut de Chimie des Milieux et Matériaux de Poitiers, Université de Poitiers (França), sob supervisão dos professores Dr. Boniface Kokoh e Dr. Têko W. Napporn. Um breve resumo das atividades realizadas durante esse estágio está apresentado no Apêndice I.

\footnotetext{
*Alguns dos resultados obtidos nessa etapa do doutorado podem ser lidos nos seguintes trabalhos: CORRADINI, P. G.; SANTOS, N. A.; SILVA, G. C.; PEREZ, J. Obtenção e caracterização de eletrocatalisadores de Pt-Terras Raras/C para reação de oxidação de etanol. In XX Simpósio Brasileiro de Eletroquímica e Eletroanalítica, 2015, Uberlândia. XX Simpósio Brasileiro de Eletroquímica e Eletroanalítica, 2015; e

CORRADINI, P. G.; SANTOS, N. A. ; SILVA, G. C.; PEREZ, J. Pt-rare earth catalysts for ethanol electrooxidation: modification of polyol synthesis. Journal of Solid State Electrochemistry, v. 20, p. 2581-2587, 2016.
} 


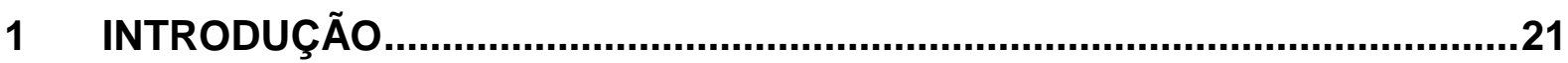

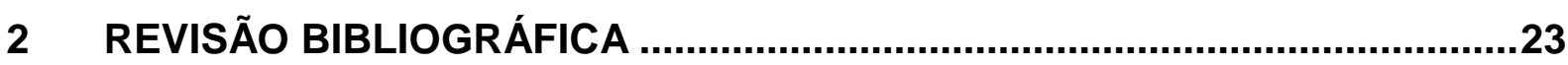

2.1 REAÇÃO DE OXIDAÇÃO DE ETANOL …...........................................24

2.1.1 Desenvolvimento de eletrocatalisadores para reação de oxidação de

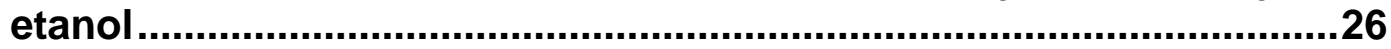

2.1.1.1 Estado atual e perspectivas da aplicação de terras raras para eletrocatalisadores para $R O E$..........................................................27

3 OBJETIVO

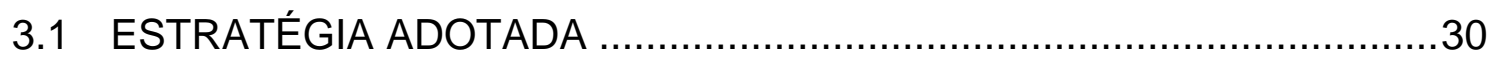

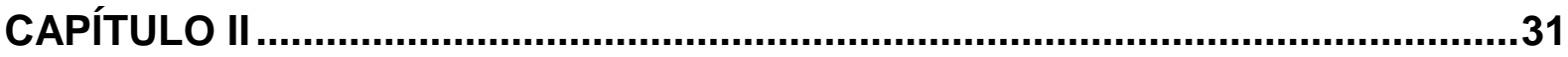

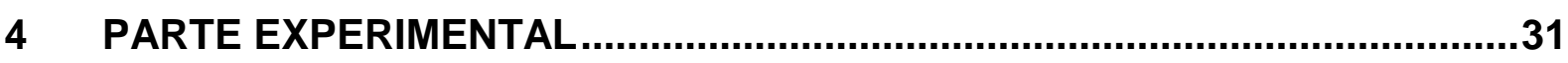

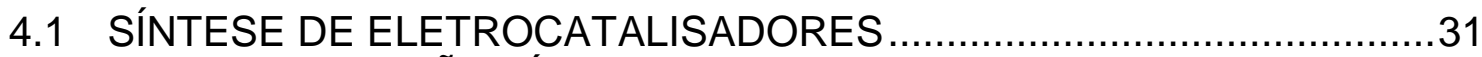

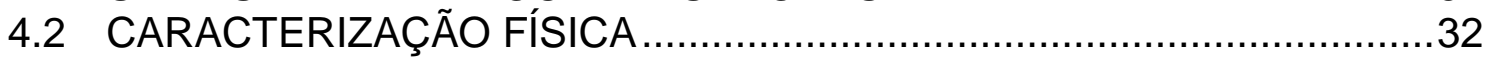

4.2.1 Espectroscopia de Raios X por Energia Dispersiva............................33

4.2.2 Espectrometria de Emissão Óptica por Plasma Acoplado

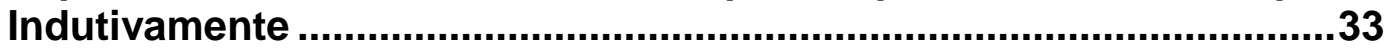

4.2.3 Análise Termogravimétrica ..................................................................34

4.2.4 Difração de Raios X.............................................................................34

4.2.5 Microscopia Eletrônica de Transmissão ..............................................34

4.2.6 Espectroscopia de Fotoelétrons excitados por Raios X.....................34

4.2.7 Espectroscopia de Absorção de Raios X $X$..............................................35

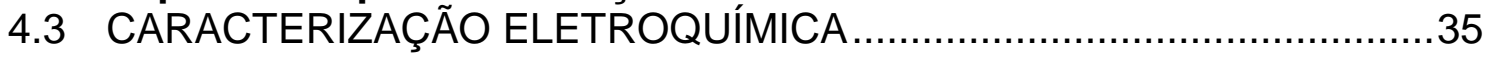

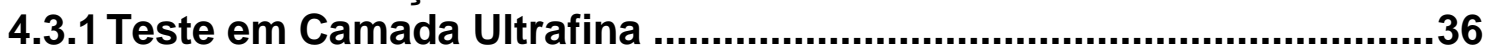

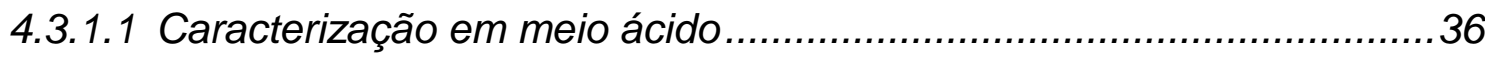

4.3.1.2 Caracterização em meio etanólico ..................................................36

4.3.1.3 Testes de envelhecimento acelerado..............................................37

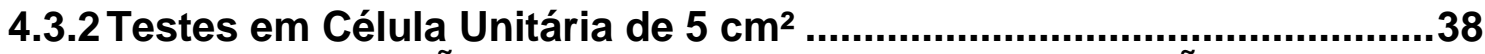

4.4 CARACTERIZAÇÃO DOS SUBPRODUTOS DA OXIDAÇÃO DE ETANOL

4.4.1 Espectroscopia vibracional de absorção na região do infravermelho in situ com transformada de Fourier

4.4.2 Cromatografia Líquida de Alta Eficiência............................................41

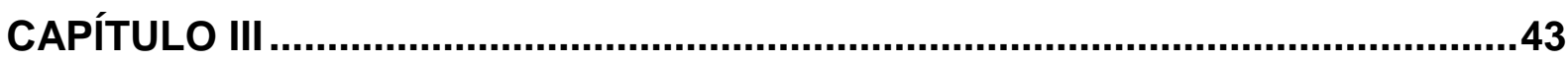

5 RESULTADOS E DISCUSSÃO: CATALISADORES PtSnEu/C ....................43

5.1 SÍNTESE DOS ELETROCATALISADORES PtSnEu/C .........................43

5.2 CARACTERIZAÇÃO FÍSICA ........................................................4 44

5.2.1 Determinação da Composição Química ................................................45

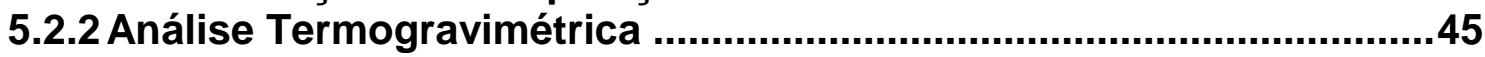

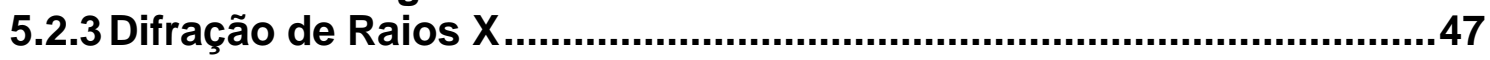

5.2.4 Espectroscopia por Fotoelétrons excitados por Raios X ...................50 
5.2.5 Espectroscopia de Absorção de Raios X ......................................... 55

5.3 CARACTERIZAÇÃO ELETROQUÍMICA …........................................ 57

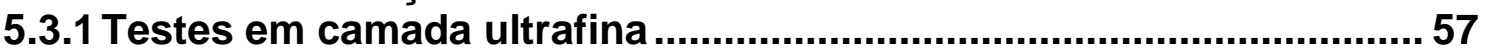

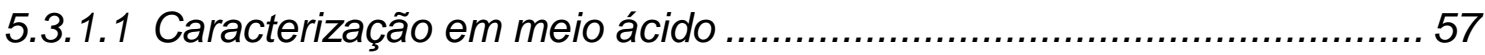

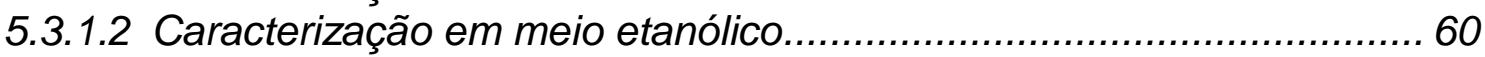

5.3.1.3 Teste de envelhecimento acelerado ............................................. 62

5.3.1.4 Caracterização dos subprodutos da reação de oxidação de etanol por espectroscopia vibracional de absorção na região do infravermelho in situ com transformada de Fourier.......................................................... 73

5.3.2 Testes em célula unitária .................................................................... 78

5.3.2.1 Configuração de meia célula ........................................................ 78

5.3.2.2 Configuração de célula completa................................................. 79

5.3.2.3 Caracterização dos subprodutos de etanol por cromatografia líquida de

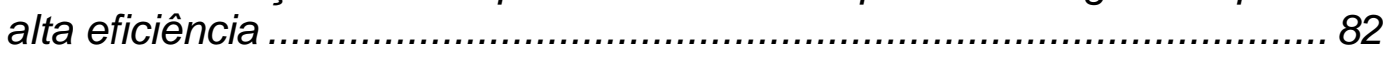

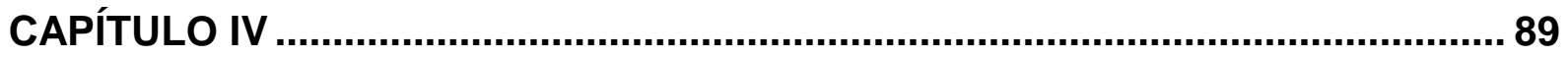

6 RESULTADOS E DISCUSSÃO: CATALISADORES PtSnTR/C..................... 89

6.1 SÍNTESE DOS ELETROCATALISADORES PtSnTR/C ........................ 89

6.2 CARACTERIZAÇÃO FÍSICA ........................................................... 90

6.2.1 Determinação da Composição Química............................................... 90

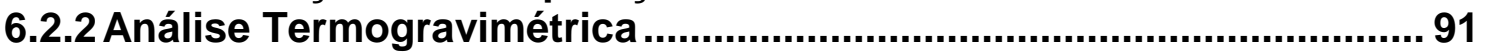

6.2.3 Microscopia Eletrônica de Transmissão ............................................ 93

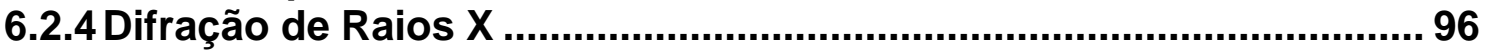

6.2.5 Espectroscopia por Fotoelétrons excitados por Raios X................... 99

6.2.6 Espectroscopia de Absorção de Raios X ........................................ 103

6.3 CARACTERIZAÇÃO ELETROQUÍMICA DOS CATALISADORES

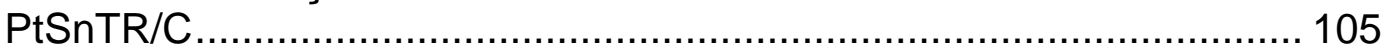

6.3.1 Teste em camada ultrafina ............................................................ 105

6.3.1.1 Caracterização em meio ácido .................................................. 105

6.3.1.2 Caracterização em meio etanólico................................................ 108

6.3.1.3 Teste de envelhecimento acelerado ........................................... 110

6.3.1.4 Caracterização dos subprodutos da reação de oxidação de etanol por espectroscopia vibracional de absorção na região do infravermelho in situ com transformada de Fourier....................................................... 120

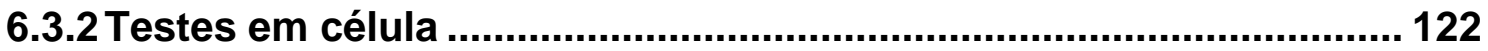

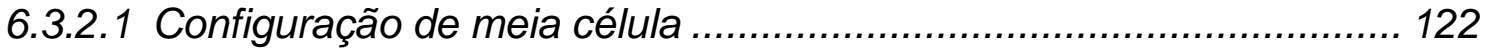

6.3.2.2 Configuração de célula completa................................................ 123

6.3.2.3 Caracterização dos subprodutos de etanol por cromatografia líquida de

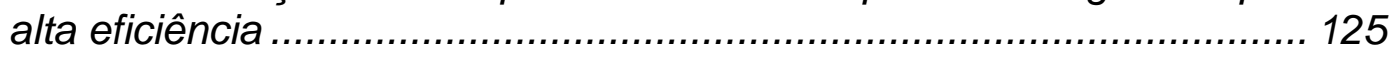

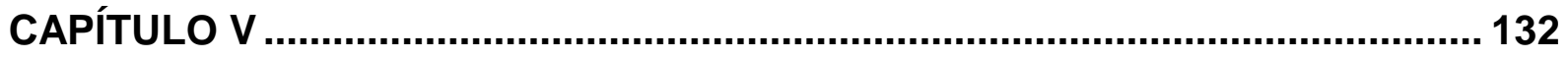

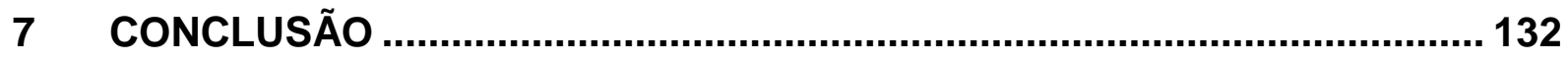

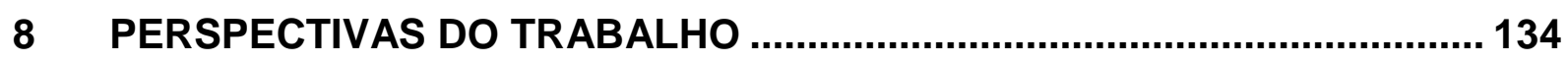

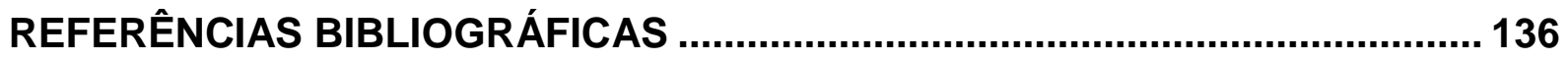

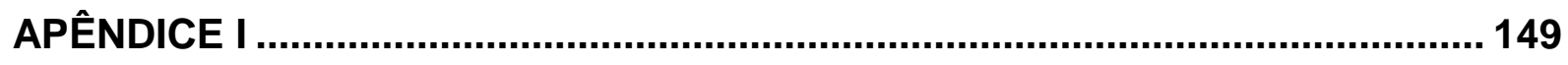

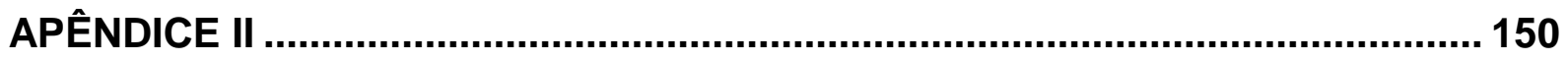




\section{CAPÍTULO I}

Este capítulo fornece uma visão geral da importância do estudo em eletrocatálise, em especial a reação de oxidação de etanol (ROE). Para isso, uma breve revisão bibliográfica é apresentada, com o estado da arte dos catalisadores para ROE. Esse capítulo também pontua a motivação e os objetivos deste trabalho.

\section{INTRODUÇÃO}

A demanda de energia elétrica cresce exponencialmente tanto em aplicações domésticas quanto industriais. O principal empenho para preencher essa lacuna consiste não em só aumentar a produção energética, mas também em reduzir o uso de combustíveis fósseis, de modo a minimizar impactos ambientais. ${ }^{1,2}$ É verdade que não existe uma única solução para esse problema, visto que cada país e/ou região enfrenta suas próprias (e diferentes) barreiras, como disponibilidade de recursos naturais, avanços tecnológicos e até mesmo inciativas governamentais. Mas algo com que a comunidade científica concorda é que a chave para uma oferta adequada de energia elétrica envolve a diversificação da matriz energética. ${ }^{1}$

Dentre as várias fontes de energia considerada como "renováveis", as células a combustível podem ser incluídas, dependendo da fonte do combustível empregado. Essa tecnologia converte energia química diretamente em energia elétrica, e apresentam maior eficiência na conversão quando comparadas às máquinas térmicas convencionais, com menores emissões de gases de efeito estufa. ${ }^{3}$ Estas características combinadas a baixos níveis de ruído e a capacidade de cogeração de calor e energia, fazem as células a combustível serem atrativas para aplicações estacionárias e portáteis. A densidade de energia de células a combustível para dispositivos portáteis cresce 3 a 10 vezes mais rápido que a densidade de energia das baterias de lítio em uso. ${ }^{4}$ Adicionalmente, estas oferecem vantagens de não precisarem ser recarregadas, serem mais ambientalmente amigáveis e possuírem mais flexibilidade no sistema de design, quando comparadas às baterias. Um dos mais recentes avanços da viabilidade dessa tecnologia foi o lançamento de um carro 
comercial movido a célula a combustível abastecido por hidrogênio (Toyota modelo Mirai). ${ }^{5}$

A célula a combustível de álcool direto (DAFC - Direct Alcohol Fuel Cell), que é uma sub-categoria da célula a combustível de troca protônica (PEMFC - Proton exchange membrane fuel cell), tem atraído muita atenção dos pesquisadores e fabricantes, devido ao fácil manuseio e transporte, além da capacidade de utilizar a infraestrutura de combustível tradicional, principalmente se o combustível utilizado for o etanol. ${ }^{2,4}$

Apesar de bastante atrativa, as DEFC (Direct Ethanol Fuel Cell) possuem algumas barreiras tecnológicas que inviabilizam a comercialização. O principal desafio é baixa atividade eletrocatalítica do ânodo em temperatura relativamente baixa $\left(20-120^{\circ} \mathrm{C}\right) \cdot{ }^{4} \mathrm{~A}$ cinética lenta da ROE produz intermediários indesejados, tais como ácido acético e acetaldeído. Outros problemas enfrentados pelas DEFCs são o cruzamento do etanol através da membrana, que reduz o desempenho do cátodo; e o custo, relacionados ao catalisador e à membrana de Nafion ${ }^{\circledR 4}$.

A abordagem mais comum para o aumento da atividade eletroquímica para oxidação de álcoois, tais como metanol e etanol, é o desenvolvimento de ligas binárias e/ou ternárias com $\mathrm{Pt}$, adicionando metais que podem ajudar a mitigar os efeitos de envenenamento. Aditivos típicos incluem $\mathrm{Sn}^{6-8}, \mathrm{Ru}^{3,7,9}, \mathrm{~W}^{7}$ e $\mathrm{Pd}^{7},{ }^{10}$. Recentemente, o uso de metais terras raras em células a combustível em baixa temperatura vem sendo reportado. ${ }^{11,12}$ Compostos de lantanídeos são muito atraentes para aplicações em catálise, pois normalmente possuem excelentes propriedades ópticas, elétricas e químicas, devido à estrutura eletrônica e aos numerosos modos de transição, proveniente dos elétrons dos orbitais $4 f .{ }^{11,13}$

A síntese de eletrocatalisadores eficientes para oxidação de etanol pode promover a comercialização de células do tipo PEM. Nesse intuito, o projeto de doutorado intitulado "Investigação de nanocatalisadores de platina-terras raras suportados em carbono para células a combustível de etanol direto" visou obter catalisadores trimetálicos platina-estanho-terras raras e avaliá-los frente à ROE. Os metais lantanídeos escolhidos para esse estudo foram lantânio, cério, praseodímio e európio. Para uma melhor comprensão dos assuntos abordados neste trabalho e do estado da arte em materiais eletrocatalíticos à base de metais terras raras, uma breve revisão bibliográfica é apresentada a seguir. 


\section{Revisão Bibliográfica}

\section{REVISÃo BIBLIOGRÁFICA}

As células do tipo PEM utilizam um eletrólito polimérico para promover a condução iônica entre o ânodo e o cátodo. ${ }^{14}$ A parte central desse sistema consiste em um "sanduíche" de eletrodos porosos com a membrana condutora, conhecido como MEA (membrane electrode assembly). ${ }^{15}$ Embora as células PEM, em princípio, possam processar uma grande variedade de combustíveis, os mais utilizados são gás hidrogênio, metanol e etanol; ${ }^{16}$ e gás oxigênio, como agente oxidante. ${ }^{14}$

A PEMFC é descrita na literatura como uma tecnologia que já fornece desempenho suficiente para ser competitiva a outras alternativas tecnológicas, ${ }^{15}$ principalmente para demandas de densidades de potência baixas (inferior a $1 \mathrm{~kW}$ ) a intermediárias (até $50 \mathrm{~kW}$ ). ${ }^{17}$ Entretanto, um dos grandes empecilhos da popularização das PEM é o custo. Moreno et al. (2015) estimaram o custo de PEMFC, abastecida com gás hidrogênio, para aplicações automotivas baseados em diferentes cenários de produção. ${ }^{18}$ Para uma análise de baixa produção (1000 unidades/ano), a membrana domina o custo do stack, e representa $32 \%$ do custo total; enquanto o catalisador, 16\%. Em grande volume (500.000 unidades/ano), essa percentagem muda para $11 \%$ para membrana e $49 \%$ para o catalisador. Na mesma projeção, o custo do MEA representa 30-35\% do custo total em larga escala. Com uma redução de $27 \%$ do custo atual do MEA, é razoável a meta de custo de US\$ 40/kW em 2020, o qual corresponde a uma redução de custo US $\$ 3,55 / \mathrm{kW}$ para o catalisador e de US\$0,80/kW para a membrana. Entretanto, para atingir um preço competitivo ao motor a combustão para veículos, seria necessário reduzir o custo para US\$30/kW, o que envolveria reduzir em $45 \%$ o custo atual do MEA. Moreno et al. acreditam que essas reduções podem ser alcançadas, considerando o aumento dos níveis de produção, o progresso da pesquisa em PEMFC e o comportamento histórico de redução de custos. Além disso, políticas ambientais, que visam a redução de emissão de gases estufa, podem ser de grande ajuda para o estímulo de produção de PEMFC. ${ }^{18}$

Apesar das maiores eficiências de aplicação para PEMFC envolverem o uso de gás hidrogênio como combustível; este ainda representa um cenário distante do atual. ${ }^{19}$ A disponibilidade de gás hidrogênio, suas tecnologias de armazenamento e quase inexistência de transporte e distribuição desse combustível são pontos que dividem opiniões sobre a comercialização de tecnologias de células. ${ }^{2}$ Wang (2015) 


\section{Revisão Bibliográfica}

comenta que o principal desafio das células não é a economia do hidrogênio, mas a falta de um consenso sobre a viabilidade da tecnologia em si. ${ }^{19}$ Mas algo muito comentado é que a utilização de combustíveis líquidos, como o etanol, nas células reduziriam as exigências de estabelecimento de novas infraestruturas requeridas no uso do hidrogênio como combustível. ${ }^{2} \mathrm{O}$ etanol é um combustível promissor, pois possui alta densidade de energia teórica (cerca de 8,00 $\mathrm{kWh} \mathrm{kg}^{-1}$ ), menos tóxico que o metanol e pode ser produzido em grande quantidade a partir da fermentação do açúcar e biomassa. ${ }^{4} \mathrm{O}$ desenvolvimento de tecnologias de células a combustível abastecido com etanol é muito estratégico para o país, visto que o Brasil é reconhecido internacionalmente por sua política de produção e utilização de etanol e bioetanol em veículos de transporte. ${ }^{2}$

Infelizmente, as células que utilizam álcoois como combustíveis, como as DEFC, além de apresentarem altos custos, como as do tipo PEM, têm outros pontos a desenvolver, como: i) membranas eletrolíticas que possuam alta condutividade iônica e baixa permeabilidade ao álcool; ii) eletrodos catódicos tolerantes a álcoois, com grande atividade para redução de oxigênio; e iii) eletrocatalisadores que efetivamente favoreçam a cinética de oxidação do combustível. ${ }^{20}$ Nesse intuito, os estudos fundamentais abrangentes da reação de oxidação de etanol (ROE) visam auxiliar a obtenção de catalisadores de alta eficiência, por correlacionarem design, composição e outras caraterísticas físicas com a atividade eletrocatalítica.

\subsection{REAÇÃO DE OXIDAÇÃO DE ETANOL}

A platina é o metal catalítico mais utilizado no ânodo de DEFCs devido às excelentes propriedades na adsorção e dissociação de etanol. ${ }^{21}$ Muitos trabalhos na literatura tentam elucidar o mecanismo da ROE em catalisadores de $\mathrm{Pt}^{21-23}$ Esse trabalho não é trivial, visto que muitas reações paralelas podem ocorrer, e mais de 40 intermediários adsorvidos e/ou derivados oxidativos são relacionados ao mecanismo global. $^{24}$ Atualmente, o mecanismo simplificado mais aceito em meio ácido envolve duas vias principais, esquematizado na Figura 2.1. A via $C_{1}$ é a oxidação completa de etanol para $\mathrm{CO}_{2}$ através de intermediários de $\mathrm{CO}$ adsorvidos $\left(\mathrm{CO}_{\mathrm{ad}}\right)$, fornecendo 12 elétrons. ${ }^{25} \mathrm{Na}$ via $\mathrm{C}_{2}$, a ligação $\mathrm{C}-\mathrm{C}$ permanece intacta durante a oxidação. ${ }^{25} \mathrm{O}$ etanol é convertido em acetaldeído e eventualmente em ácido acético/acetato. Na oxidação para acetaldeído, há transferência de 2 elétrons, 


\section{Revisão Bibliográfica}

enquanto quando o produto obtido é ácido acético e/ou acetato, o fornecimento é de 4 elétrons. $^{21}$

Figura 2.1 - Representação esquemática da reação de oxidação de etanol em meio ácido.

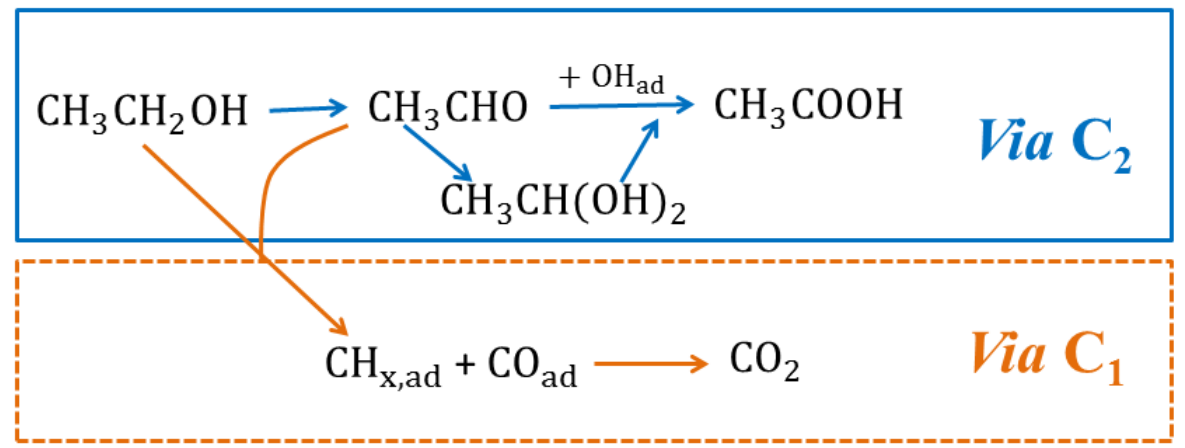

Fonte: Adaptado de LAI, S. C. S.; KLEIJN, S. E. F.; ÖZTÜRK, F. T. Z.; VELLINGA, V. C.; V. R.; KONING, J.; RODRIGUEZ, P.; KOPER, M. T. M. Catalysis Today. 154, 2010, p. $102 .^{25}$

Embora a Pt seja um material cataliticamente ativo para clivagem de ligações C-C de etanol, ${ }^{26}$ Lai et al. (2010) comentam que a via $\mathrm{C}_{2}$ é a preferida para ROE na presença de íons fortemente adsorventes, tais como fosfatos, o que sugere que a via $\mathrm{C}_{1}$ requer um maior conjunto de sítios ativos que a via $\mathrm{C}_{2} .{ }^{25}$ Foi sugerido que via $\mathrm{C}_{2}$ é iniciada pela clivagem da ligação $\mathrm{O}-\mathrm{H}$ do etanol na superfície de metal, que conduz ao etóxi adsorvido, e posteriormente convertido em acetaldeído, através de um simples passo de desidrogenação. ${ }^{25} \mathrm{O}$ acetaldeído pode difundir para o volume da solução ou permanecer próximo da superfície do eletrodo, sendo oxidado em ácido acético. ${ }^{25}$ Nessa etapa, dois caminhos são discutidos. Uma via possível é a reação direta de acetaldeído adsorvido com uma espécie oxigenada na superfície, visto que o potencial no qual essa oxidação ocorre (aproximadamente 0,6 V vs EPH - eletrodo padrão de hidrogênio) corresponde a uma superfície parcialmente oxidada. Alternativamente, o acetaldeído pode sofrer hidratação, formando o diol geminal $\left(\mathrm{CH}_{3} \mathrm{CH}(\mathrm{OH})_{2}\right)$, o qual pode desidrogenado ao ácido acético. ${ }^{21}$

Como a via $\mathrm{C}_{2}$ apresenta menor eletroeficiência, uma boa tática para melhorar o desempenho eletrocatalítico é aumentar a razão da via $\mathrm{C}_{1} / \mathrm{C}_{2}$, obtendo uma oxidação do etanol mais completa. ${ }^{21}$ Com auxílio de ferramentas computacionais, Wang e Liu (2008) identificaram duas variáveis que determinam a seletividade: ) a capacidade de ligação dos átomos superficiais com fragmentos de carbono nãosaturados; e ii) a estabilidade na superfície dos íons hidroxilas em relação a outros

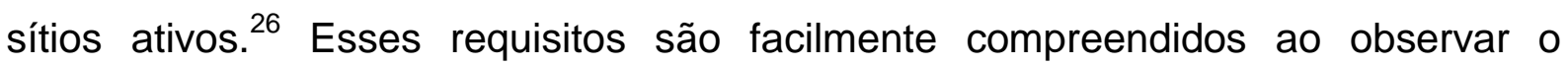




\section{Revisão Bibliográfica}

mecanismo da ROE. No primeiro caso, os sítios superficiais devem ser ativos para quebra da ligação C-C, e promover a formação e conseguinte remoção de CO e $\mathrm{CH}_{\mathrm{X}}$, favorecendo a formação de $\mathrm{CO}_{2} \cdot{ }^{21}$ Além disso, como a via $\mathrm{C}_{1}$ sempre envolve a participação de água ou um respectivo resíduo de adsorção, a estabilidade de espécies oxigenadas pode favorecer a oxidação completa do etanol. ${ }^{21}$

Um bom eletrocatalisador deve ser capaz de adsorver o etanol e fornecer espécies oxigenadas. Essas características podem ser obtidas pela variação da composição e da estrutura dos catalisadores.

\subsubsection{Desenvolvimento de eletrocatalisadores para reação de oxidação de etanol}

Para aumentar o desempenho de DEFC, os pesquisadores desenvolveram muitos projetos de estudo a fim de conceber racionalmente catalisadores a base de Pt. O alvo é produzir catalisadores com maior seletividade, atividade e durabilidade.

21 Duas vias de modificação são as mais avaliadas na literatura:

a) Controle da estrutura superficial. A ROE é sensível à superfície e sua eficiência depende em grande parte da orientação cristalina da superfície do catalisador. ${ }^{26-28}$ Assim, a construção de catalisadores com morfologia e superfície bem definidas é uma maneira de se obter catalisadores com maior desempenho eletrocatalítico ${ }^{29}$; e

b) Adição de outros metais, que podem favorecer o mecanismo bifuncional e/ou modificar a estrutura eletrônica de valência da $\mathrm{Pt}$, podendo favorecer a ROE. ${ }^{7,21}$

É inegável que a otimização da estrutura da superfície dos eletrocatalisadores de Pt permitem melhorias importantes no desempenho da célula a combustível, mas o estado da arte para a DEFC são catalisadores multimetálicos à base de Pt. ${ }^{7,29}$ Como comentado, os principais aditivos utilizados são $\mathrm{Sn}^{6-8}, \mathrm{Ru}^{3,7,9}, \mathrm{~W}^{7}$ e $\mathrm{Pd}^{7,10}$. A melhoria da catálise de oxidação do álcool sobre estes materiais geralmente é interpretada em termos da facilitação do mecanismo bifuncional, no qual o segundo metal possibilita, em menores potenciais, a formação de espécies hidroxila, necessárias para a oxidação completa do álcool e para a remoção do $\mathrm{CO}_{\text {ads }}$ formado na reação intermediária. ${ }^{30}$ Muitos estudos, porém, sugerem que os catalisadores com efeito bifuncional não aumentam particularmente a clivagem da ligação C-C, 


\section{Revisão Bibliográfica}

mas o aumento da corrente se dá pelo aumento da oxidação parcial do etanol, obtendo principalmente acetaldeído e ácido acético. ${ }^{31}$

Outra característica atribuída ao segundo metal são os efeitos eletrônicos, descritos como uma mudança no centro da banda $d\left(\varepsilon_{\mathrm{d}}\right)$ do metal. ${ }^{32,33} \bigcirc \varepsilon_{\mathrm{d}}$ está diretamente relacionado com a energia de ligação da superfície com espécies intermediárias: um maior $\varepsilon_{d}$ sugere uma superfície mais reativa, que pode se ligar mais fortemente aos adsorventes; enquanto uma superfície com menor $\varepsilon_{d}$, tende a blindar os adsorventes de maneira mais fraca, e facilitar a formação de ligações entre eles. No mecanismo ROE, o anseio é ajustar os efeitos eletrônicos, de modo que forneça um $\varepsilon_{\mathrm{d}}$ adequado, com uma energia de ligação moderada para $\mathrm{CO}, \mathrm{CH}_{\mathrm{x}}$ e acetaldeído, e uma maior energia para ligação com $\mathrm{OH} .{ }^{21}$ Alguns trabalhos mostraram que até mesmo a presença de óxidos influenciam a ocupação da banda $5 d$ da Pt e, consequentemente, a atividade catalítica. ${ }^{34,35}$

Dentre os aditivios típicos, o estanho se destaca. Muitos pesquisadores relataram que o melhor catalisador binário é $\mathrm{PtSn}$, visto que a reação de oxidação de etanol tem início em menores potenciais e apresenta maiores densidades de corrente do que catalisadores de Pt. ${ }^{36,37}$ Mesmo na forma oxidada, o estanho tem um efeito benéfico a Pt/C para ROE. Através de modelagem computacional, Wang et al. (2010) confirmaram que Sn é mais favorável à decomposição de água do que Pt pura e de outros catalisadores, como ligas de $\mathrm{Pt}-\mathrm{Ru}$; tanto do ponto de vista cinético, como termodinâmico. ${ }^{31}$ A melhora da eletrocatálise para ROE seria primariamente pelo auxílio do mecanismo bifuncional, no qual o sítio Sn acelera a dissociação da água. ${ }^{31}$ Entretanto, as atividades dos catalisadores PtSn e $\mathrm{PtSnO}_{\mathrm{x}}$ para clivagem da ligação $\mathrm{C}-\mathrm{C}$ do etanol mostram-se inferiores do que a de $\mathrm{Pt}$ sozinha, favorecendo a oxidação parcial do etanol. ${ }^{38}$

Outros aditivos que vêm ganhando atenção são os metais terras raras. ${ }^{11}$ Os terras raras possuem propriedades físicas interessantes para aplicações em catálise em geral. A seguir, um breve resumo do progresso recente do uso de metais terras raras em eletrocatálise é apresentado.

2.1.1.1 Estado atual e perspectivas da aplicação de terras raras para eletrocatalisadores para $R O E$

A IUPAC (International Union of Pure and Applied Chemistry) define os metais terras raras (TR) como um grupo de 17 elementos: 15 metais lantanídeos (La, Ce, 


\section{Revisão Bibliográfica}

Pr, Nd, Pm, Sm, Eu, Gd, Tb, Dy, Ho, Er, Tm, Yb, Lu), mais os metais Sc e Y. ${ }^{39}$ Diferente de que o nome sugere, os metais terras raras são relativamente abundantes na crosta terrestre. As reservas destes metais são presentes em aproximadamente 34 países. ${ }^{40}$ A China ainda é o maior fornecedor ${ }^{41}$, mas as reservas de TR encontradas podem colocar o Brasil como o segundo no mundo. ${ }^{42}$ De acordo com o relatório da United States Geological Survey (USGS) em 2010, a maior parte das reservas para a produção industrial está localizada no Brasil (37\%), seguido pela China (25\%), a Comunidade de Estados Independentes (ex-União Soviética, $13 \%$ ) e Vietnã (10\%). ${ }^{40} \mathrm{O}$ interesse da exploração e comercialização dos terras raras vão além da mineração; estes são recursos minerais estratégicos por serem elementos indispensáveis na indústria moderna, com usos em materiais refratários, condutores eletrônicos, além de aplicação em indústrias aeroespaciais e bélicas. ${ }^{41}$

Por possuírem orbitais $4 f$ semiocupados, os terras raras são comumente utilizados como catalisadores ou componentes catalíticos. ${ }^{43}$ Materiais baseados em TR são amplamente utilizados em células a combustível de alta temperatura, como as de carbonato fundido (MCFC- Molten Carbonate Fuel Cells) e de óxido sólido (SOFC - Solid Oxide Fuel Cells). ${ }^{11}$ Os materiais contendo TR são usados tanto como eletrólitos de óxido sólido, como nos catalisadores anódicos e catódicos. Em células do tipo PEM, terras raras também são empregados como catalisadores e cocatalisadores anódicos e catódicos; em aditivos em membranas de eletrólitos poliméricos, e como suporte. ${ }^{11}$ Estudos com óxidos de praseodímio $\left(\operatorname{Pr}_{6} \mathrm{O}_{11}\right)^{44}$, cério $\left(\mathrm{CeO}_{2}\right)^{45}$ indicaram melhora na atividade eletrocatalítica para ROE da Pt e para materiais bimetálicos à base de $\mathrm{Pt}$, como $\mathrm{PtRu} / \mathrm{C}^{46}$ e $\mathrm{PtSn} / \mathrm{C}^{47}$.

Oliveira Neto et al. (2008) sintetizaram catalisadores Pt -TR/C (TR: La, Ce, Pr, $\mathrm{Nd}$, Sm, Tb, Dy, Ho, Er, Tm e Lu), utilizando etilenoglicol como agente redutor. Nas condições estudadas, todos os catalisadores apresentaram maiores densidades de corrente que $\mathrm{Pt} / \mathrm{C}$ na faixa de potencial de interesse para etanol (0,2-0,6 V). Os autores comentaram que ainda era necessário avaliar outras metodologias de preparação dos eletrocatalisadores, a fim de obter menores tamanhos de partícula; e investigar esses eletrocatalisadores em células unitárias. ${ }^{12}$ Corradini et al. (2016) adotaram uma rota do poliol modificada para obter catalisadores Pt-TR/C (TR: La, $\mathrm{Ce}, \operatorname{Pr}$ e Eu). ${ }^{48}$ Os materiais sintetizados por poliol apresentaram tamanho de partícula próximo a 3,0 nm, o menor tamanho reportado na literatura para Pt-Terras 


\section{Revisão Bibliográfica}

Raras. Os catalisadores apresentaram um pequeno aumento na densidade de corrente em medidas de cronoamperometria, comparado a $\mathrm{Pt} / \mathrm{C}$. Os autores comentam que essa rota poderia possibilitar o preparo de catalisadores trimetálicos $\mathrm{Pt}-\mathrm{Sn}-\mathrm{TR} / \mathrm{C}{ }^{48}$

A literatura reporta alguns estudos de catalisadores trimetálicos Pt-Sn-TR. Wang et al. (2010) prepararam nanocatalisadores de PtSnEu e PtSn, suportados em carbono. ${ }^{49}$ Os resultados do trabalho demostraram que catalisadores $\mathrm{Pt}_{3} \mathrm{Sn}_{1} \mathrm{Eu}_{1} / \mathrm{C}$ apresentou densidade de corrente da $\mathrm{ROE}$ 1,4 vezes maior que o catalisador $\mathrm{Pt}_{3} \mathrm{Sn}_{1} / \mathrm{C}$ em medidas cronoamperiométricas. ${ }^{49}$ Catalisadores $\mathrm{PtSnPr} / \mathrm{C}$ e $\mathrm{PtSnCe} / \mathrm{C}$ também são relatados como ativos para oxidação de etanol. Algumas contribuições do próprio grupo nesta área podem ser lidas nos trabalhos de Corradini et al. ${ }^{50-52} \mathrm{e}$ Jacob et al. 53, 54. Entretanto, ainda há lacunas para serem preenchidas, como: estudos de novas rotas sintéticas, a fim de obter menores tamanhos de partícula e maior grau de liga Pt-Sn; avaliação da estabilidade; e caracterização dos subprodutos da reação de oxidação de etanol para catalisadores trimetálicos Pt-Sn$\mathrm{TR} / \mathrm{C}$.

Nesse intuito, o presente trabalho visou estudar o efeito da presença dos metais terras raras em catalisadores de Pt-Sn-TR/C para eletro-oxidação de etanol. Os metais terras raras estudados foram lantânio, cério, praseodímio e európio. A pesquisa pretendeu correlacionar as propriedades físicas às atividades catalíticas dos catalisadores, avaliar a estabilidade dos catalisadores em meio ácido e avaliar a densidade de potência obtida nas condições de operação da célula. A seguir, o objetivo principal e a estratégia adotada neste trabalho são detalhados. 


\section{OBJETIVO}

O objetivo geral desse trabalho foi sintetizar catalisadores de PtSnTR (TR: La, $\mathrm{Ce}, \operatorname{Pr}$ e Eu) suportados em carbono, visando obtenção de materiais ativos e estáveis para a reação de oxidação de etanol (ROE), para aplicação em DEFC.

\subsection{ESTRATÉGIA ADOTADA}

A estratégia adotada para tentar alcançar o objetivo geral foi dividir a pesquisa em metas de curto e médio prazo, que possibilitariam o acompanhamento do desenvolvimento do projeto. As metas adotadas nesse trabalho foram:

i) Preparar eletrocatalisadores de PtSnTR/C (TR: La, Ce, $\operatorname{Pr}$ e Eu), suportados sobre carbono de alta área superficial, utilizando como rota de síntese o método do poliol;

ii) Caracterizar fisicamente os materiais obtidos com diferentes técnicas, tais como: espectroscopia de raios $X$ por energia dispersiva (EDX); espectrometria de emissão óptica por plasma acoplado indutivamente (ICP); difração de raios $X$ (DRX); análise termogravimétrica (ATG); microscopia eletrônica de transmissão (TEM); espectroscopia de fotoelétrons excitados por raios X (XPS) e espectroscopia de absorção de raios $X(X A S)$;

iii) Avaliar a atividade eletrocatalítica dos catalisadores para ROE em meio ácido;

iv) Avaliar o efeito de diferentes ciclagens em meio ácido na atividade dos catalisadores para ROE;

v) Avaliar a distribuição dos produtos resultantes da oxidação de etanol com auxílio de técnicas, tais como: espectroscopia de infravermelho com transformada de Fourier (FTIR) e cromatografia líquida de alta eficiência (HLPC);

vi) Correlacionar as propriedades físicas e químicas (tamanho, composição, cristalinidade) com a atividade eletrocatalítica para a ROE em meio ácido;

vii) Avaliar o desempenho dos catalisadores preparados em célula a combustível de etanol unitária, de área de $5 \mathrm{~cm}^{2}$. 


\section{Parte Experimental}

\section{CAPÍTULO II}

Este capítulo apresenta as metodologias experimentais adotadas no trabalho. Para obtenção dos catalisadores, a rota escolhida foi método do poliol proposto por Fievet et al. ${ }^{55}$ e Sun et al. ${ }^{56}$, com algumas modificações. O próprio grupo avaliou essa rota para obtenção de catalisadores $\mathrm{Pt}-\mathrm{TR} / \mathrm{C},{ }^{48}$ e devido aos resultados promissores, adotou-se essa metodologia para obtenção de catalisadores trimetálicos.

O trabalho foi desenvolvido em duas partes. A primeira envolveu sintetizar um catalisador trimetálico Pt-Sn-TR e variar a composição atômica. Motivado pelo estudo de Wang et al. (2010) ${ }^{49}$, o európio foi o metal terra rara escolhido para o estudo inicial. Após observar a melhor composição atômica para ROE, a segunda parte do estudo foi avaliar diferentes catalisadores PtSnTR/C (TR: La, Ce e Pr), com composições próximas.

Todos os materiais sintetizados foram caracterizados fisicamente e a avaliação eletroquímica foi realizada em duas configurações: em célula de três eletrodos e teste em células unitárias. Além das medidas eletroquímicas, estudos de FTIR in situ e a caracterização dos produtos por HPLC foram realizadas, como complemento aos estudos de atividade eletrocatílica frente à ROE.

\section{PARTE EXPERIMENTAL}

\subsection{SÍNTESE DE ELETROCATALISADORES}

Os precursores metálicos dos catalisadores ternários PtSnTR/C (TR: La, Ce, Pr e Eu) foram adicionados a um balão de três bocas. Os precursores metálicos utilizados foram: acetilacetonato de platina hidratado (Sigma-Aldrich ${ }^{\circledR}, 99,9 \%$ ), acetilacetonato de lantânio III hidratado (Sigma-Aldrich ${ }^{\circledR}, 30,6 \%$ em massa de La), acetilacetonato de cério III hidratado (Sigma-Aldrich ${ }^{\circledR}, 99 \%$ ), acetilacetonato de praseodímio III hidratado (Sigma-Aldrich ${ }^{\circledR}, 99,9 \%$ ), acetilacetonato de európio III hidratado (Sigma-Aldrich ${ }^{\circledR}, 32,9 \%$ em massa de Eu) e acetato de estanho (Sigma- 


\section{Parte Experimental}

Aldrich $^{\oplus}, 99,9 \%$ ). O agente redutor, 1,2 hexadecanodiol (Sigma-Aldrich, 90\%), também foi adicionado ao balão, na proporção $3: 1$ em relação à massa de platina. $O$ solvente utilizado foi o dioctil éter (Sigma-Aldrich, 99\%). Uma modificação do método foi adicionar $2 \mathrm{~mL}$ hidróxido de potássio, dissolvido em 2-propanol (3 $\left.\mathrm{mol} \mathrm{L}^{-1}\right)$, para aumentar a concentração de hidroxilas no meio. $O$ balão foi desareado com argônio, por 10 minutos. A mistura foi aquecida a $80^{\circ} \mathrm{C}$, e um excesso de ácido oleico e oleilamina foi adicionado (proporção protetores e massa de Pt foi 3:1). O sistema foi aquecido até a temperatura de refluxo (aproximadamente $270{ }^{\circ} \mathrm{C}$ ), sob fluxo de argônio, por 40 minutos.

Para limpeza das partículas, a suspensão foi centrifugada em tubos com adição de $5 \mathrm{~mL}$ de hexano, $15 \mu \mathrm{L}$ dos protetores (ácido oleico e oleilamina) e preenchidos com etanol. A cada centrifugação, o sobrenadante era descartado, e as partículas eram dispersas em hexano e protetores, com auxílio de um ultrassom. $O$ processo foi repetido quatro vezes.

Para ancoragem das partículas no carbono, o carbono Vulcan ${ }^{\circledR}$ foi submetido ao ultrassom em $15 \mathrm{~mL}$ de 2-propanol e foram adicionadas as partículas, dispersas em hexano e com os protetores. O sistema foi mantido sob agitação magnética por $12 \mathrm{~h}$ em temperatura ambiente.

Após a ancoragem, o material foi centrifugado com acetona, por cinco vezes, para retirar excessos dos protetores no suporte. Como procedimento de limpeza final, o catalisador foi submetido à filtragem, com lavagem com $200 \mathrm{~mL}$ de etanol, $50 \mathrm{~mL}$ de acetona e $250 \mathrm{~mL}$ de água. O material filtrado foi redisperso em etanol e refiltrado três vezes, para garantir uma limpeza efetiva das partículas. Após filtragem, o catalisador foi seco em estufa a $80^{\circ} \mathrm{C}$ por 2 horas.

\subsection{CARACTERIZAÇÃO FÍSICA}

A caracterização física dos materiais ternários PtSnTR/C foi realizada por espectroscopia de raios $X$ por energia dispersiva (EDX), espectrometria de emissão óptica por plasma acoplado indutivamente (ICP-OES), análise termogravimétrica (ATG), por difração de raios $X$ (DRX), microscopia eletrônica de transmissão (TEM), espectroscopia de fotoelétrons excitados por raios X (XPS) e espectroscopia de absorção de raios $X$ (XAS). 


\section{Parte Experimental}

\subsubsection{Espectroscopia de Raios X por Energia Dispersiva}

A técnica de EDX foi utilizada para obtenção da proporção mássica entre o carbono e os metais; e da proporção atômica entre a platina, estanho e os metais terras raras (lantânio, cério, praseodímio e európio).

As análises de energia dispersiva foram realizadas na Central de Análises Químicas Instrumentais do Instituto de Química de São Carlos (CAQI/IQSC/USP) em um equipamento EDX LINK ANALYTICAL, (Isis System Series 200), com detector de SiLi Pentafet, janela ultrafina ATW II (Atmosphere Thin Window), de resolução de 133 eV à 5,9 keV e área de $10 \mathrm{~mm}^{2}$, acoplado a um microscópio eletrônico ZEISS LEO 440 (Cambridge, Inglaterra). Utilizou-se padrão de Co para calibração, feixe de elétrons de $20 \mathrm{kV}$, distância focal de $25 \mathrm{~mm}$, dead time de $30 \%$, corrente de 2,82 A e $I_{\text {probe }}$ de 950 pA. A área da amostra analisada foi de $640 \times 640 \mu \mathrm{m}$.

As amostras enviadas para análise eram pastilhas de 1,6 mm de diâmetro, preparadas pela maceração do catalisador, de aproximadamente $5 \mathrm{mg}$, com uma algumas gotas de água ultrapura e fixadas em um suporte com cola de prata. Foram obtidos valores para 3 pontos da amostra, sendo utilizada uma média desses valores como o resultado.

\subsubsection{Espectrometria de Emissão Óptica por Plasma Acoplado Indutivamente}

Para caracterizações de ICP-OES (sigla do inglês - Inductively Coupled Plasma-Optical Emission Spectroscopy), utilizou-se um reator de teflon para acomodar $10 \mathrm{mg}$ da amostra a ser analisada, juntamente com uma solução de $5 \mathrm{~mL}$ de $\mathrm{HNO}_{3}(70 \%)$ e $3 \mathrm{~mL}$ de $\mathrm{HCl}(38 \%)$. Depois, a mistura era levada para um forno de micro-ondas, durante 45 minutos, com pressão e temperatura controladas (máximo de $210^{\circ} \mathrm{C}$ ). O resultado da digestão foi analisado no espectrômetro Perkin Elmer Optima 2000 DV, com nebulizador do tipo Seaspray/Cyclonic P1400W e bomba controlada com fluxo de $1,0 \mathrm{~mL} \mathrm{~min}^{-1}$. As medidas de ICP foram realizadas no Institut de Chimie des Milieux et Matériaux de Poitiers (ICM2P), na França. 


\section{Parte Experimental}

\subsubsection{Análise Termogravimétrica}

A carga de metal nos catalisadores PtSnTR/C (TR: La,Ce, Pr e Eu) foi avaliada por análise termogravimétrica (ATG), em um aparelho TA Instruments Q600 SDT. Uma quantidade de pó do catalisador (entre $5 \mathrm{a} 10 \mathrm{mg}$ ), foi acondicionada em um cadinho de alumina, enquanto outra panela era mantida vazia, a qual servia como referência. Ambas eram tratadas termicamente, sob atmosfera de ar (fluxo de $100 \mathrm{~mL} \mathrm{~min}{ }^{-1}$ ) de 25 a $900{ }^{\circ} \mathrm{C}$, com uma taxa de aquecimento de $5{ }^{\circ} \mathrm{C} \mathrm{min}^{-1}$. As medidas de ATG foram realizadas durante o estágio no exterior, no ICM2P.

\subsubsection{Difração de Raios X}

Os difratogramas foram realizados em um difratômetro Rigaku ${ }^{\circledR}$ - ULTIMA IV. A radiação utilizada foi de CuKa $(\lambda=0,15406 \mathrm{~nm})$, gerado a $40 \mathrm{kV}$ e $20 \mathrm{~mA}$. As varreduras foram realizadas entre $10^{\circ}$ a $100^{\circ}$, a $1^{\circ} \mathrm{min}^{-1}$.

\subsubsection{Microscopia Eletrônica de Transmissão}

As micrografias das nanopartículas de Pt/C, PtSn/C e PtSnTR/C (TR: La,Ce, Pr e Eu), foi utilizado o microscópio Jeol 2100, com cátodo de $\mathrm{LaB}_{6}$, operando a $200 \mathrm{keV}$, do IQSC na Universidade de São Paulo.

A preparação das amostras para realização do TEM consistiu em dispersar, com auxílio de um ultrassom, os catalisadores em 2-propanol; depositá-las em uma grade de cobre recoberta com carbono; e posteriormente, foram secas ao ar. A análise da distribuição dos tamanhos de partículas foi feita medindo-se no mínimo o diâmetro de 200 partículas.

\subsubsection{Espectroscopia de Fotoelétrons excitados por Raios $X$}

As medidas de XPS foram obtidas no Laboratório Nacional de Nanotecnologia (LNNano), em um espectrômetro Thermo Scientific TM K-Alpha ${ }^{\mathrm{TM}+}$. Os espectros foram coletados utilizando uma energia de fóton $\left(E_{p h}\right)$ incidente de $1487 \mathrm{eV}$, fornecida pelo monocromador de alumínio ( $\mathrm{Al} \mathrm{Ka}$ ), com energia de passagem programada para $20 \mathrm{eV}$, passo de energia de $0,05 \mathrm{eV}$ e tempo de aquisição de $100 \mathrm{~ms}$. A calibração do analisador de energia foi realizada utilizando uma folha de 


\section{Parte Experimental}

Au padrão (84 eV para Au 4f $f_{7 / 2}$ ). Todas as medições de XPS foram realizadas à temperatura ambiente.

A contribuição inelástica dos espectros dos níveis eletrônicos Pt $4 f$, Sn $3 d$, La $3 d$, Ce $3 d, \operatorname{Pr} 3 d$ e Eu $3 d$ foi subtraída utilizando o método de Shirley. Os espectros foram montados usando perfis mistos de curvas Gaussiana-Lorentziana e Doniach-Sunjic para as espécies metálicas. ${ }^{57} \mathrm{~A}$ largura total à meia-máxima (FWHM) variou entre 1,6 e 2,0 eV, e a exatidão das posições dos picos foi de $\pm 0,2 \mathrm{eV}$. O fator a da curva de Doniach-Sunjic foi de 0,03. Os parâmetros de splitting, isto é, a diferença de energia de ligação de dois estados com diferentes números quânticos, foram mantidos constantes para Pt (3,3 eV), Sn (8,4 eV), La (16,8 eV), Ce (18,1 eV), $\operatorname{Pr}(20,5 \mathrm{eV})$ e Eu $(29,8 \mathrm{eV})$, de acordo com os valores listados na literatura. ${ }^{58,59}$

\subsubsection{Espectroscopia de Absorção de Raios X}

Os experimentos de XAS in situ foram realizados nas linhas XAFS1 e XAFS2 do Laboratório Nacional de Luz Síncrotron (LNLS), ${ }^{60}$ na energia de absorção da borda $L_{3}$ da Pt ( 11565 eV), acoplado a um potenciostato/galvanostato Autolab $302 N$. A configuração adotada para os testes foi de três eletrodos. Os eletrodos de trabalho foram pastilhas, confeccionadas pela mistura de $6,0 \mathrm{mg}_{\mathrm{Pt}} \mathrm{cm}^{-2}$ do catalisador com uma solução de $\operatorname{Nafion}^{\circledR}$ (Aldrich, 6\%), na proporção mássica de $35,5 \%$. O eletrodo de referência foi reversível de hidrogênio $(E R H)$; e o contraeletrodo utilizado foi uma rede de platina. A célula eletroquímica utilizada possuía uma janela que permitia a passagem da radiação pela amostra. $O$ eletrólito utilizado foi $0,5 \mathrm{~mol} \mathrm{~L}^{-1}$ de $\mathrm{H}_{2} \mathrm{SO}_{4}$. Foram realizados $\mathrm{XAS}$ em dois potenciais: $0,5 \mathrm{~V} \mathrm{e}$ $0,9 \mathrm{~V}$.

Para a normalização dos espectros de absorção, o programa Athenas foi utilizado, de acordo com os procedimentos descritos na literatura. ${ }^{61,62}$

\subsection{CARACTERIZAÇÃO ELETROQUÍMICA}

A avaliação eletroquímica dos catalisadores trimetálicos PtSnTR/C (TR: La,Ce, Pr e Eu) foram realizadas em duas configurações: célula de três eletrodos, com o eletrodo de trabalho em forma de camada ultrafina; e célula unitária, de área próxima a $5 \mathrm{~cm}^{2}$. 


\section{Parte Experimental}

\subsubsection{Teste em Camada Ultrafina}

Para avaliação eletroquímica dos catalisadores nessa configuração, preparouse uma suspensão do material sintetizado, com álcool 2-propanol e solução de Nafion ${ }^{\circledR} 6 \%$. Com auxílio de uma microsseringa, depositou-se uma camada fina, de $28 \mathrm{\mu g}_{\text {metal }} \mathrm{cm}^{-2}$, sobre um eletrodo de carbono vítreo de $0,38 \mathrm{~cm}^{2}$. A célula eletroquímica utilizada foi de três eletrodos: de trabalho, o material em camada ultrafina; auxiliar de Pt; e de referência reversível a hidrogênio (ERH). Todos os experimentos foram realizados a $25^{\circ} \mathrm{C}$, em atmosfera de argônio. As medidas eletroquímicas foram obtidas no potenciostato/galvanostato Solartron Analytical ${ }^{\circledR}$ modelo 1285.

\subsubsection{Caracterização em meio ácido}

Inicialmente, as amostras foram submetidas a dez varreduras cíclicas de potencial entre 0,05 e $0,8 \mathrm{~V}$ vs $\mathrm{ERH}$, a $50 \mathrm{mV} \mathrm{s}^{-1}$ em solução ácida de $\mathrm{H}_{2} \mathrm{SO}_{4}$ $\left(0,5 \mathrm{~mol} \mathrm{~L}^{-1}\right)$; e após não apresentar mudanças significativas no perfil voltamétrico, realizaram-se medidas de voltametria cíclica a $20 \mathrm{mV} \mathrm{s}^{-1}$, entre 0,05 e 0,8 V vs ERH.

Para determinação de área de platina ativa utilizou-se a metodologia descrita na literatura como stripping de $\mathrm{CO}^{63}$ Nessa técnica, os catalisadores eram submetidos a um pré-tratamento de 300 segundos de borbulhamento de $\mathrm{CO}$, e em sequência, 1500 segundos com gás argônio, mantendo a célula em modo potenciostático em $0,1 \mathrm{~V} v s \mathrm{ERH}$. Sequencialmente, três voltametrias foram realizadas, entre 0,1 a $1,0 \mathrm{~V}$ vs $\mathrm{ERH}$, a $5 \mathrm{mV} \mathrm{s}^{-1}$ em $0,5 \mathrm{~mol} \mathrm{~L}^{-1}$ de $\mathrm{H}_{2} \mathrm{SO}_{4}$.

\subsubsection{Caracterização em meio etanólico}

As propriedades eletrocatalíticas em relação à oxidação de etanol foram avaliadas por voltamogramas de varredura linear a $1 \mathrm{mV} \mathrm{s}^{-1}$, entre 0,05 a $1,0 \mathrm{~V}$ vs $\mathrm{ERH}$, em solução de $\mathrm{H}_{2} \mathrm{SO}_{4}\left(0,5 \mathrm{~mol} \mathrm{~L}^{-1}\right)$ e etanol $\left(1,0 \mathrm{~mol} \mathrm{~L}^{-1}\right)$.

Medidas potenciostáticas também foram utilizadas para caracterização eletroquímica dos materiais. O potencial aplicado foi $0,600 \mathrm{~V}$ vs $\mathrm{ERH}$, por 3600 segundos, e a corrente foi coletada. As medidas potenciostáticas foram realizadas em uma camada ultrafina nova, submetidas apenas a 10 ciclos entre 0,05 a $0,8 \mathrm{~V}$ vs $\mathrm{ERH}$, a $50 \mathrm{mV} \mathrm{s}^{-1}$, em solução de $\mathrm{H}_{2} \mathrm{SO}_{4}\left(0,5 \mathrm{~mol} \mathrm{~L}^{-1}\right)$ e etanol $\left(1,0 \mathrm{~mol} \mathrm{~L}^{-1}\right)$. 


\section{Parte Experimental}

\subsubsection{Testes de envelhecimento acelerado}

Os materiais de PtSnTR/C (TR: La, Ce, Pr e Eu) sintetizados foram submetidos a sucessivas ciclagens para avaliação da estabilidade do catalisador em meio ácido. A metodologia do teste de envelhecimento acelerado adotada baseouse na literatura. ${ }^{64} \mathrm{~A}$ Figura 4.1 esquematiza o procedimento realizado. A sequência de testes era iniciada com a realização de um stripping de $\mathrm{CO}$, descrito na sessão 4.3.1.1, na qual determina-se a área superficial do material. Realizaram-se três ciclos de 0,05 a $0,6 \vee v s$ ERH a $20 \mathrm{mV} \mathrm{s}^{-1}$, para uma caracterização inicial do catalisador. Em seguida, o material era submetido a 200 ciclos de 0,3 a $0,8 \mathrm{~V}$, a $50 \mathrm{mV} \mathrm{s}^{-1}$. Em intervalos de 25 ciclos, realiza-se 3 ciclos no intervalo de 0,05 a 0,8 V. Para avaliação da perda de área do material, um stripping de $\mathrm{CO}$ foi realizado ao final dos 200 ciclos. Após o stripping, os eletrodos envelhecidos foram submetidos à voltametria linear em $\mathrm{H}_{2} \mathrm{SO}_{4}\left(0,5 \mathrm{~mol} \mathrm{~L}^{-1}\right)$ e etanol $\left(1,0 \mathrm{~mol} \mathrm{~L}^{-1}\right)$ a $1 \mathrm{mV} \mathrm{s}^{-1}$, e à cronoamperometria em $0,6 \mathrm{~V}$ por 1 hora, para observar o efeito do envelhecimento na atividade catalítica na reação de oxidação de etanol. Os catalisadores ternários também foram avaliados após ciclagem entre 0,5 a 1,0 V, como ilustrado na Fig. 4.1.

Figura 4.1 - Esquematização do procedimento de envelhecimento acelerado.
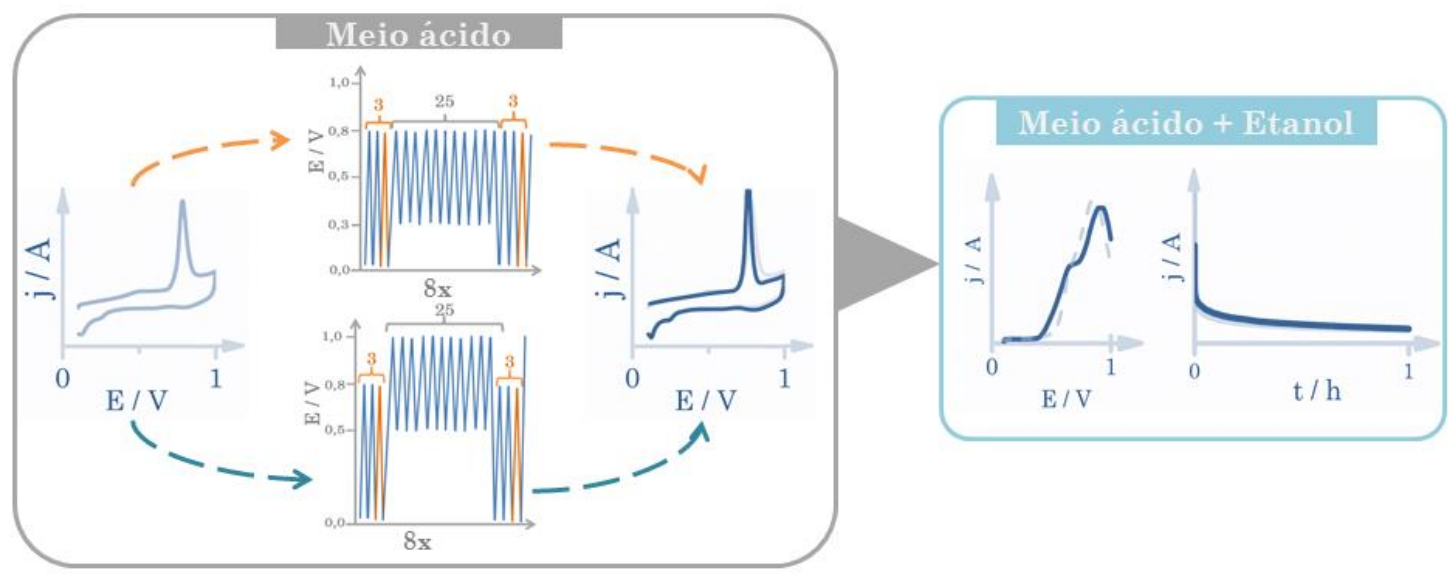

Fonte: Autoria própria.

Para os catalisadores com menor e maior perda de atividade catalítica frente a ROE, a variação da composição da camada ultrafina foi estimada por medidas de EDX antes e após dos testes de envelhecimento acelerado, entre 0,3-0,8 V. A configuração utilizada também foi de camada ultrafina, mas os eletrodos de trabalho eram removíveis (modelo Pine, área de $0,196 \mathrm{~cm}^{2}$ ), e podiam ser analisados após os 


\section{Parte Experimental}

testes eletroquímicos. Devido as limitações de detecção da técnica, uma carga metálica maior, de $100 \mu \mathrm{g}_{\text {metal }} \mathrm{cm}^{-2}$ foi utilizada nesses ensaios. Assim como os demais testes eletroquímicos, os experimentos foram realizados a $25^{\circ} \mathrm{C}$, em atmosfera de argônio e o potenciostato/galvanostato utilizado foi o Solartron Analytical ${ }^{\circledR}$ modelo 1285.

\subsubsection{Testes em Célula Unitária de $5 \mathrm{~cm}^{2}$}

Para uma avaliação mais próxima das condições de operação de uma célula a combustível, foram realizados testes em configuração de célula unitária. Nesta configuração, foram utilizados eletrodos de difusão de gás, que eram compostos de duas camadas: uma camada difusora e uma camada catalisadora. A camada difusora era composta por tecido de carbono, recoberto por pó de carbono (Vulcan XC-72R) e Teflon $^{\circledR}$ e foram confeccionadas pela metodologia desenvolvida pelo próprio grupo. ${ }^{65}$ As camadas difusoras eram fornecidas pelo laboratório e continham área geométrica de $4,625 \mathrm{~cm}^{2}$.

A camada catalisadora foi composta de $35,5 \% \mathrm{~m} / \mathrm{m}$ de Nafion ${ }^{\circledR}$ (Aldrich, 6,0\%) e de $64,5 \%$ de catalisador, com carga de $1,0 \mathrm{mg}_{\mathrm{Pt}} \mathrm{cm}^{-2}$. O catalisador e a solução de Nafion ${ }^{\circledR}$ foram homogeneizados em ultrassom e depois secos em capela. Após evaporação do solvente do $\mathrm{Nafion}^{\circledR}$, o pó obtido foi disperso em 2-propanol e, com o auxílio de um pincel, o material foi transferido uniformemente sobre a camada difusora. Após a transferência de todo o material, o eletrodo foi secado em um forno a $80^{\circ} \mathrm{C}$ por 1 hora, para retirar qualquer resíduo de solvente.

O cátodo foi mantido constante, sendo produzido com catalisador de $\mathrm{Pt} / \mathrm{C}$ comercial (ETEK $\left.{ }^{\circledR}, 30 \% \mathrm{Pt} / \mathrm{C}\right)$. O ânodo foi confeccionado de PtSnTR/C (TR: La,Ce, Pr e Eu), sintetizados por poliol.

Para o transporte de prótons entre o ânodo e cátodo, foram utilizadas membrana de Nafion ${ }^{\circledR} 115$ (DuPont). As membranas, fornecidas pelo laboratório, eram previamente tratadas com solução de $3 \%$ de $\mathrm{H}_{2} \mathrm{O}_{2}$ a $75-80{ }^{\circ} \mathrm{C}$, e com solução de $\mathrm{H}_{2} \mathrm{SO}_{4}$ 0,5 mol L $\mathrm{L}^{-1}$, para a retirada de impurezas orgânicas e metálicas; e eram acondicionadas em recipientes com água deionizada até o uso.

Os conjuntos eletrodos/membrana (MEA) foram obtidos por união de um par de eletrodos (cátodo e ânodo) à membrana e um par de espaçadores por prensagem de 50 atm, a $125^{\circ} \mathrm{C}$, por 120 segundos. Os espaçadores foram utilizados para 


\section{Parte Experimental}

compensar o excesso de volume no centro do MEA e assim, minimizar vazamentos na célula unitária.

Os MEAs foram inseridos entre duas placas de grafite, que permitiu a percolação dos combustíveis (solução de etanol no ânodo e gás oxigênio no cátodo) na camada catalítica. O sistema foi acondicionado por placas de alumínio, que eram coletores de corrente e permitiram o controle da temperatura do sistema. O fluxo dos gases e a pressão da célula foram monitorados com auxilio de uma estação de trabalho.

Para avaliação da contribuição do ânodo, medidas em meia célula foram realizadas, na qual, gás hidrogênio era injetado no cátodo, servindo como um eletrodo dinâmico de hidrogênio (EDH), e etanol 1,0 mol L-1 no ânodo. Nessa configuração foram realizadas polarizações lineares, entre 0,100 a 0,600 V vs EDH a $1,0 \mathrm{mV} \mathrm{s}^{-1}$; e medidas de cronoamperometria a $0,600 \mathrm{~V}$ por 3600 segundos.

O sistema também foi avaliado por configuração completa, na qual o gás oxigênio era injetado no cátodo, com a pressão mantida em 3 atm, e etanol no ânodo. Nesse arranjo, curvas de polarização de estado estacionário, em modo galvanostático, foram obtidas. Além disso, curvas de polarizações lineares foram realizadas, entre o potencial de circuito aberto da célula e $0,200 \vee v s$ EDH a $1,0 \mathrm{mV} \mathrm{s}^{-1}$. Todas as medidas eletroquímicas foram realizadas a $90^{\circ} \mathrm{C}$, com auxílio do potenciostato/galvanostato Autolab 302N.

\subsection{CARACTERIZAÇÃO DOS SUBPRODUTOS DA OXIDAÇÃO DE ETANOL}

A atividade catalítica frente à reação de oxidação de etanol está correlacionada ao mecanismo que o material favorece. Estudos dos subprodutos das reações podem elucidar como as propriedades físicas e eletroquímicas estão correlacionadas, algo muito controverso na literatura. Para avaliar os produtos da reação de oxidação de etanol sobre os catalisadores PtSnTR/C (TR: La, Ce, Pr e Eu), foram utilizadas as técnicas de espectroscopia vibracional na região do infravermelho com transformada de Fourier (Fourier Transform Infrared - FTIR) e cromatografia líquida de alta eficiência (High-perfomance liquid chromatography HPLC). 


\section{Parte Experimental}

\subsubsection{Espectroscopia vibracional de absorção na região do infravermelho in situ com transformada de Fourier}

As medidas de FTIR permitem a caracterização das espécies químicas em solução e/ou adsorvidas no eletrodo. É uma ferramenta útil para determinação dos subprodutos da reação de oxidação de etanol sobre os eletrocatalisadores.

Para realizar os estudos FTIR in situ foi utilizada uma célula de três eletrodos; na qual o eletrodo de trabalho de ouro policristalino (área de 0,785 $\mathrm{cm}^{2}$ ) com um filme dos catalisadores sintetizados (semelhante ao utilizado nos testes de camada ultrafina) era pressionado contra uma janela planar, de modo a se formar uma camada fina de eletrólito entre ambos. O eletrodo de referência utilizado foi reversível a hidrogênio e o contraeletrodo, uma rede de platina. A Figura 4.2 ilustra uma célula eletroquímica utilizada para as medidas de FTIR in situ. Uma parte dos experimentos foram realizados no espectrômetro Nicolet Nexus 670 e outra parte no Bruker Vertex 70V, mas ambos com janela planar de ZnSe e equipado com um detector MCT (mercúrio, cádmio e telúrio). Este sistema foi acoplado a um potenciostato Solartron SI 1287 ou Autolab 302N.

Figura 4.2 - Representação da célula eletroquímica utilizada para medidas de FTIR in situ.
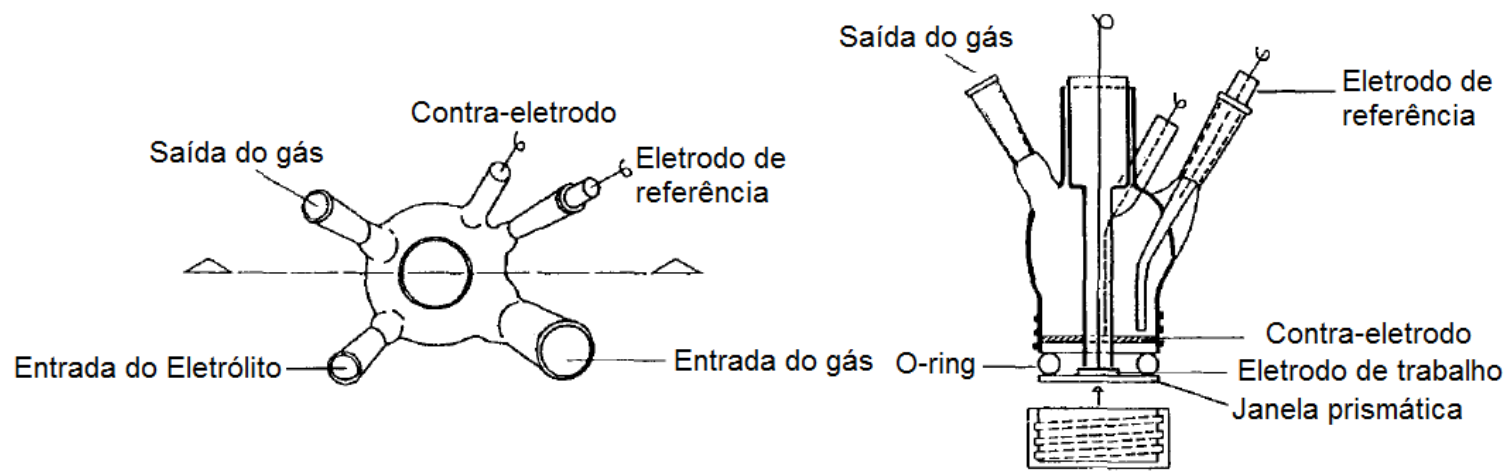

Fonte: Extraído de IWASITA, T.; NART, F.C. Progress in Surface Science. 55, 197, p. $267 .^{66}$

Os espectros coletados foram uma média de 64 interferogramas com resolução espectral de $8 \mathrm{~cm}^{-1}$. Para a obtenção dos espectros realizou-se a aquisição de um espectro de referência, $R_{0}$, que relaciona a intensidade da radiação que chega ao detector e as frequências associadas. Esse espectro foi coletado em 
$50 \mathrm{mV}$ vs ERH, potencial no qual não ocorre processos eletroquímicos na camada fina. Os espectros de refletância foram calculados por $R / R_{0}$, onde $R$ representa 0 espectro da amostra no potencial de estudo e $R_{0}$ o espectro da amostra no potencial de referência. As medidas de FTIR foram coletadas durante a aplicação de varredura linear de potencial de velocidade de $1 \mathrm{mV} \mathrm{s}^{-1}$, entre $0,2 \mathrm{~V}$ e $1,0 \mathrm{~V}$, para acompanhar a formação dos produtos da ROE e o consumo de reagente.

\subsubsection{Cromatografia Líquida de Alta Eficiência}

Para identificar e quantificar os subprodutos da ROE, utilizou-se um cromatógrafo líquido de alta eficiência da Shimadzu, modelo Prominence Ultra Fast Liquid Chromatograph, com sistema de bombeamento isocrático. Os detectores utilizados foram UV-Vis SPD-20A e RID-10A (detector de índice de refração).

Para determinação dos subprodutos da oxidação de etanol, utilizou-se a configuração de célula unitária, descrita na sessão 4.3.2. A coleta de etanol e dos subprodutos foi a mesma empregada por Rosseau et al. (2006). ${ }^{30}$ A Figura 4.3 apresenta 0 aparato experimental utilizado para coletar os produtos de reação de oxidação de etanol na saída da célula unitária de $5 \mathrm{~cm}^{2}$ (descrita na seção 4.3.2). No primeiro frasco etanol, acetaldeído e ácido acético em solução eram analisados diretamente por HPLC. No segundo frasco, o eventual acetaldeído volátil transportado do primeiro frasco reagia com um excesso de 0,45\% (em peso) de 2,4 dinitrofenilhidrazina em uma solução de $2,0 \mathrm{~mol} \mathrm{~L}^{-1}$ de $\mathrm{HCl}$, de acordo com a equação 4.1.

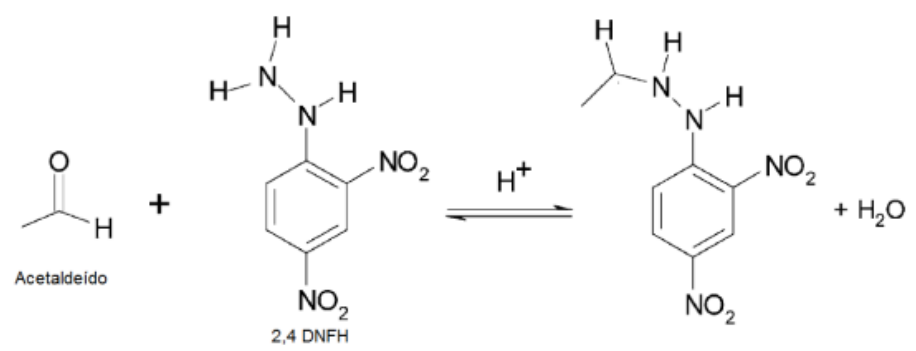




\section{Parte Experimental}

Figura 4.3 - Aparato experimental para coletar os produtos da reação de oxidação de etanol na saída da célula unitária, para análise em HPLC.

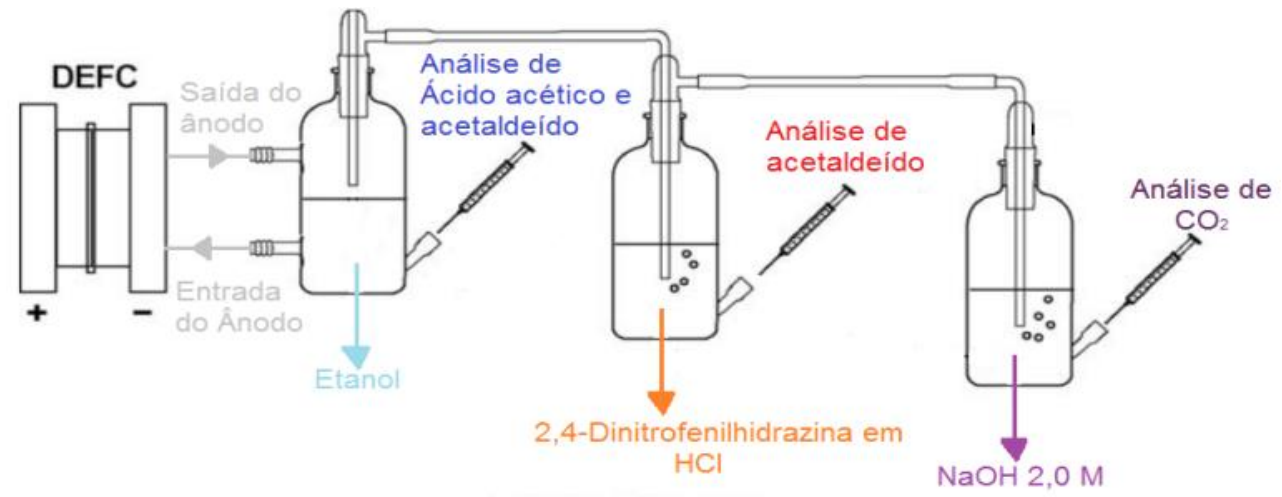

Fonte: Adaptado de ROUSSEAU, S.; COUTANCEAU, C.; LAMY, C.; LEGER, J.M. Journal of Power Sources. 158, 2006, p. 20. ${ }^{30}$

O precipitado laranja foi solubilizado em acetato de etila e analisado por HPLC. No terceiro frasco, o $\mathrm{CO}_{2}$ formado era coletado, e reagia com 2,0 mol L $\mathrm{L}^{-1} \mathrm{de}$ $\mathrm{NaOH}$, formando íons carbonato $\left(\mathrm{CO}_{3}{ }^{2-}\right)$. Os ânions $\mathrm{CO}_{3}{ }^{2-}$ eram detectados no RID, pela formação de um pico negativo.

Duas colunas diferentes foram empregadas, de acordo com os produtos a serem analisados. Para $\mathrm{CO}_{3}{ }^{2-}$, acetaldeído e ácido acético, a coluna cromatográfica HPX87H, foi utilizada (BIO-RAD, modelo Aminex de $300 \mathrm{~mm}$ de comprimento e $7,8 \mathrm{~mm}$ de diâmetro). A fase móvel foi uma solução aquosa de ácido sulfúrico 3,33 $\mathrm{mmol} \mathrm{L}^{-1}$, com fluxo de 0,6 $\mathrm{mL} \mathrm{min}^{-1}$. Para derivados de hidrazina, uma coluna C18, com eluente de acetronitrila (60:40 em água), foi utilizada, com o fluxo de $0,6 \mathrm{~mL} \mathrm{~min}^{-1}$. Ácido acético e acetaldeído foram identificados pelo detector UV, com comprimento de onda de $240 \mathrm{~nm}$, e para identificar $\mathrm{CO}_{3}{ }^{2-}$ e etanol, o detector de índice de refração foi empregado.

Para a coleta dos produtos, foram realizadas cronoamperometrias nos potenciais de $0,5 \mathrm{~V}$ e $0,6 \mathrm{~V}$ por 1 hora, em configuração de meia célula (abastecimento de etanol no ânodo e hidrogênio no cátodo). Na configuração de célula completa, no qual o cátodo era abastecido por oxigênio, foram realizadas medidas galvanostáticas em $8 \mathrm{~mA} \mathrm{~cm}^{-2}, 16 \mathrm{~mA} \mathrm{~cm}^{-2}$ e $30 \mathrm{~mA} \mathrm{~cm}^{-2}$, por 20 minutos. 


\section{CAPÍTULO III}

O capítulo III compreende a primeira seção da parte de resultados e discussão. Este contempla os catalisadores trimetálicos à base de platina-estanho e európio, no qual avaliou-se diferentes proporções entre os metais e a atividade eletrocalítica frente à reação de oxidação de etanol.

\section{RESULTADOS E DISCUSSÃO: CATALISADORES PtSnEu/C}

\subsection{SÍNTESE DOS ELETROCATALISADORES PtSnEu/C}

O uso de um diol ou poliálcool, como etileno glicol, para reduzir sais de metal para partículas metálicas é conhecido como método do poliol. ${ }^{67} \mathrm{~A}$ redução dos precursores é realizada por um alcano-diol (que no caso foi o hexadecanodiol). $O$ método de síntese foi proposto por Sun (2006) para síntese de partículas bimetálicas de Fe-Pt. ${ }^{67} \mathrm{De}$ acordo com a literatura, um pequeno grupo de átomos $\mathrm{M}$ e $\mathrm{Pt}$ se combinam para formar clusters [Pt-M], que atuam como núcleos. O crescimento prossegue e mais espécies Pt-M são depositadas ao redor do núcleo, formando nanopartículas de Pt-M. O ácido oleico e a oleilamina são usadas para proteger e estabilizar a superfície da partícula. Para materiais trimetálicos, o mecanismo de formação seria semelhante, apenas acrescentando o terceiro metal ao cluster. A Figura 5.1 representa a formação de nanopartículas trimetálicas (platina, estanho e terras raras), baseado neste modelo. ${ }^{67}$ Além da redução dos metais, há a liberação dos grupos acetil acetonato e acetonatos (representados na Fig. 5.1 por acac e ac) dos precursores, que podem ficar no meio reacional ou sofrer decomposição térmica, devido à temperatura de refluxo.

O método descrito por Sun era satisfatório para obtenção de partículas de bimetálicas de PtSn, mas não promovia a incorporação do terra rara. Baseado em alterações no método do ácido fórmico ${ }^{68}$ alterou-se a concentração de hidroxilas do meio da síntese (dioctiléter). A adição de uma base $(\mathrm{KOH})$ favoreceu a precipitação 


\section{Resultados e Discussão: Catalisadores PtSnEu/C}

do európio. Apesar desta alteração, espera-se que o mesmo mecanismo de redução das partículas metálicas, ilustrado na Figura 5.1, ocorra.

Figura 5.1 - Representação esquemática da formação de nanopartículas de Pt-Sn-TR, da redução de precursores de acetilacetonado de Pt e Terras Raras (TR) e acetato de Sn.

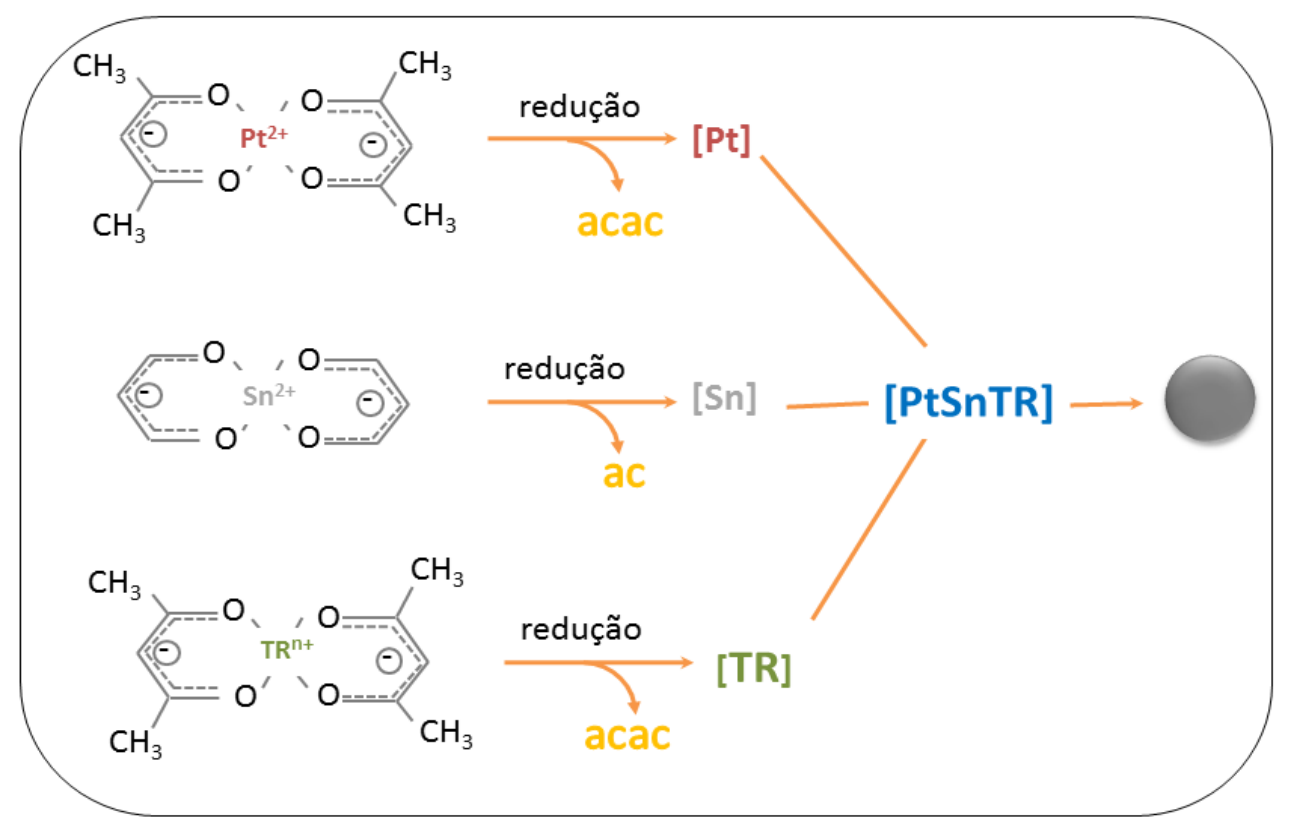

Fonte: Autoria própria.

Os catalisadores $\mathrm{Pt} / \mathrm{C}, \mathrm{PtSn} / \mathrm{C}$ e trimetálicos de $\mathrm{PtSnEu} / \mathrm{C}$ foram obtidos por esse método. Para avaliar qual a composição química e física obtidas nos catalisadores sintetizados, os materiais foram caracterizados fisicamente por várias técnicas conforme descrito a seguir.

\subsection{CARACTERIZAÇÃO FÍSICA}

A caracterização física dos materiais ternários $\mathrm{PtSnEu} / \mathrm{C}$, foi realizada por diferentes técnicas: espectroscopia de raios $X$ por energia dispersiva (EDX), emissão óptica por plasma acoplado indutivamente (ICP), difração de raios $X(D R X)$, espectroscopia de fotoelétrons excitados por raios X (XPS) e espectroscopia de absorção de raios $X$ (XAS). 


\section{Resultados e Discussão: Catalisadores PtSnEu/C}

\subsubsection{Determinação da Composição Química}

A determinação da concentração dos metais precursores nos catalisadores $\mathrm{Pt} / \mathrm{C}, \mathrm{PtSn} / \mathrm{C}$ e PtSnEu/C sintetizados por poliol foram realizadas pelas técnicas de EDX e de ICP. A Tabela 5.1 indica as proporções atômicas entre os metais e a concentração mássica do carbono (ou \%metal) dos catalisadores pelas diferentes técnicas. Observa-se que a presença de platina, estanho e európio foram confirmadas por ambas técnicas. As pequenas diferenças nas composições determinadas por EDX e ICP podem ser justificadas pelo fato do resultado do EDX ser uma média da composição de três áreas do material, enquanto a amostragem utilizada pela técnica de ICP ser mais representativa. Por esse critério, adotou-se a composição atômica nominal os resultados obtidos por ICP, que serão identificados no texto como: Pt/C, PtSn/C 60:40, PtSnEu 75:20:05, PtSnEu/C 65:25:10 e $\mathrm{PtSnEu} / \mathrm{C}$ 50:30:20.

Tabela 5.1 - Composição atômica dos materiais $\mathrm{Pt} / \mathrm{C}, \mathrm{PtSn} / \mathrm{C}$ e ternários $\mathrm{PtSnEu} / \mathrm{C}$ sintetizados pelo método do poliol.

\begin{tabular}{ccccc}
\hline Catalisador & $\begin{array}{c}\text { Composição } \\
\text { atômica por } \\
\text { EDX }\end{array}$ & $\begin{array}{c}\text { \% mássica } \\
\text { do carbono }\end{array}$ & $\begin{array}{c}\text { Composição } \\
\text { atômica por } \\
\text { ICP }\end{array}$ & $\begin{array}{c}\text { Metal por } \\
\text { ICP (\%) }\end{array}$ \\
\hline $\mathrm{Pt} / \mathrm{C}$ & 100 & 89 & & \\
$\mathrm{PtSn} / \mathrm{C} 60: 40$ & $62: 38$ & 84 & & \\
$\mathrm{PtSnEu} / \mathrm{C} 75: 20: 05$ & $74: 20: 06$ & 80 & $77: 19: 04$ & 15,2 \\
$\mathrm{PtSnEu} / \mathrm{C} 65: 25: 10$ & $61: 24: 15$ & 83 & $66: 25: 09$ & 16,2 \\
$\mathrm{PtSnEu} / \mathrm{C} 50: 30: 20$ & $49: 34: 17$ & 84 & $52: 31: 17$ & 14,0 \\
\hline
\end{tabular}

As diferenças entre as concentração de carbono foram mais expressivas. Por EDX, os valores variaram de 80 a $89 \%$; enquanto para ICP, o valores foram próximos a $85 \%$. Visto que a técnica de EDX não é tão eficaz para elementos leves, e a concentração de carbono não ser determinada diretamente pela técnica de ICP, outra técnica foi utilizada para avaliar a concentração de metal presentes nos catalisadores sintetizados: análise termogravimétrica.

\subsubsection{Análise Termogravimétrica}

Outra técnica muito útil para caracterização física de eletrocatalisadores é a análise termogravimétrica. Por essa técnica, a massa da amostra é monitorada 


\section{Resultados e Discussão: Catalisadores PtSnEu/C}

durante um aumento de temperatura a taxa constante, e processos endotérmicos e exotérmicos podem ser acompanhados. As decomposições térmicas obtidas para os catalisadores Pt/C, PtSn/C, PtSnEu/C sintetizados podem ser vistas na Figura 5.2 a. Apenas uma acentuada queda pôde ser observada entre as temperaturas 400$600^{\circ} \mathrm{C}$, dependendo da composição do catalisador. Essa queda é atribuída à queima do carbono, utilizado como suporte. ${ }^{69}$ É possível aferir que a redução da concentração de Pt aumentou a temperatura de combustão. O mesmo comportamento já foi observado por Lim et al. (2009), que relaciona a platina como catalisador da reação de oxidação do carbono. ${ }^{70}$ Para melhor visualização do processos térmicos, a diferencial da curva está demonstrada na Figura $5.2 \mathrm{~b}$. A combustão do carbono variou de $460{ }^{\circ} \mathrm{C}$ para $\mathrm{Pt} / \mathrm{C}$, a $590{ }^{\circ} \mathrm{C}$ para $\mathrm{PtSnEu} / \mathrm{C}$ 50:30:20. Nesse gráfico, ainda é possível observar mais um processo, próximo a $150{ }^{\circ} \mathrm{C}$, para todos os catalisadores sintetizados por poliol (inset na Fig. $5.2 \mathrm{~b}$ ). Processos próximos a essas temperaturas são normalmente relacionados à remoção de água adsorvida fisicamente dos catalisadores. ${ }^{70}$ Como esse processo foi observado tanto para catalisadores de $\mathrm{Pt} / \mathrm{C}$, bimetálico $\mathrm{PtSn} / \mathrm{C}$ e para os trimetálicos $\mathrm{PtSnEu} / \mathrm{C}$, dificilmente esses picos estão correlacionado a mudança dos óxidos e óxi-hidróxidos de estanho e európio presentes no catalisador. Ao analisar a não existência de outros picos expressivos relacionados a contaminantes orgânicos, pode-se afirmar que a limpeza das partículas foi satisfatória.

Figura 5.2 - (a) Decomposição térmica e (b) diferencial das curvas térmicas dos catalisadores $\mathrm{Pt} / \mathrm{C}, \mathrm{PtSn} / \mathrm{C}$ e $\mathrm{PtSnEu} / \mathrm{C}$ sintetizados por poliol. $\Delta \mathrm{T}=5^{\circ} \mathrm{C} \mathrm{min}^{-1}$;

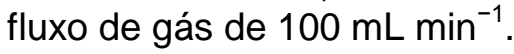
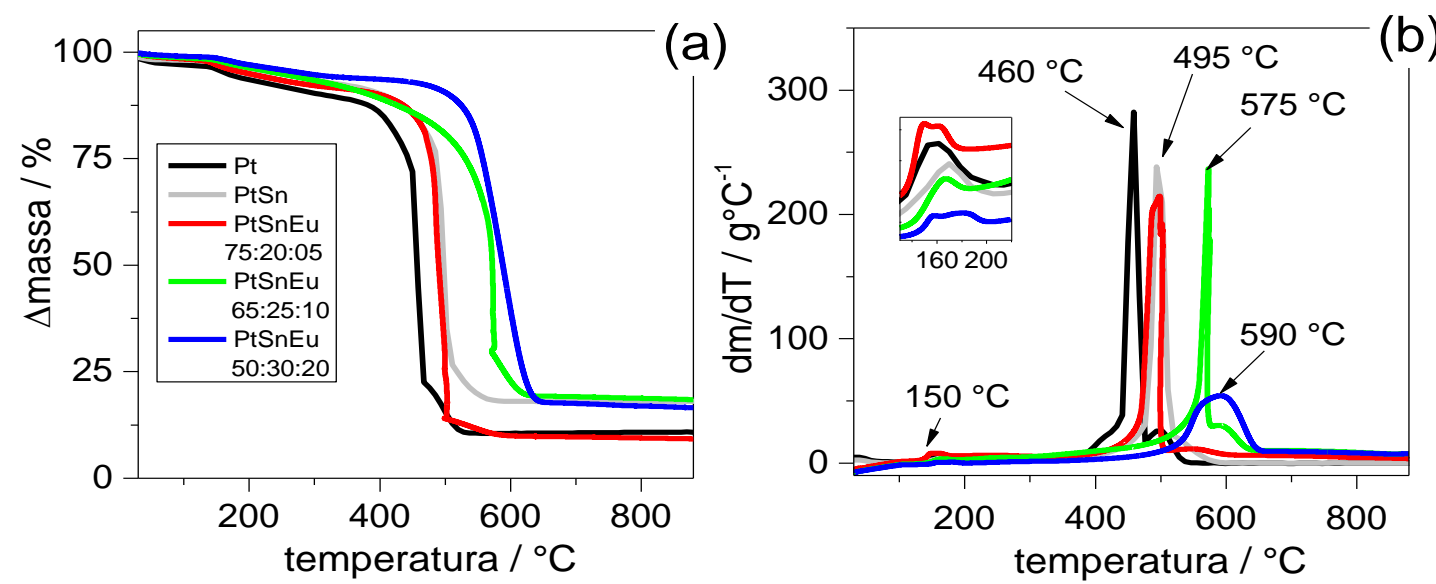

Fonte: Autoria própria. 
Resultados e Discussão: Catalisadores PtSnEu/C

As cargas metálicas obtidas por termogravimetria estão apresentadas na Tabela 5.2. Exceto para Pt/C e PtSnEu/C 75:20:05, os demais catalisadores apresentaram valores maiores próximos a $20 \%$ massa/massa; maiores que os obtidos por ICP e EDX. Devido a diferenças dos valores, quando necessário a comparação de atividade mássica, os valores obtidos por ATG serão considerados.

Tabela 5.2 - Carga metálica obtida por análise termogravimétrica dos catalisadores Pt/C, $\mathrm{PtSn} / \mathrm{C}$ e PtSnEu/C, obtidos por poliol.

\begin{tabular}{cc}
\hline Catalisador & Carga de metal (\%) \\
\hline $\mathrm{Pt} / \mathrm{C}$ & 10,5 \\
$\mathrm{PtSn} / \mathrm{C}$ 60:40 & 18,0 \\
$\mathrm{PtSnEu} / \mathrm{C}$ 75:20:05 & 9,0 \\
$\mathrm{PtSnEu} / \mathrm{C}$ 65:25:10 & 19,1 \\
$\mathrm{PtSnEu} / \mathrm{C}$ 50:30:20 & 17,5 \\
\hline
\end{tabular}

\subsubsection{Difração de Raios X}

Os difratogramas dos materiais $\mathrm{Pt} / \mathrm{C}, \mathrm{PtSn} / \mathrm{C}$ e $\mathrm{PtSnEu} / \mathrm{C}$ sintetizados por poliol estão representados na Figura 5.3. $O$ pico em $2 \theta$ igual a $26,0^{\circ}$, presente em todas as composições, refere-se ao plano hexagonal (002) do carbono utilizado como suporte. Em todos os materiais sintetizados foi possível observar os picos (111), (200), (220) e (311) referentes a platina cfc (cúbica de face centrada). ${ }^{71}$ Para os catalisadores $\mathrm{PtSn} / \mathrm{C}$ e $\mathrm{PtSnEu} / \mathrm{C}$, os picos da $\mathrm{Pt}$ cfc apresentaram um pequeno deslocamento. A Fig. 5.3 apresenta um destaque referente ao plano (220) da Pt, para melhor visualização deste efeito. Para o catalisador PtSn/C 60:40, foi possível observar os picos relacionados à presença de óxidos de estanho IV, listados na literatura em $33^{\circ}$ e $52^{\circ}$, (indicados por duas setas na Fig. 5.3). ${ }^{71}$ Para os demais catalisadores, os quais os picos de $\mathrm{SnO}_{2}$ não foram observados, provavelmente 0 estanho não ligado deve estar na forma de óxido amorfo. Também não foi possível observar picos relacionados aos planos cristalinos (102), (110) e (202) da liga PtSn,

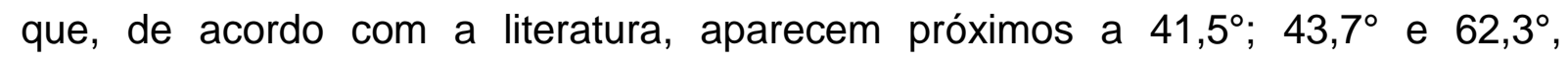
respectivamente. ${ }^{72}$ Apesar de não ser observados picos referentes a óxidos de európio ou európio metálico, não se descarta a presença do terra rara, pois este pode se encontrar em pequenas concentrações ou na forma de óxidos e oxihidróxidos amorfos. 


\section{Resultados e Discussão: Catalisadores PtSnEu/C}

Figura 5.3 - Difratogramas dos eletrocatalisadores de Pt/C, PtSn/C 60:40 e PtSnEu/C sintetizados pelo método do poliol. No destaque, a linha tracejada refere-se ao plano Pt (220) em estrutura cfc.

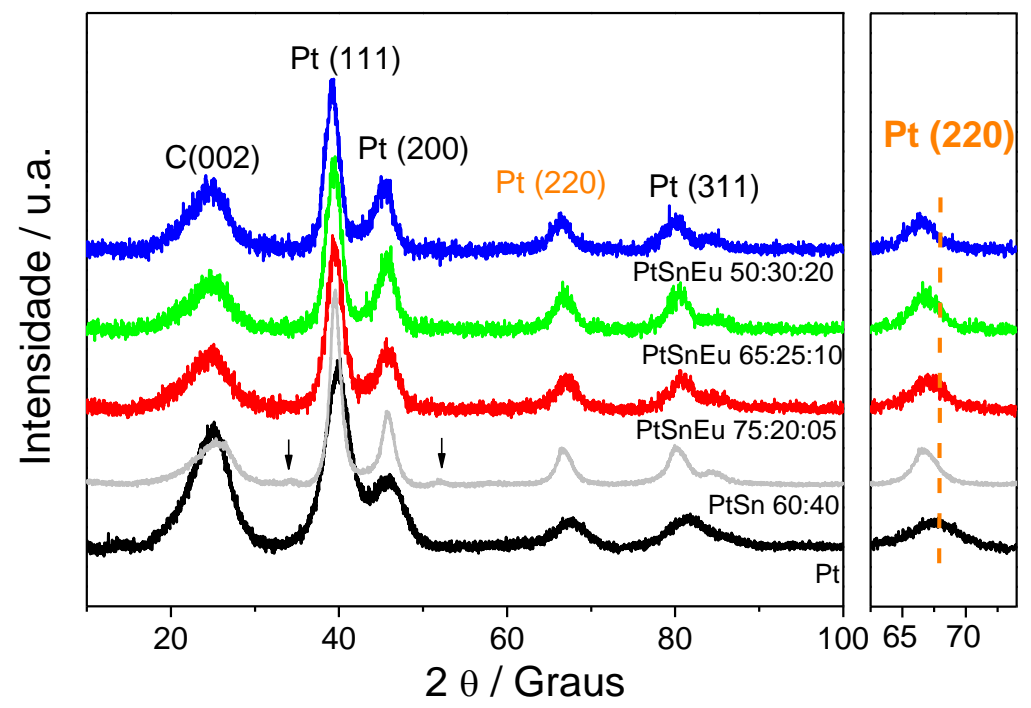

Fonte: Autoria própria.

Os tamanhos médios de cristalito dos catalisadores foram estimados pela equação de Scherrer, que assume que as partículas são esféricas: ${ }^{73}$

$$
d=\frac{k \lambda}{\beta \cos \theta}
$$

onde $(\mathrm{d})$ = tamanho médio do cristalito na direção do plano de difração; $(\mathrm{k})=$ constante de proporcionalidade igual a 0,$9 ;(\lambda)=$ comprimento de onda da radiação incidente; $(\theta)$ = ângulo de difração; $(\beta)$ = largura da meia altura do pico de difração, aproximado por uma gaussiana.

O pico de difração Pt (220) foi escolhido para estimar o tamanho de cristalito médio pela equação de Scherrer, pois este é o que apresenta menor influência do suporte de carbono. ${ }^{74}$ A partir do pico Pt (220) também foi calculado o parâmetro de rede dos materiais $\left(a_{\text {exp }}\right)$, determinado pela equação $5.2^{75}$; e a distância interatômica entre dois átomos de platina $\left(d_{c f c}\right)$, determinada pela equação $5.3:^{35}$

$$
\begin{aligned}
& a_{\text {exp }}=\frac{\lambda \sqrt{2}}{\operatorname{sen} \theta} \\
& d_{c f c}=\frac{\sqrt{2}}{2} a_{\text {exp }}
\end{aligned}
$$

A incorporação de metais terras raras em forma de liga é pouco favorecida nas condições de síntese adotadas. Mesmo em processos metalúrgicos, a formação de 


\section{Resultados e Discussão: Catalisadores PtSnEu/C}

liga Pt-Eu é difícil. landelli e Palenzona (1981) estudaram diagramas de fase de EuPt e demostraram que a formação de ligas são favorecidas apenas para maiores concentrações de európio, por volta de $80 \%$ em proporção atômica. ${ }^{76}$ Com o aumento da concentração de $\mathrm{Pt}$, o ponto de fusão da mistura aumenta significativamente, até $1055^{\circ} \mathrm{C}$ a 44,5\% Pt. Parece não existir uma única fase $\mathrm{Pt}_{3} \mathrm{Eu}$; ligas dessa composição são difásicas e as reflexões dos raios $\mathrm{X}$ indicam uma limitação de solubilidade para $\mathrm{Pt}_{2,8} \mathrm{Eu} .{ }^{76}$ Por outro lado, a formação de ligas $\mathrm{Sn}$-Eu, pode ser mais favorecida. De acordo com estudos termodinâmicos de Liu et al. (2004), é possível obter a fase $\mathrm{EuSn}_{3}$ por volta de $502 \mathrm{~K} .{ }^{77}$ Entretanto, não foi observado nenhum pico referente a essa fase nos difratogramas obtidos para os catalisadores PtSnEu.

O deslocamento do pico do Pt (200) provavelmente refere-se apenas à formação de liga PtSn. Supondo que todo o deslocamento observado esteja relacionado com a formação de liga $\mathrm{Pt}_{3} \mathrm{Sn}$ (a composição mais próxima aos catalisadores sintetizados), estimou-se o grau de liga do estanho utilizando a equação $5.4:^{6}$

$$
f_{S n}=\left[\frac{a_{c}-a_{0}}{a_{S}-a_{0}}\right] \chi_{S n}
$$

onde $\left(a_{c}\right)=$ parâmetro de rede obtido experimentalmente; $\left(a_{0}\right)=$ parâmetro da $\mathrm{Pt} / \mathrm{C}$ obtido da literatura $(3,9206 \AA)^{78}$, comparável ao tamanho dos catalisadores obtidos; $\left(a_{s}\right)=$ parâmetro para liga $\mathrm{Pt}_{3} \mathrm{Sn} / \mathrm{C}(4,0015 \AA, 100 \% \text { ligado })^{79}$, 80 ; e $\left(\chi_{S n}\right)=$ fração atômica de $\mathrm{Sn}$ no material de referência.

Os tamanhos médio de cristalito $(d)$, parâmetro de rede $\left(a_{\text {exp }}\right)$ e a distância interatômica $\left(d_{c f c}\right)$ para os materiais $\mathrm{Pt} / \mathrm{C}, \mathrm{PtSn} / \mathrm{C}$ e PtSnEu/C estão na Tabela 5.3. Os valores de $d$ observados para o material binário e para os materiais ternários foram maiores que a Pt/C (2,3 nm). Os tamanhos obtidos para os materiais ternários ficaram próximos em todas as composições sintetizadas, por volta de $3,6 \mathrm{~nm}$ e inferior ao catalisador binário $\mathrm{PtSn} / \mathrm{C}$, que apresentou $d$ igual $4,3 \mathrm{~mm}$. Os valores de $a_{\text {exp }}$ e $d_{c f c}$ para os catalisadores $\mathrm{PtSn} / \mathrm{C}$ e ternários foram maiores que os apresentados pela platina pura, indicando que a adição de estanho promoveu uma expansão da rede cristalina cfc da Pt. Ao estimar o grau de liga, observa-se que o todos os catalisadores apresentaram certo grau de incorporação, e o quanto maior a razão atômica Pt/Sn, maior a incorporação de estanho na liga. Para o catalisador 
Resultados e Discussão: Catalisadores PtSnEu/C

binário $\mathrm{PtSn} / \mathrm{C}$ 60:40, a incorporação estimada foi de $20 \%$, e para os catalisadores ternários, o grau de liga em estanho variou de 6\% para a composição PtSnEu 75:20:05, a 27\% para o catalisador PtSnEu/C 50:30:20.

Tabela 5.3 - Tamanho médio de cristalito $(d)$, parâmetro de rede $\left(a_{\exp }\right)$ e a distância interatômica $\left(d_{c f c}\right)$ e grau de estanho na forma de liga $\left(f_{S n}\right)$ para os catalisadores $\mathrm{Pt} / \mathrm{C}$ e $\mathrm{PtSn} / \mathrm{C}$ 60:40 e PtSnEu/C obtidos por poliol.

\begin{tabular}{ccccc}
\hline Catalisador & $\boldsymbol{d}(\mathbf{n m})$ & $\boldsymbol{a}_{\exp }(\dot{\mathbf{A}})$ & $\boldsymbol{d}_{\text {cfc }}(\dot{\mathbf{A}})$ & $\boldsymbol{f}_{\boldsymbol{S n}}(\%)$ \\
\hline Pt/C & 2,3 & 3,92 & 2,77 & \\
PtSn/C 60:40 & 4,3 & 3,96 & 2,80 & 20 \\
PtSnEu/C 75:20:05 & 3,4 & 3,94 & 2,79 & 6 \\
PtSnEu/C 65:25:10 & 3,6 & 3,95 & 2,79 & 12 \\
PtSnEu/C 50:30:20 & 3,6 & 3,98 & 2,81 & 27 \\
\hline
\end{tabular}

Wang et al. (2010) sintetizaram PtSnEu/C, dissolvendo os precursores em meio ácido, e utilizaram etilenoglicol e ácido fórmico como redutores. Os $a_{\text {exp }}$ obtidos por este método para os catalisadores PtSnEu variaram de 3,925 $\AA$ a 3,929 $\AA$. Nesse trabalho, apenas os catalisadores $\mathrm{Pt}_{3} \mathrm{Sn}_{1} / \mathrm{C}$ (76:24) e $\mathrm{Pt}_{3} \mathrm{Sn}_{1} \mathrm{Eu}_{1} / \mathrm{C}$ (61:22:17) tiveram os graus de liga $\mathrm{Pt}-\mathrm{Sn}$ estimados, de $15 \%$ e $17 \%$, respectivamente. ${ }^{49}$ Ao analisar os dados obtidos para catalisadores PtSnEu/C sintetizados por poliol, observa-se que a síntese adotada promoveu a obtenção de maiores parâmetros de rede e consequentemente, maior incorporação de estanho grau em forma de liga.

\subsubsection{Espectroscopia por Fotoelétrons excitados por Raios X}

XPS é muito empregado no estudo de catalisadores heterogêneos. A técnica mede a energia de ligação do caroço de fotoelétrons ejetados a partir de átomos próximos da superfície da amostra. A técnica pode ser usada como uma ferramenta analítica visto que as informações das alturas e áreas de pico, em relação às energias de ligação, permitem a identificação dos compostos presentes e fornecem estimativas de sua concentrações relativas. ${ }^{81}$ A Figura 5.4 apresenta os espectros de XPS dos catalisadores Pt/C, PtSn/C e PtSnEu/C sintetizados por poliol em um amplo intervalo de energia. Nesta varredura é possível observar picos dominantes de carbono, utilizado como suporte; a presença de oxigênio, de platina, de estanho e de európio. Não foi identificada nenhuma possível contaminação nos catalisadores sintetizados. 


\section{Resultados e Discussão: Catalisadores PtSnEu/C}

Figura 5.4 - Espectros amplos de XPS dos catalisadores Pt/C, PtSn/C e PtSnEu/C sintetizados por poliol.

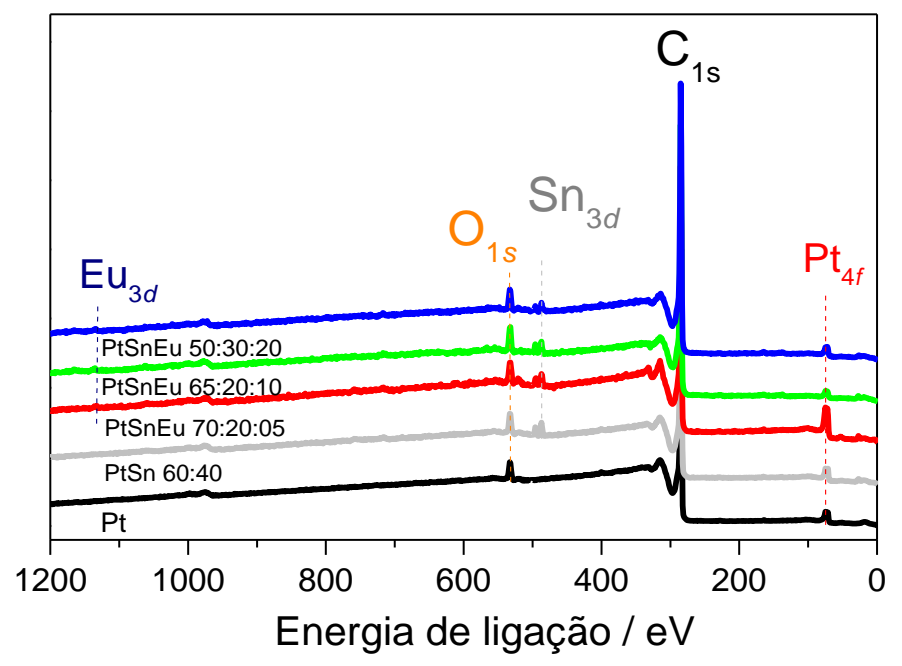

Fonte: Autoria própria.

A Figura 5.5 representa os espectros de XPS nas regiões de energia de ligação relacionadas aos orbitais $\mathrm{Pt} 4 f, \mathrm{Sn} 3 d$ e Eu $3 d$ dos catalisadores sintetizados por poliol. Os espectros de $\mathrm{Pt} 4 f$ foram deconvoluídos em três dubletos, que correspondem a diferentes estados de oxidação da Pt $4 f_{7 / 2}$ e da Pt $4 f_{5 / 2}$. As energias de ligação obtidas para os componentes dos picos de $\mathrm{Pt} 4 f_{7 / 2}$ estão apresentadas na Tabela 5.4, juntamente com a porcentagem atômica para cada sinal.

$\mathrm{Na}$ região do espectro $\mathrm{Pt} 4 \mathrm{f}_{7 / 2}$, a linha com maior intensidade está centrada em $71,2( \pm 0,2)$ eV e de acordo com a literatura, é atribuída à presença de Pt metálica; de valência zero. ${ }^{58}$ A linha de intensidade intermediária está centrada em 72,1 $( \pm 0,2)$ eV e é atribuída a valência $\mathrm{Pt}^{2+}$, normalmente apresentada como $\mathrm{Pt}(\mathrm{OH})_{2}$ ou $\mathrm{PtO} .^{70,82}$ Em 74,2 $( \pm 0,1)$ eV há outro pico, de menor intensidade, relacionado com $\mathrm{Pt}^{4+}$, que pode ser relacionada a óxidos ou a oxi-hidratados, como $\mathrm{PtO}_{2}$ e $\mathrm{PtO}_{2} \cdot n \mathrm{H}_{2} \mathrm{O}$. ${ }^{70,82} \mathrm{Os}$ catalisadores $\mathrm{Pt} / \mathrm{C}$ e $\mathrm{PtSn} / \mathrm{C}$ apresentaram valores de $\mathrm{Pt}^{0}, \mathrm{Pt}^{2+}$ e $\mathrm{Pt}^{4+}$ semelhantes entre si, próximos a 54\%, 35\% e 10\%, respectivamente (Tabela 5.4). Os catalisadores trimetálicos $\mathrm{PtSnEu/C}$ apresentaram semelhante contribuição de $\mathrm{Pt}^{4+}$ comparado aos materiais $\mathrm{Pt} / \mathrm{C}$ e $\mathrm{PtSn} / \mathrm{C}$. Também foi observada uma maior contribuição para a Pt metálica para os catalisadores trimetálicos, de 65 a 72\%; e uma redução na concentração da $\mathrm{Pt}^{2+}$, que variou entre 19 a $26 \%$. 
Resultados e Discussão: Catalisadores PtSnEu/C

Figura 5.5 - Espectros de XPS para Pt 4f, Sn 3d e Eu $3 d$ para os catalisadores Pt/C, PtSn/C 60:40 e PtSnEu/C sintetizados por poliol.

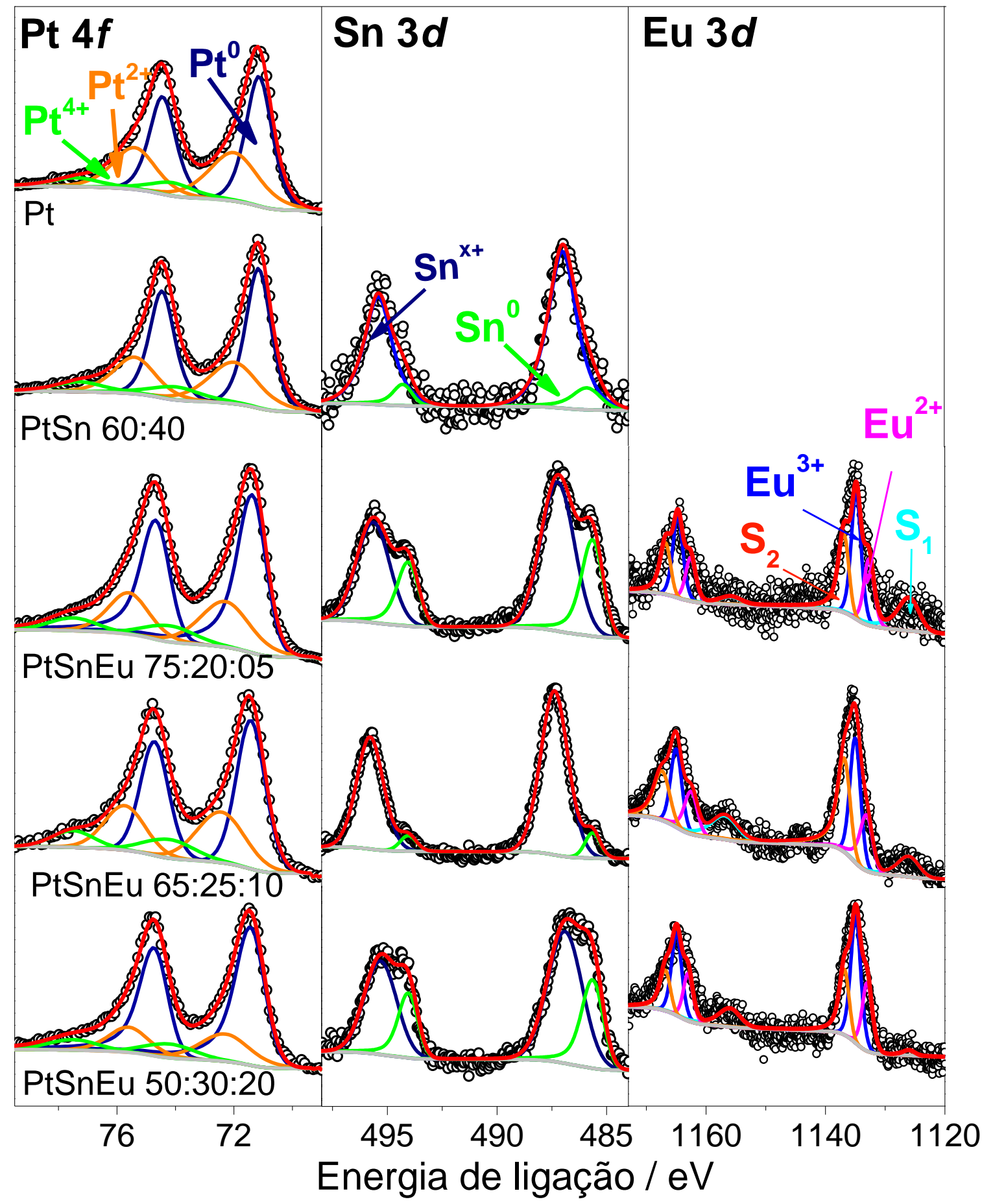

Fonte: Autoria própria. 
Resultados e Discussão: Catalisadores PtSnEu/C

Tabela 5.4 - Energia de ligação, em eV, dos Pt $4 f_{7 / 2}$, Sn $3 d_{5 / 2}$ e Eu $3 d_{5 / 2}$ para os catalisadores Pt/C, PtSn/C 60:40 e PtSnEu/C sintetizados por poliol; as porcentagens atômicas para cada sinal; e a composição atômica superficial, calculada por XPS.

\begin{tabular}{|c|c|c|c|c|c|c|c|}
\hline Materiais & $\begin{array}{l}\text { Composição } \\
\text { superficial } \\
\text { por XPS (at\%) }\end{array}$ & Pt $4 f_{7 / 2}$ & Espécies & $\operatorname{Sn} 3 d_{5 / 2}$ & Espécies & Eu $3 d_{5 / 2}$ & Espécies \\
\hline Pt & 100 & $\begin{array}{l}71,1(53) \\
72,0(37) \\
74,1(10) \\
\end{array}$ & $\begin{array}{l}\mathrm{Pt}^{0} \\
\mathrm{Pt}^{2+}-\mathrm{Pt}(\mathrm{OH})_{2} \\
\mathrm{Pt}^{4+}-\mathrm{PtO}_{2} ; \mathrm{PtO}_{2} \cdot \mathrm{nH}_{2} \mathrm{O}\end{array}$ & & & & \\
\hline \multirow{2}{*}{$\begin{array}{l}\text { PtSn } \\
60: 40\end{array}$} & \multirow{2}{*}{$86: 14$} & $\begin{array}{l}71,2(56) \\
72,0(33)\end{array}$ & $\begin{array}{l}\mathrm{Pt}^{0} \\
\mathrm{Pt}^{2+}-\mathrm{Pt}(\mathrm{OH})_{2}\end{array}$ & 485,6 (23) & & & \\
\hline & & $74,0(11)$ & $\mathrm{Pt}^{4+}-\mathrm{PtO}_{2} ; \mathrm{PtO}_{2} \cdot n \mathrm{H}_{2} \mathrm{O}$ & 487,3 (77) & $\begin{array}{l}\mathrm{Sn}^{2,4+}-\mathrm{SnO} \\
\mathrm{SnO}_{2}\end{array}$ & & \\
\hline \multirow{3}{*}{$\begin{array}{l}\text { PtSnEu } \\
75: 20: 05\end{array}$} & \multirow{3}{*}{$77: 19: 4$} & $71,4(65)$ & $\mathrm{Pt}^{0}$ & \multirow{2}{*}{ 485,6 (32) } & \multirow{2}{*}{$\mathrm{Sn}^{0}$} & $1134,9(34)$ & $\mathrm{Eu}^{3+}-\mathrm{Eu}_{2} \mathrm{O}_{3}$ \\
\hline & & $72,3(26)$ & $\mathrm{Pt}^{2+}-\mathrm{Pt}(\mathrm{OH})_{2}$ & & & $1126,0(18)$ & Satélite 1- "Shake-down" \\
\hline & & $74,2(9)$ & $\mathrm{Pt}^{4+}-\mathrm{PtO}_{2} ; \mathrm{PtO}_{2} \cdot n \mathrm{H}_{2} \mathrm{O}$ & $487,2(68)$ & $\begin{array}{l}\mathrm{Sn}^{2,4+}-\mathrm{SnO} \\
\mathrm{SnO}_{2}\end{array}$ & $\begin{array}{l}1132,8(18) \\
1137,0(30) \\
\end{array}$ & $\begin{array}{l}\mathrm{Eu}^{2+}-\mathrm{EuO} \\
\text { Satélite 2- "Shake-up" }\end{array}$ \\
\hline \multirow{3}{*}{$\begin{array}{l}\text { PtSnEu } \\
65: 25: 10\end{array}$} & \multirow{3}{*}{$39: 42: 19$} & $71,4(68)$ & $\mathrm{Pt}^{0}$ & $485,6(10)$ & $\mathrm{Sn}^{0}$ & $1135,0(29)$ & $\mathrm{Eu}^{3+}-\mathrm{Eu}_{2} \mathrm{O}_{3}$ \\
\hline & & $72,3(22)$ & $\mathrm{Pt}^{2+}-\mathrm{Pt}(\mathrm{OH})_{2}$ & & & $1126,0(17)$ & Satélite 1- "Shake-down" \\
\hline & & $74,2(10)$ & $\mathrm{Pt}^{4+}-\mathrm{PtO}_{2} ; \mathrm{PtO}_{2} \cdot n \mathrm{H}_{2} \mathrm{O}$ & $487,4(90)$ & $\begin{array}{l}\mathrm{Sn}^{2,4+}-\mathrm{SnO} \\
\mathrm{SnO}_{2}\end{array}$ & $\begin{array}{l}1133,1(19) \\
1136,8(36)\end{array}$ & $\begin{array}{l}\mathrm{Eu}^{2+}-\mathrm{EuO} \\
\text { Satélite 2- "Shake-up" }\end{array}$ \\
\hline \multirow{3}{*}{$\begin{array}{l}\text { PtSnEu } \\
50: 30: 20\end{array}$} & \multirow{3}{*}{$56: 32: 12$} & $71,4(72)$ & $\mathrm{Pt}^{\mathrm{O}}$ & $485,6(32)$ & $\mathrm{Sn}^{0}$ & $1134,9(40)$ & $\mathrm{Eu}^{3+}-\mathrm{Eu}_{2} \mathrm{O}_{3}$ \\
\hline & & $72,3(19)$ & $\mathrm{Pt}^{2+}-\mathrm{Pt}(\mathrm{OH})_{2}$ & & $c_{n}^{2,4+} C_{n}$ & 1126,0 (11) & Satélite 1- "Shake-down" \\
\hline & & $74,2(9)$ & $\mathrm{Pt}^{4+}-\mathrm{PtO}_{2} ; \mathrm{PtO}_{2} \cdot n \mathrm{H}_{2} \mathrm{O}$ & $486,9(68)$ & $\begin{array}{l}\mathrm{Sn}^{2}-\mathrm{SnO} \\
\mathrm{SnO}_{2}\end{array}$ & $\begin{array}{l}1133,0(22) \\
1136,8(27) \\
\end{array}$ & Satélite 2- "Shake-up" \\
\hline
\end{tabular}


Os espectros Sn 3d, também apresentados na Figura 5.5, foram deconvoluídos por dois dubletos para os sinais $\mathrm{Sn} 3 d_{5 / 2}$ e $\mathrm{Sn} 3 d_{3 / 2}$. A Tabela 5.4 apresenta a energia de ligação e a porcentagem para cada componente observado no espectro de $\mathrm{Sn} 3 d_{5 / 2}$. A linha centrada em 485,6 eV pode ser atribuída ao $\mathrm{Sn}$ na valência zero. $^{71}$ Já as atribuições dos estados químicos $\mathrm{Sn}^{2+}$ e $\mathrm{Sn}^{4+}$ são difíceis, devido a sobreposição das energias de ligação dessas formas. Desta forma, para os catalisadores PtSn/C e PtSnEu/C sintetizados por poliol, os valores centralizados em $487,2( \pm 0,3)$ eV para $S n 3 d_{5 / 2}$ foram atribuídos a forma oxidada do estanho, englobando as valências II e IV. ${ }^{58,70}$ Para todos os catalisadores sintetizados, a contribuição de óxidos de estanho foi maior que a do estanho metálico, especialmente na composição PtSnEu 65:25:10, no qual esse valor foi de 90\%. Ao analisar a proporção metálica, as composições PtSnEu 75:20:05 e 50:30:20 apresentaram a mesma concentração percentual, de 32\%; e o PtSn/C apresentou uma contribuição menor, de 23\%. A presença de espécies oxidadas no PtSn/C corroboram picos observados de $\mathrm{SnO}_{2}$ nos difratogramas de DRX. A presença de estanho metálico em todas as composições também são coerentes com os deslocamentos dos picos cfc da Pt observados no DRX.

A região do orbital $3 d$ do $\mathrm{Eu}$, também apresentada na Figura 5.5, foi deconvoluída em quatro dubletos. Um pico corresponde ao estado inicial divalente $5 d^{0} 4 f^{7}$ da configuração $\mathrm{Eu}^{2+}$, entre 1132,8-1133,1 eV. O pico com energia de ligação deslocado de 3,5-8,0 eV, é atribuído a configuração $5 d^{1} 4 f^{6}$, referente ao estado excitado de $\mathrm{Eu}^{2+}$, chamado de satélite "shake-up". O picos ente 1134,9-1135,0 eV são atribuídos a espécie $\mathrm{Eu}^{3+} .{ }^{83}$ Referente aos estados de degenerescência, 0 processo reverso é observado ao composto $\mathrm{Eu}^{3+}$, pois este apresenta satélites em energia menor que o pico principal de ocupação das regiões $3 d$, conhecidos como "shake-down". Além de interações eletrostáticas entre vacâncias e os elétrons 4f, esses picos satélites também podem ser originados de transferência de cargas de coexcitações, principalmente entre $O 2 p$ para Ln $4 f$, com subníveis semiocupados. Independente da origem dos processos físicos, estes satélites tornam impossível estimar o grau de valência mista de compostos lantanídeos por XPS. ${ }^{83}$ O que pode ser comentado ao analisar a Tabela 5.4, é que as duas formas iônicas $\mathrm{Eu}^{2+}$ e $\mathrm{Eu}^{3+}$ são obtidas, indicando que o método de síntese adotado não privilegia um determinado estado de oxidação do terra rara. 


\section{Resultados e Discussão: Catalisadores PtSnEu/C}

Para correlacionar a concentração superficial dos metais nos catalisadores de $\mathrm{PtSnEu} / \mathrm{C}$, utilizou-se a relação das áreas dos espectros $4 f$ da $\mathrm{Pt}, 3 d$ do $\mathrm{Sn}$ e $3 d$ do Eu, corrigidos pelos fatores catalogados. Pelas equações:

$$
\begin{aligned}
& \frac{n_{P t}}{n_{S n}}=\frac{A_{P t}}{A_{S n}} \frac{a_{S n}}{a_{P t}}=k_{1} \\
& \frac{n_{P t}}{n_{E u}}=\frac{A_{P t}}{A_{E u}} \frac{a_{E u}}{a_{P t}}=k_{2}
\end{aligned}
$$

onde: $\left(n_{P t}\right)=$ fração atômica da Pt; $\left(n_{S n}\right)=$ fração atômica do $\mathrm{Sn} ;\left(n_{E u}\right)=$ fração atômica do Eu; $\left(A_{P t}\right)=$ área total dos orbitais Pt $4 f ;\left(A_{S n}\right)=$ área total dos orbitais $\mathrm{Sn}$ $3 d ;\left(A_{E u}\right)=$ área total dos orbitais $E u 3 d ;\left(a_{E u}\right)=$ fator de correção do európio, de 73,2; e $\left(a_{S n}\right)=$ fator de correção do estanho, de 25,1; e $\left(a_{P t}\right)=$ fator de correção da platina, de 15,5. Os fatores de correção adotados estavam disponíveis no software utilizado no tratamento dos dados (CasaXPS).

Considerando que a amostra apenas apresenta platina, estanho e európio, a soma da frações atômicas destes metais deve ser igual a 1, como descrito pela equação 5.7. Ao rearranjar as equações 5.5 e 5.6, obtém-se a equação 5.8, pela qual foi possível determinar a fração atômica da Pt e consequentemente, dos demais metais.

$$
\begin{aligned}
& n_{P t}+n_{S n}+n_{E u}=1 \\
& \frac{1}{\left(\frac{1}{k 1}\right)+\left(\frac{1}{k 2}\right)+1}=n_{P t}
\end{aligned}
$$

As porcentagens atômicas obtidas para PtSnEu/C sintetizados estão apresentadas na Tabela 5.4. Apesar das diferenças de interpretação da composição determinada por diferentes técnicas, os valores obtidos por XPS foram próximos às composições nominais para as concentrações PtSnEu 75:20:05 e 50:30:20. Para o catalisador PtSnEu 65:25:10, a composição por XPS apresentou um valor maior de estanho na superfície, de 42; enquanto para o catalisador PtSn/C 60:40, a concentração de estanho foi menor que a nominal, de $14 \%$.

\subsubsection{Espectroscopia de Absorção de Raios X}

Enquanto XPS fornece informações sobre estados ocupados de um sistema, a espectroscopia de absorção de raios X (XAS) fornece informações sobre estados desocupados. ${ }^{81}$ Como estes estados desocupados estão distribuídos em uma ampla faixa de energia, a interpretação de XAS é mais complexa do que para XPS. ${ }^{81} \mathrm{~A}$ 


\section{Resultados e Discussão: Catalisadores PtSnEu/C}

grande vantagem dessa técnica é a possiblidade de acompanhamento das mudanças de natureza eletrônica e nas interações atômicas de curto alcance em sistemas eletroquímicos in situ. ${ }^{84}$

A Figura 5.6 apresenta os espectros XANES (do inglês, $X$-absorption nearedge structure) na borda $L_{3}$ da Pt para catalisadores comerciais $\left(\right.$ Etek $\left.^{\circledR}\right)$ de Pt/C e $\mathrm{PtSn} / \mathrm{C}$ 75:25 e para os catalisadores trimetálicos de PtSnEu/C obtidos por poliol. O pico observado em $11564 \mathrm{eV}$ refere-se à absorção da borda $\mathrm{L}_{3}$ da $\mathrm{Pt}$, corresponde $a$ transição $2 p_{3 / 2} 5 d$, normalmente conhecido por linha branca. A magnitude deste pico está relacionada com a ocupação do estado eletrônico $5 d$ da platina e quanto maior a intensidade, menor é a ocupação deste orbital. ${ }^{64,74}$

No potencial de $500 \mathrm{mV}$ (Fig. 5.6 a), foi possível observar que os catalisadores $\mathrm{PtSn} / \mathrm{C}$ comercial e PtSnEu/C apresentaram uma redução de intensidade da linha branca comparado a $\mathrm{Pt} / \mathrm{C}$ comercial. Provavelmente a adição de estanho e de európio promoveram um preenchimento da banda $5 d$ da Pt. A intensidade da linha branca seguiu a ordem PtSnEu 65:25:10 < PtSnEu 75:10:05 PtSn Etek 75:25 < PtSnEu 50:30:20. No potencial de $900 \mathrm{mV}$ (Fig. 5.6 b), a mesma ordem de intensidade foi observada, mas a o efeito de preenchimento da banda $5 d$ foi mais pronunciado e as diferenças de absorção entre diferentes materiais foram minimizadas. Ao comparar com as informações obtidas por XPS, observa-se que a composição PtSnEu/C 65:25:10 apresenta a maior concentração de estanho superficial. Os resultados sugerem que a presença de óxidos de európio e de estanho metálico afetaram o preenchimento da banda $5 d$ da $\mathrm{Pt}$, mas quanto maior a concentração de óxidos adicionados, menor o efeito de preenchimento, como observado pelos espectros das composições PtSnEu 75:20:05 e PtSnEu 50:30:20.

Kim et al. (2008) ${ }^{74}$ avaliaram a influência do Sn na região de XANES da Pt, para catalisadores $\mathrm{PtSn} / \mathrm{C}$, de diferentes composições (0 a $50 \%$ de $\mathrm{Sn}$ ). A intensidade da linha branca da Pt/C foi maior que todos os catalisadores $\mathrm{PtSn} / \mathrm{C}$, e os autores atribuem esse fato à transferência de carga de Sn para Pt. Os autores comentam que um átomo de $\mathrm{Sn}$ tem quatro elétrons de valência disponíveis para modificar a $\mathrm{Pt}$, e que uma pequena incorporação de $\mathrm{Sn}$ já é suficiente para preencher estados da banda $d$. Essa modificação eletrônica pode enfraquecer a ligação entre átomos de carbono e os átomos Pt na superfície, reduzindo ou prevenindo o envenenamento catalítico. ${ }^{74} \mathrm{Em}$ outras palavras, a capacidade de 


\section{Resultados e Discussão: Catalisadores PtSnEu/C}

adsorção do catalisador de Pt com outras moléculas, tais como o hidrogênio e álcoois pode ser diminuída, mas uma tolerância maior ao veneno durante os processos de eletro-oxidação pode ser obtido.

Figura 5.6 - Espectros de XANES in situ na borda $L_{3}$ da Pt para os catalisadores Pt/C Etek, $\mathrm{PtSn} / \mathrm{C}$ Etek 75:25 e PtSnEu/C, em (a) $500 \mathrm{mV}$ e (b) $900 \mathrm{mV}$.
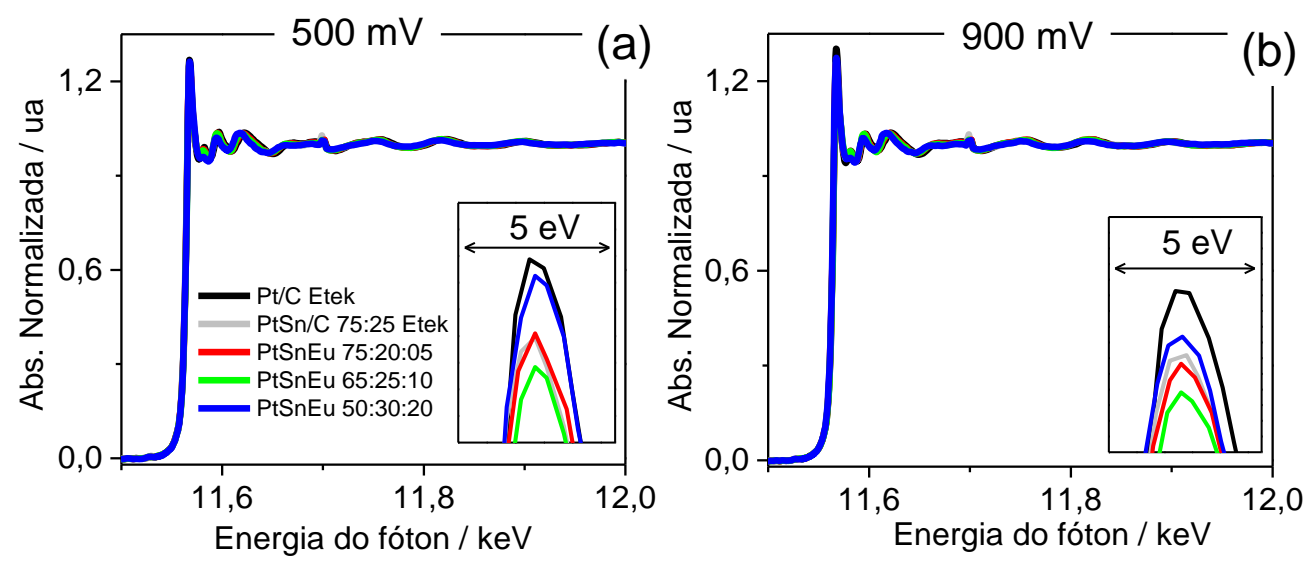

Fonte: Autoria própria.

\subsection{CARACTERIZAÇÃO ELETROQUÍMICA}

Como comentado no Capítulo II, a caracterização eletroquímica dos catalisadores obtidos por poliol foram realizadas em duas configurações: célula de três eletrodos e em células unitárias.

A configuração de camada ultrafina (três eletrodos) foi utilizada para estimar a área ativa dos catalisadores sintetizados, a atividade frente à reação de oxidação etanol (ROE), a estabilidade e os subprodutos obtidos da (ROE). Os ensaios foram realizados em dois meios: ácido $\left(0,5 \mathrm{~mol} \mathrm{~L}^{-1}\right.$ de $\left.\mathrm{H}_{2} \mathrm{SO}_{4}\right)$ e ácido etanólico $\left(0,5 \mathrm{~mol} \mathrm{~L}^{-1}\right.$ de $\mathrm{H}_{2} \mathrm{SO}_{4}$ e $1,0 \mathrm{~mol} \mathrm{~L}^{-1}$ de etanol).

\subsubsection{Testes em camada ultrafina}

\subsubsection{Caracterização em meio ácido}

Os voltamogramas em meio ácido dos catalisadores de PtSnEu/C estão apresentados na Figura 5.7. Nas voltametrias de catalisadores trimetálicos, a interpretação das curvas não é simplesmente uma simples sobreposição de diferentes comportamentos voltamétricos, como o somatório das correntes da Pt, Sn e Eu. Por exemplo, ao comparar os voltamogramas com $\mathrm{Pt} / \mathrm{C}$, observa-se que os picos dos catalisadores ternários são significantemente menores. O material com 


\section{Resultados e Discussão: Catalisadores PtSnEu/C}

menor adição de estanho (PtSnEu/C 75:20:05) apresentou maior definição da região de adsorção/dessorção de $\mathrm{H}_{2}$ que os outros catalisadores de PtSnEu/C. A presença de estanho inibe esses picos característicos e quanto maior sua concentração, menos evidente é a região de adsorção/dessorção de $\mathrm{H}_{2}$. A literatura explica que $\mathrm{o}$ efeito de bloqueio do Sn na superfície dos sítios ativos da Pt para adsorção de hidrogênio ocorre por efeitos geométricos e modificações nas propriedades eletrônicas na Pt pela presença deste metal. ${ }^{85} \mathrm{O}$ mesmo comportamento de supressão de picos de adsorção de hidrogênio é observado para outros metais, tais como Fe, Ni, Ru e Cr. ${ }^{64,86,87}$

Figura 5.7 - Voltamogramas dos catalisadores $\mathrm{Pt} / \mathrm{C}, \mathrm{PtSn} / \mathrm{C}$ e trimetálicos $\mathrm{PtSnEu} / \mathrm{C}$ sintetizados por poliol em $0,5 \mathrm{~mol} \mathrm{~L}^{-1}$ de $\mathrm{H}_{2} \mathrm{SO}_{4}$ a $20 \mathrm{mV} \mathrm{s}^{-1}$, em atmosfera de argônio.

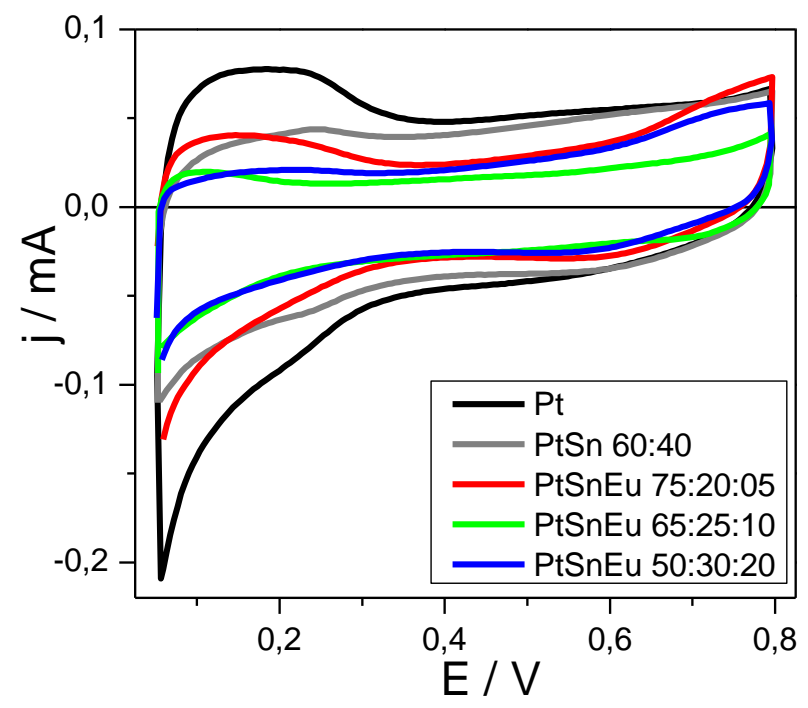

Fonte: Autoria própria.

A técnica de stripping de $\mathrm{CO}$ foi utilizada para estimar a área ativa dos catalisadores ternários. Os primeiros ciclos, subtraídos de uma linha de base, para os materiais PtSnEu/C sintetizados, estão apresentados na Figura 5.8. Os catalisadores com adição de estanho apresentam dois picos largos de oxidação, o primeiro entre 0,25 e 0,55 V, e um segundo pico maior, entre 0,6 e 0,9 V. Estes picos de oxidação mais amplos inferiram menores potenciais de início para eletrooxidação de $\mathrm{CO}$ ao comparar com o perfil observado para $\mathrm{Pt} / \mathrm{C}$, com pico de oxidação próximo a $0,76 \mathrm{~V}$. Ao comparar os materiais com adição de estanho (ampliação na Fig. 5.8a'), observa-se que todas as composições apresentaram perfis 


\section{Resultados e Discussão: Catalisadores PtSnEu/C}

semelhantes e a composição PtSnEu 65:25:10 apresentou maior densidade de corrente para oxidação de CO.

Figura 5.8 - (a) Curvas obtidas da subtração do $1^{\circ}$ ciclo de stripping de CO por uma linha de base para os catalisadores de $\mathrm{Pt} / \mathrm{C}, \mathrm{PtSn} / \mathrm{C}$ 60:40 e PtSnEu/C sintetizados por poliol. v: $5 \mathrm{mV} \mathrm{s}^{-1}$, atmosfera de argônio. (a') Ampliação da figura (a) em menores correntes, sem a curva da Pt/C.

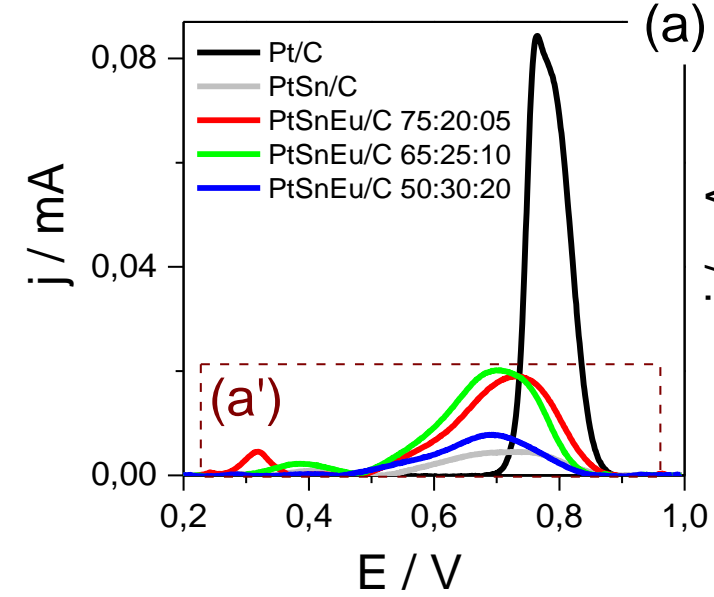

(a)

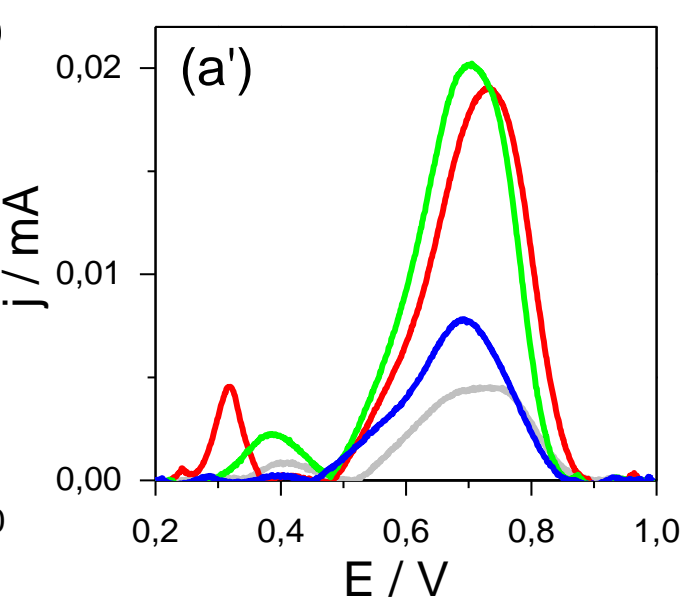

Fonte: Autoria própria.

Na literatura há estudos que afirmam que a interação de Pt-Sn enfraquece a adsorção de CO sobre Pt e promove a dissociação da água para formar $\mathrm{Sn}-\mathrm{OH}_{\mathrm{ad}}$ perto de $\mathrm{Pt}-\mathrm{CO}$, facilitando a rápida oxidação de CO. ${ }^{88,89}$ Os dados DRX indicam a formação de liga Pt-Sn e os dados de XAS comprovam o efeito eletrônico de preenchimento da borda $5 d$ da $\mathrm{Pt}$, principalmente para a composição $\mathrm{PtSnEu}$ 65:25:10. A adição de európio também pode ter contribuído para oxidação de CO, por beneficiar o mecanismo bifuncional.

A área ativa dos materiais pode ser determinada pela integração da área abaixo dos picos observados na Figura 5.8. Os valores médios obtidos e os respectivos desvios médios das repetições das medidas estão apresentados na Tabela 5.5. A área ativa da Pt/C foi superior aos materiais bimetálicos e trimetálicos, como esperado, pois o estanho e európio diluem os sítios da Pt, responsáveis pela adsorção de CO. As amostras trimetálicas apresentaram áreas próximas, variando entre 0,81 a 1,6 $\mathrm{cm}^{2}$. O catalisador de $\mathrm{PtSn} / \mathrm{C}$ apresentou menor área ativa, com $0,42 \mathrm{~cm}^{2}$. Os dados foram coerentes com os dados obtidos por DRX, no qual o catalisador binário apresentou maior tamanho de cristalito que os ternários. Além da possível diferença de tamanho, o európio pode ter algum efeito benéfico na oxidação do $\mathrm{CO}$, e promover maiores valores de área ativa. 


\section{Resultados e Discussão: Catalisadores PtSnEu/C}

Tabela 5.5 - Áreas ativas obtida por stripping de CO para os catalisadores Pt/C, PtSn/C e PtSnEu/C obtidos por poliol.

\begin{tabular}{cc}
\hline Material & Área ativa $/ \mathbf{~ c m}^{\mathbf{2}}$ \\
\hline $\mathrm{Pt}$ & $3,6 \pm 0,3$ \\
PtSn 60:40 & $0,42 \pm 0,05$ \\
PtSnEu 75:20:05 & $1,0 \pm 0,1$ \\
PtSnEu 65:25:10 & $1,6 \pm 0,2$ \\
PtSnEu 50:30:20 & $0,81 \pm 0,09$ \\
\hline
\end{tabular}

\subsubsection{Caracterização em meio etanólico}

As voltametrias lineares obtidas em etanol, normalizadas pela área ativa obtida por stripping de $\mathrm{CO}$, estão representados na Figura 5.9 a. As densidades de corrente de todos os catalisadores foram superiores a Pt/C, mas inferiores a PtSn/C. Os materiais PtSnEu 50:30:20 e 65:25:10 apresentaram densidades de corrente bem próximas, mas composição de PtSnEu 75:20:05 foi o material ternário que apresentou o maior valor no intervalo de potencial estudado. O potencial de início de oxidação de etanol foram menores, por volta de $0,45 \mathrm{~V}$.

As curvas derivadas das voltametria linear fornecem informações interessantes sobre os catalisadores sintetizados. Algumas vantagens listadas na literatura em analisar as derivadas da voltametria são: i) o potencial de pico pode ser localizado mais precisamente; ii) a presença de picos distintos no processo de oxidação de álcoois podem estar relacionados aos mecanismos da reação estudada; e iii) $\mathrm{dj} / \mathrm{dE}$ minimiza a interferência de fundo, na qual a capacidade da dupla camada muda lentamente em comparação com corrente faradaica em relação ao potencial. ${ }^{90}$ As derivadas voltamétricas em função do potencial estão apresentadas na Fig. 5.9b. $O$ início de oxidação de etanol para os catalisadores PtSn/C e PtSnEu/C 75:20:05 acontece por volta de 0,45 V vs ERH; para PtSnEu 65:25:10 e 50:30:20 em 0,55 V, e para $\mathrm{Pt} / \mathrm{C}$, próximo a $0,60 \mathrm{~V}$. O aparecimento de picos nas curvas derivadas indica que ocorrem mudanças da taxa de reação com a variação do potencial. A curva dos catalisadores Pt/C e trimetálicos PtSnEu 65:25:10 e 50:30:20 apresentam um perfil semelhante, com dois picos, em torno de 0,66 e 0,82 V. Para o catalisador PtSn/C e PtSnEu 75:20:05, observou-se os dois picos deslocados para menores potenciais, em 0,60 e 0,77 V. Pode-se afirmar que a presença de estanho e európio altera as taxas da ROE, antecipando o início da reação e provavelmente alterando os subprodutos. 


\section{Resultados e Discussão: Catalisadores PtSnEu/C}

Figura 5.9 - (a) Voltamogramas lineares dos catalisadores de $\mathrm{Pt} / \mathrm{C}, \mathrm{PtSn} / \mathrm{C}$ e $\mathrm{PtSnEu} / \mathrm{C}$ sintetizados por poliol e (b) as derivadas da corrente em função do potencial em $0,5 \mathrm{~mol} \mathrm{~L}^{-1}$ de $\mathrm{H}_{2} \mathrm{SO}_{4}$ e $1,0 \mathrm{~mol} \mathrm{~L}^{-1}$ de $\mathrm{C}_{2} \mathrm{H}_{5} \mathrm{OH}$ a $1 \mathrm{mV} \mathrm{s}^{-1}$ em atmosfera de argônio. Normalização por área ativa.

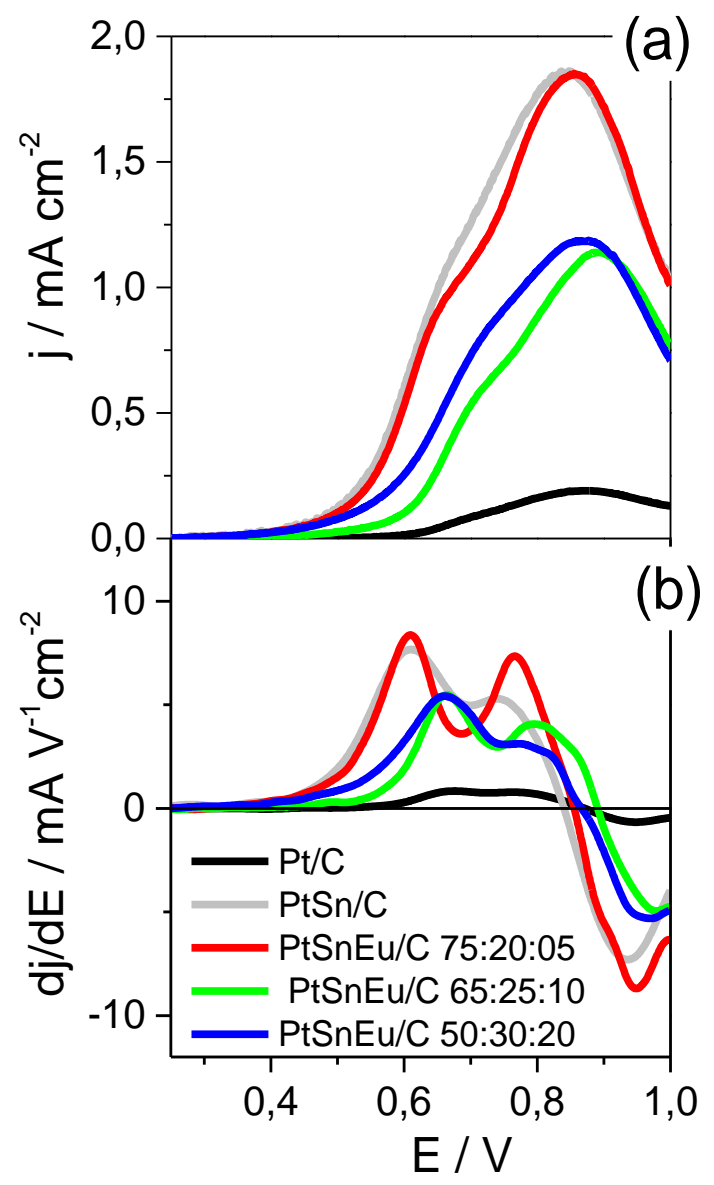

Fonte: Autoria própria.

Os cronoamperogramas obtidos, normalizados pela área ativa, estão apresentados na Figura 5.10a. Todas as composições atômicas de PtSnEu/C avaliadas apresentaram maiores densidades de corrente para reação de oxidação de etanol que a Pt/C, mas apenas a composição PtSnEu 75:20:05 apresentou maior densidade de corrente que PtSn/C 60:40. Para melhor comparação, as densidades de corrente em 2800 segundos para os catalisadores sintetizados estão apresentadas na Figura 5.10b. A variação da concentração de estanho e európio afetou a atividade eletrocatalítica para a reação de oxidação de etanol. A atividade catalítica para oxidação de etanol, normalizada por área obtida por strippping de CO, segue a ordem: Pt < PtSnEu 65:25:10 < PtSnEu 50:30:20 < PtSn 60:40 < PtSnEu 75:20:05. Por normalização da corrente por grama de platina, no qual foi-se 


\section{Resultados e Discussão: Catalisadores PtSnEu/C}

considerado a concentração determinada por ICP (Tabela 5.1) e por análise térmica (Tabela 5.2), observa-se que o todos os catalisadores PtSnEu apresentam maior densidade de corrente que $\mathrm{Pt} / \mathrm{C}$ e $\mathrm{PtSn} / \mathrm{C}$, sendo a composição 75:20:05 que

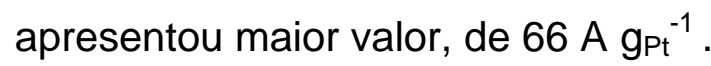

Figura 5.10 - (a) Cronoamperogramas dos catalisadores Pt/C, PtSn/C 60:40 e PtSnEu/C em $0,5 \mathrm{~mol} \mathrm{~L}^{-1}$ de $\mathrm{H}_{2} \mathrm{SO}_{4}$ e $1,0 \mathrm{~mol} \mathrm{~L}^{-1}$ de $\mathrm{C}_{2} \mathrm{H}_{5} \mathrm{OH}$ a $0,600 \mathrm{~V}$, em atmosfera de argônio. Representação com normalização pela área ativa. (b) Densidade de corrente em 2800 segundos obtidas da cronoamperometria em 0,600 V, normalizado por área ativa e por massa de platina.
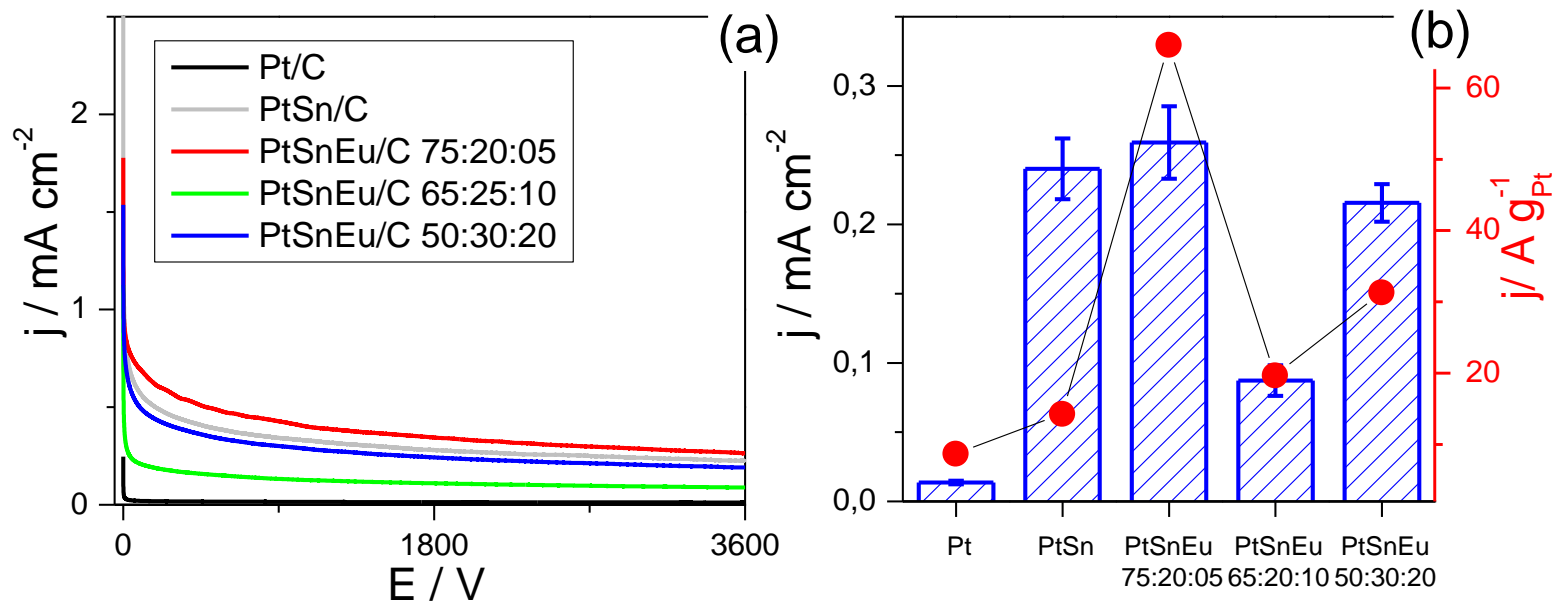

Fonte: Autoria própria.

A adição de estanho em catalisadores de Pt/C promoveu um aumento da densidade de corrente para a oxidação de etanol. Tal efeito não foi tão evidenciado para a adição de európio, visto que catalisadores $\mathrm{PtSnEu} / \mathrm{C}$ apresentaram densidades de correntes iguais ou menores que PtSn/C. No entanto, a adição de európio poderia ter algum efeito benéfico na estabilidade dos catalisadores, e por isso, a estabilidade desses catalisadores foi avaliada.

\subsubsection{Teste de envelhecimento acelerado}

Uma das questões-chave para comercialização das células a combustível de membrana de troca protônica (PEMFC) é a durabilidade dos componentes utilizados. Para melhorar o tempo de vida desse sistema, é necessário um profundo entendimento de como cada componente se comporta com o uso. Alguns fatores em foco de estudo são: desgaste da camada difusora e da membrana de troca protônica; ${ }^{91}$ degradação da camada catalítica, por sinterização da $\mathrm{Pt}{ }^{92}$; por ou 


\section{Resultados e Discussão: Catalisadores PtSnEu/C}

corrosão do suporte. ${ }^{93,94}$ A literatura aponta que ocorre uma severa perda de atividade catalítica pelo catalisador tanto em aplicações estacionárias quanto móveis. ${ }^{95}$ Aumentar a durabilidade da camada catalítica é um grande desafio e torna-se um foco crescente de atenção da pesquisa em células a combustível do tipo PEM. ${ }^{95}$

Dentre os diversos tipos de testes de estabilidade descritos na literatura, ${ }^{95} 0$ envelhecimento por voltametria cíclica foi escolhido para avaliar os materiais sintetizados por poliol. Os materiais baseados em platina apresentam mudança na atividade catalítica com a mudança do potencial de estudo. O processo é dependente da dissolução da $\mathrm{Pt}$, algo relacionado ao processo de degradação empregado, visto que em baixa concentração de íons $\mathrm{Pt}$, menor a cinética de degradação para os catalisadores de Pt/C. Por isso, diferentes processos de envelhecimento do eletrodo podem promover diferentes reações de dissolução no ânodo e no cátodo. Por exemplo, estudos de dissolução com protocolos de varreduras anódicas indicam que o mecanismo de dissolução da Pt é: ${ }^{95}$

$\mathrm{Pt} \rightarrow \mathrm{Pt}^{4+}+4 \mathrm{e}^{-}$

ou

$\mathrm{PtO}_{2}+4 \mathrm{H}^{+} \rightarrow \mathrm{Pt}^{4+}+2 \mathrm{H}_{2} \mathrm{O}$

Para varreduras catódicas, o mecanismo de dissolução da Pt apresenta transferência de carga de 2 elétrons, como observado na equação 5.11:

$$
\mathrm{PtO}_{2}+4 \mathrm{H}^{+}+2 \mathrm{e}^{-} \rightarrow \mathrm{Pt}^{2+}+2 \mathrm{H}_{2} \mathrm{O}
$$

Além da dissolução, processos secundários de crescimento de partícula são muito comuns em processos de envelhecimento. Esses processos são chamados de crescimento $3 \mathrm{D}$ de Ostwald, no qual a platina se dissolve e se deposita em nanopartículas maiores, devido às diferenças na energia superficial. ${ }^{96}$

Valores de potenciais também são importantes durante 0 processo de degradação da Pt. A literatura sugere que a concentração de Pt dissolvida aumenta de 0,65 a $1,1 \mathrm{~V}$, e depois decresce para potenciais maiores que $1,1 \mathrm{~V}$, devido à formação de um filme de óxido protetor. Entretanto, o potencial limite para degradação de catalisadores de Pt é geralmente menor que 1,0 V, para minimizar a corrosão do carbono, utilizado como suporte. ${ }^{95} \mathrm{~A}$ corrosão do carbono é extremamente indesejável, visto que pode iniciar outros processos, como 


\section{Resultados e Discussão: Catalisadores PtSnEu/C}

aglomeração e/ou remoção de partículas. Além disso, pode causar degradação estrutural da camada catalítica, com graves consequências para o transporte de massa. $^{97}$ A Figura 5.11 esquematiza alguns processos corrosivos para nanopartículas de platinas suportadas em carbono.

Figura 5.11 - Representação esquemática de alguns processos relacionados a mecanismos de degradação de catalisadores nanoparticulados de Pt suportados em carbono.

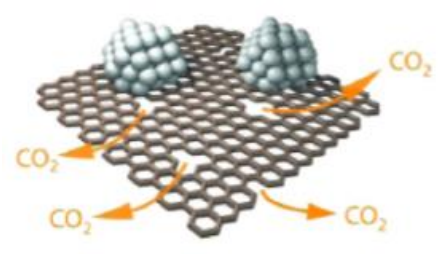

Corrosão do carbono

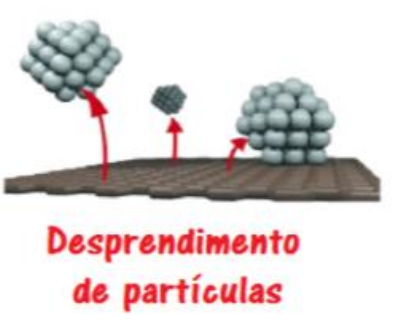

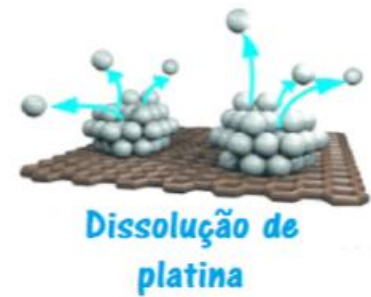

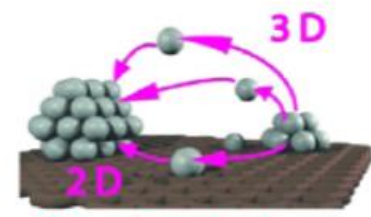

Crescimento de

Ostwald

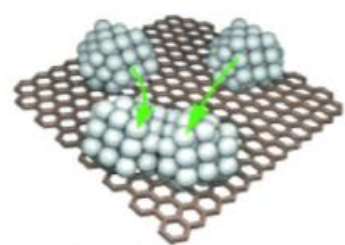

Aglomeração

Fonte: Extraído de CHEREVKO, S.; KULYK, N.; MAYRHOFER, K. J. J. Nano Energy. 29, 2016, p. $277 .^{96}$

Para materiais bimetálicos, baseados em PtSn, a mudança da degradação com o potencial pode ser ainda mais significativa, pois além dos processos da $\mathrm{Pt}$, 0 estanho apresenta processo de oxidação irreversível em potencial próximo a 0,8 V. De acordo com estudos de corrosão, o estanho dissolve para $\mathrm{Sn}^{2+} \mathrm{em} \mathrm{pH}<2$, mas o contato com outros metais podem alterar sua estabilidade em meio ácido. ${ }^{98}$

Zignani et al. (2013) estudaram o comportamento eletroquímico de uma DEFC por cronoamperometria (potencial de célula de $0,4 \mathrm{~V}$ ) e com procedimento de acionamento e desligamento de célula, operando com PtSn/C 75:25 no ânodo e Pt/C no cátodo. Os autores comentam que, dentre os fatores vários fatores que afetam a performance da célula, algumas das perdas irrecuperáveis estão relacionadas com a 
Resultados e Discussão: Catalisadores PtSnEu/C

dissolução de Sn do catalisador Pt-Sn, uma vez que isso pode afetar a capacidade de remover espécies contaminantes adsorvidas no ânodo. ${ }^{99}$

Melhorias na estabilidade podem ser adquiridas por mudança em algumas características físicas dos catalisadores. Hsieh et al. (2011) sintetizaram ligas de PtSn pelo método de poliol assistido por micro-ondas, e após síntese, realizaram alguns tratamentos térmicos em atmosfera de hidrogênio. ${ }^{100}$ Os autores avaliaram a área eletroativa para hidrogênio em $1,0 \mathrm{~mol} \mathrm{~L}^{-1}$ de ácido sulfúrico durante 1000 ciclos, entre $-0,2$ a $0,8 \vee v s$. $\mathrm{Ag} / \mathrm{AgCl}(\sim 0,02$ a 1,02 V vs EPH). O material calcinado em $600{ }^{\circ} \mathrm{C}$ apresentou o melhor resultado na promoção da atividade e da durabilidade a longo prazo dos catalisadores PtSn. A melhoria da estabilidade foi atribuída às seguintes razões: I) a adesão entre os catalisadores de liga binária e o suporte de nanotubo de carbono; ii) a transformação da fase cristalina na liga de Pt$\mathrm{Sn}$; e iii) a redução da fase $\mathrm{Pt}^{2+}$, com espécies de oxigênio quimisorvidas. ${ }^{100}$

Outra maneira de melhorar a estabilidade dos catalisadores Pt-Sn é adicionar um terceiro metal, que possa dificultar a dissolução do Sn. Ao avaliar o diagrama de Pourbaix do európio, apresentado a Figura 5.12, a forma esperada nos testes eletroquímicos em ácido sulfúrico $0,5 \mathrm{~mol} \mathrm{~L}^{-1}$ é $\mathrm{Eu}^{3+}$. Apesar da provável solubilidade deste terra rara, a presença deste metal pode modificar a estabilidade dos catalisadores $\mathrm{PtSn} / \mathrm{C}$, por talvez ter algum tipo de interação como os metais presentes e com o próprio carbono, utilizado como suporte.

Figura 5.12 - Diagrama de Pourbaix do európio.

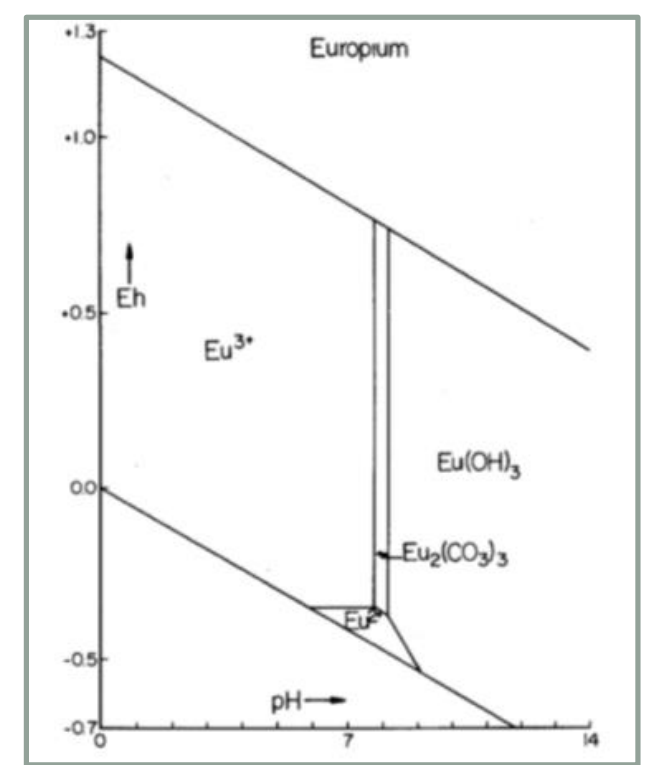

Fonte: Extraído de BROOKINS, D. G. Geochemical Journal. 17, 1983, p. $226 .{ }^{101}$ 


\section{Resultados e Discussão: Catalisadores PtSnEu/C}

Para avaliar melhor a influência do potencial para a eficiência na atividade catalítica em etanol, os materiais sintetizados por poliol foram estudados em duas rampas de potencial: (a) 0,3-0,8 V, uma região mais próxima a aplicação de oxidação de álcoois, e (b) 0,5-1,0 V, região mais próxima do processo de liga/desliga da célula, como descrito na sessão 4.3.1.3. A Figura 5.13 apresenta o voltamogramas antes e após a ciclagem. Para o envelhecimento realizado entre 0,3$0,8 \mathrm{~V}$, a mudança do perfil não foi tão significativa (Fig. 5.13a). Entretanto, para o envelhecimento entre 0,5-1,0 V (Fig. 5.13b) é possível observar uma grande variação tanto na área quanto no perfil da região de adsorção/dessorção de hidrogênio associados a Pt policristalina.

Figura 5.13 - Comparação dos voltamogramas antes (linha tracejada) e após (linha cheia) os testes de envelhecimento entre (a) 0,3-0,8 V e (b) 0,5-1,0 V dos catalisadores $\mathrm{Pt} / \mathrm{C}, \mathrm{PtSn} / \mathrm{C}$ e $\mathrm{PtSnEu} / \mathrm{C}$ sintetizados por poliol. v: $20 \mathrm{mV} \mathrm{s}^{-1}$, atmosfera de argônio, em $0,5 \mathrm{~mol} \mathrm{~L}^{-1}$ de $\mathrm{H}_{2} \mathrm{SO}_{4}$.
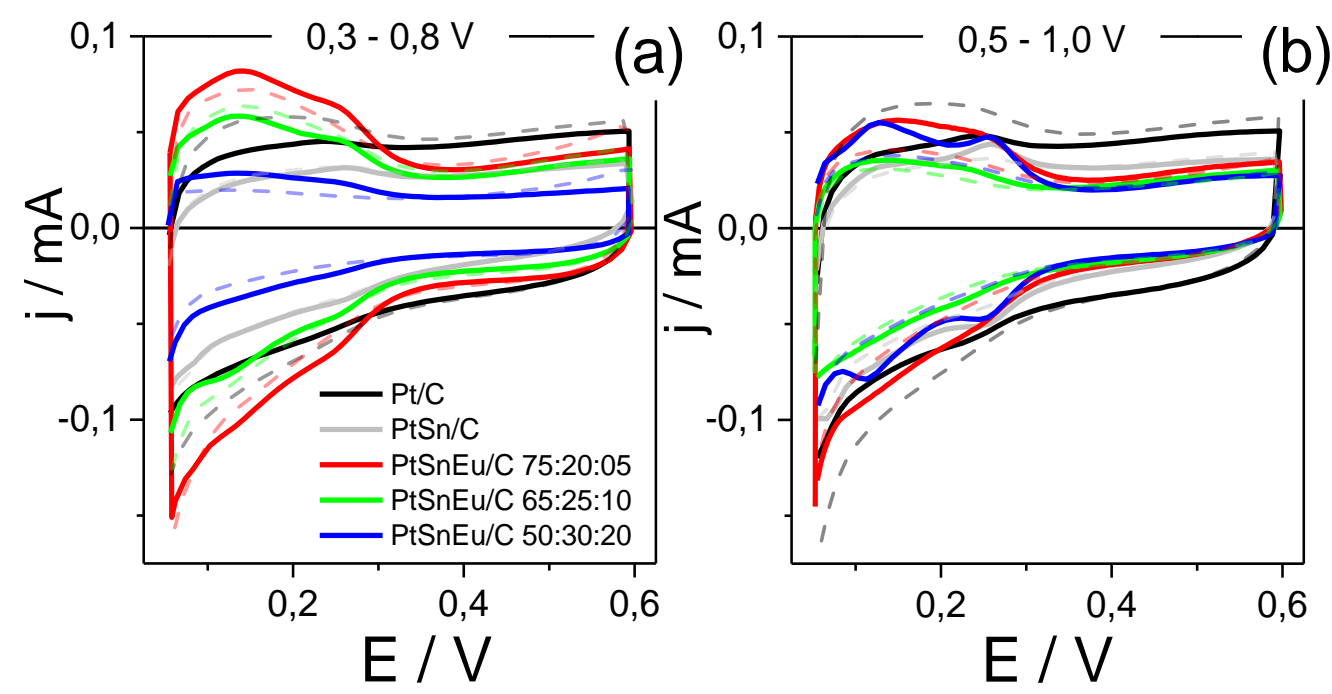

Fonte: Autoria própria.

Para avaliar melhor as mudanças da área de processo de adsorção de hidrogênio durante o processo de ciclagem, a Figura 5.14 apresenta área ativa de platina determinada na região de hidrogênio pelo número de ciclos. Observa-se que as cargas apresentaram menor variação para a protocolo até 0,8 V (Fig. 5.14 a) do que o protocolo até 1,0 V (Fig. 5.14 b), conforme esperado. 


\section{Resultados e Discussão: Catalisadores PtSnEu/C}

Figura 5.14 - Variação da área ativa determinada por hidrogênio pelo número de ciclos dos catalisadores $\mathrm{Pt} / \mathrm{C}, \mathrm{PtSn} / \mathrm{C}$ e $\mathrm{PtSnEu} / \mathrm{C}$ sintetizados por poliol: envelhecimento entre (a) 0,3-0,8 $\mathrm{V}$ e (b) 0,5-1,0 V.
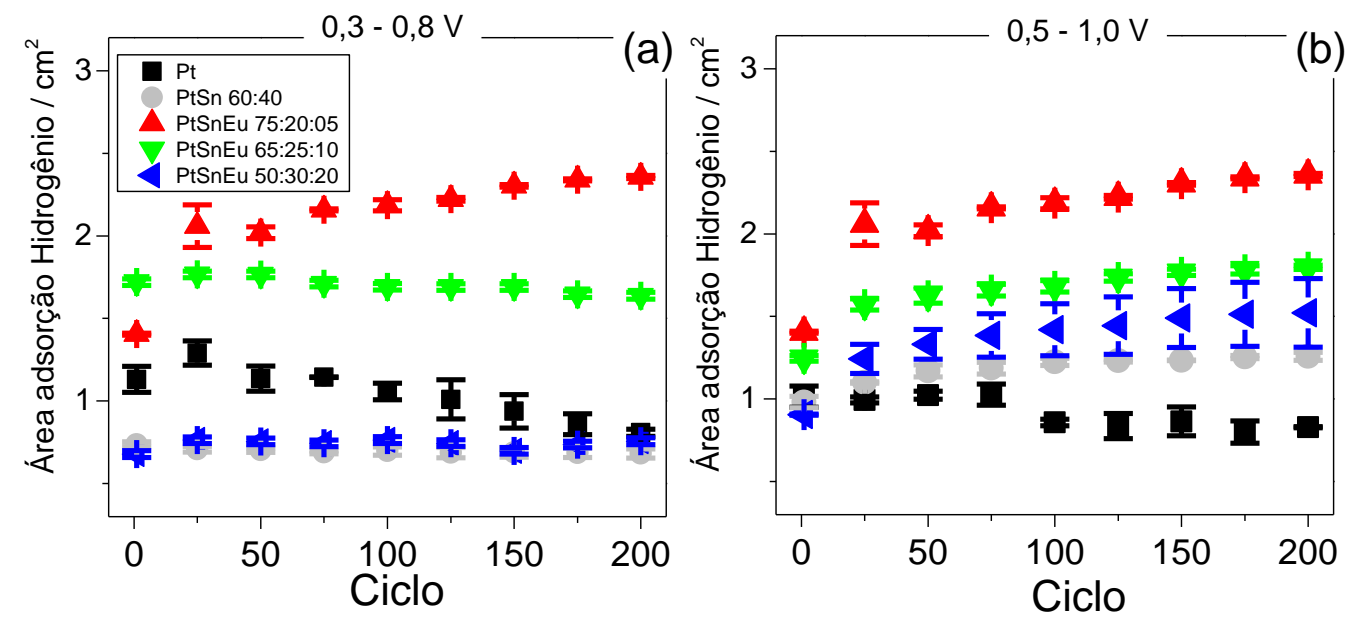

Fonte: Autoria própria.

A Figura 5.15 apresenta as curvas de stripping de CO antes (a) e após os testes de envelhecimentos de (b) 0,3-0,8 V e (c) 0,5-1,0 V para os catalisadores sintetizados. Foi possível observar grandes variações nos perfis da oxidação de CO para ambos envelhecimentos, para todos os materiais avaliados. A mudança mais significativa foi observada para o catalisador $\mathrm{Pt} / \mathrm{C}$, que apresentou redução da densidade de corrente, e o pico de oxidação de $\mathrm{CO}$ em menores potenciais, para ambos envelhecimentos (Fig. 5.15b e Fig. 5.15c). O catalisador PtSnEu/C 65:25:10 também apresentou redução de densidade de corrente, mas para os demais catalisadores, a mudança do perfil foi inversa: ocorreu um aumento de densidade de corrente para oxidação de CO após os testes de envelhecimento. 


\section{Resultados e Discussão: Catalisadores PtSnEu/C}

Figura 5.15 - Curvas obtidas da subtração do $1^{\circ}$ ciclo do stripping de CO por uma linha de base para os catalisadores $\mathrm{Pt} / \mathrm{C}, \mathrm{PtSn} / \mathrm{C}$ 60:40 e $\mathrm{PtSnEu} / \mathrm{C}$ sintetizados por poliol (a) antes do envelhecimento, (b) após ciclagem entre 0,3-0,8 $\mathrm{V}$ e (c) após ciclagem entre 0,5-1,0 V. v: $5 \mathrm{mV} \mathrm{s}^{-1}$, atmosfera de argônio. Linhas tracejadas representam curvas do respectivo material não envelhecido.
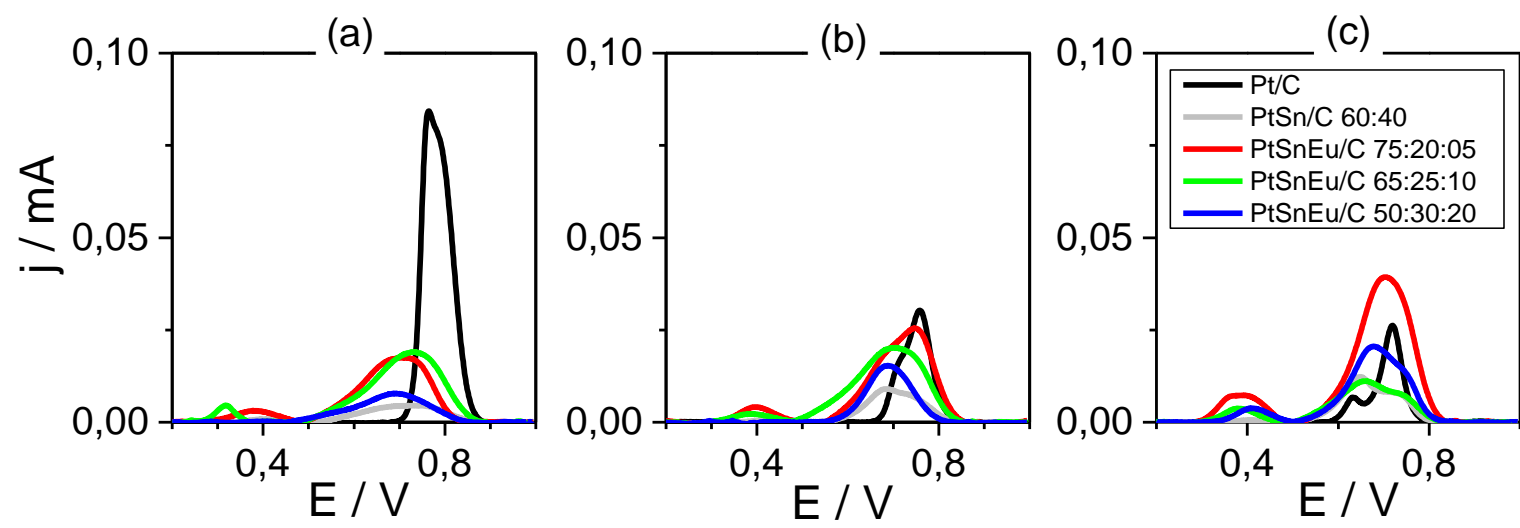

Fonte: Autoria própria.

A Tabela 5.6 apresenta os valores das áreas ativas obtidas por stripping de CO para os catalisadores obtidos por poliol, e os respectivos desvios médios. Nos testes de envelhecimento entre 0,3-0,8 V, as maiores variações de área ativa foram observadas para os catalisadores $\mathrm{Pt} / \mathrm{C}$ e $\mathrm{PtSn} / \mathrm{C}$, superiores a 50\%. Para os catalisadores trimetálicos, a variação da área ativa determinada por stripping de CO não ultrapassou 35\%. Assim como observado para área de hidrogênio, o envelhecimento até $1,0 \mathrm{~V}$ promoveu maiores variações que o envelhecimento até até $0,8 \mathrm{~V}$. Até $1,0 \mathrm{~V}$, os catalisadores $\mathrm{Pt} / \mathrm{C}$ e $\mathrm{PtSn} / \mathrm{C}$ apresentaram variações de área ativa semelhantes, próximas a 75\%. Os catalisadores PtSnEu/C 65:25:10 e PtSnEu 50:30:20 apresentaram menores variações de área ativa, entre 40 e 60\%. Dentre os trimetálicos, apenas o a composição PtSnEu 75:20:05 apresentou maior variação da área ativa que os demais catalisadores. A concentração de estanho e európio nesse catalisador foi a menor estudada. Provavelmente, a dissolução dos metais nessa composição foi mais significativa, e a ausência destes prejudicou a oxidação de CO sobre este material. 


\section{Resultados e Discussão: Catalisadores PtSnEu/C}

Tabela 5.6 - Áreas ativas obtidas por stripping de CO, após teste de envelhecimento e a variação da área dos catalisadores $\mathrm{Pt} / \mathrm{C}, \mathrm{PtSn} / \mathrm{C}$ e $\mathrm{PtSnEu} / \mathrm{C}$ sintetizados por poliol.

\begin{tabular}{ccc|cc}
\hline \multirow{2}{*}{ Catalisador } & \multicolumn{2}{c|}{$\begin{array}{c}\text { Envelhecimento } \\
\text { entre 0,3-0,80 V }\end{array}$} & \multicolumn{2}{c}{$\begin{array}{c}\text { Envelhecimento } \\
\text { entre 0,5-1,0 V }\end{array}$} \\
\cline { 2 - 5 } & $\begin{array}{c}\text { Área ativa } \\
\text { final }\left(\mathbf{c m}^{2}\right)\end{array}$ & $\begin{array}{c}\text { Variação } \\
\text { (\%) }\end{array}$ & $\begin{array}{c}\text { Área ativa final } \\
\left.\text { (cm }^{2}\right)\end{array}$ & $\begin{array}{c}\text { Variação } \\
\text { (\%) }\end{array}$ \\
\hline Pt/C & $1,4 \pm 0,3$ & $-62 \pm 2$ & $0,88 \pm 0,01$ & $-75 \pm 1$ \\
PtSn/C 60:40 & $0,62 \pm 0,05$ & $50 \pm 13$ & $0,75 \pm 0,07$ & $76 \pm 13$ \\
PtSnEu/C 75:20:05 & $1,91 \pm 0,06$ & $34 \pm 2$ & $2,6 \pm 0,1$ & $96 \pm 16$ \\
PtSnEu/C 65:25:10 & $1,3 \pm 0,1$ & $18 \pm 5$ & $0,89 \pm 0,02$ & $-40 \pm 5$ \\
PtSnEu/C 50:30:20 & $0,99 \pm 0,1$ & $27 \pm 13$ & $1,3 \pm 0,1$ & $66 \pm 15$ \\
\hline
\end{tabular}

Após os testes de envelhecimento acelerado, os catalisadores ternários foram avaliados frente à reação de oxidação de etanol, por voltametria linear e cronoamperometria. Os voltamogramas lineares de $\mathrm{PtSnEu} / \mathrm{C}$ em meio ácido etanólico estão apresentadas na Figura 5.16. Foi possível observar uma mudança significativa nos perfis dos voltamogramas em etanol para ambos envelhecimentos. As principais mudanças foram o aparecimento de um ombro entre 0,65-0,75 V para os catalisadores PtSn/C e ternários; e a antecipação do onset de potencial de oxidação de etanol. Para o envelhecimento em menores potenciais (Fig. 5.16 a), todos os catalisadores ternários apresentaram maiores densidade de corrente que a $\mathrm{Pt} / \mathrm{C}$ e PtSn/C após envelhecimento. Os catalisadores Pt/C e PtSnEu/C na composição de 65:25:10 e 50:30:20 apresentaram aumento nas densidades de corrente após o teste de envelhecimento, enquanto PtSn/C e PtSnEu/C 75:20:05, apresentaram diminuição da atividade. Pelas curvas derivadas, poucas mudanças nos perfis foram observadas (Figura $5.16 \mathrm{c}$ ). A mais significativa foi para 0 catalisador PtSnEu 65:25:10, que ocorreu a formação de um ombro em 0,45 V, além dos dois picos entre 0,6 V e 0,85 V. Para o envelhecimento entre 0,5-1,0 V (Fig. 5.16 b), os catalisadores PtSnEu/C 50:30:20 e 65:25:10 apresentaram maiores densidades de corrente dentre os catalisadores avaliados. O catalisador de $\mathrm{PtSn} / \mathrm{C}$ apresentou densidade de corrente maior que PtSnEu/C 75:20:05 após envelhecimento. Nas curvas derivadas (Fig. 5.16 d), também foram observados dois picos, com aparecimento de um ombro em menores potenciais para a composição de PtSnEu/C 65:25:10. 


\section{Resultados e Discussão: Catalisadores PtSnEu/C}

Figura 5.16 - Voltamogramas lineares dos catalisadores $\mathrm{Pt} / \mathrm{C}, \mathrm{PtSn} / \mathrm{C}$ e $\mathrm{PtSnEu} / \mathrm{C}$ em $0,5 \mathrm{~mol} \mathrm{~L}^{-1}$ de $\mathrm{H}_{2} \mathrm{SO}_{4}$ e $1,0 \mathrm{~mol} \mathrm{~L}^{-1}$ de $\mathrm{C}_{2} \mathrm{H}_{5} \mathrm{OH}$ a $1 \mathrm{mV} \mathrm{s}^{-1}$ após teste de estabilidade, envelhecidos entre (a) 0,3-0,8 V e entre (b) 0,5-1,0 V. Curvas das densidades de corrente derivadas em função do potencial, envelhecidos entre (c) $0,3-0,8 \mathrm{~V}$ e (d) $0,5-1,0 \mathrm{~V}$. Normalização por área ativa. Linhas tracejadas representam curvas do respectivo material não envelhecido.

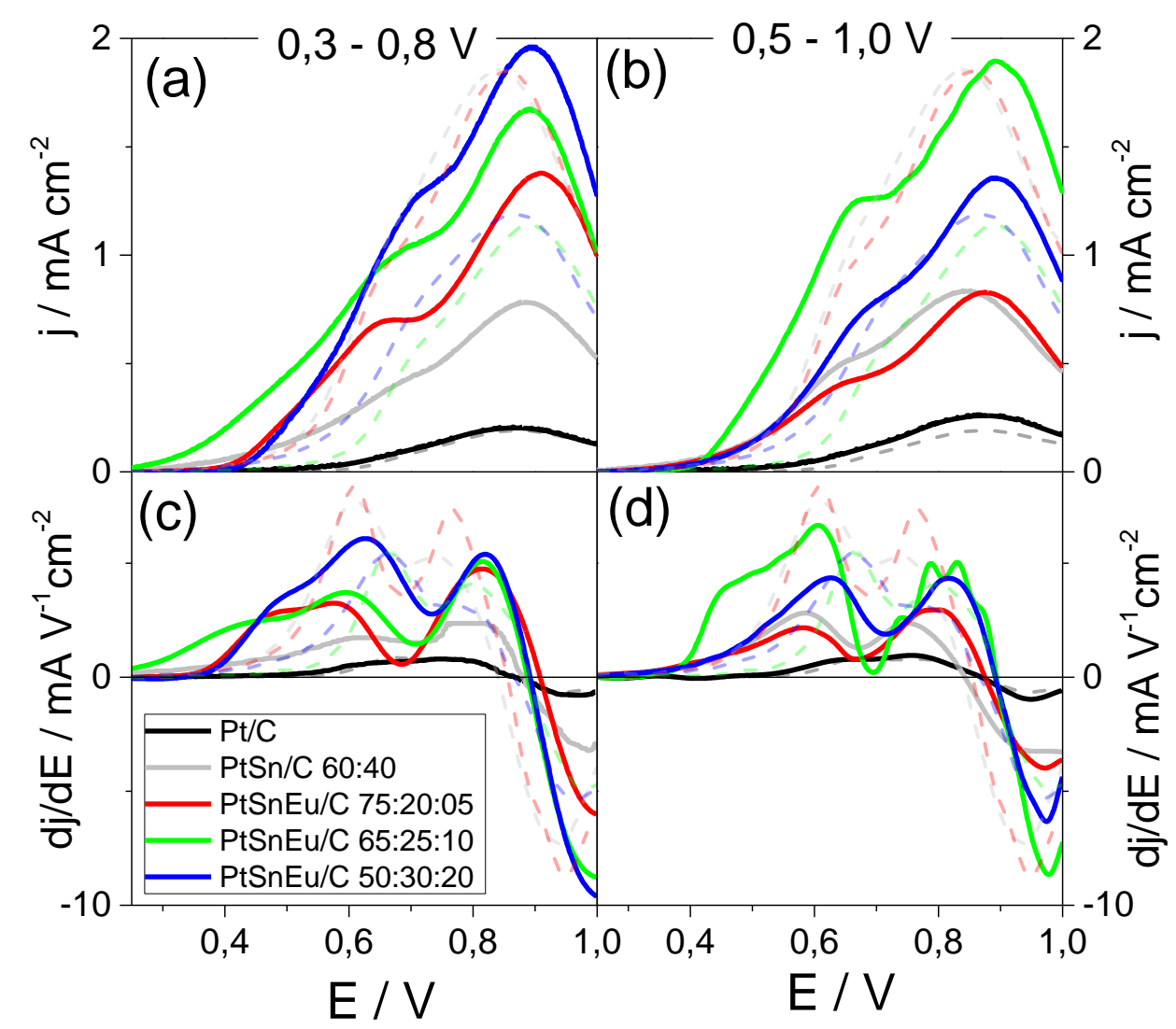

Fonte: Autoria própria.

Nas cronoamperometrias dos catalisadores PtSnEu/C após envelhecimento, apresentadas na Figura 5.17, é possível aferir que os catalisadores envelhecidos até $0,8 \mathrm{~V}$ (Fig. $5.17 \mathrm{a}$ ) apresentaram maiores densidades de corrente que os envelhecidos até 1,0 V (Fig. 5.17 b). Para o envelhecimento até 0,8 V (Fig. 5.17 a), todas as densidades de corrente dos catalisadores ternários ficaram bem próximas após 2800 segundos, mas superiores a Pt/C e PtSn/C. No envelhecimento até 1,0 V, a diferença entre os catalisadores $\mathrm{PtSn} / \mathrm{C}$ e $\mathrm{PtSnEu} / \mathrm{C}$ foram minimizadas, e estes apresentaram densidades de correntes mais próximas a $\mathrm{Pt} / \mathrm{C}$. 


\section{Resultados e Discussão: Catalisadores PtSnEu/C}

Figura 5.17 - Cronoamperogramas dos catalisadores $\mathrm{Pt} / \mathrm{C}, \mathrm{PtSn} / \mathrm{C}$ 60:40 e PtSnEu/C sintetizados por poliol, em $0,5 \mathrm{~mol} \mathrm{~L}^{-1}$ de $\mathrm{H}_{2} \mathrm{SO}_{4}$ e $1,0 \mathrm{~mol} \mathrm{~L}^{-1}$ de $\mathrm{C}_{2} \mathrm{H}_{5} \mathrm{OH}$ em 0,600 V, após teste de envelhecimento, entre (a) 0,3-0,8 V e (b) 0,5-1,0 V em atmosfera de argônio. Normalização pela área ativa.
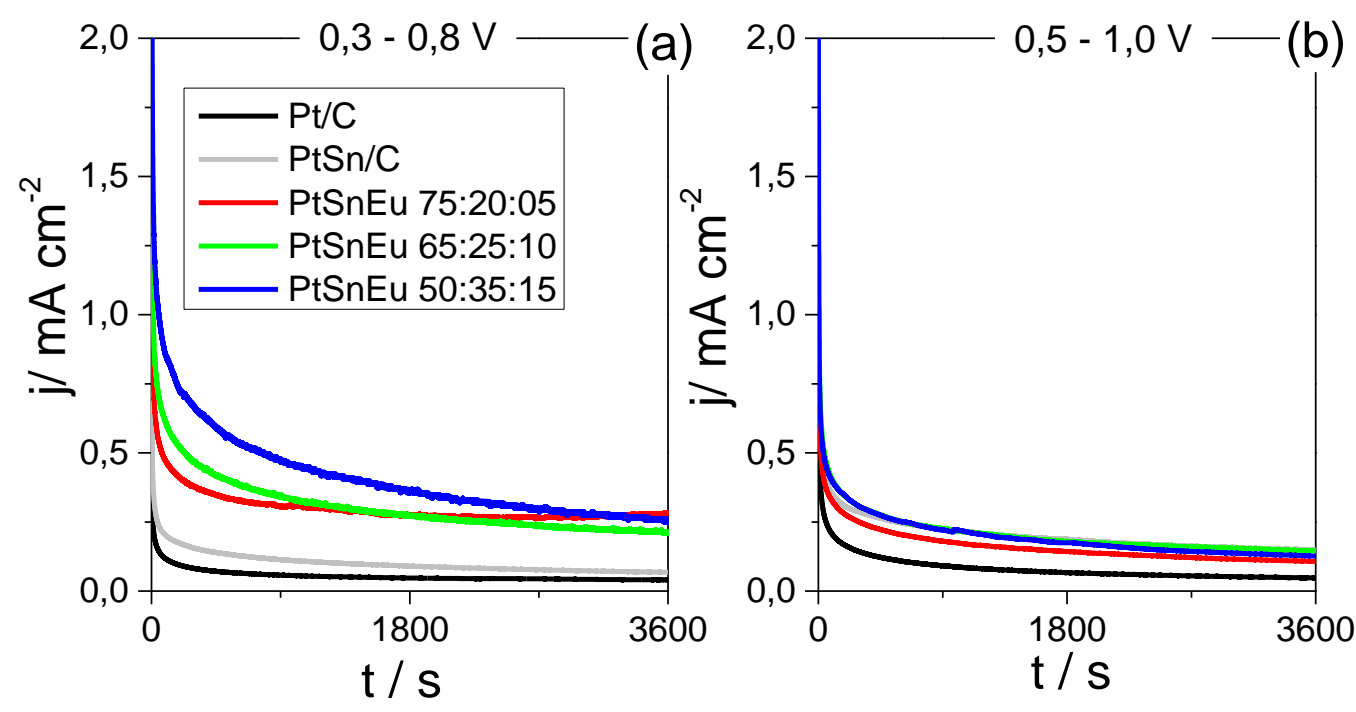

Fonte: Autoria própria.

A Figura 5.18 compara as densidades de corrente em 2800 segundos da cronoamperometria, antes e após envelhecimentos. Todos os catalisadores ternários apresentaram maior densidade de corrente que a $\mathrm{Pt} / \mathrm{C}$, antes e após os envelhecimentos. Para os envelhecimentos até $0,8 \mathrm{~V}$, os catalisadores trimetálicos apresentaram aumento da densidade de corrente, comparados aos valores iniciais. As densidades de correntes dos catalisadores PtSnEu/C foram próximas para todas as composições, variando entre 0,23 a $0,29 \mathrm{~mA} \mathrm{~cm}^{-2}$; e superiores a $\mathrm{Pt} / \mathrm{C}(0,02$ $\left.\mathrm{mA} \mathrm{cm}{ }^{-2}\right)$ e $\mathrm{PtSn} / \mathrm{C}\left(0,1 \mathrm{~mA} \mathrm{~cm}^{-2}\right)$. Após envelhecimento até $1,0 \mathrm{~V}$, apenas os catalisadores Pt/C e PtSnEu 65:25:10 apresentaram aumento da densidade de corrente em relação a densidade inicial. Para este protocolo, o material PtSn/C apresentou densidade de corrente de $0,18 \mathrm{~mA} \mathrm{~cm}^{-2}$, valor bem próximo aos catalisadores trimetálicos, que variaram entre 0,12 a $0,16 \mathrm{~mA} \mathrm{~cm}^{-2}$. Mesmo após ciclagem entre 0,5-1,0 V, os catalisadores $\mathrm{PtSn} / \mathrm{C}$ e PtSnEu/C apresentaram maiores densidade de corrente que a $\mathrm{Pt} / \mathrm{C}\left(0,05 \mathrm{~mA} \mathrm{~cm}^{-2}\right)$. 


\section{Resultados e Discussão: Catalisadores PtSnEu/C}

Figura 5.18 - Densidades de correntes no tempo de 2800 segundos nas medidas de cronoamperometria para os materiais de $\mathrm{Pt} / \mathrm{C}, \mathrm{PtSn} / \mathrm{C}$ e $\mathrm{PtSnEu} / \mathrm{C}$ antes do envelhecimento (azul), após ciclagem 0,3-0,8 V (laranja) e após 0,5-1,0 V. (cinza). Normalização por área ativa.

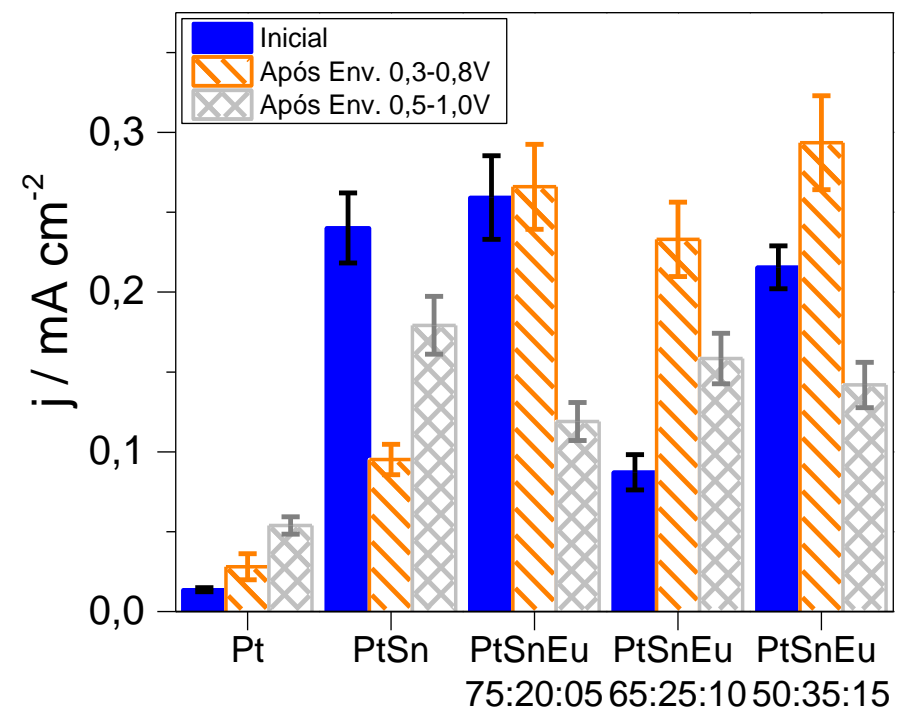

Fonte: Autoria própria.

Ao avaliar as variações das curvas voltamétricas e as cronoamperometrias após os testes de envelhecimento, pode-se concluir que a adição de európio é benéfica para o aumento da estabilidade e atividade eletrocatalítica de oxidação de etanol, principalmente para envelhecimentos entre 0,3-0,8 V. Mesmo com a provável dissolução do európio dos catalisadores em meio ácido, a atividade frente a ROE após estabilidade é maior que a inicial. Talvez a dissolução do európio ocorra preferencialmente a dissolução do estanho, o que promoveria a atividade para oxidação de etanol mesmo após sucessivas ciclagens. Além disso, a saída do európio possa promover a formação de defeitos e exposição de outras áreas para a oxidação de etanol. Por não observar mudanças significativas nas derivadas das curvas da voltametria para a maioria das composições, o mecanismo da oxidação de etanol provavelmente não deva sofrer alteração após ciclagem. Para avaliar os principais subprodutos da oxidação de etanol para os catalisadores sintetizados, foram realizados medidas de FTIR in situ, como apresentado a seguir. 


\section{Resultados e Discussão: Catalisadores PtSnEu/C}

5.3.1.4 Caracterização dos subprodutos da reação de oxidação de etanol por espectroscopia vibracional de absorção na região do infravermelho in situ com transformada de Fourier

A espectroscopia por infravermelho in situ em interfaces eletroquímicas fornece dados sobre as espécies adsorvidas no eletrodo de trabalho sob a influência do campo elétrico ou da dupla camada. ${ }^{66}$ Por essa técnica, é possível avaliar os produtos gerados das reações eletroquímicas de oxidação e/ou redução no eletrodo de trabalho.

Os estudos FTIR in situ dos catalisadores ternários foram realizados em célula de três eletrodos, na configuração de camada fina. Os espectros de FTIR in situ com variação do potencial para os catalisadores $\mathrm{Pt}$, PtSn e PtSnEu estão apresentados na Figura 5.19. As linhas pontilhadas em azul escuro indicam a produção da espécie, e as marcadas vermelho indicam consumo (Fig. 5.19). A correlação do número de onda e atribuições dos picos estão apresentados na Tabela 5.7.

Tabela 5.7 - Atribuições das bandas observadas em FTIR. Adaptado de Shao e Adzic $(2005)^{102}$, Wang et al. $(2007)^{103}$ e Delpeuch et al. (2016). ${ }^{104}$

\begin{tabular}{|c|c|}
\hline Número de onda $\left(\mathrm{cm}^{-1}\right)$ & Espécie \\
\hline 2345 & $\mathrm{CO}_{2}$, estiramento assimétrico \\
\hline 1710 & $\begin{array}{l}\text { Estiramento da ligação } \mathrm{C}=\mathrm{O} \text { de acetaldeído }(-\mathrm{CHO}) \text { e/ou } \\
\text { ácido acético }(-\mathrm{COOH})\end{array}$ \\
\hline$\sim 1508$ & $\begin{array}{l}\text { Acoplamento da vibração da ligação } \mathrm{O}-\mathrm{H} \text { com } \\
\text { estiramento } \mathrm{C}-\mathrm{O} \text { no etanol }\end{array}$ \\
\hline 1355 & $\begin{array}{l}\text { Deformação simétrica do } \mathrm{CH}_{3} \text { do acetaldeído e/ou de } \\
\text { acetato adsorvido }\end{array}$ \\
\hline$\sim 1270$ & $\begin{array}{l}\text { Acoplamento da deformação } \mathrm{O}-\mathrm{H} \text { com o estiramento da } \\
\text { ligação } \mathrm{C}=\mathrm{O} \text { de ácido acético }(-\mathrm{COOH})\end{array}$ \\
\hline $\begin{array}{l}\sim 1090 \\
\sim 1040\end{array}$ & $\begin{array}{l}\text { Vibração em balanço da ligação C-H do acetaldeído } \\
\text { Estiramento da ligação C-O no etanol }\end{array}$ \\
\hline$\sim 930$ & $\begin{array}{l}\text { Estiramento assimétrico da ligação } \quad \text { C-C-O } \\
\text { acetaldeído }\end{array}$ \\
\hline
\end{tabular}




\section{Resultados e Discussão: Catalisadores PtSnEu/C}

Figura 5.19 - Espectros de FTIR obtidos de eletrodos (a) Pt/C; (b) PtSn/C 60:40; (c) PtSnEu/C 75:20:05; (d) PtSnEu/C 65:25:10; e (e) PtSnEu/C 50:30:20 obtidos em $0,5 \mathrm{~mol} \mathrm{~L}^{-1}$ de $\mathrm{H}_{2} \mathrm{SO}_{4}$ e $0,5 \mathrm{~mol} \mathrm{~L}^{-1}$ de etanol. A janela utilizada foi $\mathrm{ZnSe}$. O espectro de referência foi coletado em 0,05 V vs. ERH e os espectros das amostras foram coletados após aplicação dos potenciais em sentido positivo (variação de $0,1 \mathrm{~V}$ entre espectros), com o início em 0,2 V. O potencial de 0,6 V está destacado em azul.

(a)

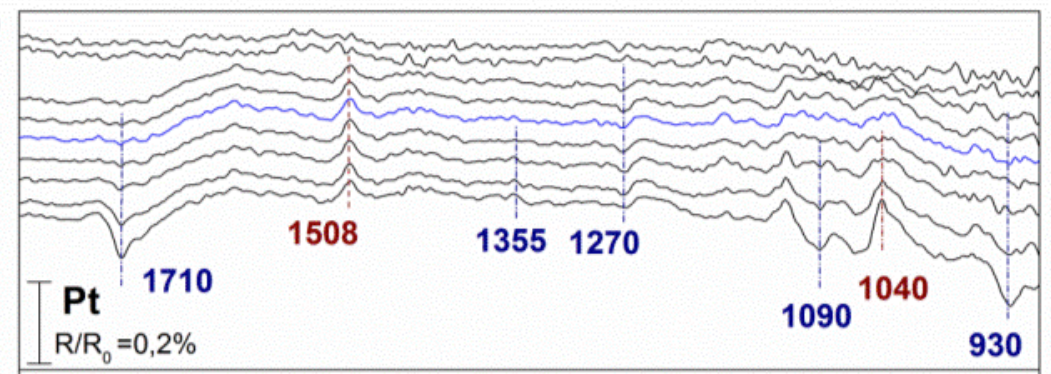

(b)
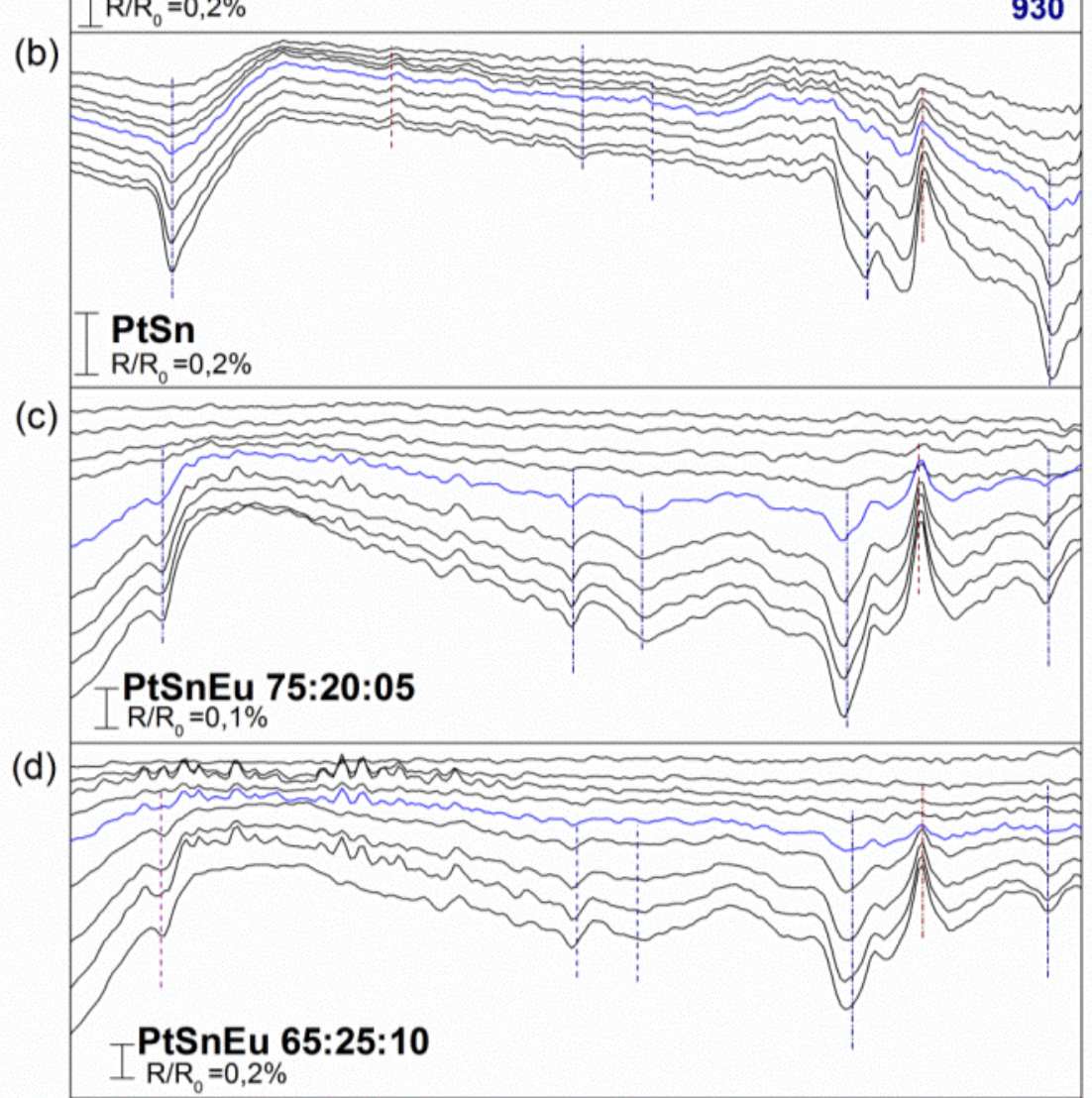

(e)

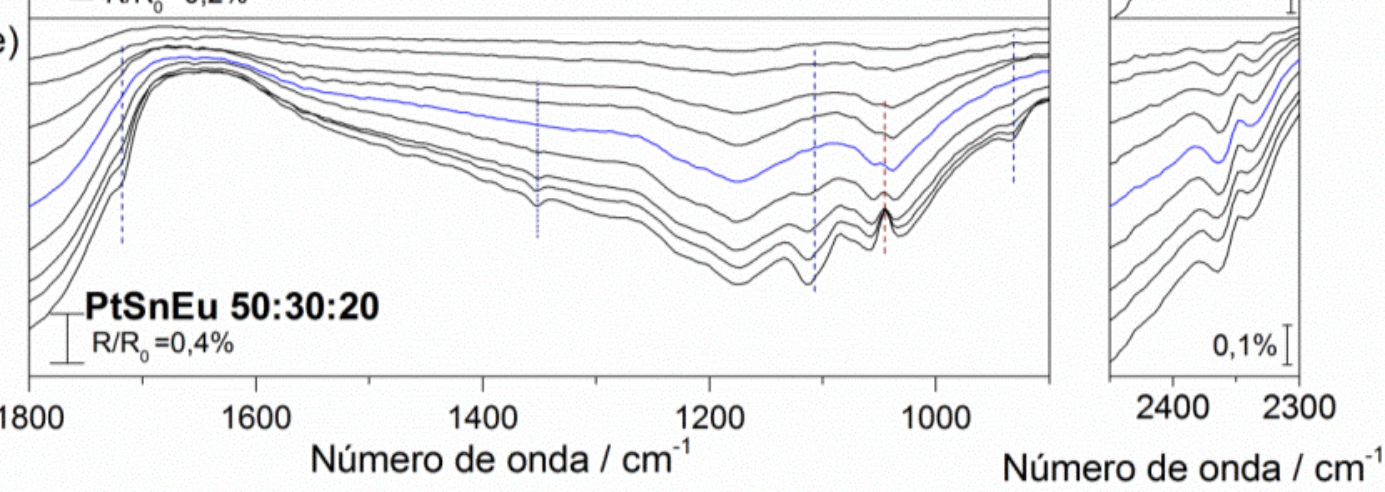

Fonte: Autoria própria. 


\section{Resultados e Discussão: Catalisadores PtSnEu/C}

A produção de $\mathrm{CO}_{2}$ foi observada por bandas negativas em $2342 \mathrm{~cm}^{-1}$ apenas para o catalisador PtSnEu/C 65:25:10. A formação de $\mathrm{CO}_{2}$ pode ser observada a partir de $500 \mathrm{mV}$. Entretanto, não foram observados bandas de CO linear em 2030$2065 \mathrm{~cm}^{-1}$, provavelmente pela baixa concentração deste.

A obtenção de ácido acético (AA) e acetaldeído (AL) foi confirmada para todos os catalisadores. As bandas típicas são observadas em $1270 \mathrm{~cm}^{-1}$, relacionada ao acoplamento da deformação da ligação O-H e estiramento da ligação C-O do grupo $\mathrm{CH}_{3} \mathrm{COO}$-; e em $1710 \mathrm{~cm}^{-1}$, descrita pelo estiramento do $-\mathrm{COOH}$ e/ou $-\mathrm{CHO}$. As bandas características para acetaldeído podem ser encontradas em $1355 \mathrm{~cm}^{-1}$ (deformação simétrica do $-\mathrm{CH}_{3}$, também relacionado a acetato) ${ }^{102}, 1090 \mathrm{~cm}^{-1}$ (vibração em balanço do $\mathrm{C}$-H) e em $1715 \mathrm{~cm}^{-1}$ (estiramento do grupo carbonílico). ${ }^{104}$ As bandas de AA e AL são discretas e observada a partir de $600 \mathrm{mV}$ para Pt/C. Para $\mathrm{PtSn} / \mathrm{C}$ 60:40, a formação de AL já é evidenciada em baixos potenciais $(400 \mathrm{mV})$ e o aumento do potencial aumenta a formação deste. Os catalisadores trimetálicos PtSnEu/C 75:20:05 e 65:25:10, apresentam bandas mais intensas, para os produtos AA e AL, e a obtenção pode ser vista após $500 \mathrm{mV}$. A composição PtSnEu/C 50:30:20, as bandas destes produtos também foram discretas, e a formação é evidenciada em maiores potenciais, superiores de $700 \mathrm{mV}$. O aumento do potencial favoreceu o aumento das bandas de consumo de etanol, em $1048 \mathrm{~cm}^{-1}$ e $1508 \mathrm{~cm}^{-1}$.

A literatura indica que a adsorção de etanol envolve o deslocamento de moléculas de água da superfície da Pt, seguida pela dissociação da ligação $\mathrm{C}-\mathrm{H}$, para formação de acetaldeído adsorvido: ${ }^{102}$

$$
\mathrm{C}_{2} \mathrm{H}_{5} \mathrm{OH}+\mathrm{Pt}\left(\mathrm{H}_{2} \mathrm{O}\right) \rightarrow \mathrm{Pt}\left(\mathrm{CH}_{3} \mathrm{CHO}\right)+\mathrm{H}_{2} \mathrm{O}+2 \mathrm{H}^{+}+2 \mathrm{e}^{-}
$$

E a partir da dissociação da ligação C-C do acetaldeído/acetato adsorvido, a formação de $\mathrm{CO}_{\mathrm{ad}}$ poderia acontecer pela reação: ${ }^{105}$

$$
\mathrm{Pt}\left(\mathrm{CH}_{3} \mathrm{CHO}\right)+\mathrm{Pt} \rightarrow \mathrm{Pt}(\mathrm{CO})+\mathrm{Pt}\left(\mathrm{CH}_{3}\right)+\mathrm{H}^{+}+\mathrm{e}^{-}
$$

Apesar da observação de formação de bandas relativas à formação de acetaldeído e acetato adsorvido, não foi observada para Pt/C a formação de bandas de $\mathrm{CO}_{\mathrm{ad}}$, nem na forma linear nem em ponte. De acordo com Shao e Adzic (2005), a 


\section{Resultados e Discussão: Catalisadores PtSnEu/C}

cobertura do $\mathrm{CO}$ adsorvido diminui em torno de $0,2 \mathrm{~V} v s \mathrm{Ag} / \mathrm{AgCl}(\sim 0,42 \vee v s \mathrm{EPH})$, e a oxidação de espécies com 2 carbonos $\left(\mathrm{C}_{2}\right)$ começa em torno de $0,35 \mathrm{~V}_{\mathrm{AgCl}}$ ( 0,57 $\vee$ vs EPH). As duas reações requerem uma fonte de oxigênio. As reações de espécies $\mathrm{C}_{2}$ podem ser escritas pelas seguintes equações: ${ }^{102}$

$$
\begin{aligned}
& \mathrm{Pt}\left(\mathrm{CH}_{3} \mathrm{CO}\right)+\mathrm{Pt}(\mathrm{OH}) \rightarrow \mathrm{Pt}\left(\mathrm{CH}_{3} \mathrm{COO}\right)+\mathrm{Pt}+\mathrm{H}^{+}+\mathrm{e}^{-} \\
& \mathrm{Pt}\left(\mathrm{CH}_{3} \mathrm{CHO}\right)+\mathrm{Pt}(\mathrm{OH}) \rightarrow \mathrm{Pt}\left(\mathrm{CH}_{3} \mathrm{COO}\right)+\mathrm{Pt}+2 \mathrm{H}^{+}+2 \mathrm{e}^{-}
\end{aligned}
$$

Segundo Kim et al. (2008) ${ }^{74}$, a adsorção de etanol em materiais bimetálicos, como $\mathrm{PtSn} / \mathrm{C}$, é diferenciada em relação a $\mathrm{Pt} / \mathrm{C}$, por motivos estruturais e eletrônicos. Alguns autores afirmam que a transferência eletrônica do $\mathrm{Sn}$ para $\mathrm{Pt}$ tornam os átomos superficiais de $\mathrm{Sn}$ mais eletropositivos, o que poderia atrair espécies oxigenadas para a superfície do catalisador. ${ }^{21}$ Nesses materiais bimetálicos, o etanol sofreria a adsorção e desidrogenação sobre os sítios ativos de $\mathrm{Pt}$, antes da clivagem da ligação $\mathrm{C}-\mathrm{C}$ e C-O, enquanto a adsorção dissociativa da água ocorreria no $\mathrm{Sn}$, que disponibilizariam espécies oxigenadas, capazes de facilitar a remoção de resíduos intermediários. ${ }^{74}$ Zhou et al. (2003) afirmam que a adição de Sn é benéfica para a quimissorção de etanol na $\mathrm{Pt}$ e a consequente reação de desidrogenação, pois este desfavorece a formação de estados $\mathrm{Pt}$ oxidados, elevando o número de sítios livres para estas reações. ${ }^{36}$

A Figura 5.20 apresenta uma esquematização da oxidação de etanol em partículas bimetálicas PtSn. Com a disponibilidade de espécies oxigenadas no Sn, os passos críticos na eletro-oxidação do álcool, que determinam a taxa de reação global e eficiência, seriam a clivagem da ligação C-C, com consecutiva desidrogenação (Fig. 5.20). O resultado da clivagem C-C podem gerar intermediários com um ou dois carbonos, respectivamente tipo $C_{1}$ e $C_{2}$. Estas espécies permaneceriam na superfície, envenenando o catalisador de Pt. A reação subsequente seria a reação superficial entre $C O$ (ou intermediários do tipo $C_{1}$ ou $C_{2}$ ) e $\mathrm{OH}$ (ou espécies oxigenadas) na superfície do catalisador, tal como oxidação de $\mathrm{CO}$, descrita pela equação 5.16 :

$$
\mathrm{CO}_{\mathrm{ads}}+\mathrm{OH}_{\mathrm{ads}} \rightarrow \mathrm{CO}_{2}+\mathrm{H}^{+}+\mathrm{e}^{-}
$$




\section{Resultados e Discussão: Catalisadores PtSnEu/C}

Figura 5.20 - Ilustração esquemática da eletro-oxidação de etanol na superfície bimetálica de catalisadores $\mathrm{PtSn} / \mathrm{C}$.

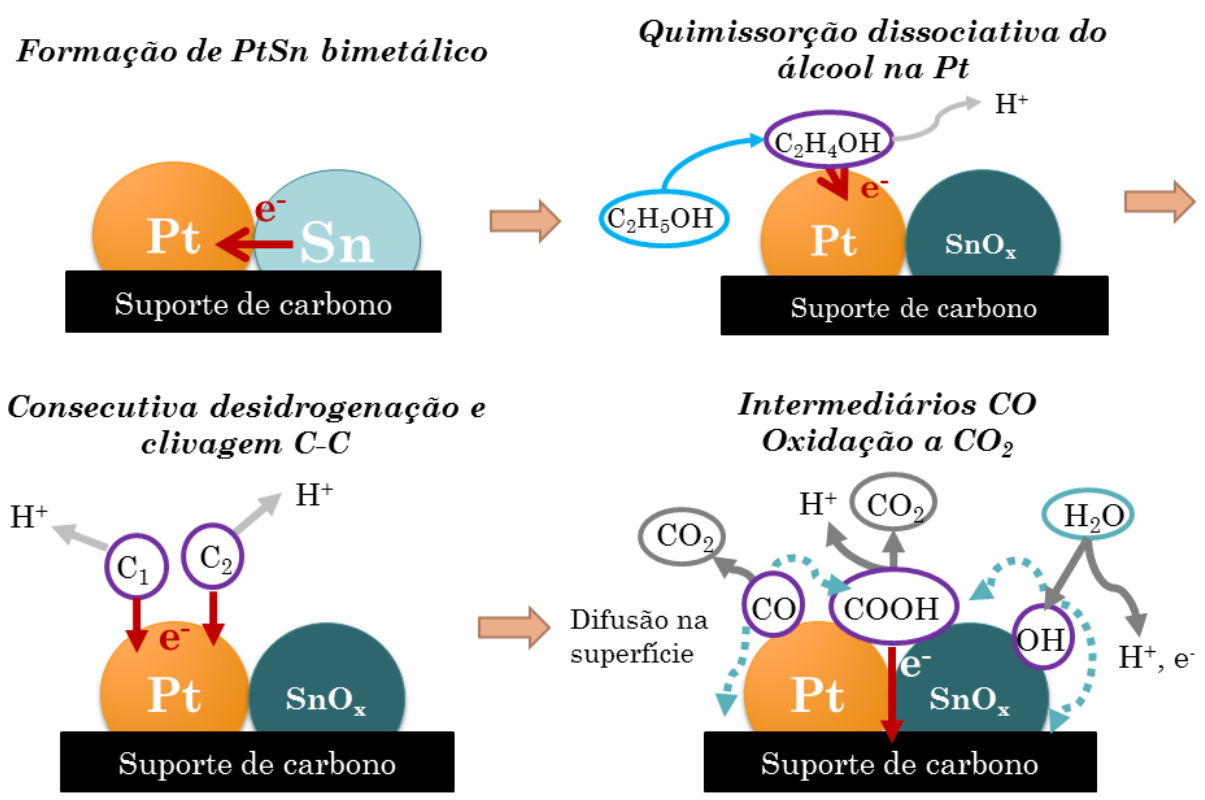

Fonte: Adaptado de KIM, J. H.; CHOI, S. M.; NAM, S. H.; SEO, M. H.; CHOI, S. H.; KIM, W.

B. Applied Catalysis B. 82,2008, p. $100 .^{7}$

Sobre a oxidação em materiais ternários Pt-Sn-Terras Raras, Jacob et al. $(2015)^{54}$ estudaram a formação de produtos da reação de ROE para catalisadores de $\mathrm{PtSnCe} / \mathrm{C}$. Os autores comentam que $\mathrm{O}$ etanol pode se adsorver dissociativamente em sítios de $\mathrm{Pt}$, via adsorção por $\mathrm{O}$ ou por $\mathrm{C}$, para formar espécies de acetaldeído. Ao passo que o acetaldeído é formado, este pode ser adsorvido pela $\mathrm{Pt}$ e formar espécies $\mathrm{Pt}\left(\mathrm{CH}_{3}-\mathrm{COO}\right)$, conforme a equação 5.15. O papel do cério seria semelhante ao estanho, de fornecer espécies oxigenadas a partir da água, em menores potenciais que obtidos para a Pt/C, de acordo com a reação: ${ }^{54}$

$$
\mathrm{MO}_{\mathrm{x}}+\mathrm{H}_{2} \mathrm{O} \rightarrow \mathrm{MO}_{\mathrm{x}}-(\mathrm{OH})_{\mathrm{ad}}+\mathrm{e}^{-}+\mathrm{H}^{+}
$$

$\mathrm{O}$ acetaldeído adsorvido pode reagir com as espécies $\mathrm{OH}_{\mathrm{ad}}$ para produzir ácido acético, de acordo com a reação: ${ }^{54}$

$$
\mathrm{Pt}-\left(\mathrm{CO}-\mathrm{CH}_{3}\right)_{\mathrm{ad}}+\mathrm{MO}_{\mathrm{x}}-(\mathrm{OH})_{\mathrm{ad}} \rightarrow \mathrm{Pt}+\mathrm{MO}_{\mathrm{x}}+\mathrm{CH}_{3}-\mathrm{COOH}
$$

Assim como o $\mathrm{Ce}$, a adição de Eu deve favorecer a formação de espécies oxigenadas a baixos potenciais. Os espectros de infravermelho confirmaram a formação de intermediários $\mathrm{C}_{2}$, pela presença de bandas de acetato, e bandas de formação de acetaldeído e ácido acético. De forma qualitativa, o material PtSnEu 


\section{Resultados e Discussão: Catalisadores PtSnEu/C}

50:30:20 apresentou a formação de início de $A A$ em $300 \mathrm{mV}$, enquanto as demais composições, as bandas ficaram mais evidentes após $600 \mathrm{mV}$. Apesar de não evidente, a formação de intermediários $C_{1}$ também deve ter ocorrido para 0 catalisador PtSnEu 65:25:10, visto que a posterior oxidação para o produto $\mathrm{CO}_{2}$ foi observada (Fig. 5.19 d).

Conforme observado nas medidas de FTIR, a adição de estanho e európio promoveu a formação de ácido acético e acetaldeído, e quanto maior a concentração destes metais, menor o potencial de início de formação de ácido acético.

\subsubsection{Testes em célula unitária}

Os catalisadores de PtSnEu/C sintetizados por poliol foram caracterizados eletroquimicamente em uma célula unitária, para uma avaliação mais próxima das condições de operação. Foram realizados experimentos em duas configurações: meia célula e célula completa.

\subsubsection{Configuração de meia célula}

Para avaliação da contribuição do ânodo, medidas em meia célula foram realizadas, na qual gás hidrogênio era injetado no cátodo, servindo como um eletrodo dinâmico a hidrogênio; e etanol no ânodo. A Figura 5.21a apresenta as voltametrias lineares para $\mathrm{ROE}$ a $90^{\circ} \mathrm{C}$ para os catalisadores $\mathrm{PtSnEu} / \mathrm{C}$. Os catalisadores de PtSn/C e PtSnEu apresentaram valores maiores de densidade de corrente que a Pt pura no intervalo estudado. A diferença entre os catalisadores ternários e a Pt é bem evidenciada, visto que a oxidação de etanol na Pt apresenta início por volta de $0,40 \mathrm{~V}$, e nos demais catalisadores, próximos a $0,25 \mathrm{~V}$. Ao comparar as densidades de corrente dos catalisadores binários e ternários, é possível observar o efeito benéfico da adição de európio em baixas concentrações (5 e 10\% atômico). Nos cronoamperogramas em 0,6 V, representado pela Figura $5.21 \mathrm{~b}$, a tendência da densidade de corrente da polarização linear foi mantida, e o catalisador PtSnEu 75:20:05 apresentou a maior densidade de corrente dentre os catalisadores avaliados, de $45 \mathrm{~mA} \mathrm{~cm}^{-2}$, em 2800 segundos. Os catalisadores $\mathrm{PtSn} / \mathrm{C}$ e PtSnEu 65:25:10 apresentaram densidades de corrente próximas a $30 \mathrm{~mA} \mathrm{~cm}^{-2}$, seguidos pelo PtSnEu 50:30:20, de $25 \mathrm{~mA} \mathrm{~cm}^{-2}$ e Pt, $9 \mathrm{~mA} \mathrm{~cm}{ }^{-2}$. 
Resultados e Discussão: Catalisadores PtSnEu/C

Figura 5.21 - (a) Voltamogramas a $1 \mathrm{mV} \mathrm{s}^{-1}$ e (b) cronoamperogramas em 0,600V para ROE dos catalisadores $\mathrm{Pt} / \mathrm{C}, \mathrm{PtSn} / \mathrm{C}$ 60:40 e PtSnEu/C a $90^{\circ} \mathrm{C}$, solução de etanol $1 \mathrm{~mol} \mathrm{~L}^{-1}$. Densidades de corrente normalizadas pela área geométrica. Ânodo: $1 \mathrm{mg}_{\mathrm{Pt}} \mathrm{cm}^{-2}$. Cátodo: $30 \% \mathrm{Pt} / \mathrm{C}, 1 \mathrm{mg}_{\mathrm{Pt}} \mathrm{cm}^{-2}$.

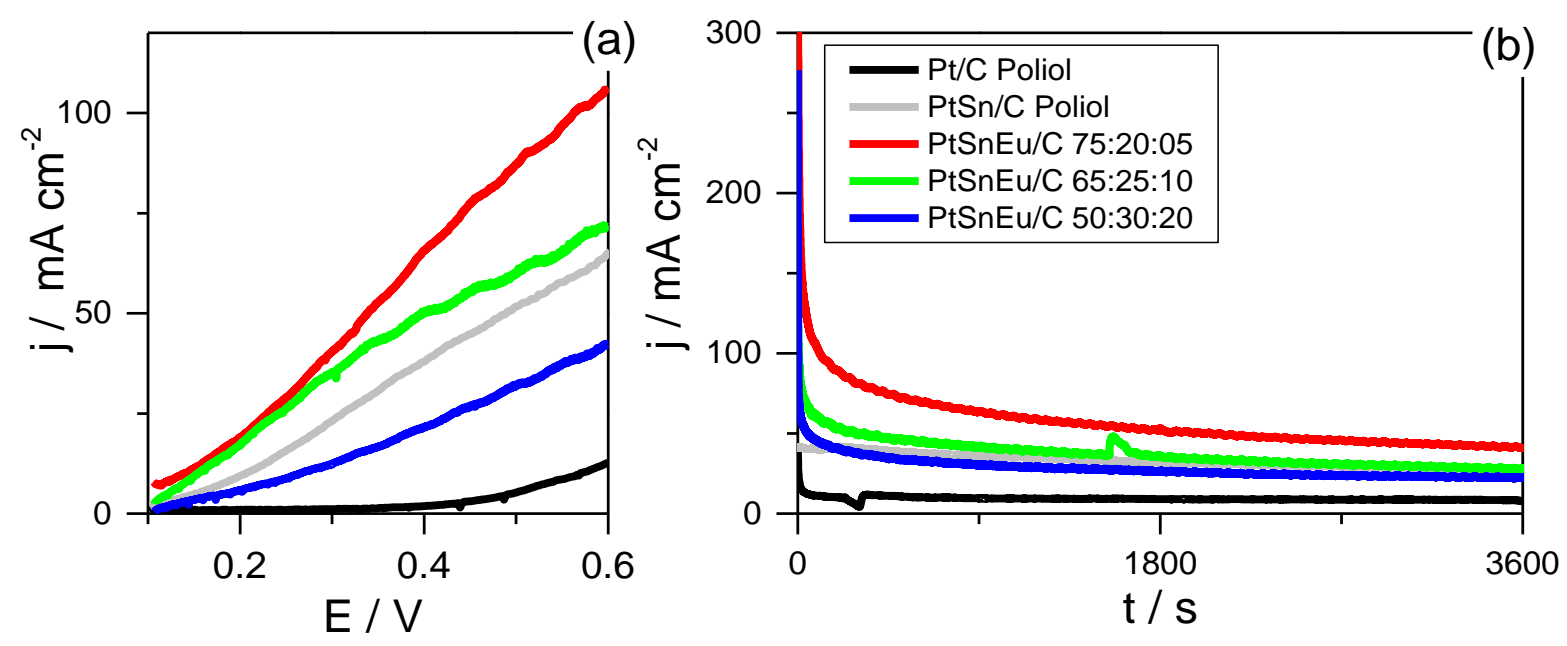

Fonte: Autoria própria.

\subsubsection{Configuração de célula completa}

O sistema também foi avaliado por configuração completa, na qual o gás oxigênio era injetado no cátodo, com a pressão mantida em 3 atm, e etanol $1,0 \mathrm{~mol} \mathrm{~L}^{-1}$ no ânodo. Nesse arranjo, o potencial da célula não é referente a um eletrodo de referência, mas em relação ao cátodo. As curvas de polarizações lineares para os catalisadores $\mathrm{Pt} / \mathrm{C}, \mathrm{PtSn} / \mathrm{C}$ e PtSnEu/C estão apresentadas na Figura 5.22. Nota-se que para o sistema completo, todos os catalisadores ternários apresentaram densidades de corrente superiores a Pt/C no intervalo de potencial aplicado, e a diferença de atividade entre PtSnEu 50:30:20 e PtSn/C 60:40 foram pequenas. A composição com maior densidade de corrente foi PtSnEu 75:20:05, fornecendo o valor de $65,7 \mathrm{~mA} \mathrm{~cm}^{-2}$ em 0,2 V. 


\section{Resultados e Discussão: Catalisadores PtSnEu/C}

Figura 5.22 - Voltamogramas lineares em PEMFC de etanol direto para os catalisadores $\mathrm{Pt} / \mathrm{C}, \mathrm{PtSn} / \mathrm{C} 60: 40$ e PtSnEu/C a $90 \stackrel{\circ}{\circ}$ e pressão 3 atm $\mathrm{O}_{2}$, solução de etanol 1 mol L-1. Ânodo: $1 \mathrm{mg}_{\mathrm{Pt}} \mathrm{cm}^{-2}$. Cátodo: $30 \% \mathrm{Pt} / \mathrm{C}, 1 \mathrm{mg}_{\mathrm{Pt}} \mathrm{cm}^{-2}$.

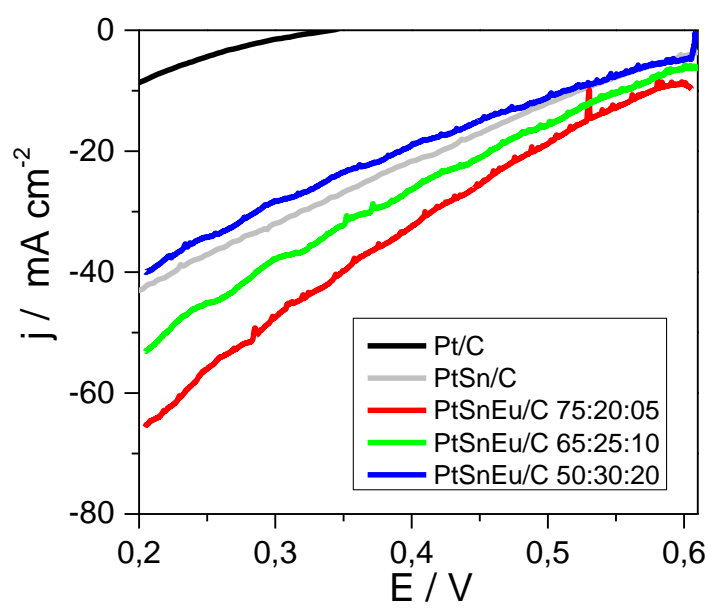

Fonte: Autoria própria.

A Figura 5.23 apresenta as curvas de densidade de potência e potencial em função da densidade de corrente em PEMFC de etanol direto nos catalisadores de $\mathrm{PtSnEu} / \mathrm{C}$ para ROE a $90^{\circ} \mathrm{C}$. Os catalisadores de PtSn/C e PtSnEu/C apresentam potencial de circuito aberto próximos a $0,7 \mathrm{~V}$, bem superiores ao apresentado pela $\mathrm{Pt} / \mathrm{C}$, de $0,35 \mathrm{~V}$. As densidades máximas de potência para os catalisadores variaram de $2,5 \mathrm{~mW} \mathrm{~cm}^{-2}$ para Pt/C, $8 \mathrm{~mW} \mathrm{~cm}^{-2}$ para PtSnEu/C 50:30:20; de 8,3 $\mathrm{mW} \mathrm{cm}^{-2}$ para $\mathrm{PtSn} / \mathrm{C}$, de $10 \mathrm{~mW} \mathrm{~cm}^{-2}$ para PtSnEu/C 60:20:20 e de $12 \mathrm{~mW} \mathrm{~cm}^{-2}$ para PtSnEu/C 75:20:05.

Figura 5.23 - Curvas de densidade de potência e potencial em função da densidade de corrente em PEMFC de etanol direto dos catalisadores Pt/C, PtSn/C 60:40 e $\mathrm{PtSnEu} / \mathrm{C}$ a $90{ }^{\circ} \mathrm{C}$ e pressão $3 \mathrm{~atm} \mathrm{O}_{2}$, solução de etanol $1 \mathrm{~mol} \mathrm{~L}^{-1}$. Ânodo: $1 \mathrm{mg}_{\mathrm{Pt}} \mathrm{cm}^{-2}$. Cátodo: $30 \% \mathrm{Pt} / \mathrm{C}, 1 \mathrm{mg}_{\mathrm{Pt}} \mathrm{cm}^{-2}$.

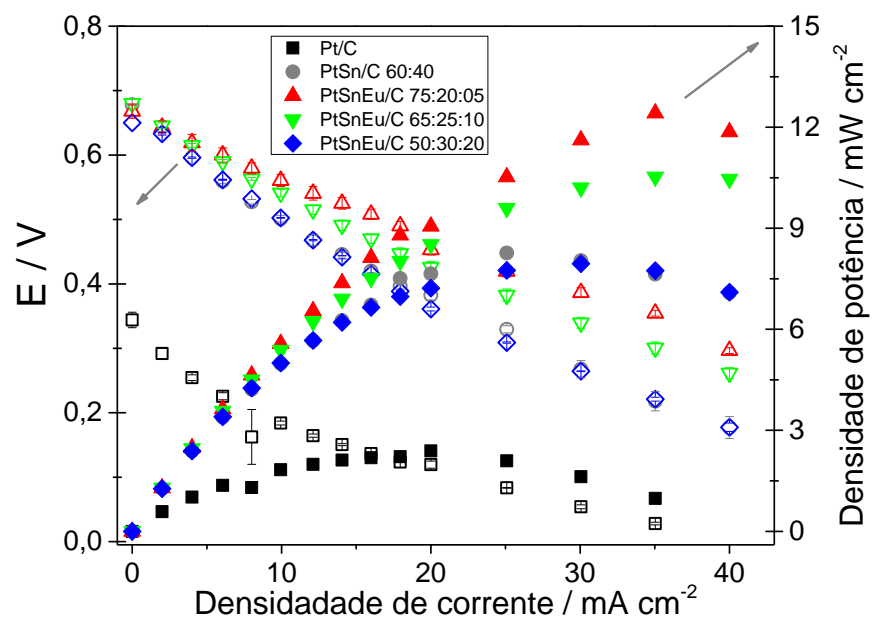

Fonte: Autoria própria. 


\section{Resultados e Discussão: Catalisadores PtSnEu/C}

$\mathrm{Na}$ literatura, densidades de potência máxima de cerca de $100 \mathrm{~mW} \mathrm{~cm}^{-2}$ já foram reportadas para nanopartículas bimetálitcas com Pt. ${ }^{106}$ Entretanto, a comparação de valores deve ser feita com cautela, visto que diferenças no aparato experimental, tais como: temperatura de operação, carga metálica da camada catalítica, uso de catalisadores catódicos mais eficientes para crossover de etanol, entre outros; podem ter um grande impacto nas potências obtidas. Em geral, materiais com carga metálica de 1 a $2 \mathrm{mg} \mathrm{cm}^{-2}$ reportam o máximo de densidade de potência entre 10 a $80 \mathrm{~mW} \mathrm{~cm}^{-2}$, com células individuais de pequena escala operando entre $70{ }^{\circ} \mathrm{C}$ a $110^{\circ} \mathrm{C}$. ${ }^{2}$ Para células operando com ânodo de Pt comercial (Etek, 20\%) e cátodo também de Pt comercial (Etek, 30\%) com carga de Pt de $1 \mathrm{mg} \mathrm{cm}^{-2}$, os valores observados de densidade de potência foram $6,8 \mathrm{~mW} \mathrm{~cm}^{-2} 107$, superiores aos valores apresentados pela $\mathrm{Pt} / \mathrm{C}$ poliol. Para catalisadores $\mathrm{PtSn} / \mathrm{C}$ 75:25 comerciais (Etek, 20\%), os valores de potência listados na literatura estão próximos a $12 \mathrm{~mW} \mathrm{~cm}^{-2}$. ${ }^{108}$

Colmati e et al. (2007) sintetizaram PtSn/C 3:1 pelo método do ácido fórmico (MAF), e a densidade de potência obtida chegou a $20 \mathrm{~mW} \mathrm{~cm}^{-2}$ a $90{ }^{\circ} \mathrm{C} .{ }^{108}$ Antolini et al. (2009), ao avaliarem catalisadores $\mathrm{PtSn} / \mathrm{C}$ e $\mathrm{PtSnPd} / \mathrm{C}$ obtidos por MAF, obtiveram a densidade de potência máxima próxima a $15 \mathrm{~mW} \mathrm{~cm}^{-2}$ para catalisadores $\mathrm{PtSn} / \mathrm{C}$ 50:50, e para catalisadores trimetálicos $\mathrm{PtSnPd} / \mathrm{C}$ nas proporções estudadas (40:45:15 e 33:35:32), os valores máximos observados não ultrapassaram $6 \mathrm{~mW} \mathrm{~cm}^{-2}$ para ROE em células unitárias a $90^{\circ} \mathrm{C} .{ }^{109}$ As densidades de potência relatada estão próximas às observadas para os catalisadores PtSnEu/C, próximas a $10 \mathrm{~mW} \mathrm{~cm}^{-2}$.

Para evitar muitas discrepâncias nas comparações, alguns autores preferem comparar a densidade de potência específica mássica máxima do que densidade de potência por total mg de Pt no catalisador Pt (ânodo + cátodo). ${ }^{29}$ Neste caso, o estado da arte relatado é $0,05 \mathrm{~mW} \mu \mathrm{gPt}^{-1} \cdot{ }^{29}$ Os catalisadores $\mathrm{PtSnEu} / \mathrm{C}$

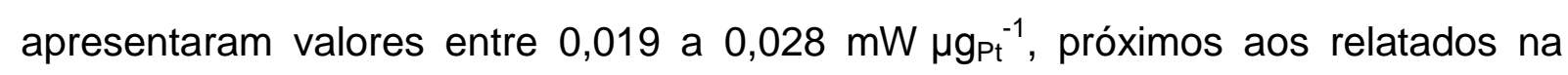
literatura, não se destacando em densidade de potência em relação ao que já foi relatado. No entanto, apesar de discreto, torna-se inegável o efeito benéfico do európio aos catalisadores $\mathrm{PtSn} / \mathrm{C}$ obtidos por poliol, mas é necessário observar que o valor ótimo de concentração é baixo, sendo menor que 10\% atômico. 


\section{Resultados e Discussão: Catalisadores PtSnEu/C}

A melhora nas densidades de corrente obtidas pode estar relacionada com os produtos resultantes da oxidação de etanol. Hitmi et al. (1994) detectaram que acetaldeído era formado na Pt em potenciais menores que $0,6 \vee v s \mathrm{ERH}$, enquanto nenhum ácido acético era detectado nessa região de potencial. ${ }^{22} \mathrm{O}$ acetaldeído formado adsorvia-se nos sítios de Pt e formava espécies $\mathrm{CH}_{3} \mathrm{CO}_{\text {ad }}$ que bloqueavam a oxidação de etanol subsequente. A oxidação dessas espécies intermediárias em catalisadores binários ocorrem pelo mecanismo bifuncional. ${ }^{22}$ As espécies $\mathrm{OH}$, formadas em baixos potencias no estanho, permitem a oxidação de espécies $\mathrm{CH}_{3} \mathrm{CO}_{a d}$ em ácido acético, ${ }^{71}$ conforme confirmado pelas medidas de FTIR. A adição de európio foi benéfica, visto que ao comparar as densidades de corrente obtidas dos catalisadores ternários, as composições PtSnEu 70:20:05 e 65:25:10 apresentaram maior densidade de corrente que o catalisador PtSn/C 60:40. Mas para um estudo mais quantitativo do efeito da adição de estanho e európio nas concentrações de subprodutos da oxidação de etanol, medidas de HPLC foram realizadas.

5.3.2.3 Caracterização dos subprodutos de etanol por cromatografia líquida de alta eficiência

As coletas dos subprodutos da reação de oxidação de etanol para as medidas de HPLC foram realizadas acopladas a configuração de célula unitária, visto que é o sistema eletroquímico mais próximo do sistema operacional. As medidas foram realizadas a $90^{\circ} \mathrm{C}$. Foram coletadas amostras tanto no arranjo de célula completa, no qual o cátodo é abastecido com oxigênio; quanto em meia célula, no qual o cátodo é abastecido com hidrogênio. Na configuração de célula completa foram escolhidas três densidades de corrente para avalição dos produtos: $8 \mathrm{~mA} \mathrm{~cm}{ }^{-2}$, $16 \mathrm{~mA} \mathrm{~cm}^{-2}, 30 \mathrm{~mA} \mathrm{~cm}^{-2}$; e estas foram aplicadas durante 20 minutos. Para a configuração de meia célula, foram aplicados os potenciais $0,5 \vee$ e $0,6 \vee$ durante 1 hora.

A Tabela 5.8 reporta os resultados obtidos para as diferentes densidades de corrente aplicada para os catalisadores de Pt/C, PtSn/C 60:40 e PtSnEu/C sintetizados. A determinação por HPLC foi realizada para as espécies de acetaldeído ( $\mathrm{AL}$ ), ácido acético (AA) e $\mathrm{CO}_{2}$ formado. Nenhum outro produto foi 


\section{Resultados e Discussão: Catalisadores PtSnEu/C}

detectado pelas medidas de cromatografia. As curvas de calibração para cada produto estão no Apêndice II, Figura A1.

Para os catalisadores foi possível determinar o número teórico e experimental de elétrons para cada medida. ${ }^{30}$ Para a PtSnEu/C 75:20:05, em $16 \mathrm{~mA} \mathrm{~cm}^{-2}$ (74 mA), foram formados $[A L]=24 \mathrm{mmol} \mathrm{L}^{-1},[A A]=16 \mathrm{mmol} \mathrm{L}^{-1}$ e $\left[\mathrm{CO}_{2}\right]=3,0 \mathrm{mmol} \mathrm{L}^{-1}$. A formação desses produtos requer uma quantidade de eletricidade que pode ser calculada da seguinte forma

$$
\mathrm{q}=\mathrm{I} \times \mathrm{t}
$$

onde q é a carga em Coulomb, I, a corrente em Ampere e t é o tempo, em segundos. Neste exemplo, a carga foi:

$$
\mathrm{q}=0,074 \times 1200=88,8 \mathrm{C}
$$

A qual pode ser expressa em mols de elétrons de troca, $n_{e, \text { teórico: }}$

$$
\mathrm{n}_{\mathrm{e}}=\frac{88,8}{96500}=0,0009 \mathrm{~mol}=0,9 \mathrm{mmol}
$$

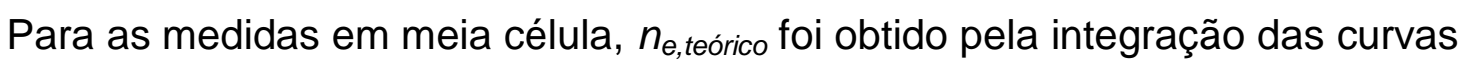
amperiométricas. É possível determinar a quantidade para cada produto de reação formado na célula. Primeiramente o número de cada produto é calculado separadamente e sabendo que $1 \mathrm{~mol}$ de $\mathrm{AL}, \mathrm{AA}$ e $\mathrm{CO}_{2}$ necessita de 2, 4 e 6 elétrons de troca, respectivamente. O número de elétrons de troca experimental $\left(n_{e, \text { exp }}\right)$ para o catalisador PtSnEu/C 75:20:05 em $16 \mathrm{~mA} \mathrm{~cm}^{-2}$, lembrando que o volume total de amostra era $10 \mathrm{~mL}$, pode ser obtido pela soma:

$$
\begin{aligned}
& \mathrm{n}_{\mathrm{AL}}=24,0 \cdot 10^{-3} \times 0,010=2,4 \times 10^{-4} \times 2=4,8 \times 10^{-4} \mathrm{~mol} \\
& \mathrm{n}_{\mathrm{AA}}=16,0 \cdot 10^{-3} \times 0,010=1,6 \times 10^{-4} \times 4=6,4 \times 10^{-4} \mathrm{~mol} \\
& \mathrm{n}_{\mathrm{CO}_{2}}=3,0 \cdot 10^{-3} \times 0,010=3 \cdot 10^{-5} \times 6=1,8 \cdot 10^{-4} \mathrm{~mol} \\
& \mathrm{n}_{\mathrm{e}, \exp }=\mathrm{n}_{\mathrm{AL}}+\mathrm{n}_{\mathrm{AA}}+\mathrm{n}_{\mathrm{CO}_{2}}=4,8 \cdot 10^{-4}+6,4 \cdot 10^{-4}+1,8 \cdot 10^{-4}=1,3 \cdot 10^{-3} \mathrm{~mol}=
\end{aligned}
$$

1,3 mmol

O $n_{e, t e o ́ r i c o}$ real deve igual ou ser maior que o $n_{e, \exp }$, visto que normalmente há perdas na coleta dos produtos. Mas nos experimentos realizados, essa tendência não foi observada, visto que o $n_{e, \text { exp }}$ foi muito superior ao teórico, para a maioria dos

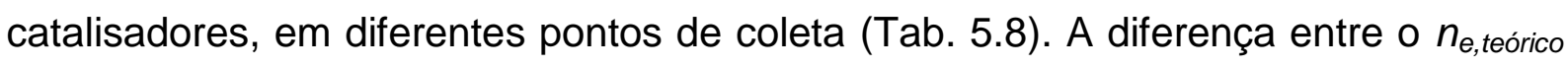
e o $n_{e, \exp }$ deve-se pelo provável crossover do etanol para o cátodo e/ou perdas por resistências ôhmicas, que acarretam em uma diminuição do desempenho da célula,

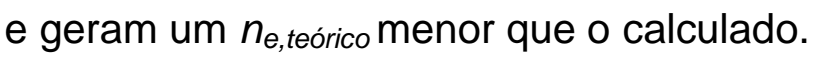


Capítulo III

Resultados e Discussão: Catalisadores PtSnEu/C

Tabela 5.8 - Características elétricas e as concentrações de acetaldeído ( $\mathrm{AL}$ ), ácido acético (AA) e $\mathrm{CO}_{2}$ formado durante a aplicação de 20 minutos em diferentes densidades de corrente, ou aplicação de um potencial fixo por 1 hora, em uma célula de $5 \mathrm{~cm}^{2}$, com cátodo de $\mathrm{Pt} / \mathrm{C}$ Etek $30 \%$ e ânodo com $1 \mathrm{mg}_{\mathrm{Pt}} \mathrm{cm}^{-2}$.

\begin{tabular}{|c|c|c|c|c|c|c|c|c|c|c|c|c|}
\hline \multirow{2}{*}{ Catalisador } & \multirow{2}{*}{$\mathrm{j}\left(\mathrm{mA} \mathrm{cm} \mathrm{cm}^{-2}\right)$} & \multirow{2}{*}{$E_{\text {cel }}(V)$} & \multirow{2}{*}{$\begin{array}{l}n_{e, \text { teórico }} \\
\text { (mmol) }\end{array}$} & \multicolumn{4}{|c|}{ Concentração $\left(\mathrm{mmol} \mathrm{L}^{-1}\right)$} & \multirow{2}{*}{$n_{e, \exp }$} & \multirow{2}{*}{$\begin{array}{l}V_{\text {ânodo }} \\
(\mathrm{mL})\end{array}$} & \multicolumn{3}{|c|}{$\begin{array}{l}\text { Distribuição dos } \\
\text { produtos (\%) }\end{array}$} \\
\hline & & & & $A L$ & AA & $\mathrm{CO}_{2}$ & EtOH & & & $\mathbf{A L}$ & AA & $\mathrm{CO}_{2}$ \\
\hline \multirow{5}{*}{$\mathrm{Pt} / \mathrm{C}$} & 8 & $0,199-0,239$ & 0,46 & 10 & 18 & 1,2 & 883 & 0,98 & \multirow{3}{*}{10} & 30 & 68 & 2 \\
\hline & 16 & $0,192-0,209$ & 0,92 & 8 & 15 & 1,3 & 943 & 0,82 & & 34 & 63 & 3 \\
\hline & 30 & $0,124-0,152$ & 1,73 & 9 & 14 & 1,3 & 959 & 0,79 & & 39 & 58 & 3 \\
\hline & \multirow{2}{*}{ Meia célula } & 0,500 & 0,54 & 7 & 9 & 1,1 & 895 & 1,28 & \multirow{2}{*}{25} & 43 & 55 & 1 \\
\hline & & 0,600 & 1,60 & 9 & 3 & 0,7 & 902 & 0,79 & & 74 & 25 & 1 \\
\hline \multirow{5}{*}{$\mathrm{PtSn} / \mathrm{C}$ 60:40 } & 8 & $0,487-0,531$ & 0,46 & 7 & 23 & 1,2 & 937 & 1,07 & \multirow{3}{*}{10} & 23 & 75 & 2 \\
\hline & 16 & $0,362-0,470$ & 0,92 & 8 & 34 & 1,2 & 882 & 1,57 & & 19 & 79 & 1 \\
\hline & 30 & $0,177-0,406$ & 1,73 & 12 & 44 & 0,7 & 851 & 2,00 & & 21 & 78 & 1 \\
\hline & \multirow{2}{*}{ Meia célula } & 0,500 & 5,55 & 10 & 8 & 0,8 & 928 & 1,35 & \multirow{2}{*}{25} & 56 & 43 & 1 \\
\hline & & 0,600 & 5,69 & 15 & 9 & 1,3 & 900 & 1,71 & & 60 & 39 & 1 \\
\hline \multirow{5}{*}{$\begin{array}{c}\text { PtSnEu } \\
75: 20: 05\end{array}$} & 8 & $0,64-0,57$ & 0,46 & 17 & 14 & 0,8 & 935 & 0,96 & \multirow{3}{*}{10} & 53 & 44 & 3 \\
\hline & 16 & $0,56-0,49$ & 0,92 & 24 & 16 & 3,0 & 879 & 1,30 & & 55 & 38 & 7 \\
\hline & 30 & $0,52-0,37$ & 1,73 & 30 & 17 & 1,4 & 924 & 1,36 & & 62 & 35 & 3 \\
\hline & \multirow{2}{*}{ Meia célula } & 0,500 & 8,9 & 77 & 27 & 2,1 & 805 & 6,7 & \multirow{2}{*}{25} & 72 & 26 & 2 \\
\hline & & 0,600 & 9,9 & 88 & 23 & 2,3 & 818 & 6,8 & & 78 & 20 & 2 \\
\hline \multirow{5}{*}{$\begin{array}{l}\text { PtSnEu } \\
65: 25: 10\end{array}$} & 8 & $0,62-0,55$ & 0,46 & 24 & 16 & 0,6 & 919 & 1,2 & \multirow{3}{*}{10} & 59 & 40 & 1 \\
\hline & 16 & $0,57-0,44$ & 0,92 & 37 & 20 & 5,5 & 902 & 1,9 & & 59 & 32 & 9 \\
\hline & 30 & $0,49-0,29$ & 1,73 & 50 & 22 & 1,2 & 906 & 2,0 & & 68 & 30 & 2 \\
\hline & \multirow{2}{*}{ Meia célula } & 0,500 & 6,8 & 71 & 22 & 2,4 & 839 & 5,9 & \multirow{2}{*}{25} & 75 & 23 & 2 \\
\hline & & 0,600 & 6,5 & 99 & 19 & 2,9 & 841 & 7,0 & & 82 & 16 & 2 \\
\hline \multirow{5}{*}{$\begin{array}{c}\text { PtSnEu } \\
50: 30: 20\end{array}$} & 8 & $0,54-0,53$ & 0,46 & 19 & 21 & 0,7 & 827 & 3,1 & \multirow{5}{*}{25} & 48 & 51 & 2 \\
\hline & 16 & $0,43-0,41$ & 0,92 & 22 & 24 & 1,6 & 829 & 3,6 & & 45 & 51 & 3 \\
\hline & 30 & $0,27-0,26$ & 1,73 & 40 & 32 & 1,8 & 745 & 5,3 & & 54 & 44 & 2 \\
\hline & \multirow{2}{*}{ Meia célula } & 0,500 & 3,8 & 27 & 10 & 1,1 & 587 & 2,4 & & 71 & 26 & 3 \\
\hline & & 0,600 & 4,9 & 36 & 14 & 2,1 & 655 & 3,3 & & 69 & 27 & 4 \\
\hline
\end{tabular}




\section{Resultados e Discussão: Catalisadores PtSnEu/C}

Considerando que a coleta foi semelhante para todos os materiais, determinouse as concentrações dos produtos em forma relativa para comparação entre catalisadores. Ao observar a concentração das espécies identificadas, o catalisador PtSnEu/C 50:30:20 apresentou maior consumo de etanol, próximo a $25 \%$ em condição de célula e $40 \%$ em meia célula. Para as demais composições, observa-se que a conversão de etanol foi inferior a $20 \%$, visto que em todas as condições estudadas, a concentração de etanol foi superior a $0,80 \mathrm{~mol} \mathrm{~L}^{-1}$.

Para visualizar a distribuição dos produtos quantificados para ROE, a Figura 5.24 apresenta a porcentagem de acetaldeído (AL), ácido acético (AA) e $\mathrm{CO}_{2}$ para cada catalisador. $O$ catalisador $\mathrm{Pt} / \mathrm{C}$ apresentou maior formação de $\mathrm{AA}$ do que $\mathrm{AL}$ em todas as configurações (Fig. $5.24 \mathrm{a}$ ). A produção de $\mathrm{CO}_{2}$ foi maior em configuração de célula completa, em $16 \mathrm{~mA} \mathrm{~cm}^{-2}$ e $30 \mathrm{~mA} \mathrm{~cm}^{-2}$. Para PtSn/C 60:40 (Fig. 5.24b), a produção de $\mathrm{CO}_{2}$ só foi observada na configuração de meia célula. Com o aumento da densidade de corrente exigido do sistema, observa-se aumento da concentração de AL. O catalisador PtSnEu 75:20:05 apresentou maior produção de $\mathrm{CO}_{2}$, principalmente em $16 \mathrm{~mA} \mathrm{~cm}^{-2}$ (Fig. 5.24 c). Isso é coerente com as medidas eletroquímicas, visto que este apresentou maior a densidade de potência. A composição $\mathrm{PtSnEu} \mathrm{65:25:10} \mathrm{também} \mathrm{apresentou} \mathrm{maior} \mathrm{produção} \mathrm{de} \mathrm{CO}_{2}$ em $16 \mathrm{~mA} \mathrm{~cm}^{-2}$ (densidade de corrente no qual o catalisador apresentou maior densidade de potência) mas nas demais condições, a produção majoritária foi de $A L$ (Fig. 5.24 d). Já o catalisador com maior concentração de estanho (PtSnEu 50:30:20) foi observada a maior produção de $A A$ em configuração de célula completa, mas em meia célula a produção majoritária foi de AL (Fig. 5.24 e). 
Figura 5.24 - Distribuição dos produtos quantificados por HPLC dos catalisadores de (a) $\mathrm{Pt} / \mathrm{C}$; (b) PtSn/C 60:40; (c) PtSnEu/C 75:20:05; (d) PtSnEu/C 65:25:10; e (e) $\mathrm{PtSnEu} / \mathrm{C}$ 50:30:20 em $8 \mathrm{~mA} \mathrm{~cm}{ }^{-2}, 16 \mathrm{~mA} \mathrm{~cm}^{-2}$ e $30 \mathrm{~mA} \mathrm{~cm}{ }^{-2}$ na configuração de célula completa; e em $0,5 \mathrm{~V}$ e $0,6 \mathrm{~V}$ na configuração de meia célula.

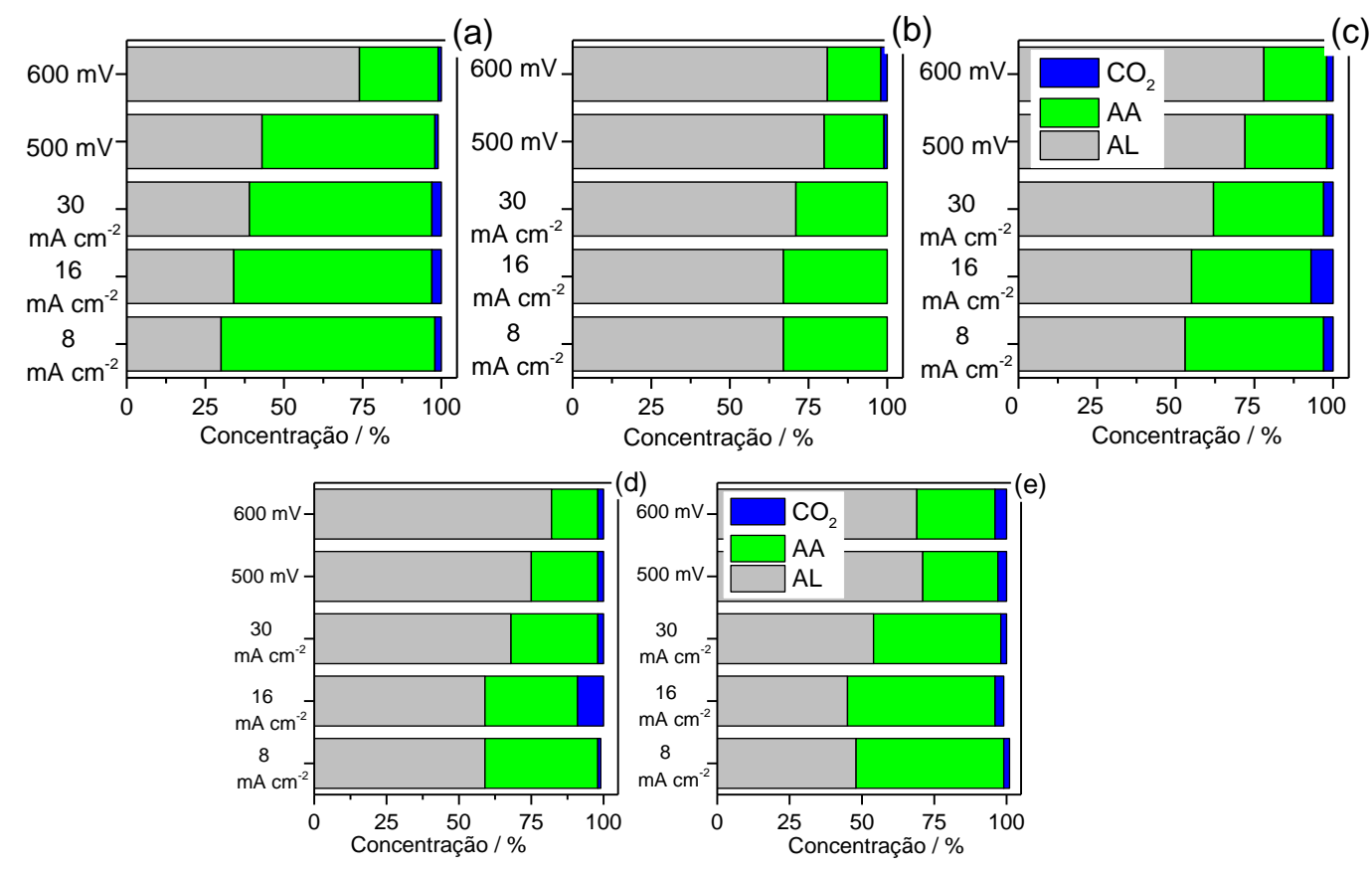

Fonte: Autoria própria.

A Figura 5.25 compara os produtos obtidos pelos diferentes catalisadores para uma mesma configuração experimental. Em 8 mA cm${ }^{-2}$ (Fig. 5.25 a), o catalisador que apresentou maior produção de $\mathrm{CO}_{2}$ foi a composição 75:20:05, enquanto a composição com maior produção de AA foi PtSnEu 50:30:20. Para a densidade de corrente de $16 \mathrm{~mA} \mathrm{~cm}^{-2}$ (Fig. $5.25 \mathrm{~b}$ ), valor no qual a maioria dos catalisadores apresentou maior densidade de potência, os catalisadores apresentaram maior produção de AA, e o catalisador PtSnEu 65:25:10 apresentou maior produção de $\mathrm{CO}_{2}$. Mas, ao aumentar a demanda de corrente do sistema para $30 \mathrm{~mA} \mathrm{~cm}{ }^{-2}$, é possível observar a maior produção de $A L$, e diminuição de produção de $A A$ e $\mathrm{CO}_{2}$ (Fig. 5.25c). Em meia célula, tanto em 0,5 V quanto em 0,6 V (Fig. 5.25 d e 5.25 e), a produção majoritária de produtos foi $A L$. Provavelmente a menor formação de ácido acético observada em meia célula se deva à modificação na superfície dos catalisadores devido aos potenciais aplicados. Potenciais superiores de 0,5 V já são suficiente para promover oxidação da Pt. Como normalmente a formação de ácido acético envolve a adsorção e conseguinte oxidação de acetaldeído na $\mathrm{Pt}$, em uma superfície mais oxidada, a obtenção de AA pode ser diminuída, como observado. 


\section{Resultados e Discussão: Catalisadores PtSnEu/C}

Figura 5.25 - Distribuição dos produtos quantificados por HPLC dos catalisadores de Pt/C, $\mathrm{PtSn} / \mathrm{C}$ 60:40 e PtSnEu/C na configuração de célula completa em (a) $8 \mathrm{~mA} \mathrm{~cm}^{-2}$, (b) $16 \mathrm{~mA} \mathrm{~cm}^{-2}$, (c) $30 \mathrm{~mA} \mathrm{~cm}^{-2}$ e em meia célula a (d) $0,5 \mathrm{~V}$ e (e) $0,6 \mathrm{~V}$.

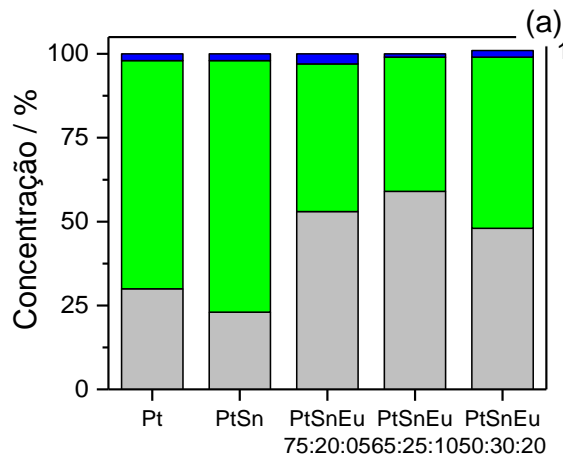

(a)
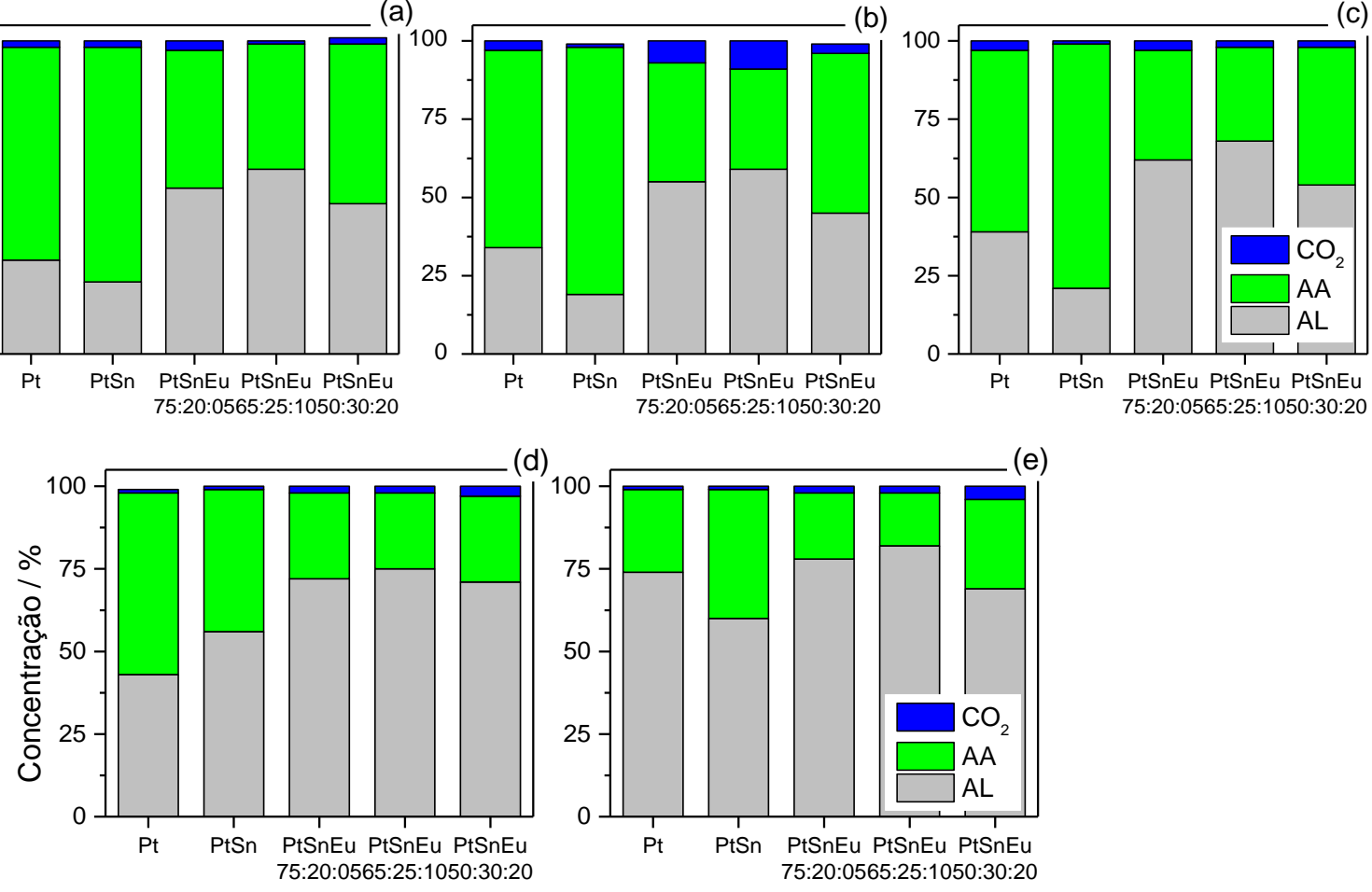

Fonte: Autoria própria.

A formação de ácido acético em DEFC não é desejável, pois a sua conseguinte oxidação não é viável no potencial de aplicação da célula, e a formação deste evita a oxidação completa do etanol, com obtenção de $\mathrm{CO}_{2}$. Por outro lado, apesar da obtenção de acetaldeído não fornecer alta eficiência energética, este composto pode ser utilizado como combustível, e permite a recirculação do combustível. ${ }^{110}$

A quantificação por HPLC corroborou com as medidas eletroquímicas realizadas em célula unitária. O catalisador PtSn/C 60:40 promoveu maiores produções de ácido acético $(\mathrm{AA})$ do que acetaldeído $(\mathrm{AL})$ que o catalisador $\mathrm{Pt} / \mathrm{C}$, nas mesmas condições de operação da célula, corroborando com as maiores densidades de potência observadas. A melhora da atividade eletrocatalítica para ROE que o estanho promoveu provavelmente se relaciona com a facilitação do mecanismo bifuncional, e com efeito eletrônico observado por XAS. Por outro lado, ao comparar os subprodutos dos catalisadores trimetálicos com os de $\mathrm{PtSn} / \mathrm{C}$, não observa-se uma maior produção de $\mathrm{AA}$, mas sim de $\mathrm{CO}_{2}$, especialmente para 0 catalisador PtSnEu/C 75:20:05, o qual apresentou maior densidade de potência. A 
adição de európio afetou a distribuição dos subprodutos e apresentou um efeito benéfico na eletroatividade, quando adicionado em concentrações menores que $10 \%$. Assim como o estanho, o európio auxilia o mecanismo bifuncional e apresenta um efeito eletrônico na $\mathrm{Pt}$, o que promoveu a obtenção de maiores densidades de corrente em menores potenciais.

Mas, uma dúvida que surgiu é se a melhora da atividade eletrocatalítica está relacionada apenas ao terra rara európio, ou se outros metais terras raras também apresentariam melhoras à atividade para ROE, mesmo em baixas concentrações. Para responder essa dúvida, catalisadores PtSnTR/C (TR: La, Ce e Pr) foram sintetizados e estudados. 


\section{CAPÍTULO IV}

Na segunda parte dos resultados e discussão, procurou-se avaliar o efeito de diferentes terras raras à atividade catalítica para ROE para o catalisador $\mathrm{PtSn} / \mathrm{C}$. Os terras raras escolhidos para comparação foram lantânio, cério e praseodímio.

\section{RESULTADOS E DISCUSSÃO: CATALISADORES PISnTR/C}

\subsection{SÍNTESE DOS ELETROCATALISADORES PtSnTR/C}

Depois de avaliar a influência do európio em catalisadores $\mathrm{PtSn} / \mathrm{C}$, catalisadores PtSnTR/C (TR= La, Ce e Pr) foram sintetizados pela síntese do poliol para tentar correlacionar o metal terra rara com a atividade catalítica frente à reação de oxidação de etanol. Como discutido anteriormente, o método do poliol utiliza um poliálcool para reduzir partículas metálicas. Para partículas bimetálicas, o mecanismo de formação e crescimento mais aceito na literatura é a formação de clusters entre os metais a serem reduzidos, ${ }^{55,67}$ no caso, entre a platina, estanho e o terras raras. Mas ao realizar as medidas de caracterização física para os materiais trimetálicos PtSnEu/C, observa-se que, apesar da formação de partículas cristalinas de Pt, e de certa incorporação de Sn na rede cristalina da Pt, também ocorre a formação de óxido de estanho e óxido de európio. Como não é possível garantir que todas as espécies formadas estejam unidas, ou vizinhas uma a outras, a Figura 6.1 esquematiza de uma forma mais realista algumas das possíveis formas que os catalisadores PtSnTR/C (Tr: La, Ce, Pr e Eu) possam ser formados. Como a Pt é um metal mais sucessível a redução, há maior probabilidade deste se encontrar na forma metálica, vizinha aos óxidos formados, seja de terra raras, como de estanho. Partículas bimetálicas Pt-Sn também podem ser formadas, e estas também podem ou não, estar próximas dos óxidos formados. É provável que em todos os catalisadores, uma mistura de formas oxidadas e metálicas seja obtida. 
Resultados e Discussão: Catalisadores PtSnTR/C

Figura 6.1 - Representação esquemática da formas possíveis dos catalisadores de PtSnTR/C, a partir do método do poliol.

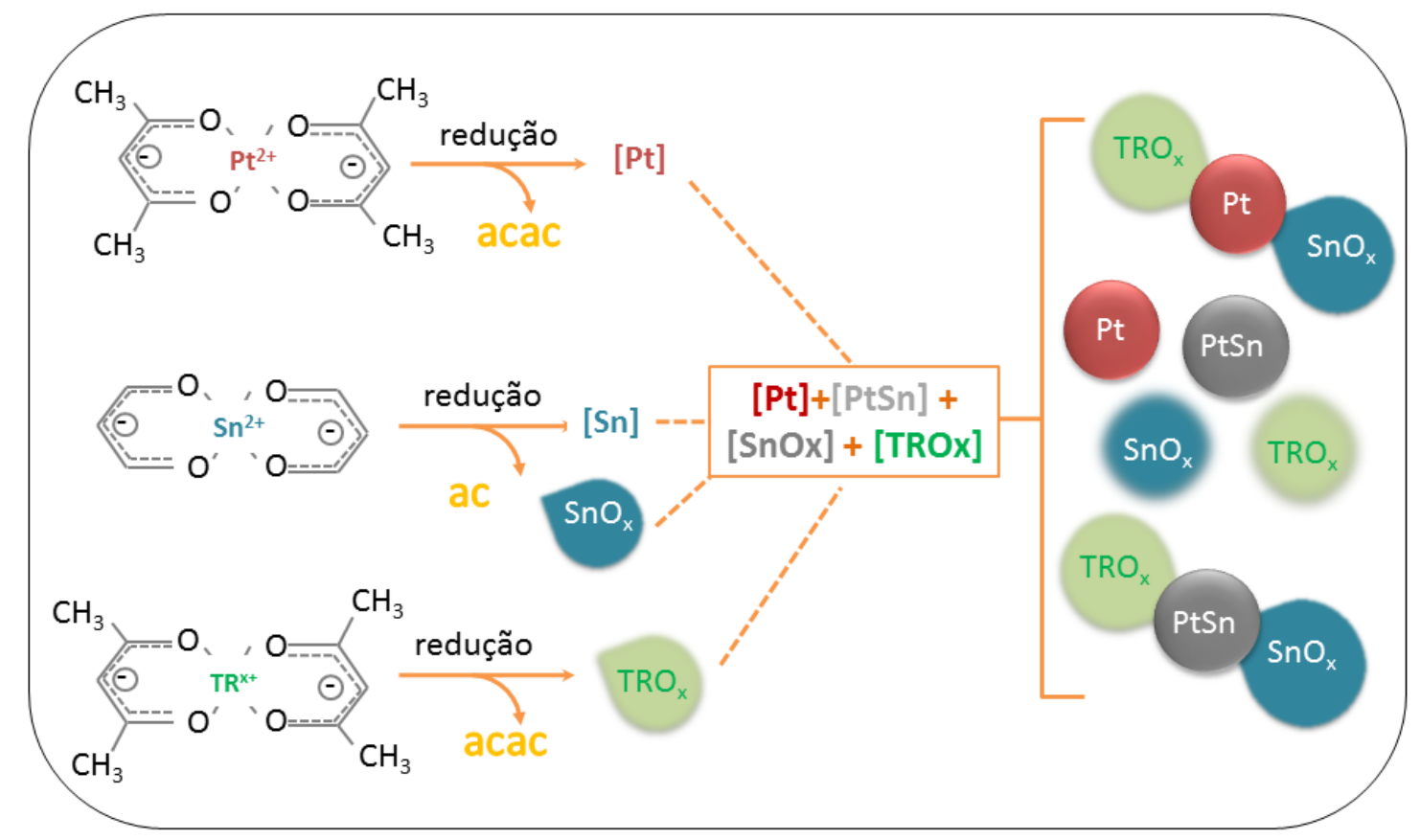

Fonte: Autoria própria.

A presença de diferentes espécies metálicas e oxidadas pode ser benéfica para oxidação de etanol. Para tentar obter mais informações sobre os catalisadores $\mathrm{PtSnTR/C} \mathrm{e} \mathrm{as} \mathrm{respectivas} \mathrm{estruturas} \mathrm{químicas} \mathrm{e} \mathrm{físicas} \mathrm{obtidas,} \mathrm{os} \mathrm{materiais}$ sintetizados foram caracterizados por EDX, ICP, ATG, TEM, DRX, XPS e XAS.

\subsection{CARACTERIZAÇÃO FÍSICA}

\subsubsection{Determinação da Composição Química}

A presença dos metais precursores (platina, estanho, lantânio, cério e praseodímio) nos catalisadores sintetizados por poliol foi determinada pela técnica de EDX e por ICP. A Tabela 6.1 indica as proporções atômicas obtidas para cada material. Há variação na determinação da composição pelas duas técnicas. Essa diferença pode ser justificada pelas diferenças dos métodos, visto que a técnica de EDX é mais pontual, uma média da determinação de três áreas; enquanto ICP necessita de uma maior amostragem de material, e por isso normalmente é considerado um método mais representativo. Essa variação também pode estar relacionada a uma distribuição não homogênea dos metais no catalisador. A 


\section{Resultados e Discussão: Catalisadores PtSnTR/C}

quantidade atômica de platina para todos os catalisadores ficou próxima, entre $66( \pm 5) \%$, por EDX, e por 75 ( \pm 6$)$ \% por ICP. A concentração atômica relativa de estanho também ficou próxima, entre 18 a 24 \% por EDX e próxima a 20 \% por ICP. Para os metais terras raras, a concentração ficou próxima a $5 \%$ por ICP. A carga metálica, determinada por ICP, ficou próxima a 15\% para todos os catalisadores.

Tabela 6.1 - Composição atômica, determinada por EDX e por ICP; e porcentagem metálica, determinada por ICP, dos catalisadores PtSnTR/C (TR=La, Ce, Pr) sintetizados por poliol.

\begin{tabular}{cccc}
\hline Catalisador & $\begin{array}{c}\text { Composição } \\
\text { atômica por EDX }\end{array}$ & $\begin{array}{c}\text { Composição } \\
\text { atômica por ICP }\end{array}$ & $\begin{array}{c}\text { Metal por } \\
\text { ICP (\%) }\end{array}$ \\
\hline PtSnLa/C & $65: 24: 11$ & $69: 20: 11$ & 16,3 \\
PtSnCe/C & $67: 18: 15$ & $81: 14: 05$ & 13,8 \\
PtSnPr/C & $70: 20: 10$ & $76: 18: 06$ & 16,4 \\
\hline
\end{tabular}

No decorrer do trabalho, a composição nominal utilizada será a próxima a determinada por ICP, de 75:20:05. A título de comparação, os dados do catalisador PtSnEu/C na composição 75:20:05 foram reapresentados em algumas caracterizações físicas e eletroquímicas. Apesar da variação da composição, a concentração dos metais terras raras nos catalisadores PtSnTR/C ficaram próximas, justificando assim a comparação.

\subsubsection{Análise Termogravimétrica}

Na Figura 6.2 (a) e (b) estão apresentadas respectivamente a decomposição térmica e diferencial das curvas dos catalisadores PtSnTR/C (TR: La, Ce, Pr, Eu) obtidos por poliol. As curvas dos catalisadores $\mathrm{Pt} / \mathrm{C}, \mathrm{PtSn} / \mathrm{C}$ foram reapresentados para comparação. Nesse conjunto de dados também foi observado uma diferença da temperatura de combustão do carbono para os diferentes materiais, a qual variou de $440{ }^{\circ} \mathrm{C}$ para $\mathrm{PtSnPr} / \mathrm{C}$ e $495^{\circ} \mathrm{C}$ para os catalisadores PtSnLa, PtSnCe e PtSnEu. Ao comparar a composição química determinada por ICP, observa-se que também nesse caso, as temperaturas de combustão estão correlacionadas à concentração de Pt: quanto maior a concentração deste, menor a temperatura de combustão. O processo observados em $150{ }^{\circ} \mathrm{C}$ (inset Fig. 6.2b) é relacionado a remoção de água adsorvida fisicamente dos catalisadores. ${ }^{70}$ Os catalisadores $\mathrm{PtSnLa} / \mathrm{C}$ e $\mathrm{PtSnCe} / \mathrm{C}$ 
Resultados e Discussão: Catalisadores PtSnTR/C

apresentaram picos em $565{ }^{\circ} \mathrm{C}$ e $547^{\circ} \mathrm{C}$, respectivamente. Provavelmente esses processos estão relacionados a mudanças nos óxidos de terra raras correspondentes. Ao analisar a não-existência de outros picos expressivos relacionados a contaminantes orgânicos, pode-se afirmar que a limpeza das partículas foi satisfatória.

Figura 6.2 - Decomposição térmica (a) e diferencial das curvas térmicas (b) dos catalisadores Pt/C, PtSn/C e PtSnTR/C (TR=La, Ce, Pr e Eu) sintetizados por poliol. $\Delta \mathrm{T}=5^{\circ} \mathrm{C} \mathrm{min}^{-1}$; fluxo de gás de $100 \mathrm{~mL} \mathrm{~min}^{-1}$.
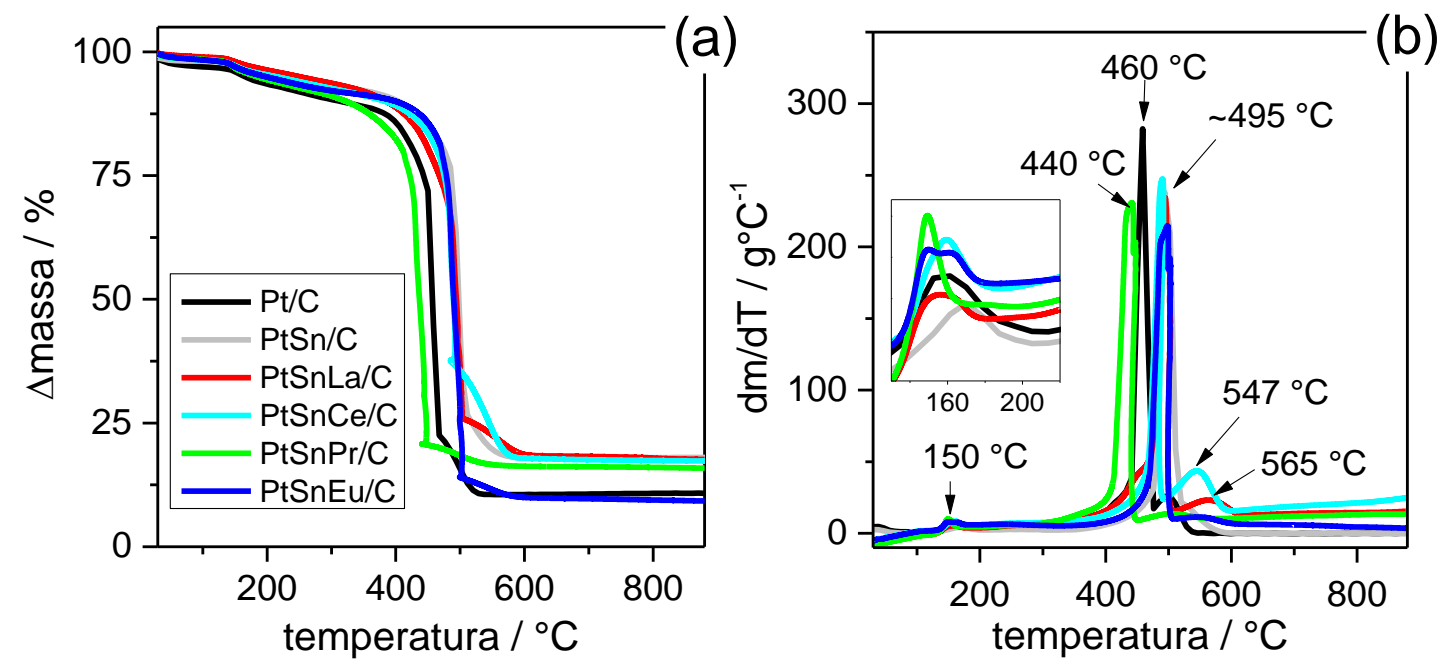

Fonte: Autoria própria.

As cargas metálicas obtidas por termogravimetria estão apresentadas na Tabela 6.2. Todos os catalisadores PtSnTR/C sintetizados apresentaram carga metálica próximas a $17 \%$. Os valores de carga metálica determinados por ATG foram considerados quando realizou-se comparações de atividades mássicas dos catalisadores.

Tabela 6.2 - Porcentagem metálica determinada por análise termogravimétrica dos catalisadores PtSnTR/C (TR= La, Ce e Pr) 75:20:05 obtidos por poliol.

\begin{tabular}{cc}
\hline Catalisador & Metal (\%) \\
\hline $\mathrm{PtSnLa} / \mathrm{C}$ & 18,1 \\
$\mathrm{PtSnCe} / \mathrm{C}$ & 17,4 \\
$\mathrm{PtSnPr} / \mathrm{C}$ & 16,2 \\
\hline
\end{tabular}




\section{Resultados e Discussão: Catalisadores PtSnTR/C}

\subsubsection{Microscopia Eletrônica de Transmissão}

A técnica de microscopia eletrônica de transmissão foi utilizada para determinar as faixas de distribuição de tamanho das partículas e avaliar a dispersão destas no suporte de carbono. A Figura 6.3 representa as micrografias obtidas para os catalisadores Pt/C, PtSn/C 60:40 e PtSnTR/C (La, Ce, Pr e Eu) 75:20:05 obtidos por poliol. Pode-se observar que todos os materiais obtidos têm forma esférica. Apesar da presença de algumas áreas vazias no suporte, observa-se que as nanopartículas não apresentaram grande grau de aglomeração, com exceção apenas do catalisador PtSnCe/C.

Os histogramas obtidos para cada catalisador sintetizado estão apresentados na Figura 6.3, ao lado das respectivas micrografias. Os histogramas foram obtidos pela média de dois raios por partícula, e no mínimo de 200 partículas foram contadas. As faixas de distribuição de tamanhos de partícula apresentadas pelos materiais variaram de 1,5 a $6 \mathrm{~nm}$ para $\mathrm{Pt} / \mathrm{C}$ e $\mathrm{PtSnPr} / \mathrm{C}$; 1,5 a $8 \mathrm{~nm}$ para $\mathrm{PtSnLa} / \mathrm{C}$ $\mathrm{PtSnCe}$ e PtSnEu/C; e entre 2 a $10 \mathrm{~nm}$ para $\mathrm{PtSn} / \mathrm{C}$ 60:40. O tamanho médio das partículas foi determinado por uma curva log-normal ajustada ao histograma obtido, que forneceu o valor de 3,7 nm para $\mathrm{Pt} / \mathrm{C}$; 4,8 nm para $\mathrm{PtSn} / \mathrm{C} ; 4,7 \mathrm{~nm}$ para $\mathrm{PtSnLa} / \mathrm{C}$; 3,1 nm para PtSnCe/C; 3,0 nm para $\mathrm{PtSnPr} / \mathrm{C}$ e 4,5 nm para PtSnEu/C, com um erro médio de $\pm 0,2 \mathrm{~nm}$. Pode-se observar que a adição de estanho ao catalisador de $\mathrm{Pt} / \mathrm{C}$ aumentou o tamanho médio de partícula. A adição de terras raras ao catalisador de $\mathrm{PtSn} / \mathrm{C}$, por outro lado, reduziu o tamanho médio obtido. 


\section{Capítulo IV}

\section{Resultados e Discussão: Catalisadores PtSnTR/C}

Figura 6.3 - Micrografia eletrônica de transmissão dos catalisadores (a) Pt/C; (b) PtSn/C 60:40; (c) PtSnLa/C 75:20:05; (d) PtSnCe/C 75:20:05; (e) PtSnPr 75:20:05 e

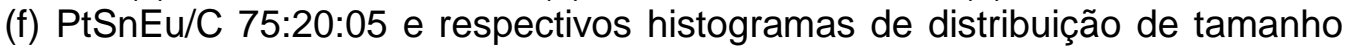
das partículas.
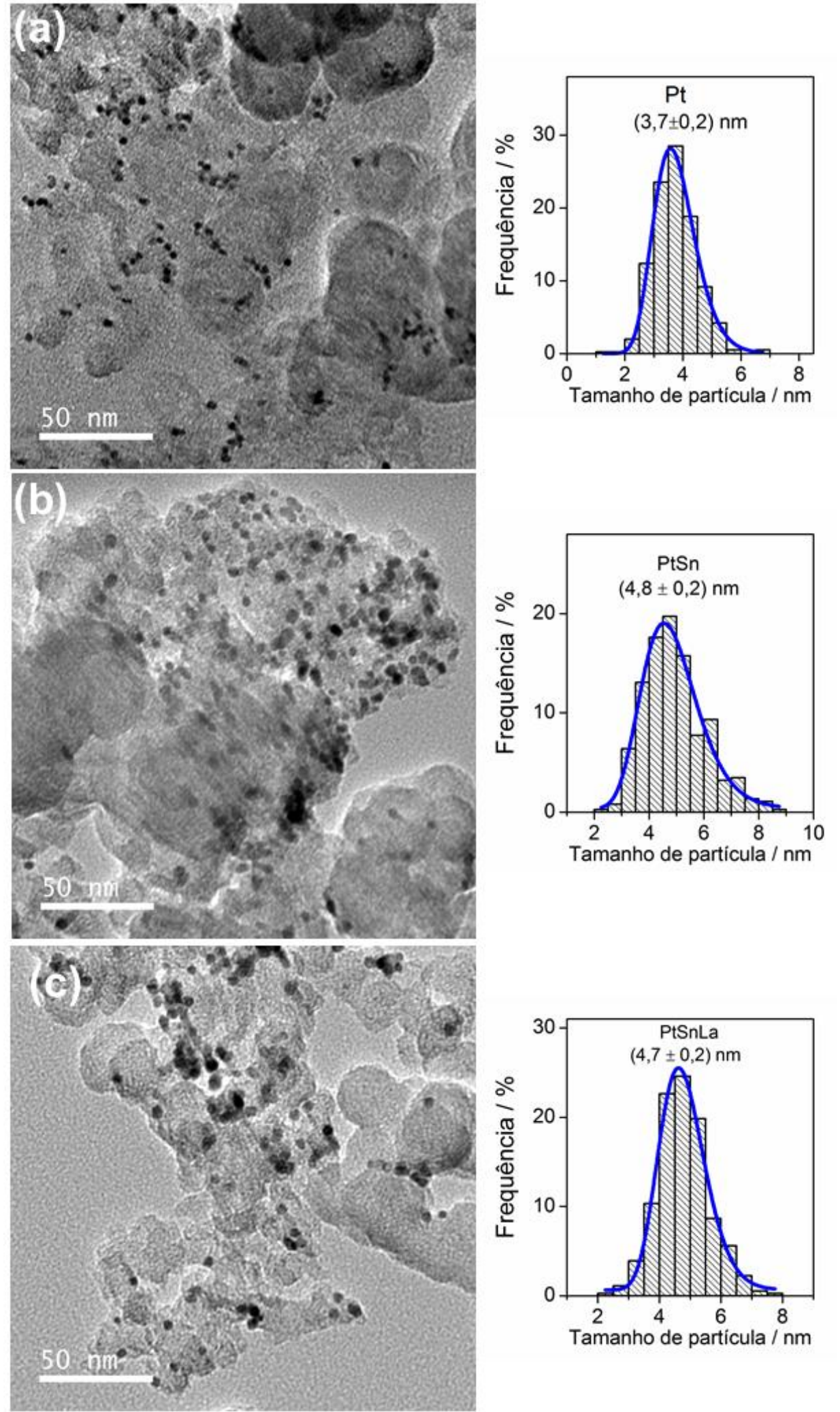

Continua na próxima página 
Resultados e Discussão: Catalisadores PtSnTR/C

Continuação Fig. 6.3
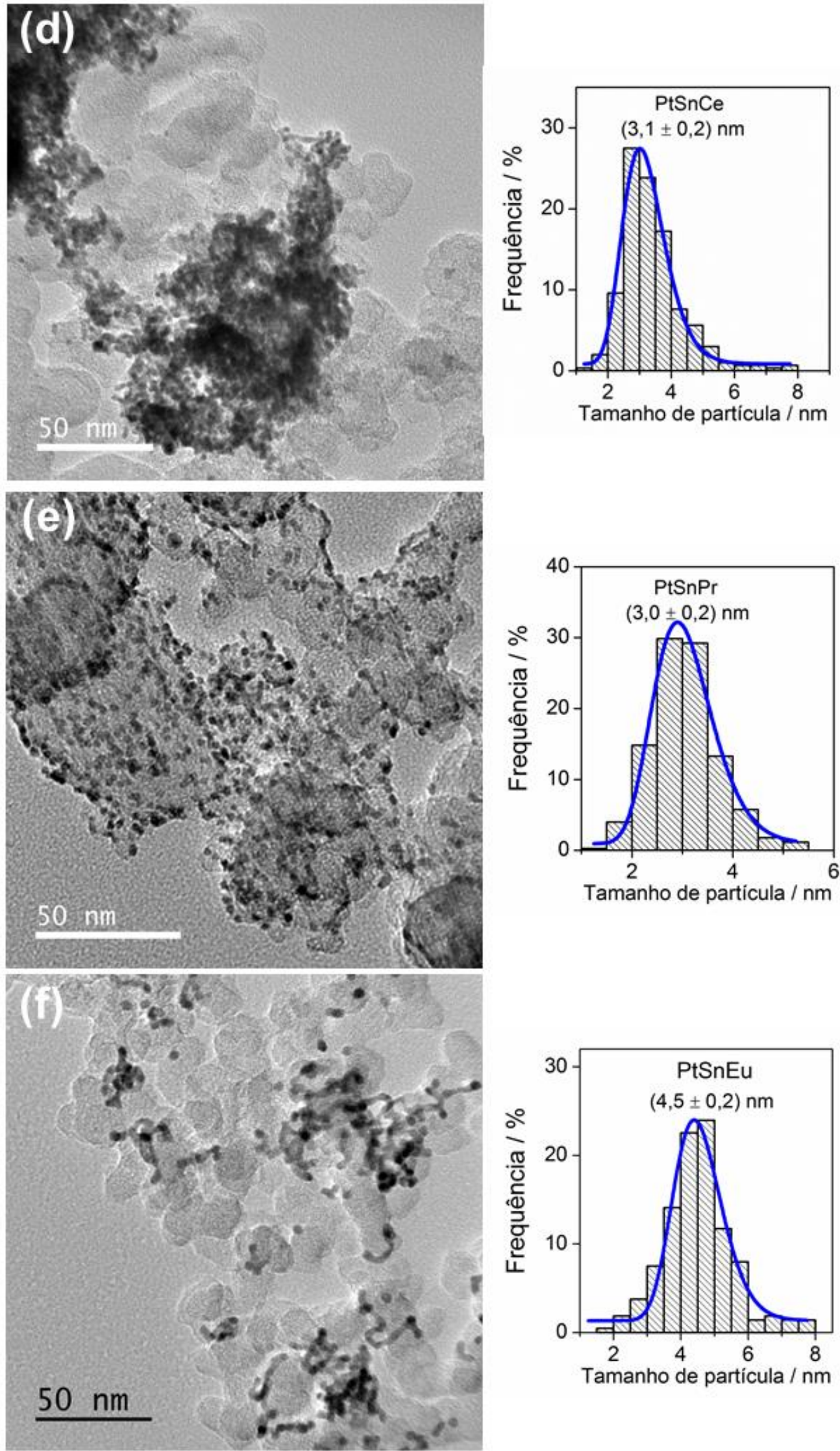

Fonte: Autoria própria 


\section{Resultados e Discussão: Catalisadores PtSnTR/C}

\subsubsection{Difração de Raios X}

Os difratogramas dos catalisadores PtSnTR/C (TR: La, Ce e Pr), obtidos pelo método poliol, estão representados na Figura 6.4. Os dados de Pt/C, PtSn/C 60:40 e PtSnEu 75:20:05 foram reapresentados para comparação. Cinco picos de difração são observados para todos os materiais. Na região de $20-25^{\circ}$, o pico é atribuído ao plano (002) da estrutura hexagonal do carbono, utilizado como suporte. Os demais picos, próximos a $39,5^{\circ}, 46^{\circ}, 67^{\circ}$ e $81^{\circ}$, são atribuídos à estrutura Pt cfc, referentes aos planos (111), (200), (220) e (311), respectivamente. No entanto, é possível observar no detalhe da Fig. 6.4, um pequeno deslocamento do pico (220) para os materiais PtSnLa e PtSnCe, assim como para os catalisadores PtSn/C e PtSnEu/C 75:20:05, que são propagados para os demais picos da estrutura cfc da Pt. De acordo com a literatura, esse deslocamento de picos pode estar relacionado à incorporação de metais na estrutura cristalina da Pt. Apesar disso, não foi observado nenhum pico referente aos planos cristalinos (102), (110) e (202) da liga PtSn, que de acordo com a literatura, aparecem próximos a $41,5^{\circ} ; 43,7^{\circ}$ e $62,3^{\circ}$, respectivamente. Referente aos terras raras $\mathrm{La}, \mathrm{Ce}, \mathrm{Pr}$, não foi detectado algum pico relacionado a hidróxidos e óxidos, normalmente listados em $28^{\circ}{ }^{111}$ Também não foram identificados picos de óxido de estanho IV nos catalisadores trimetálicos; apenas observados para o catalisador $\mathrm{PtSn} / \mathrm{C}$, em $33^{\circ}$ e $52^{\circ}{ }^{71}$ (indicados por duas setas na Fig. 6.4). Apesar da não visualização desses picos, a presença desses óxidos e hidróxidos não pode ser descartada, pois podem estar em baixas concentrações ou na forma amorfa.

Como comentado para os catalisadores PtSnEu/C, a incorporação de metais terras raras em forma de liga é pouco favorecida nas condições de síntese adotadas. O potencial de redução dos metais terras raras são menores que $-2,0 \mathrm{~V} v s$ EPH. ${ }^{112}$ Mesmo em processos metalúrgicos, a formação de liga Pt-TR é difícil. Alguns problemas relacionados ao estudo de diagramas de fases metálicas relacionados aos metais terras raras são: altas temperaturas de fusão das ligas (especialmente com metais nobres e semimetais), alta pressão de vapor e a volatilidade de algumas terras raras; e existência de diferentes transformações polimórficas. $^{113}$ 


\section{Resultados e Discussão: Catalisadores PtSnTR/C}

Figura 6.4 - Difratogramas dos materiais PtSnTR/C (TR=La, Ce, Pr) 75:20:05 sintetizados pelo método poliol. Os dados de Pt/C, PtSn/C 60:40 e PtSnEu/C 75:20:05 foram acrescentados para comparação. Detalhe na região próxima ao plano $\mathrm{Pt}$ (220) em estrutura cfc.
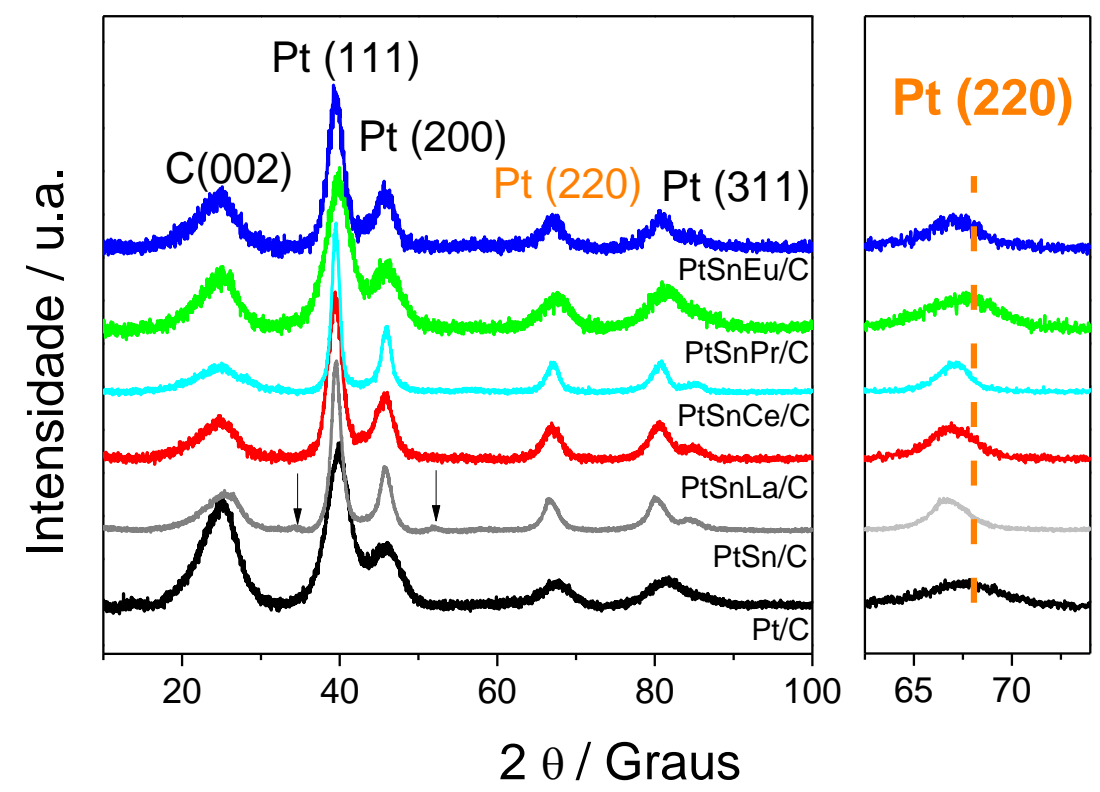

Fonte: Autoria própria.

Reimann e Schaller (2006) ${ }^{114}$ estudaram a formação de ligas platina-lantânio através de modelos termodinâmicos. A solubilidade sólida estimada de La em Pt a $1073 \mathrm{~K}$ é de $(0,03 \pm 0,01) \%$ para cada porcentagem de La adicionada. A solubilidade sólida extremamente baixa em Pt foi justificada pela grande distorção do parâmetro de rede causada pela incorporação do La. Apesar do baixo grau de liga, o estudo teórico demonstrou que a solução sólida enriquecida de Pt apresentou elevada estabilidade termodinâmica, devido à estrutura eletrônica dos componentes. A transferência de carga a partir do nível de Fermi do La para o nível de Fermi da Pt favorece a estabilidade do arranjo, com uma consequente contribuição eletrônica. ${ }^{114}$

Janghorban et al. (2010) sintetizaram metalurgicamente diferentes composições de soluções sólidas de Ce-Pt. ${ }^{115} \mathrm{~A}$ formação de fases $\mathrm{CePt}_{5}$ é observada para composições atômicas entre 84,8\% a 95\% de Pt e as fases de $\mathrm{CePt}_{\mathrm{x}}$ são observadas entre 75 e $83 \%$ de Pt. Entretanto, essas ligas são obtidas em temperaturas superiores a $1660{ }^{\circ} \mathrm{C}$, sendo as temperaturas eutéticas estimadas de $1688{ }^{\circ} \mathrm{C}$ para fase $\mathrm{CePt}_{\mathrm{x}}$ e entre $1740-1770^{\circ} \mathrm{C}$ para $\mathrm{CePt}_{5}$. Em temperaturas menores que $1000^{\circ} \mathrm{C}$, os autores relataram não haver substituição de $\mathrm{Ce}$ em 


\section{Resultados e Discussão: Catalisadores PtSnTR/C}

soluções enriquecidas de Pt. A pouca solubilidade foi relacionada à diferença de raio

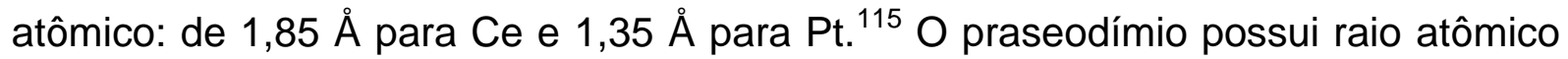
próximo ao lantânio e cério, assim é esperado uma baixa solubilidade, e não obtenção de liga Pt-Pr.

Para estimar os tamanhos médios de cristalito dos catalisadores, utilizou-se a equação de Scherrer (equação 5.1). Os tamanhos médio de cristalito (d), parâmetro de rede $\left(a_{\text {exp }}\right)$ e a distância interatômica $\left(d_{c f c}\right)$ para os materiais PtSnTR/C (TR: La, $\mathrm{Ce}, \operatorname{Pr}$ e Eu) estão na Tabela 6.3. Os valores de $d$ observados para os materiais ternários variaram de 2,2 $\mathrm{nm}$, para $\mathrm{PtSnPr} / \mathrm{C}$, a $4,9 \mathrm{~nm}$ para $\mathrm{PtSnCe} / \mathrm{C}$. A literatura indica que para boa resposta eletrocatalítica em catalisadores de $\mathrm{Pt} / \mathrm{C}$, especialmente para a reação de oxidação de etanol, o tamanho médio de cristalito deve ser abaixo de $5 \mathrm{~nm}$ e, com valor ótimo foi de 2,6 nm. ${ }^{107}$ Todos os catalisadores PtSnTR/C sintetizados por poliol apresentaram valores de $d$ próximos aos desejáveis.

Tabela 6.3 - Tamanho médio de cristalito $(d)$, parâmetro de rede $\left(a_{\text {exp }}\right)$ e a distância interatômica $\left(d_{c f c}\right)$, e grau de estanho na forma de liga $\left(f_{S n}\right)$ e tamanhos médios de partículas obtidos por TEM $\left(d_{T E M}\right)$ para os catalisadores PtSnTR/C 75:20:05 obtidos por poliol.

\begin{tabular}{cccccc}
\hline Catalisador & $\boldsymbol{d}(\mathbf{n m})$ & $\boldsymbol{a}_{\exp }(\dot{\mathbf{A}})$ & $\boldsymbol{d}_{\text {cfc }}(\dot{\mathbf{A}})$ & $\boldsymbol{f}_{\boldsymbol{S n}}$ & $\boldsymbol{d}_{\text {TEM }}(\mathbf{n m})$ \\
\hline${ }^{*} \mathrm{Pt} / \mathrm{C}$ & 2,3 & 3,92 & 2,77 & & 3,7 \\
${ }^{*} \mathrm{PtSn} / \mathrm{C} 60: 40$ & 4,3 & 3,96 & 2,80 & 20 & 4,8 \\
$\mathrm{PtSnLa} / \mathrm{C}$ & 3,5 & 3,95 & 2,79 & 8 & 4,7 \\
$\mathrm{PtSnCe} / \mathrm{C}$ & 4,9 & 3,95 & 2,79 & 7 & 3,1 \\
$\mathrm{PtSnPr} / \mathrm{C}$ & 2,2 & 3,93 & 2,78 & 1 & 3,0 \\
${ }^{*} \mathrm{PtSnEu} / \mathrm{C}$ & 3,4 & 3,94 & 2,79 & 6 & 4,5 \\
\hline
\end{tabular}

*Dados reapresentados para comparação.

Os valores de $a_{\text {exp }}$ e $d_{c f c}$ para os catalisadores ternários foram maiores que os apresentados pela platina pura, indicando que houve incorporação de algum metal na rede cristalina. Considerando que as diferenças observadas foram causadas apenas pela incorporação de estanho, estimou-se o grau de liga utilizando a equação 5.4. O grau de liga Pt-Sn variou de $1 \%$ para $\mathrm{PtSnPr} / \mathrm{C}$ a $8 \% \mathrm{PtSnLa} / \mathrm{C}$ (Tab. 6.3). Os tamanhos médios de partículas obtidos por TEM também foram reapresentados na Tabela 6.3. Os dados foram coerentes com os dados de tamanhos médio de cristalito, sendo estes ligeiramente menores. Essa diferença é esperada pois uma partícula pode ser formada por um ou mais cristalitos. Apenas 0 catalisador PtSnCe apresentou um valor de tamanho médio de partícula inferior ao $d$ 


\section{Resultados e Discussão: Catalisadores PtSnTR/C}

obtido por DRX. Esse desacordo pode ser atribuído ao fato de que a fórmula de Scherrer estima um tamanho médio de volume ${ }^{10}$ e presença de grandes partículas ou aglomerados, podem superestimar os valores de $d$. Como observado pela Fig. 6.3, o catalisador PtSnCe/C apresentou maior grau de aglomeração das partículas que os demais catalisadores sintetizados.

Jacob et al. (2015) obtiveram catalisadores PtSnCe/C pelo método do ácido fórmico. ${ }^{54}$ Não foi observado deslocamentos nos difratogramas dos catalisadores $\mathrm{PtSnCe} / \mathrm{C}$ em nenhuma composição, indicando que não houve formação de liga PtSn. Os tamanhos médios de cristalito foram próximos a $5,5 \mathrm{~nm} .{ }^{54}$ Corradini et al. (2015) sintetizaram catalisadores $\mathrm{PtSnPr} / \mathrm{C}$ pelo método do ácido fórmico. ${ }^{52}$ Os tamanhos médios de cristalito obtidos variaram de 4,8 a 6,4 nm e não houve variação dos parâmetros de rede e das distâncias interatômicas em relação a $\mathrm{Pt}^{52} \mathrm{~A}$ síntese do poliol adotada neste estudo promoveu a obtenção de tamanho de cristalitos menores que os relatados e maior grau de liga Pt-Sn.

\subsubsection{Espectroscopia por Fotoelétrons excitados por Raios $\mathrm{X}$}

A Figura 6.5 apresenta os espectros de longa varredura para os catalisadores PtSnTR/C (TR: La, Ce e Pr) 75:20:05. Nesse caso, adicionou-se as varreduras dos catalisadores Pt/C e PtSn/C 60:40, para comparação. Todos os materiais trimetálicos apresentaram os sinais referentes à platina, ao estanho, ao oxigênio e, em baixa intensidade, aos respectivos metais terras raras. Não foi observado nenhum outro pico, relacionado a impurezas nos catalisadores.

Figura 6.5 - Espectros de XPS dos catalisadores PtSnTR/C (TR: La, Ce, Pr) sintetizados por poliol. Os dados de Pt/C e PtSn/C 60:40 foram reapresentados para comparação.

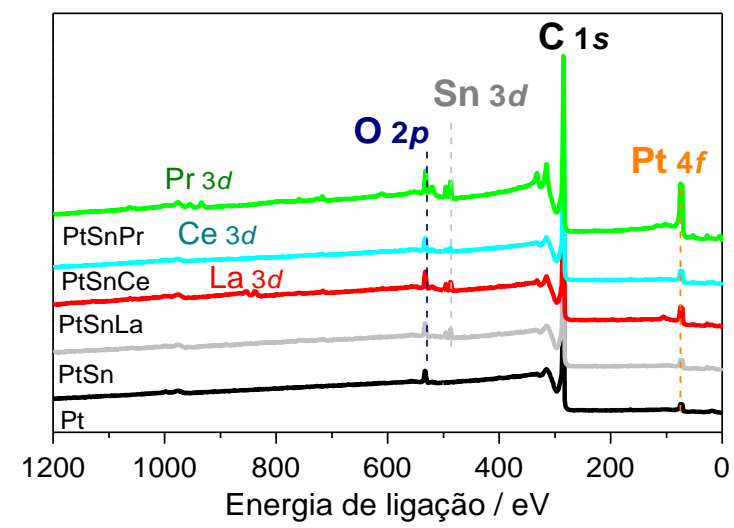

Fonte: Autoria própria. 
Resultados e Discussão: Catalisadores PtSnTR/C

Os espectros de XPS nas regiões de energia de ligação relacionadas aos orbitais $4 f \mathrm{Pt}, 3 d \mathrm{Sn}$, La $3 d$, Ce $3 d$ e $\mathrm{Pr} 3 d$ dos catalisadores sintetizados por poliol estão apresentados na Figura 6.6. Para o espectro Pt 4f, três espécies foram identificadas: $\mathrm{Pt}^{0}, \mathrm{Pt}^{2+}$ e $\mathrm{Pt}^{4+}$. As energias de ligação dos picos $\mathrm{Pt} 4 f_{7 / 2}$ estão apresentadas na Tabela 6.4, juntamente com a porcentagem atômica para cada sinal. A distribuição das espécies de Pt ficaram próximas entre os diferentes catalisadores PtSnTR/C (TR: La, Ce e Pr). A quantidade relativa de $\mathrm{Pt}^{0}$ foi de $60 \%$, indicando que o método de síntese promoveu a redução significativa desse metal. A quantidade de espécie $\mathrm{Pt}^{2+}$ e $\mathrm{Pt}^{4+}$ ficaram próximas a 30 e 10\%, respectivamente.

Figura 6.6 - Espectros de XPS para Pt 4f, Sn 3d, La 3d, Ce 3d e Pr 3d para os catalisadores $\mathrm{Pt} / \mathrm{C}, \mathrm{PtSn} / \mathrm{C}$ 60:40 e PtSnTR/C (TR: La,Ce e Pr) 75:20:05 sintetizados por poliol.

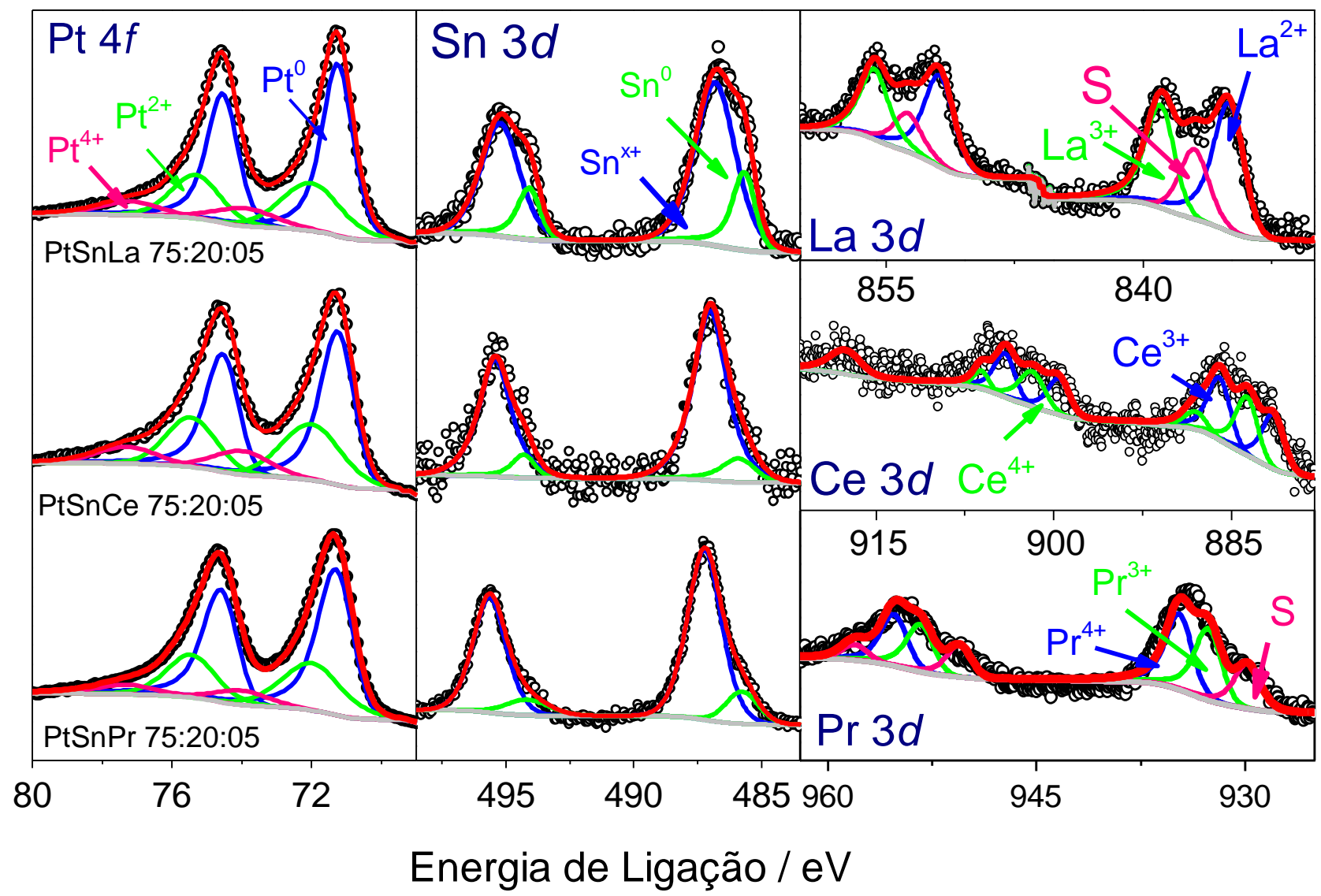

Fonte: Autoria própria. 
Capítulo IV

Resultados e Discussão: Catalisadores PtSnTR/C

Tabela 6.4 - Energia de ligação, em eV, dos Pt $4 f_{7 / 2}$, Sn $3 d_{5 / 2}$ e TR $3 d_{5 / 2}$ para os PtSnTR/C (TR: La, Ce e Pr), as porcentagens atômicas para cada sinal e a composição atômica superficial, calculada por XPS.

\begin{tabular}{|c|c|c|c|c|c|c|c|}
\hline Materiais & $\begin{array}{l}\text { Composição } \\
\text { superficial por } \\
\text { XPS (at\%) }\end{array}$ & Pt $4 f_{7 / 2}$ & Espécies & $\operatorname{Sn} 3 d_{5 / 2}$ & Espécies & $\operatorname{TR} 3 d_{5 / 2}$ & Espécies \\
\hline \multirow{3}{*}{$\begin{array}{l}\text { PtSnLa/C } \\
75: 20: 05\end{array}$} & \multirow{3}{*}{ 92:07:01 } & $71,2(61)$ & $\mathrm{Pt}^{0}$ & $485,7(25)$ & $\mathrm{Sn}^{0}$ & $837,0(19)$ & \multirow{3}{*}{$\begin{array}{l}\text { Satélite } \\
\mathrm{La}^{2+}-\mathrm{LaO} ; \\
\mathrm{La}(\mathrm{OH})_{2} \\
\mathrm{La}^{3+}-\mathrm{La}_{2} \mathrm{O}_{3}\end{array}$} \\
\hline & & $72,0(28)$ & $\mathrm{Pt}^{2+}-\mathrm{Pt}(\mathrm{OH})_{2}$ & $486,8(75)$ & $\mathrm{Sn}^{2,4+}-\mathrm{SnO}$ & $834,9(33)$ & \\
\hline & & $73,9(11)$ & $\mathrm{Pt}^{4+}-\mathrm{PtO}_{2} ; \mathrm{PtO}_{2} \cdot n \mathrm{H}_{2} \mathrm{O}$ & & $\mathrm{SnO}_{2}$ & $838,9(47)$ & \\
\hline \multirow{2}{*}{$\begin{array}{l}\text { PtSnCe/C } \\
75: 20: 05\end{array}$} & \multirow[b]{2}{*}{$94: 04: 02$} & $71,2(56)$ & $\mathrm{Pt}^{0}$ & $485,8(15)$ & \multirow{2}{*}{$\begin{array}{l}\mathrm{Sn}^{0} \\
\mathrm{Sn}^{2,4+}-\mathrm{SnO}, \\
\mathrm{SnO}_{2}\end{array}$} & \multirow{2}{*}{$\begin{array}{c}886,0 ; 881,4(55) \\
883,7 ; 888,0 ; 918 \\
(45)\end{array}$} & $\mathrm{Ce}^{3+}-\mathrm{Ce}_{2} \mathrm{O}_{3}$ \\
\hline & & $\begin{array}{l}72,0(31) \\
74,0(13)\end{array}$ & $\begin{array}{l}\mathrm{Pt}^{2+}-\mathrm{Pt}(\mathrm{OH})_{2} \\
\mathrm{Pt}^{4+}-\mathrm{PtO}_{2} ; \mathrm{PtO}_{2} \cdot n \mathrm{H}_{2} \mathrm{O}\end{array}$ & $487,2(85)$ & & & $\mathrm{Ce}^{4+}-\mathrm{CeO}_{2}$ \\
\hline \multirow{2}{*}{$\begin{array}{l}\mathrm{PtSnPr} / \mathrm{C} \\
75: 20: 05\end{array}$} & \multirow{2}{*}{$97: 01: 02$} & $71,3(63)$ & & $485,8(15)$ & \multirow{2}{*}{$\begin{array}{l}\mathrm{Sn}^{0} \\
\mathrm{Sn}^{2,4+}-\mathrm{SnO} \\
\mathrm{SnO}_{2}\end{array}$} & \multirow{2}{*}{$\begin{array}{c}934,7(39) \\
932,6(35) \\
929,8 ; 958,1(26) \\
\end{array}$} & \multirow{2}{*}{$\begin{array}{l}\mathrm{Pr}^{3+}-\mathrm{Pr}_{2} \mathrm{O}_{3} \\
\mathrm{Pr}^{4+}-\mathrm{PrO}_{2} \\
\text { Satélites }\end{array}$} \\
\hline & & $\begin{array}{l}72,0(29) \\
74,0(8)\end{array}$ & $\begin{array}{l}\mathrm{Pt}^{2+}-\mathrm{Pt}(\mathrm{OH})_{2} \\
\mathrm{Pt}^{4+}-\mathrm{PtO}_{2} \cdot \mathrm{PtO}_{2} \cdot n \mathrm{H}_{2} \mathrm{O}\end{array}$ & $487,2(85)$ & & & \\
\hline
\end{tabular}




\section{Capítulo IV}

\section{Resultados e Discussão: Catalisadores PtSnTR/C}

Nos perfis observados para Sn $3 d$ na Fig. 6.6, dois dubletos foram identificados, referente aos estados de estanho metálico e oxidado. A diferenciação do estado $\mathrm{Sn}^{2+}$ e $\mathrm{Sn}^{4+}$ não é observada, devido a proximidade da energia de ligação das espécies. ${ }^{58,71} \mathrm{~A}$ maior contribuição é do $\mathrm{SnO}_{\mathrm{x}}$ (Tabela 6.4), próximo de $85 \%$ para $\mathrm{PtSnCe} / \mathrm{C}$ e $\mathrm{PtSnPr} / \mathrm{C}$; e de $75 \%$ para $\mathrm{PtSnLa} / \mathrm{C}$. Mesmo com a alta concentração de óxidos, é possível observar a presença de estanho metálico, coerente com as medidas de DRX, que indicaram um pequena incorporação de estanho na rede cristalina da Pt.

Os espectros para metais terras raras não são triviais para serem avaliados, em decorrência do aparecimento de picos satélites. Como comentado anteriormente, esses satélites podem ter diferentes origens, como interações eletrostáticas entre vacâncias e os elétrons $4 f$; ou transferência de cargas de coexcitações, principalmente entre $\mathrm{O} 2 p$ para TR $4 f$, com subníveis semiocupados. Esses processos impossibilitam a estimar o grau das valências mistas desses compostos por XPS. ${ }^{52,83,116} \mathrm{O}$ tratamento dos espectros de TR $3 d$ na literatura consiste em estimar os multipletos para o spin-orbitais, correspondendo às contribuições $3 d_{3 / 2} \mathrm{e}$ $3 d_{5 / 2}$ e os picos simétricos para cada contribuição. Os valores das energias de ligação e as intensidades relativas ao La, Ce e $\operatorname{Pr} 3 d_{5 / 2}$ nos catalisadores estão resumidos na Tabela 6.4. Para o La $3 d_{5 / 2}$, dois dubletos foram identificados: em 834,9 eV e 838,9 eV, que se referem às espécies $\mathrm{La}^{2+}$ e $\mathrm{La}^{3+}$. O pico em torno de 837,0 eV descreve um pico satélite, resultante de dois estados finais: uma vacância e/ou uma vacância com a transferência de um elétron de valência de $02 p$ para um orbital de La $4 f$ vazio. ${ }^{117,118}$ Desconsiderando a contribuição do satélite, a maior contribuição identificada foi de espécie de $\mathrm{La}^{3+}$.

Para Ce $3 d$, apenas duas espécies foram identificadas: $\mathrm{Ce}^{3+} \mathrm{e} \mathrm{Ce}^{4+}$. O estado final de $\mathrm{Ce}^{4+}\left[\mathrm{Ce}\left(3 d^{9} 4 f^{\rho}\right) \mathrm{O}\left(2 p^{6}\right)\right]$ está relacionado com dois dubletos, em 883,7 eV e 888,0 eV; e um pico em 918,0 eV. Para a configuração de $\mathrm{Ce}^{3+}\left[\mathrm{Ce}\left(3 d^{9} 4 f^{1}\right) \mathrm{O}\left(2 p^{6}\right)\right]$ dois dubletos estão relacionados, com picos em $886,0 \mathrm{eV}$ e $881,4 \mathrm{eV}$ pra Ce $3 d_{5 / 2}$. ${ }^{119}$ As concentrações relativas estimadas de $\mathrm{Ce}^{3+}$ e $\mathrm{Ce}^{4+}$ ficaram próximas entre si ( 50\%).

Para o espectro de $\operatorname{Pr} 3 d$, são esperados dois possíveis estados oxidados: $\mathrm{Pr}^{3+}$, em 934,7 eV e $\mathrm{Pr}^{4+}$, em 932,6 eV, visto que os perfis observados não indicam presença de $\operatorname{Pr}$ metálico. ${ }^{59,120} \mathrm{O}$ espectro de $\operatorname{Pr} 3 d$ também exibe um ombro, em 929,8 eV, chamado de satélite shake-off. Alguns autores explicam que esse satélite 
surge de acoplamento da vacância $3 d$ com a camada $4 f$ nos picos $3 d_{5 / 2}$, de configuração $3 d_{5 / 2} 4 f^{3}{ }^{121} \mathrm{Na}$ Tabela 6.4 , é possível observar que as contribuições

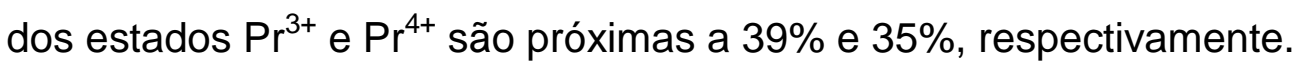

As composições superficiais também foram determinadas para os catalisadores $\mathrm{PtSnTR/C}$, utilizando as equações 5.5 a 5.8 , já apresentadas. Os fatores de correção do lantânio, cério e praseodímio estavam disponíveis no software utilizado no tratamento dos dados (CasaXPS), sendo estes, respectivamente: 47,6; 51,6 e 55,6. Na Tab. 6.4 é possível observar que a porcentagem atômica da platina foi superior à composição nominal, sendo superior a $90 \%$ em todos os materiais. As concentrações do estanho e do metal terra rara determinado por XPS foram menores que as determinadas pelas técnicas de ICP e EDX para todos os catalisadores. As diferenças observadas podem ser justificadas pelas diferenças de detecção da própria técnica, visto que o XPS tem uma penetração de 3 a $4 \mathrm{~nm}$, enquanto a determinação química envolve uma amostragem maior de material.

\subsubsection{Espectroscopia de Absorção de Raios X}

A Figura 6.7 apresenta os espectros XANES in situ na borda $L_{3}$ da Pt para catalisadores PtSnTR/C sintetizados por poliol. Para comparação, as absorções de catalisadores comerciais Pt/C Etek e PtSn/C 75:25 Etek, e o catalisador PtSnEu/C 75:20:05, foram reapresentados. Em ambos potenciais, a adição dos metais estanho e dos metais terras raras promoveu uma redução da linha branca da $\mathrm{Pt}$, indicando uma ocupação do estado eletrônico $5 d$ da platina. ${ }^{64,} 74$ Em $500 \mathrm{mV}$ (Fig. 6.7a) a intensidade da linha branca seguiu a ordem PtSn Etek $~ \mathrm{PtSnEu}<\mathrm{PtSnCe}$ $\mathrm{PtSnLa}<\mathrm{PtSnPr}<\mathrm{Pt}$ Etek. No potencial de $900 \mathrm{mV}$ (Fig. 6.7b), a diferença entre o salto da Pt e dos demais materiais foi reduzida, o que provavelmente indica que na região de óxidos, o efeito eletrônico na banda $d$ seja menos pronunciado. A ordem do salto também sofreu uma pequena diferenciação, PtSnEu < PtSn Etek PtSnCe $<\mathrm{PtSnLa}<\mathrm{PtSnPr}<\mathrm{Pt}$ Etek. 
Figura 6.7 - Espectros de XANES in situ na borda $\mathrm{L}_{3}$ da Pt para os catalisadores Pt/C Etek, $\mathrm{PtSn} / \mathrm{C}$ Etek 75:25 e PtSnTR/C (TR:La, Ce, Pr e Eu) 75:20:05, em (a) 500 mV e (b) $900 \mathrm{mV}$.
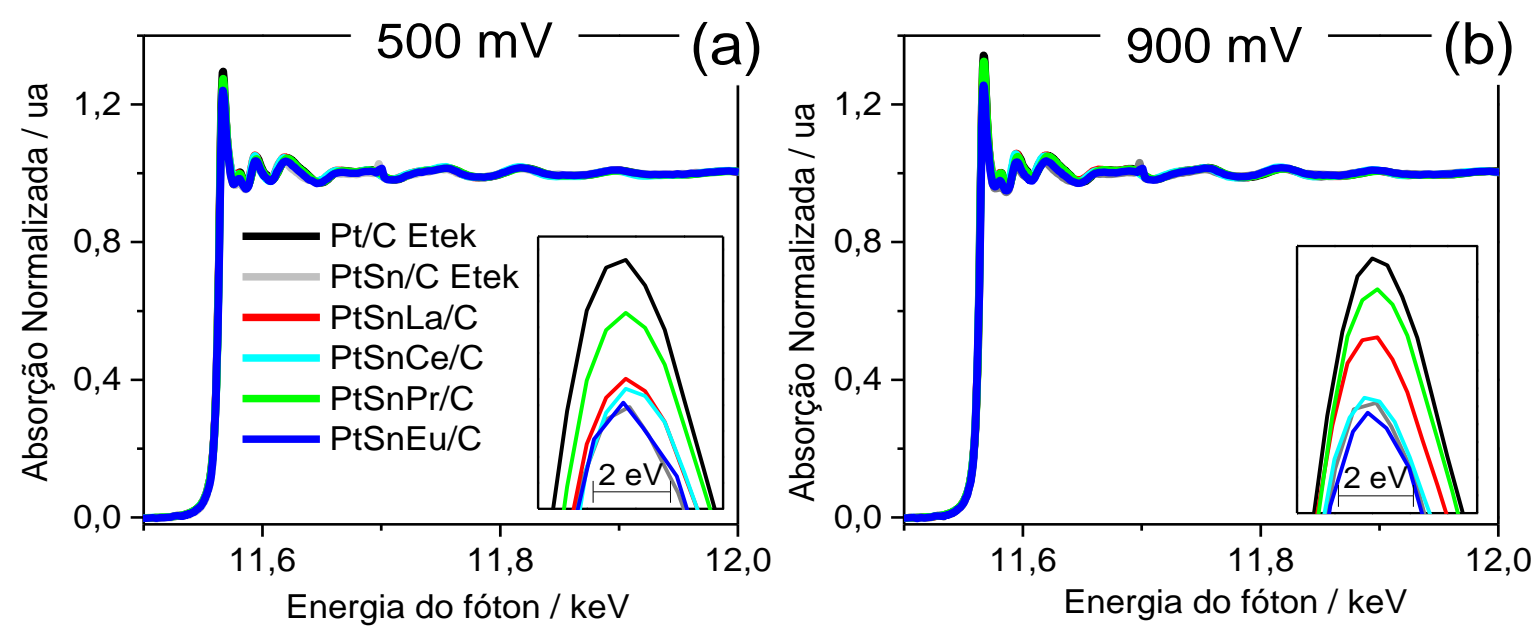

Fonte: Autoria própria.

Como discutido anteriormente, a adição de uma pequena concentração de estanho já é suficiente para promover a redução da absorção de raios $\mathrm{X}$ da $\mathrm{Pt}$. ${ }^{74}$ Entretanto, apenas a mudança de concentração de estanho não justificaria a ordem de adsorção observada para os catalisadores PtSnTR/C sintetizados.

De acordo com a literatura, o estanho e os terras raras têm efeitos opostos em relação ao preenchimento da banda $d$ da Pt. Corradini et al. (2016) sintetizaram catalisadores bimetálicos Pt-TR (TR: La, Ce, Pr e Eu) pelo método do poliol, similar ao adotado neste trabalho. ${ }^{48}$ Os resultados de XAS indicaram que as banda $d$ da $\mathrm{Pt}$ desses catalisadores $\mathrm{Pt}-\mathrm{TR} / \mathrm{C}$ foram menos preenchidas que a $\mathrm{Pt} / \mathrm{C}$. Os autores atribuíram o esvaziamento observado à transferência de elétrons da banda $\mathrm{Pt} 5 d$ para a orbital $4 f$ dos metais terras raras estudados. ${ }^{48}$ Assim como nos catalisadores $\mathrm{Pt}-\mathrm{TR} / \mathrm{C}$, os dados de XAS obtidos dos catalisadores PtSnTR/C indicaram que a adição de terras raras contribuiu para o aumento da linha da branca, em relação ao catalisador bimetálico PtSn/C 75:25 comercial. Apesar de não se poder separar a contribuição de cada metal (estanho e terra rara), as mudanças observadas no perfil eletrônico da Pt podem acarretar em mudanças nas atividades catalíticas dos catalisadores obtidos frente à ROE. ${ }^{74}$ 


\subsection{CARACTERIZAÇÃO ELETROQUÍMICA DOS CATALISADORES PtSnTR/C}

Os catalisadores de PtSnTR/C (TR: La, Ce, Pr) sintetizados por poliol foram caracterizados eletroquimicamente em uma célula de três eletrodos, na qual o eletrodo de trabalho foi depositado em forma de uma camada ultrafina. Os materiais foram avaliados em dois meios: ácido $\left(0,5 \mathrm{~mol} \mathrm{~L}^{-1} \mathrm{H}_{2} \mathrm{SO}_{4}\right)$ e etanol ácido $\left(0,5 \mathrm{~mol} \mathrm{~L}^{-1}\right.$ $\mathrm{H}_{2} \mathrm{SO}_{4}$ e $1,0 \mathrm{~mol} \mathrm{~L}^{-1} \mathrm{C}_{2} \mathrm{H}_{5} \mathrm{OH}$ ), por voltametrias cíclicas, voltametrias lineares e cronoamperometrias. Os dados dos catalisadores de Pt/C, PtSn/C e PtSnEu/C 75:20:05 estão reapresentados nessa seção, para comparação com os materiais trimetálicos PtSnTR/C (TR: La, Ce e Pr).

\subsubsection{Teste em camada ultrafina}

\subsubsection{Caracterização em meio ácido}

As medidas eletroquímicas realizadas em camada ultrafina dos materiais PtSnTR/C método do poliol estão representadas na Figura 6.8. É possível observar uma supressão dos picos característicos na Pt de adsorção e dessorção de hidrogênio, entre 0,05 - 0,3 V vs ERH. Esse comportamento é relacionado à redução da concentração de Pt no catalisador, e da adição de outros metais, principalmente o estanho, visto que este promove efeitos geométricos e modificações nas propriedades eletrônicas da $\mathrm{Pt}$, que afetam a atividade dos sítios ativos da Pt para adsorção de hidrogênio. ${ }^{85}$

Figura 6.8 - Voltametria cíclica dos catalisadores Pt/C, PtSn/C 60:40 e PtSnTR/C (TR: La, $\mathrm{Ce}, \mathrm{Pr}$ e Eu) 75:20:05 em meio ácido $\left(0,5 \mathrm{~mol} \mathrm{~L}^{-1} \mathrm{H}_{2} \mathrm{SO}_{4}\right)$. Atmosfera de argônio, v: $20 \mathrm{mV} \mathrm{s}^{-1}$.

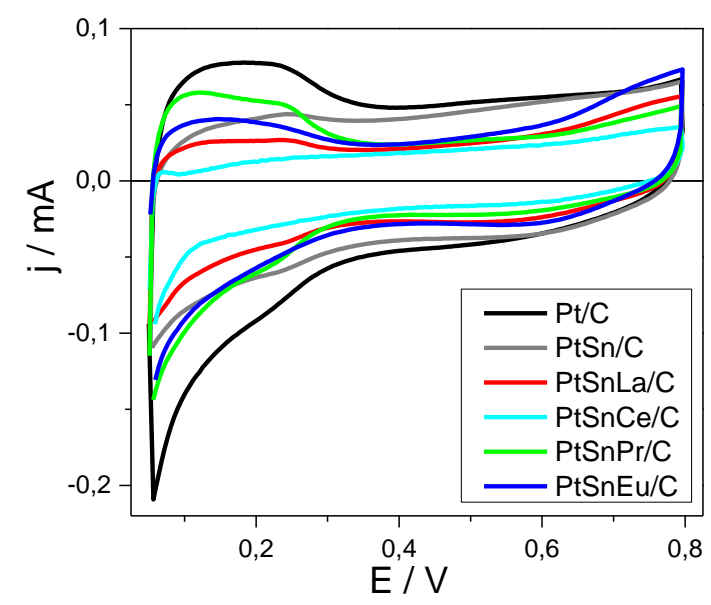

Fonte: Autoria própria. 


\section{Capítulo IV}

\section{Resultados e Discussão: Catalisadores PtSnTR/C}

Os materiais trimetálicos apresentaram maior semelhança com o perfil do catalisador $\mathrm{PtSn} / \mathrm{C}$ do que a $\mathrm{Pt} / \mathrm{C}$, demonstrando que uma pequena concentração de estanho já suficiente para promover redução dos picos de hidrogênio. As diferenças das áreas e na dupla camada observada para os materiais PtSnTR/C provavelmente estão relacionadas pelos diferentes tamanhos de partículas dos catalisadores. Além disso, há uma variação dos tipos de óxidos terras raras sintetizados. Cada material pode apresentar características elétricas, como capacitância e resistência, bem diferentes uns dos outros, e isso pode influenciar a corrente observada na região da dupla camada, entre $0,35 \vee$ a $0,6 \vee v s \mathrm{ERH}$.

Para determinar a área ativa do material, realizou-se stripping de CO. ${ }^{29,30} \mathrm{~A}$ Figura 6.9 representa a subtração do primeiro ciclo do stripping à uma linha de base. Todos os catalisadores trimetálicos apresentaram pico de oxidação de CO em menores potenciais do que a platina. A antecipação da oxidação de $\mathrm{CO}$ indica que a presença de estanho e terras raras, mesmo em baixas concentrações, tem um efeito benéfico. Além disso, é possível aferir que a adição de terras raras ao $\mathrm{PtSn} / \mathrm{C}$ foi benéfica para a reação de oxidação de $\mathrm{CO}$, visto que maiores densidades de corrente foram observadas para os catalisadores trimetálicos $\mathrm{PtSnLa} / \mathrm{C}, \mathrm{PtSnPr} / \mathrm{C}$ e PtSnEu/C. Para melhor visualização, a Fig. 6.9a' apresenta uma ampliação, sem a curva da Pt/C. É possível observar que alguns catalisadores apresentaram um ombro na diferença dos dois voltamogramas, como PtSnLa/C, PtSnCe/C e PtSnEu/C. A literatura esclarece que picos múltiplos ou surgimento de ombros podem ser relacionados a fatores eletrônicos, distribuição das partículas e a estrutura de superfície. ${ }^{122} \mathrm{O}$ catalisador $\mathrm{PtSnPr} / \mathrm{C}$ apresentou o maior pico dos catalisadores sintetizados, e os demais apresentaram pequenas diferenças de corrente na oxidação de $\mathrm{CO}$, mas com perfil semelhante. Os dados DRX indicam pequeno grau de liga Pt-Sn, e pelos dados de XAS, é possível aferir que o estanho promove o preenchimento da banda $d$ da $\mathrm{Pt}$, o que diminui a interação entre Pt$\mathrm{CO}_{\mathrm{ad}}$. Os óxidos de terras raras também apresentaram um efeito benéfico à reação de oxidação de CO. A literatura comenta que óxidos de cério facilitam a oxidação de $\mathrm{CO}$, por utilizar a ligação intrínseca de $\mathrm{CeO}_{2}-\mathrm{OH}$ para doar hidróxidos aos sítios vizinhos de $\mathrm{Pt}$, oxidando diretamente as espécies em baixos potenciais, de acordo com o mecanismo bifuncional. ${ }^{123}$ Provavelmente os óxidos de lantânio, praseodímio e európio também contribuem para o mecanismo bifuncional. 


\section{Resultados e Discussão: Catalisadores PtSnTR/C}

Figura 6.9 - (a) Primeiro ciclo obtido por stripping de CO, subtraído por uma linha de base, dos catalisadores Pt/C, PtSn e PtSnTR/C (TR= La, Ce, Pr e Eu) sintetizados por poliol em $0,5 \mathrm{~mol} \mathrm{~L}^{-1}$ de $\mathrm{H}_{2} \mathrm{SO}_{4}$ a $20 \mathrm{mV} \mathrm{s}^{-1}$, em atmosfera de argônio, $\mathrm{v}=5$ $\mathrm{mV} \mathrm{s}^{-1}$. (a') Ampliação em menores correntes, sem a curva da $\mathrm{Pt} / \mathrm{C}$.
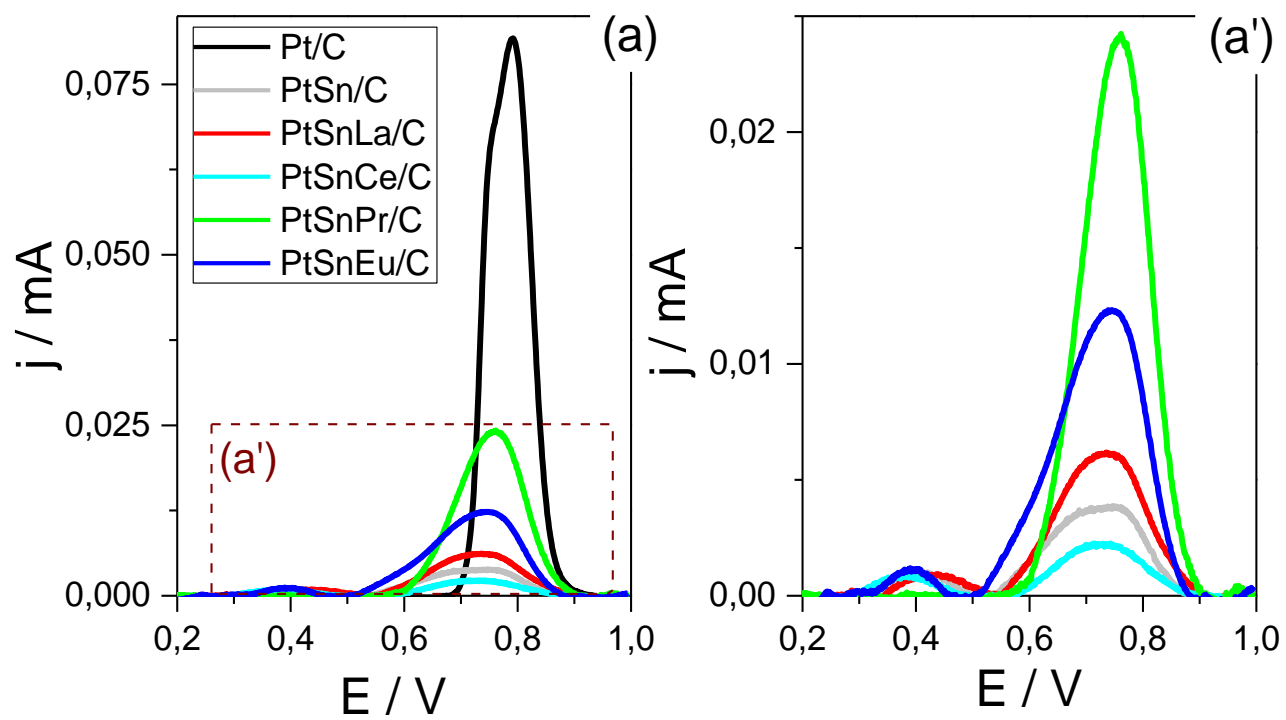

Fonte: Autoria própria.

A área ativa dos catalisadores PtSnTR/C (TR: La, Ce e Pr) foram determinados pela integração da área abaixo dos picos observados na Fig. 6.9. Os valores médios obtidos e os respectivos desvios médios das repetições das medidas estão apresentados na Tabela 6.5. O catalisador PtSnCe/C 75:20:05 apresentou 0,20 $\mathrm{cm}^{2}$ de área ativa, menor que o catalisador binário $\mathrm{PtSn} / \mathrm{C}$, de área de $0,42 \mathrm{~cm}^{2}$ (Tab. 5.5). Provavelmente a aglomeração, observada pela micrografia do catalisador $\mathrm{PtSnCe} / \mathrm{C}$ obtida por TEM, deve ter um efeito maléfico, contribuindo para a redução de área ativa. O catalisador PtSnLa/C 75:20:05 apresentou maior área que o catalisador que o binário $\mathrm{PtSn} / \mathrm{C}$, mas a maior área ativa foi obtida para o catalisador PtSnPr/C 75:20:05. Essas diferenças de áreas são coerentes com os dados obtidos por DRX, no qual o catalisador $\mathrm{PtSnPr} / \mathrm{C}$ apresentou o menor tamanho de cristalito, de $2,2 \mathrm{~nm}$.

Tabela 6.5 - Área ativa obtida do stripping de CO para os materiais $\mathrm{PtSnLa} / \mathrm{C}, \mathrm{PtSnCe} / \mathrm{C}$ e $\mathrm{PtSnPr} / \mathrm{C}$ 75:20:05, obtidos por poliol.

\begin{tabular}{cc}
\hline Catalisador & Área Ativa $\left(\mathbf{c m}^{\mathbf{2}}\right)$ \\
\hline $\mathrm{PtSnLa} / \mathrm{C} 75: 20: 05$ & $0,58 \pm 0,03$ \\
$\mathrm{PtSnCe} / \mathrm{C} 75: 20: 05$ & $0,20 \pm 0,05$ \\
$\mathrm{PtSnPr} / \mathrm{C} 75: 20: 05$ & $1,70 \pm 0,01$ \\
\hline
\end{tabular}


Resultados e Discussão: Catalisadores PtSnTR/C

\subsubsection{Caracterização em meio etanólico}

Para avaliar a eletroatividade para oxidação de etanol dos catalisadores PtSnTR/C (TR: La, Ce, Pr e Eu) 75:20:05 utilizou-se voltametrias lineares e cronoamperometria em soluções de $0,5 \mathrm{~mol} \mathrm{~L}^{-1}$ de $\mathrm{H}_{2} \mathrm{SO}_{4}$ e $1,0 \mathrm{~mol} \mathrm{~L}^{-1}$ de etanol. $\mathrm{Na}$ Figura 6.10a estão apresentadas as curvas lineares obtidas em etanol, normalizadas pela áreas ativas obtidas por stripping de CO (Tab. 5.5 e 6.5). Os catalisadores $\mathrm{PtSn} / \mathrm{C}, \mathrm{PtSnLa} / \mathrm{C}, \mathrm{PtSnCe} / \mathrm{C}$ e PtSnEu/C apresentaram potencial onset próximos a $0,45 \mathrm{~V}$ vs $\mathrm{ERH}$. As densidades de correntes entre estes materiais foram próximas no intervalo de potencial estudado, sendo que o catalisador $\mathrm{PtSnCe/C}$ apresentou a densidade de oxidação de etanol ligeiramente maior que os demais. Já o catalisador $\mathrm{PtSnPr} / \mathrm{C}$ apresentou um potencial onset próximo a Pt/C, em 0,56 V vs ERH. Apesar de apresentar uma das maiores áreas ativas dos catalisadores obtidos, $\mathrm{PtSnPr} / \mathrm{C}$ apresentou a menor densidade de corrente, superior apenas a Pt/C.

Figura 6.10 - (a) Voltamogramas lineares dos catalisadores de Pt/C, PtSn/C 60:40 e dos catalisadores PtSnTR/C (TR: La, Ce, Pr e Eu) 75:20:05 sintetizados por poliol. (b) Derivadas da corrente em função do potencial. Meio: $0,5 \mathrm{~mol} \mathrm{~L}^{-1}$ de $\mathrm{H}_{2} \mathrm{SO}_{4}$ e $1,0 \mathrm{~mol} \mathrm{~L}{ }^{-1}$ de $\mathrm{C}_{2} \mathrm{H}_{5} \mathrm{OH} ; \mathrm{v}=1 \mathrm{mV} \mathrm{s}^{-1}$, atmosfera de argônio. Normalização pela área ativa.

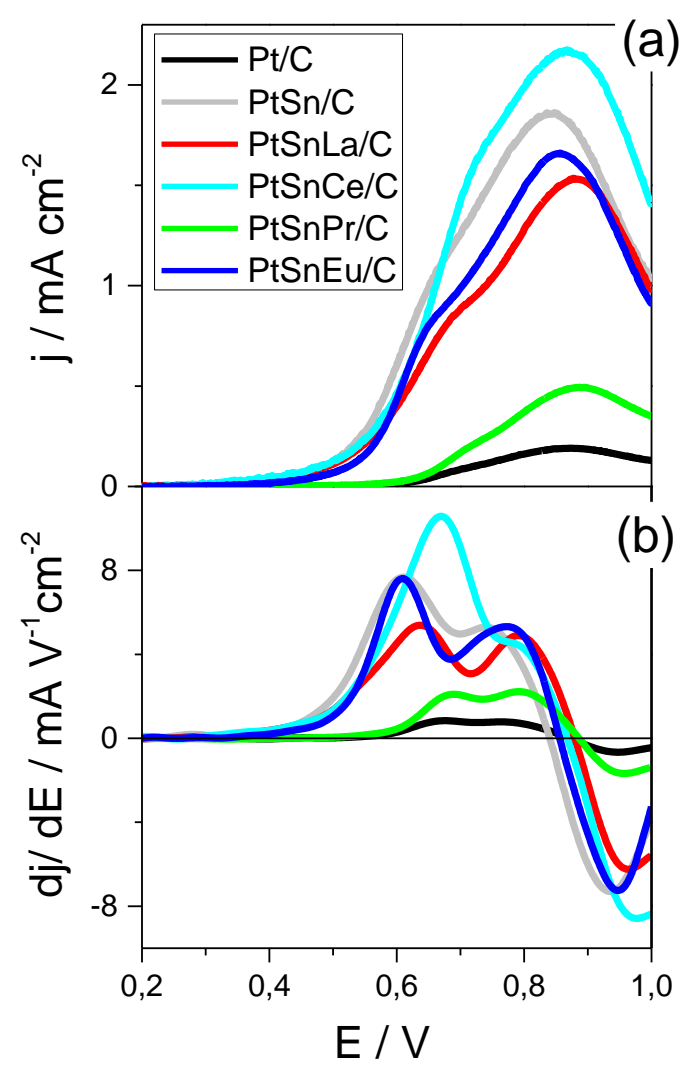

Fonte: Autoria própria. 


\section{Resultados e Discussão: Catalisadores PtSnTR/C}

Para extrair mais informações das curvas de polarização linear em meio etanólico, realizaram-se as derivadas das curvas em função do potencial, apresentadas na Fig. 6.10b. Para todos catalisadores, dois picos foram observados. Para os catalisadores $\mathrm{PtSn} / \mathrm{C}$ e PtSnEu/C, o primeiro pico foi próximo de $0,60 \mathrm{~V}$ vs $\mathrm{ERH}$; para $\mathrm{PtSnLa} / \mathrm{C}$, em 0,63 V vs ERH; PtSnCe/C em 0,66 V vs ERH, e para Pt/C e $\mathrm{PtSnPr} / \mathrm{C}$, em 0,68 V vs ERH. Apesar das diferenças nos potenciais no pico inicial, o segundo pico foi próximo para todas as composições, em torno de 0,8 V vs $\mathrm{ERH}$. Considerando que as variações das curvas de derivada de potencial podem estar relacionadas aos subprodutos da oxidação de etanol ${ }^{90}$, pode-se aferir que o primeiro produto a ser formado é mais influenciado pela composição do catalisador que o(s) subproduto(s) relacionado(s) ao segundo pico. Pode-se afirmar que a presença de estanho, lantânio, cério e európio anteciparam o início da reação de oxidação de etanol, talvez favorecendo a formação subproduto relacionado ao pico em menor potencial. Apesar das diferenças nos potenciais, os perfis foram semelhantes para todos os catalisadores, indicando que a mudança no catalisador provavelmente não alterou os mecanismos da reação estudada.

Os cronoamperogramas obtidos para os catalisadores PtSnTR/C (TR: La, Ce, Pr e Eu), normalizados pela área ativa, estão apresentados na Figura 6.11a. Para melhor comparação, as densidades de corrente em 2800 segundos para os catalisadores sintetizados estão apresentadas na Fig. 6.11b. Ao avaliar as densidades de corrente normalizadas por área ativa, observa-se a ordem: $\mathrm{Pt}$ $\left(0,014 \mathrm{~mA} \mathrm{~cm}^{-2}\right)<\operatorname{PtSnPr} 75: 20: 05\left(0,108 \mathrm{~mA} \mathrm{~cm}^{-2}\right)<\operatorname{PtSn} 60: 40\left(0,240 \mathrm{~mA} \mathrm{~cm}^{-2}\right)$ $<$ PtSnEu 75:20:05 (0,259 mA cm$\left.{ }^{-2}\right)<$ PtSnCe 75:20:05 $\left(0,289 \mathrm{~mA} \mathrm{~cm}^{-2}\right)<$ PtSnLa 75:20:05 $\left(0,337 \mathrm{~mA} \mathrm{~cm}^{-2}\right)$. As densidades de corrente obtidas pelos materiais ternários PtSnTR/C (TR: La, Ce e Eu) 75:20:05 são 20-24 vezes maiores que apresentada pela $\mathrm{Pt} / \mathrm{C}$, e $8 \%$ a 40\% maiores do $\mathrm{PtSn} / \mathrm{C}$ 60:40. Apesar do $\mathrm{PtSnPr} / \mathrm{C}$ 75:20:05 apresentar uma densidade de corrente quase 8 vezes maior que a $\mathrm{Pt} / \mathrm{C}$, este ainda apresentou menor densidade de corrente quando comparado ao $\mathrm{PtSn} / \mathrm{C}$ 60:40. Ao estimar a densidade de corrente por massa de platina, considerando a concentração determinada por ICP e por ATG, observa-se que os catalisadores $\mathrm{PtSnLa} / \mathrm{C}$ e PtSnPr/C apresentaram densidades de corrente próximas, de $25 \mathrm{~A} \mathrm{~g}^{-1}$. $\mathrm{O}$ catalisador $\mathrm{PtSnCe} / \mathrm{C}$ apresentou o menor valor, próximo a $7 \mathrm{~A} \mathrm{~g}^{-1}$, mas em sua maioria, as densidades apresentadas foram superiores que a $\mathrm{Pt} / \mathrm{C}\left(8,7 \mathrm{~A} \mathrm{~g}^{-1}\right) \mathrm{e}$ 
Resultados e Discussão: Catalisadores PtSnTR/C

$\mathrm{PtSn} / \mathrm{C}\left(14,7 \mathrm{~A} \mathrm{~g}^{-1)}\right.$, sendo o catalisador PtSnEu/C que apresentou maior valor, de $66 \mathrm{~A} \mathrm{~g}^{-1}$.

Figura 6.11 - (a) Cronoamperogramas dos catalisadores Pt/C, PtSn/C 60:40 e PtSnTR/C (TR: La, Ce, $\mathrm{Pr}$ e Eu) 75:20:05 em 0,5 mol L-1 de $\mathrm{H}_{2} \mathrm{SO}_{4}$ e $1,0 \mathrm{~mol} \mathrm{~L}^{-1}$ de $\mathrm{C}_{2} \mathrm{H}_{5} \mathrm{OH}$ a $0,600 \mathrm{~V}$, em atmosfera de argônio. Representação com normalização pela área ativa.(b) Densidade de corrente em 2800 segundos obtidas da cronoamperometria em $0,600 \mathrm{~V}$, normalizada por área ativa e por massa de platina.
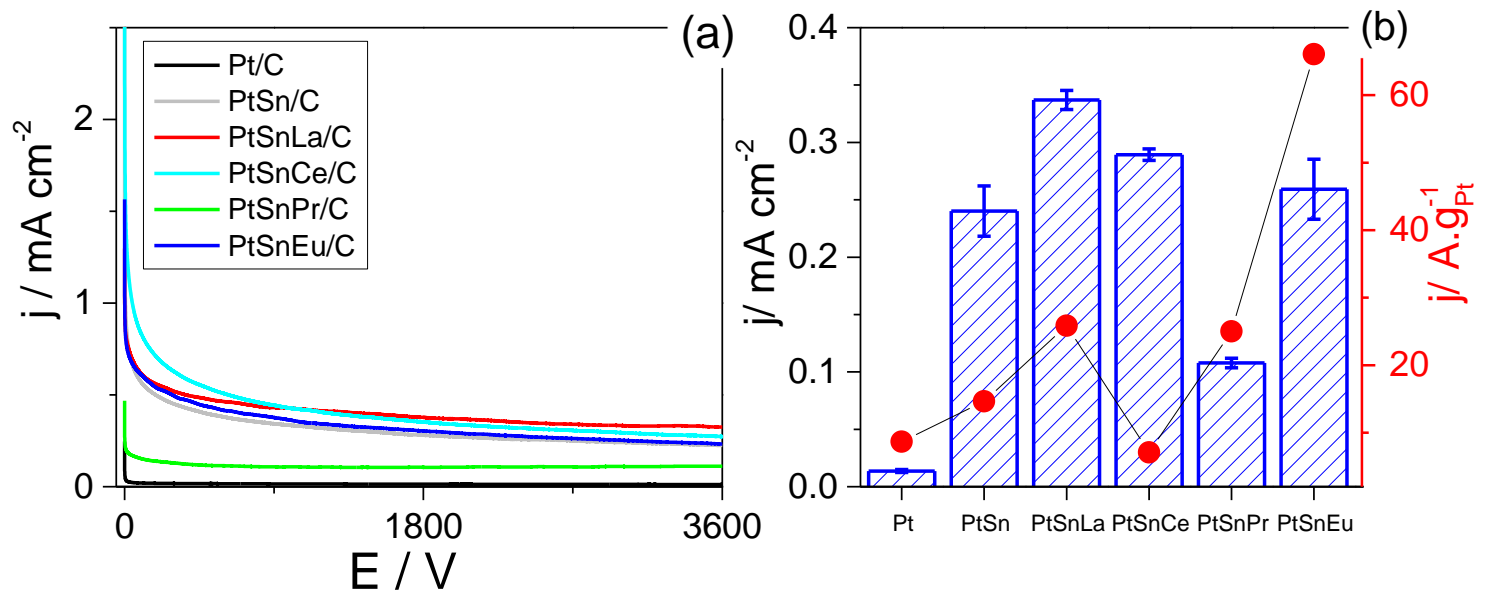

Fonte: Autoria própria.

Apesar da discreta diferenciação, é possível observar que as adições de lantânio, cério e európio em catalisadores de Pt/C e PtSn/C promoveram um aumento da densidade de corrente para a oxidação de etanol. Tal efeito não foi evidenciado para a adição de praseodímio, pois este apresentou densidades de correntes inferiores a PtSn/C.

\subsubsection{Teste de envelhecimento acelerado}

Assim como comentado para os catalisadores PtSnEu/C, uma questão muito importante a ser avaliada em catalisadores suportados em carbono é a variação da atividade catalítica com o uso. A literatura mostra tal preocupação com a estabilidade de materiais suportados, e apesar de muitos estudos voltados para nanopartículas e materiais bimetálicos de platina, ainda pouco se sabe sobre a estabilidade de materiais ternários Pt-Sn-Terras raras. Um grande desafio à estabilidade de metais terras raras na aplicação em PEMFC é o pH do meio. A Figura 6.12 representa os diagramas de Pourbaix para o lantânio, cério e 


\section{Resultados e Discussão: Catalisadores PtSnTR/C}

praseodímio. É possível observar que todos são passíveis de dissolução em pH ácido, no intervalo de potencial de $0 \mathrm{~V}$ a próximo de $1,2 \mathrm{~V} v s \mathrm{EPH}$, para a forma catiônica $T^{3+}$.

Figura 6.12 - Diagramas do Pourbaix para os metais terras (a) lantânio, (b) cério e (c) praseodímio.

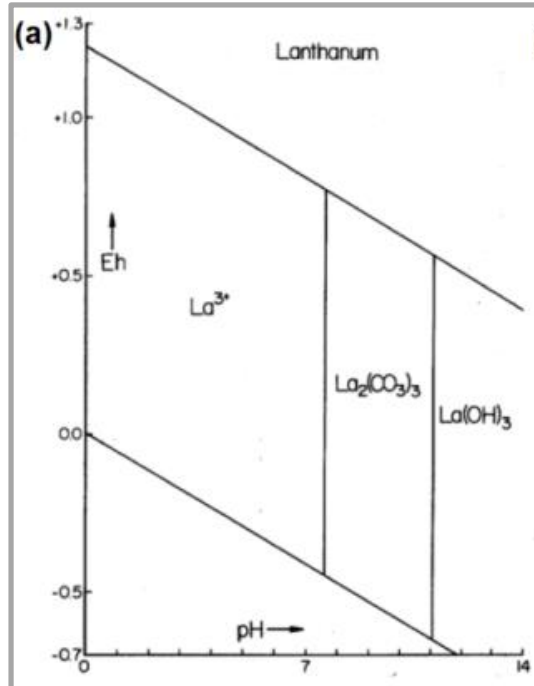

(b)

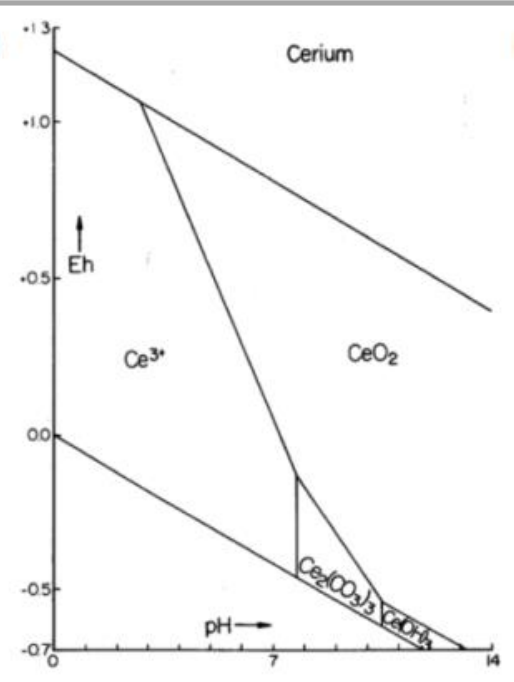

(c)

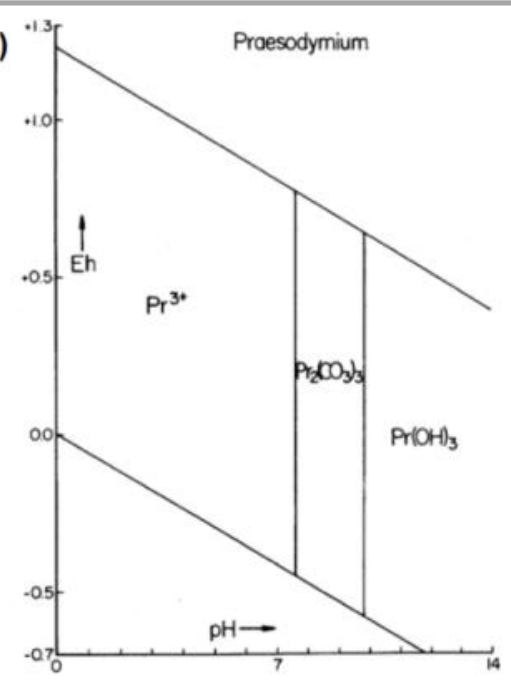

Fonte: Extraído de BROOKINS, D. Geochemical Journal, 17, 1983, p. 225-226. ${ }^{101}$

Apesar da possibilidade de dissolução, esse processo pode ter uma cinética lenta, ou até mesmo diferenciada pela presença de platina e estanho. Para avaliar a mudança da atividade catalítica frente à oxidação de etanol para os catalisadores PtSnTR/C. Dois intervalos de potenciais foram utilizados: entre 0,3-0,8 V a 0,5-1,0 V, conforme descrito na seção 4.3.1.3. A comparação dos voltamogramas antes e após os testes de envelhecimentos está demonstrada na Figura 6.13. Para ambos processos foi possível observar mudanças na região de adsorção e dessorção de hidrogênio, entre 0,05 a 0,3 V vs ERH. Essas variações pode estar relacionadas às mudanças superficiais no catalisador; à dissolução dos metais estanho e terras raras; e/ou a processos corrosivos para nanopartículas de platina, ilustrados na Figura 5.11, como desprendimento de partículas, crescimento de Ostwald, entre outros. As mudanças mais significativas nos perfis são observadas na Fig. 6.13b, o qual o potencial de envelhecimento foi entre 0,5-1,0 V. 


\section{Resultados e Discussão: Catalisadores PtSnTR/C}

Figura 6.13 - Comparação dos voltamogramas antes (linha tracejada) e após (linha cheia) os testes de envelhecimento entre (a) 0,3-0,8 V e (b) 0,5-1,0 V dos catalisadores Pt/C, PtSn/C e PtSnTR/C (TR: La, Ce, Pr e Eu) 75:20:05 sintetizados por poliol. v: $20 \mathrm{mV} \mathrm{s}^{-1}$, atmosfera de argônio, em $0,5 \mathrm{~mol} \mathrm{~L}^{-1} \mathrm{de}$ $\mathrm{H}_{2} \mathrm{SO}_{4}$.
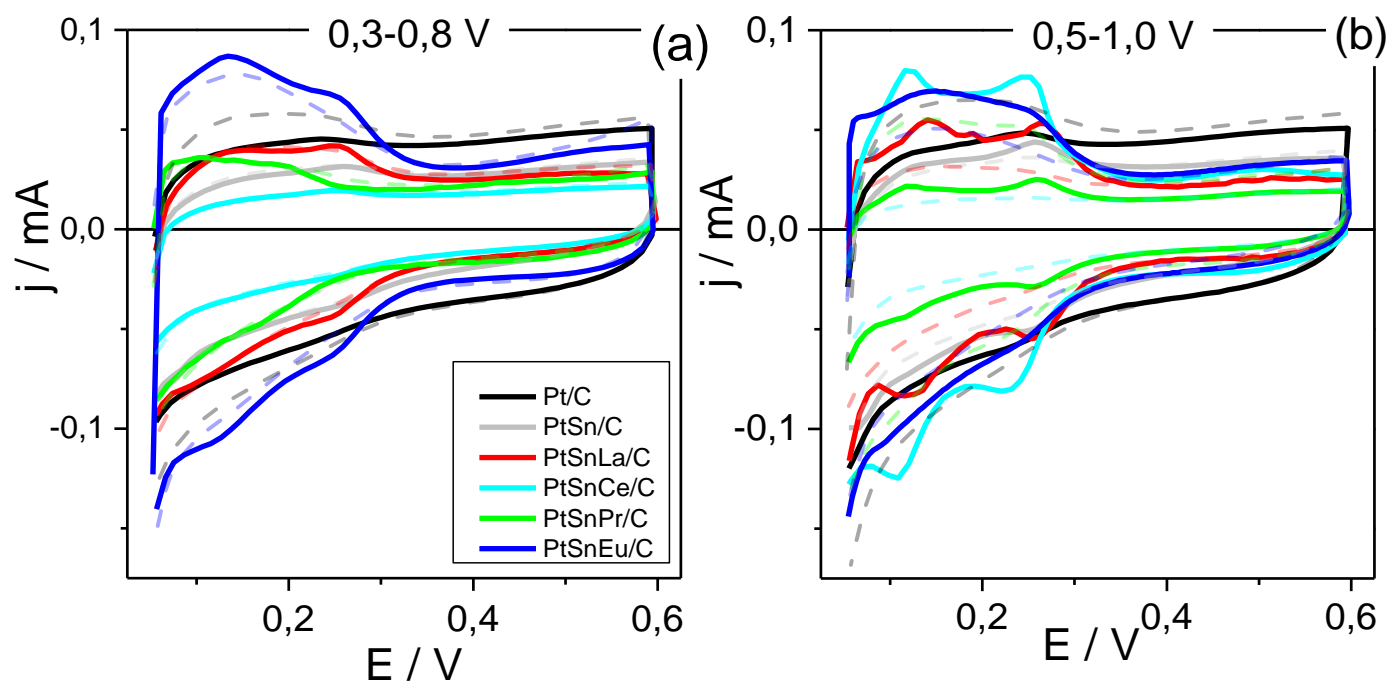

Fonte: Autoria própria.

A variação da área ativa determinada na região de hidrogênio pelo número de ciclos está representada na Figura 6.14. No intervalo de 0,3-0,8 V (Fig. 6.14a), os catalisadores PtSnLa/C 75:20:05 e PtSnCe/C 75:20:05 apresentaram pouca variação na região de hidrogênio com os números de ciclos. Entretanto, a ciclagem entre 0,3-0,8 V já foi suficiente para promover um aumento da área para os catalisadores PtSnPr/C 75:20:05 e PtSnEu/C 75:20:05, estimada em 1,5 $\mathrm{cm}^{2}$ antes do envelhecimento; para 2,5 $\mathrm{cm}^{2}$ ao final dos 200 ciclos (Fig. 6.14a). Ao avaliar o efeito das ciclagens entre 0,5-1,0 V, apresentado na Fig. 6.14b, observou-se que todos os catalisadores testados apresentaram as maiores variações nas áreas até $100^{\circ}$ ciclo; e após o $125^{\circ}$ ciclo, as áreas estimadas na região de hidrogênio mantiveram-se constante. 


\section{Resultados e Discussão: Catalisadores PtSnTR/C}

Figura 6.14 - Variação da área determinada por hidrogênio dos catalisadores Pt/C, PtSn/C e $\mathrm{PtSnTR/C} \mathrm{(TR:} \mathrm{La,} \mathrm{Ce,} \mathrm{Pr} \mathrm{e} \mathrm{Eu)} \mathrm{sintetizados} \mathrm{por} \mathrm{poliol:} \mathrm{envelhecimento} \mathrm{entre}$ (a) $0,3-0,8 \mathrm{~V}$ e (b) $0,5-1,0 \mathrm{~V}$.
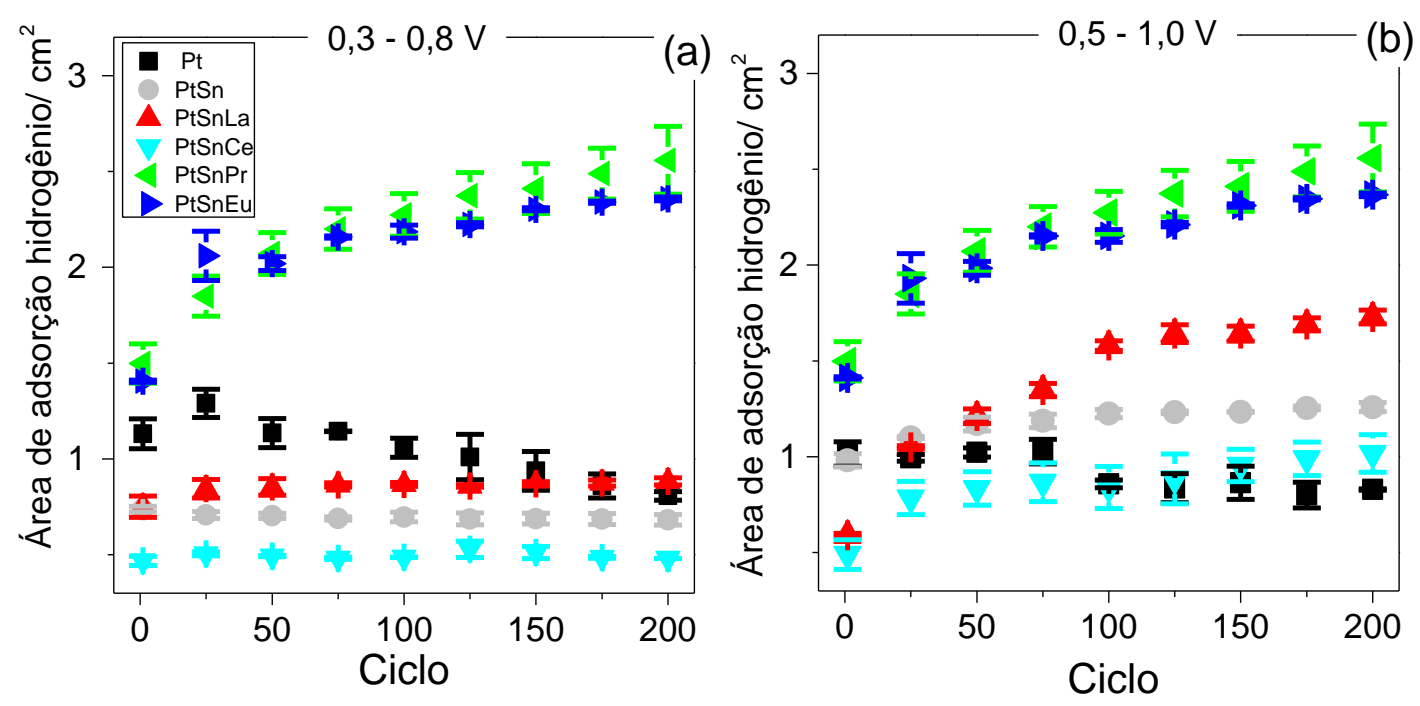

Fonte: Autoria própria.

Para avaliar a mudança de área ativa, a Figura 6.15 apresenta as curvas de stripping de $\mathrm{CO}$ antes (a) e após os testes de envelhecimentos para os catalisadores sintetizados. Para os materiais envelhecidos entre 0,3-0,8 V (Fig. 6.15b), a ciclagem não modificou o perfil de oxidação de CO dos materiais PtSnTR/C, mas é possível observar um aumento na corrente e diminuição do potencial de onset da reação. A ciclagem entre 0,5-1,0 V (Fig. 6.15c), por outro lado, modificou o perfil de oxidação de $\mathrm{CO}$, por promover o aparecimento de um ombro em potenciais próximos a $0,70 \mathrm{~V}$, observado em quase todos os catalisadores trimetálicos. Também é possível observar um aumento na corrente para oxidação de CO após os testes de envelhecimento entre 0,5-1,0 V. 
Resultados e Discussão: Catalisadores PtSnTR/C

Figura 6.15 - Curvas obtidas da subtração do $1^{\circ}$ ciclo do stripping de CO por uma linha de base para os catalisadores Pt/C, PtSn/C 60:40, PtSnTR/C (La, Ce, Pr e Eu) 75:25:05 (a) antes do envelhecimento, (b) após ciclagem entre 0,3-0,8 V e (c) após ciclagem entre $0,5-1,0 \mathrm{~V}$. v: $5 \mathrm{mV} \mathrm{s}^{-1}$, atmosfera de argônio. Linhas tracejadas representam curvas do respectivo material não envelhecido.
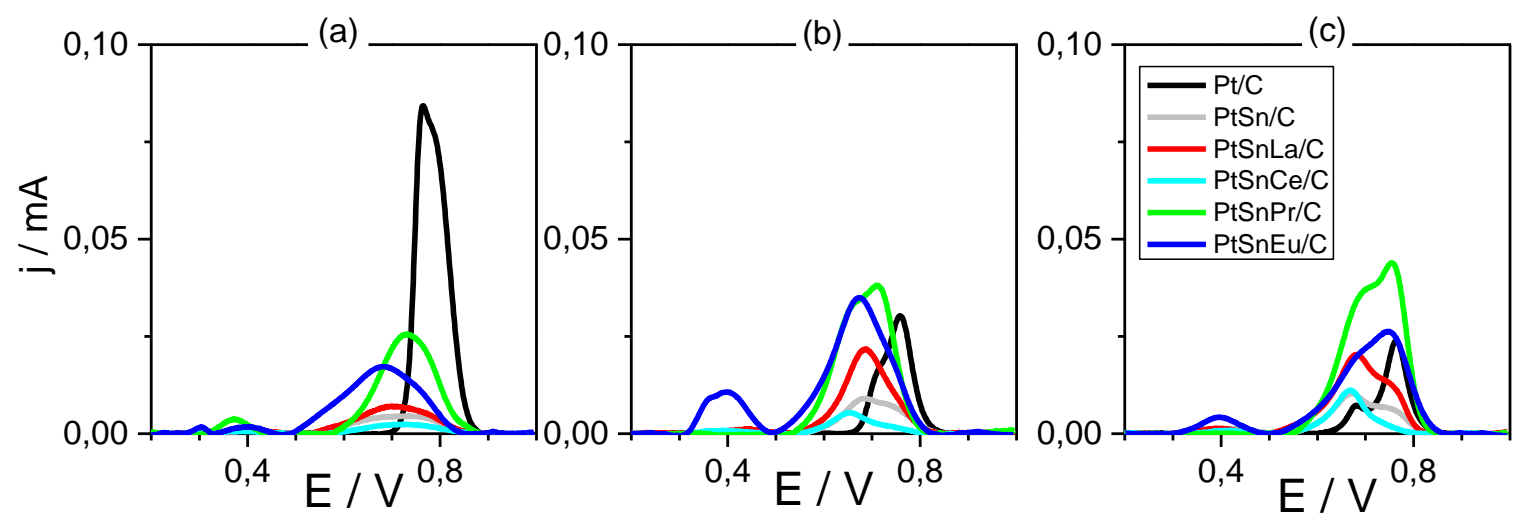

Fonte: Autoria própria.

López-Cudero et al. (2010) demonstrou que multiplicidades no pico de oxidação do monóxido de carbono em nanopartículas de platina pode ser relacionadas à presença de aglomerados, que facilitam a oxidação do $\mathrm{CO} .^{122}$ Os autores explicam que a aglomeração é um processo puramente físico, ou seja, as nanopartículas e as propriedades individuais destas não sofrem perda significativa de área de superfície ativa. O surgimento de picos em menores potenciais é justificado pelo menor distanciamento entre duas nanopartículas. Assim, o pico em potenciais inferiores provavelmente pode ser correlacionado à oxidação do CO nos agregados, enquanto que o pico em potenciais superiores à oxidação nas nanopartículas. ${ }^{122}$

Os valores das áreas ativas após os envelhecimentos estão apresentados na Tabela 6.6. Para a ciclagem entre 0,3-0,8 V, a variação da área ativa foi próxima a 45\% para os catalisadores PtSnCe/C 75:20:05, PtSnPr/C 75:20:05 e PtSnEu/C 75:20:05, e próxima a 100\% para PtSnLa/C. Apesar da mudança de área ativa, é possível observar que variação da maioria dos catalisadores não ultrapassou a variação apresentada pelo catalisador PtSn/C, de 50\%. Entretanto, ao ciclar os materiais entre 0,5-1,0 V, é possível observar maior aumento de área, entre 85\% para $\mathrm{PtSnPr} / \mathrm{C}$ a $170 \%$ pata $\mathrm{PtSnCe} / \mathrm{C}$. As variações apresentadas pelos catalisadores $\mathrm{PtSnTR} / \mathrm{C}$ foram superiores ao apresentado pelo catalisador $\mathrm{Pt} / \mathrm{C}$ e PtSn/C. 


\section{Resultados e Discussão: Catalisadores PtSnTR/C}

Tabela 6.6 - Áreas ativas obtidas por stripping de CO, após teste de envelhecimento e a variação da área dos catalisadores $\mathrm{Pt} / \mathrm{C}, \mathrm{PtSn} / \mathrm{C}$ e PtSnTR/C (TR:La, Ce, Pr e Eu) 75:20:05 sintetizados por poliol.

\begin{tabular}{|c|c|c|c|c|}
\hline \multirow{2}{*}{ Catalisador } & \multicolumn{2}{|c|}{$\begin{array}{l}\text { Envelhecimento } \\
\text { entre } 0,3-0,80 \mathrm{~V}\end{array}$} & \multicolumn{2}{|c|}{$\begin{array}{c}\text { Envelhecimento } \\
\text { entre } 0,5-1,0 \mathrm{~V}\end{array}$} \\
\hline & $\begin{array}{l}\text { Área ativa } \\
\text { final }\left(\mathrm{cm}^{2}\right)\end{array}$ & $\begin{array}{l}\text { Variação } \\
(\%)\end{array}$ & $\begin{array}{l}\text { Área ativa } \\
\text { final }\left(\mathrm{cm}^{2}\right)\end{array}$ & $\begin{array}{l}\text { Variação } \\
(\%)\end{array}$ \\
\hline${ }^{\star} \mathrm{Pt} / \mathrm{C}$ & $1,4 \pm 0,3$ & $-62 \pm 2$ & $0,88 \pm 0,01$ & $-75 \pm 1$ \\
\hline${ }^{\star} P t S n / C$ 60:40 & $0,62 \pm 0,05$ & $50 \pm 13$ & $0,75 \pm 0,07$ & $76 \pm 13$ \\
\hline PtSnLa/C 75:20:05 & $1,21 \pm 0,09$ & $99 \pm 5$ & $1,36 \pm 0,10$ & $142 \pm 7$ \\
\hline PtSnCe/C 75:20:05 & $0,29 \pm 0,03$ & $46 \pm 5$ & $0,51 \pm 0,05$ & $170 \pm 15$ \\
\hline PtSnPr/C 75:20:05 & $2,45 \pm 0,2$ & $44 \pm 5$ & $2,9 \pm 0,3$ & $85 \pm 6$ \\
\hline *PtSnEu/C 75:20:05 & $1,91 \pm 0,06$ & $34 \pm 2$ & $2,6 \pm 0,1$ & $96 \pm 16$ \\
\hline
\end{tabular}

*Dados reapresentados para comparação.

Após os testes de envelhecimento acelerado, os catalisadores ternários foram avaliados frente à reação de oxidação de etanol, por voltametria linear e cronoamperometria. Os voltamogramas lineares de PtSnTR/C (TR: La, Ce, Pr e Eu) em meio ácido etanólico estão apresentadas na Figura 6.16. Assim como comentado para os catalisadores $\mathrm{PtSnEu} / \mathrm{C}$, a ciclagem dos materiais promoveram um aparecimento de um ombro entre $0,60-0,75 \mathrm{~V}$ e a antecipação do onset de potencial de oxidação de etanol. Exceto para Pt/C, o envelhecimento entre 0,3-0,8 V (Fig. 6.16a) promoveu uma redução da densidade de corrente para todos os catalisadores. Apesar das diferenças da densidade de corrente, a mesma tendência de atividade foi observada após o envelhecimento: PtSnCe/C 75:20:05 apresentou maiores correntes, e início de oxidação de etanol em menores potenciais, seguido por PtSn/C 60:40; PtSnEu/C 75:20:05 e PtSnLa/C 75:20:05 com atividades próximas; PtSnPr/C 75:20:05 e Pt/C. Pelas curvas derivadas (Figura 6.16c), os perfis foram bem semelhantes entre os catalisadores sintetizados, com aparecimento de dois picos entre 0,6 V e 0,85 V. Para o envelhecimento entre 0,5-1,0 V (Fig. 6.16b), apenas o catalisador PtSnPr/C 75:20:05 apresentou aumento da densidade de corrente após o envelhecimento. Após essas ciclagens, os catalisadores PtSnEu/C 75:20:05 e PtSnCe/C 75:20:05 apresentaram maiores densidades de corrente que o catalisador PtSn/C 60:40. Nas curvas derivadas (Fig. 6.16d), o perfil dos picos foram diferentes da condição inicial, no qual também foram observados dois picos para os catalisadores trimetálicos. A principal diferença está na antecipação do potencial de onset para PtSnPr/C, PtSnCe/C e PtSnEu/C. 
Resultados e Discussão: Catalisadores PtSnTR/C

Figura 6.16 - Voltamogramas lineares dos catalisadores Pt/C, PtSn/C e PtSnTR/C (TR: La, Ce, $\operatorname{Pr}$ e Eu) 75:20:05 em 0,5 mol L-1 de $\mathrm{H}_{2} \mathrm{SO}_{4}$ e 1,0 mol L-1 de etanol a $1 \mathrm{mV} \mathrm{s}^{-1}$ após teste de envelhecimento acelerado, ciclados entre (a) 0,3-0,8 V e (b) 0,5-1,0 V. Curvas das densidades de corrente derivadas em função do potencial, ciclados entre (c) 0,3-0,8 V e (d) 0,5-1,0 V. Normalização por área ativa. Linhas tracejadas representam curvas do respectivo material não envelhecido.

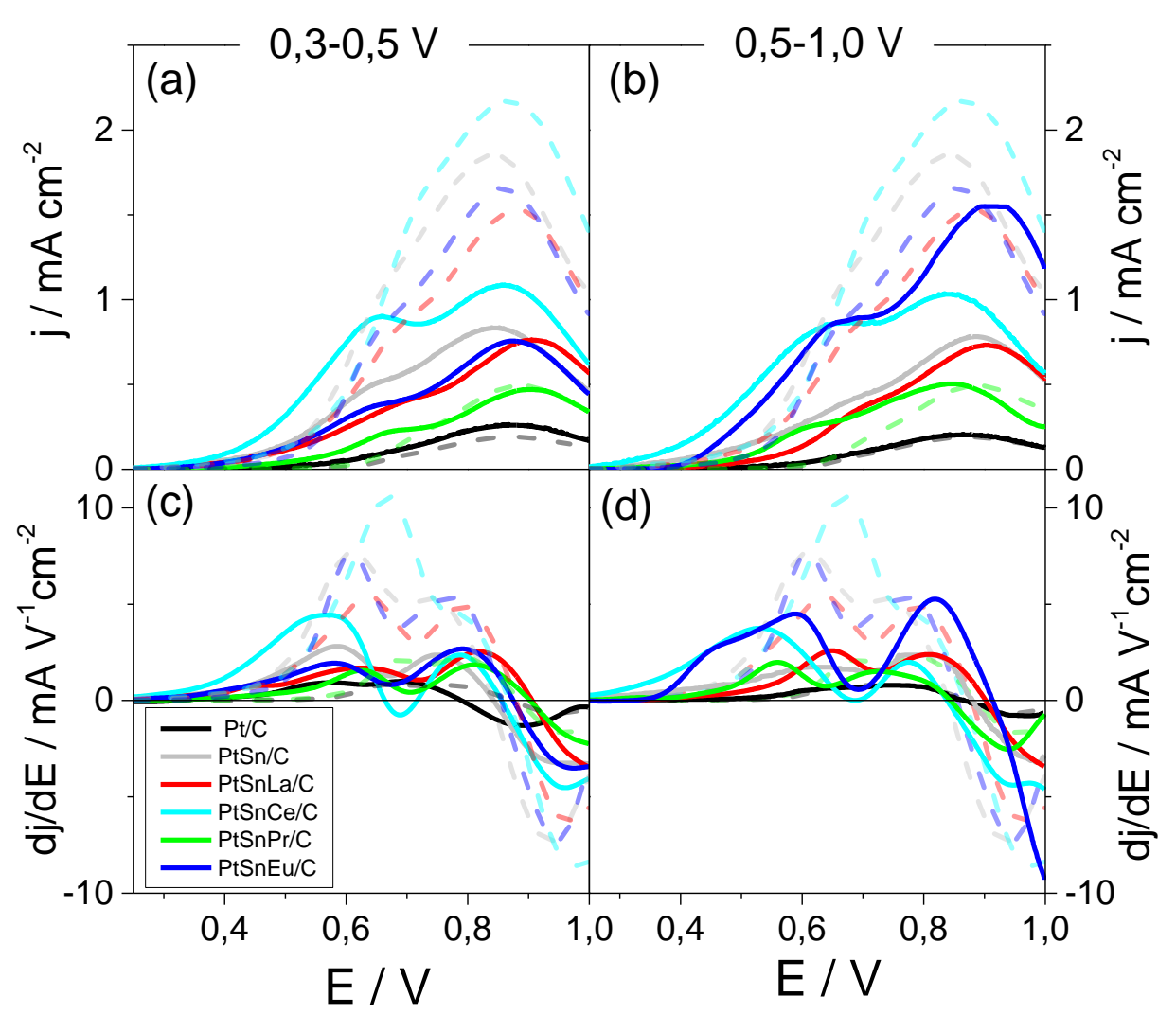

Fonte: Autoria própria.

As cronoamperometrias obtidas após os testes de envelhecimento estão apresentadas na Figura 6.17. Após o envelhecimento entre 0,3-0,8 V (Fig. 6.17a), todos os catalisadores ternários apresentaram maior densidade de corrente que a $\mathrm{Pt} / \mathrm{C}$. O catalisador PtSn/C 60:40 apresentou densidade de corrente próxima ao catalisador PtSnLa/C, e o catalisador que apresentou maior densidade de corrente após envelhecimento foi o PtSnEu/C 75:20:05. Para os envelhecimentos até 1,0 V (Fig. 6.17b), o catalisador $\mathrm{PtSnPr} / \mathrm{C}$ 75:20:05 apresentou grande redução na densidade de corrente, se aproximando a Pt/C. Os catalisadores de PtSnLa/C 75:20:05 e PtSnEu/C 75:20:05 apresentaram correntes próximas, mas inferiores a $\mathrm{PtSn} / \mathrm{C}$ 60:40. Nesse protocolo, o catalisador PtSnCe/C apresentou maior densidade de corrente. 


\section{Resultados e Discussão: Catalisadores PtSnTR/C}

Figura 6.17 - Cronoamperogramas dos catalisadores Pt/C, PtSn/C 60:40 e PtSnTR/C (TR: $\mathrm{La}, \mathrm{Ce}$, Pr e Eu) 75:20:05 em 0,5 $\mathrm{mol} \mathrm{L}^{-1}$ de $\mathrm{H}_{2} \mathrm{SO}_{4}$ e $1,0 \mathrm{~mol} \mathrm{~L}^{-1}$ de $\mathrm{C}_{2} \mathrm{H}_{5} \mathrm{OH}$ em 0,600 V, após teste de envelhecimento, entre (a) 0,3-0,8 V e (b) 0,5-1,0 V. Atmosfera de argônio, normalização por área ativa.
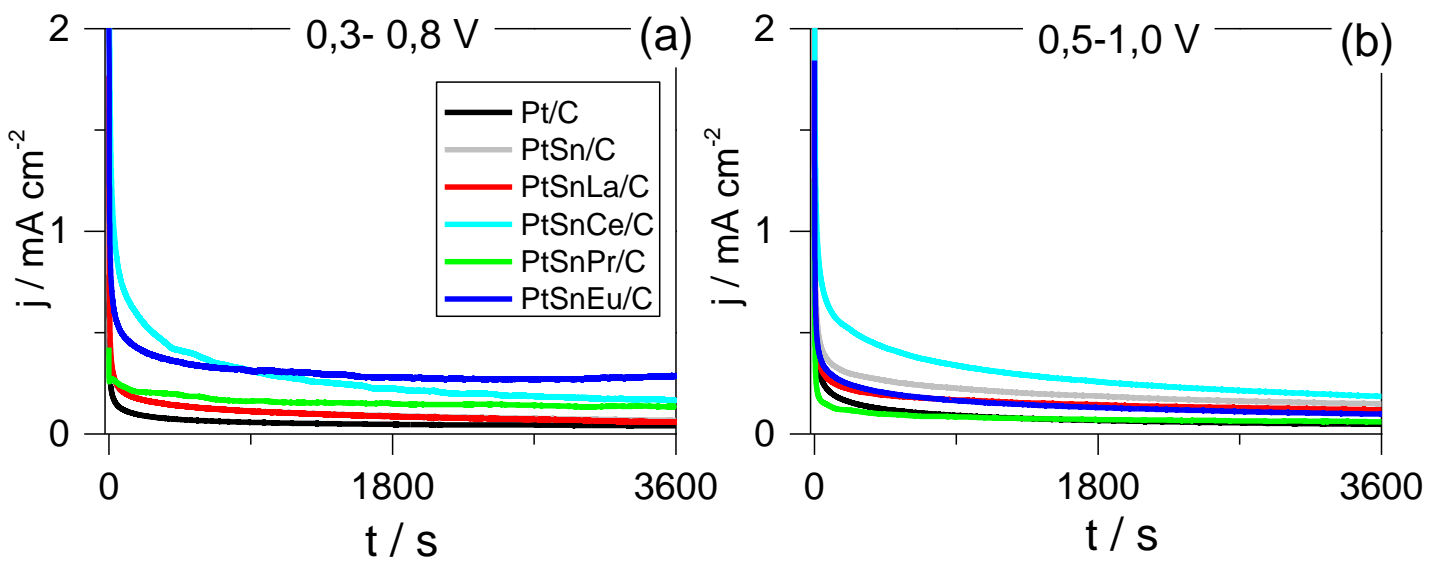

Fonte: Autoria própria.

Para uma ideia mais quantitativa, a Figura 6.18 apresenta as densidades de corrente em 2800 segundos da cronoamperometria, antes e após os envelhecimentos. Todos os catalisadores ternários apresentaram maior densidade de corrente que a $\mathrm{Pt} / \mathrm{C}\left(0,02 \mathrm{~mA} \mathrm{~cm}^{-2}\right)$, antes e após os envelhecimentos. Para a ciclagem até $0,8 \mathrm{~V}$, apenas os catalisadores PtSnPr/C 75:20:05 (0,139 mA cm$\left.{ }^{-2}\right)$ e PtSnEu/C 75:20:05 (0,266 $\left.\mathrm{mA} \mathrm{cm}^{-2}\right)$ apresentaram aumento da densidade de corrente comparados aos valores iniciais, de $29 \%$ e $3 \%$, respectivamente. A ciclagem em baixos potenciais reduziu a atividade eletrocatalítica dos catalisadores trimetálicos. As reduções mais significativas foram para o $\mathrm{PtSnLa} / \mathrm{C}$ 75:20:05, $\left(0,071 \mathrm{~mA} \mathrm{~cm}^{-2}\right)$, de 79\%; e para PtSn 60:40 (0,095 $\left.\mathrm{mA} \mathrm{cm}^{-2}\right)$ de $60 \%$. A menor redução foi para o catalisador $\mathrm{PtSnCe} / \mathrm{C}$ 75:20:05 $\left(0,184 \mathrm{~mA} \mathrm{~cm}^{-2}\right)$, de 39\%. Após envelhecimento até $1,0 \mathrm{~V}$, apena $\mathrm{Pt} / \mathrm{C}$ apresentou aumento da densidade de corrente em relação a densidade inicial $\left(0,054 \mathrm{~mA} \mathrm{~cm}^{-2}\right)$. Para este protocolo, as densidades de corrente para etanol foram maiores que após envelhecimento em 0,30,8 V. Por exemplo, a diferença entre as densidades de correntes iniciais para os catalisadores $\mathrm{PtSn} / \mathrm{C}\left(0,179 \mathrm{~mA} \mathrm{~cm}^{-2}\right), \mathrm{PtSnLa} / \mathrm{C} 75: 20: 05, \quad\left(0,129 \mathrm{~mA} \mathrm{~cm}^{-2}\right)$ e $\mathrm{PtSnCe} / \mathrm{C} 75: 20: 05\left(0,213 \mathrm{~mA} \mathrm{~cm}^{-2}\right)$ foram de 25\%, 62\% e 30\%, respectivamente. Apenas os catalisadores PtSnPr/C 75:20:05 (0,065 mA cm$\left.{ }^{-2}\right)$ e PtSnEu/C 75:20:05 $\left(0,119 \mathrm{~mA} \mathrm{~cm}^{-2}\right)$ apresentaram menores densidades de corrente após 0 envelhecimento até $1,0 \mathrm{~V}$, comparado ao envelhecimento até $0,8 \mathrm{~V}$. Ao analisar as 
Resultados e Discussão: Catalisadores PtSnTR/C

densidades de corrente, é possível observar o efeito benéfico dos metais terras na estabilidade do catalisador PtSn/C. Esse efeito é mais observado para envelhecimento até $0,8 \mathrm{~V}$.

Figura 6.18-Densidades de correntes no tempo de 2800 segundos nas medidas de cronoamperometria para os materiais de $\mathrm{Pt} / \mathrm{C}, \mathrm{PtSn} / \mathrm{C}$ 60:40 e PtSnTR/C (TR: $\mathrm{La}, \mathrm{Ce}, \mathrm{Pr}$ e Eu) 75:20:05 antes do envelhecimento (cinza escuro), após ciclagem 0,3-0,8 (cinza claro) e após 0,5 a 1,0 V. (laranja). Normalização por área ativa.

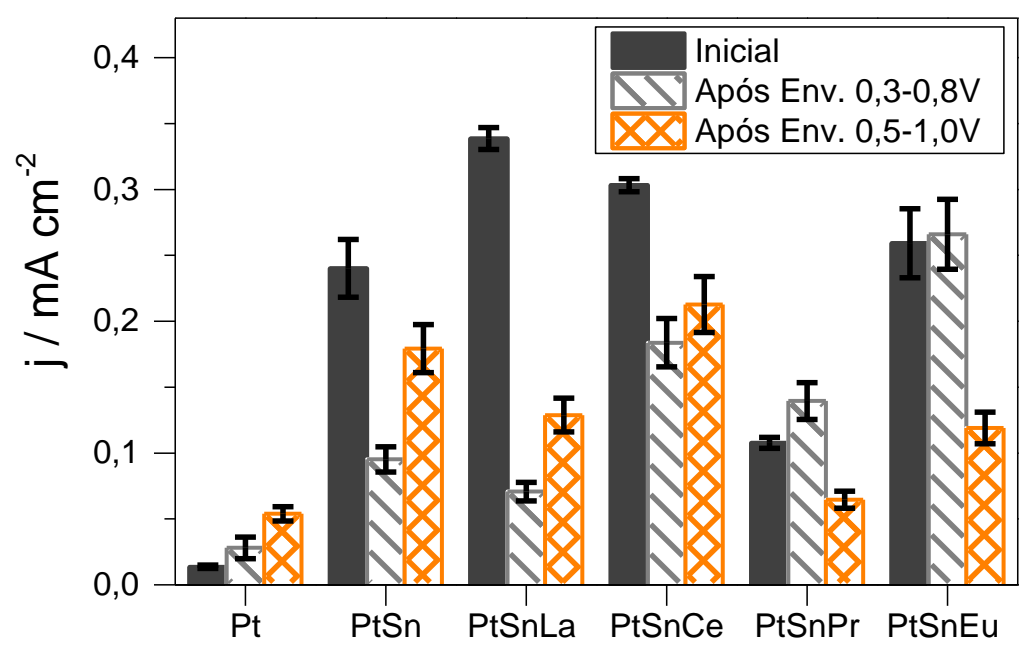

Fonte: Autoria própria.

Para tentar avaliar as possíveis mudanças do catalisador pelo envelhecimento

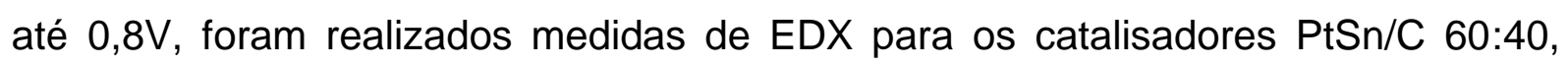
PtSnCe/C 75:20:05 e PtSnPr/C 75:20:05. A Figura 6.19 apresenta as composições atômicas determinadas. Para avaliar se a mudança de composição é apenas do efeito do $\mathrm{pH}$ do meio, o teste também foi realizado para os catalisadores apenas submersos em solução de $0,5 \mathrm{~mol} \mathrm{~L}^{-1}$ de ácido sulfúrico, sem submete-los à variação de potencial (representados na Fig.6.19 pela cor laranja). Para o catalisador PtSn/C (Fig. 6.19 a), é possível observar uma redução da concentração de Sn apenas pelo contato com meio ácido, mas a redução é mais significativa com a ciclagem do material. Como a composição atômica obtida EDX é porcentual, a dissolução de estanho promove um aparente aumento da concentração da Pt. Para o PtSnCe/C 75:20:05, a concentração de cério diminui apenas pelo contato com meio ácido, como esperado pelo diagrama de Pourbaix (Fig. 6.19 b). A dissolução de cério é 


\section{Resultados e Discussão: Catalisadores PtSnTR/C}

ainda mais significativa após as ciclagens (Fig. 6.19 b). O estanho do PtSnCe/C também apresenta dissolução em contato com meio ácido. Mas de algum modo, a saída do cério pelas voltametrias promovem a permanência do estanho no catalisador, pois pouca mudança da composição de Sn é observada nessa situação (Fig. 6.19 b). No catalisador PtSnPr/C 75:20:05 não foi observado praseodímio após submergi-lo em meio ácido, e apenas um resquício foi obtido após a ciclagem (Fig. 6.19 c). A concentração de estanho sofre dissolução em contato com o meio, mas essa dissolução é menor na ciclagem. De algum modo a presença de um terceiro metal favorece a permanência do estanho no catalisador, mesmo que este sofra dissolução durante as medidas.

Figura 6.19-Comparação das composições atômicas determinadas por EDX dos catalisadores (a) $\mathrm{PtSn} / \mathrm{C}$; (b) $\mathrm{PtSnCe} / \mathrm{C}$ e (c) $\mathrm{PtSnPr} / \mathrm{C}$, antes e após envelhecimento eletroquímico até $0,8 \mathrm{~V}$.
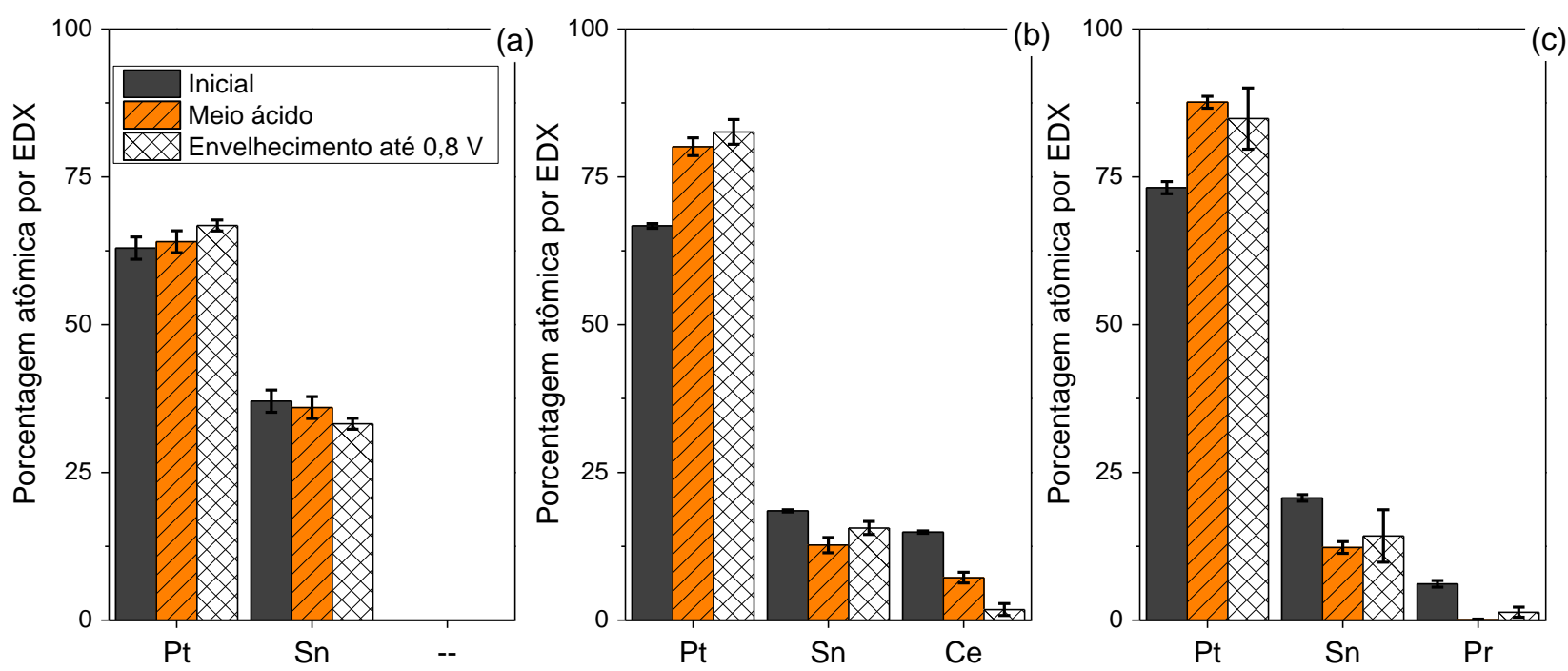

Fonte: Autoria própria.

Ao avaliar a estabilidade dos catalisadores trimetálicos é possível observar mudanças das áreas relacionadas ao hidrogênio e nas áreas ativas. Entretanto, ao avaliar a atividade eletrocatalítica para etanol após envelhecimento, observa-se menores perdas, ou até ganhos nas densidades de corrente nesses catalisadores. Mesmo comprovada a dissolução dos metais terras raras nos materiais, é provável que a adição destes promova a permanência do estanho, e de algum modo, contribua para a estabilidade do catalisador bimetálico. Para avaliar se a adição de 


\section{Resultados e Discussão: Catalisadores PtSnTR/C}

lantânio, praseodímio ou cério promovem modificações no mecanismo de oxidação de etanol, medidas de FTIR foram realizadas.

6.3.1.4 Caracterização dos subprodutos da reação de oxidação de etanol por espectroscopia vibracional de absorção na região do infravermelho in situ com transformada de Fourier

Assim como para os catalisadores PtSnEu/C, medidas de FTIR in situ dos catalisadores ternários PtSnTR/C (TR: La, Ce e Pr) 75:20:05 foram realizadas em célula de três eletrodos, na configuração de camada fina. A Figura 6.20 apresenta os espectros com variação entre $0,2 \mathrm{~V}$ a $1,0 \mathrm{~V}$, com a variação de $0,1 \mathrm{~V}$ entre os espectros, para os catalisadores PtSnTR/C (TR: La, Ce e Pr). Os espectros da Pt/C, PtSn/C 60:40 e PtSnEu/C 75:20:05 foram reapresentados para comparação.

O primeiro pico ocorre próximo de $1705 \mathrm{~cm}^{-1}$, que pode ser atribuída ao estiramento CCO do grupo carbonila, presente no acetaldeído e no ácido acético. ${ }^{124}$ Em $1356 \mathrm{~cm}^{-1}$, há uma banda discreta, que pode ser atribuída ao $\mathrm{CH}_{3}$ no plano do acetato adsorvido $\left(\delta \mathrm{CH}_{3}\right)$. Não foi observado bandas referentes a formação de $\mathrm{CO}_{2}$, ou CO adsorvido $\left(\mathrm{CO}_{\mathrm{L}}\right)$, em $2035 \mathrm{~cm}^{-1}$, indicando que a adsorção dissociativa não é tão favorecida nos catalisadores PTSnTR/C. A partir de $500 \mathrm{mV}$, é possível ver bandas de consumo de etanol $\left(1048 \mathrm{~cm}^{-1}\right)$ e formação de acetaldeído $\left(933 \mathrm{~cm}^{-1}\right)$, e com o aumento do potencial, as bandas ficam mais evidentes. Assim como comentado para os catalisadores PtSnEu/C, apesar de não observar bandas referentes a subprodutos $\mathrm{C}_{1}$, a formação destes não deve ser descartada. 


\section{Resultados e Discussão: Catalisadores PtSnTR/C}

Figura 6.20 - Espectros de FTIR obtidos para os catalisadores (a) Pt/C; (b) PtSn/C 60:40; (c) PtSnLa/C 75:20:05; (d) PtSnCe/C 75:20:05; (e) PtSnPr/C 75:20:05; e (f) PtSnEu/C 75:20:05 obtidos em 0,5 mol L-1 de $\mathrm{H}_{2} \mathrm{SO}_{4}$ e 0,5 $\mathrm{mol} \mathrm{L}^{-1}$ de etanol. A janela utilizada foi ZnSe. O espectro de referência foi coletado em 0,05 V vs $\mathrm{ERH}$ e os espectros das amostras foram coletados após aplicação dos potenciais em sentido positivo (variação de $0,1 \mathrm{~V}$ entre espectros), com o início em 0,2 V. O potencial de 0,6 V está destacado em azul.

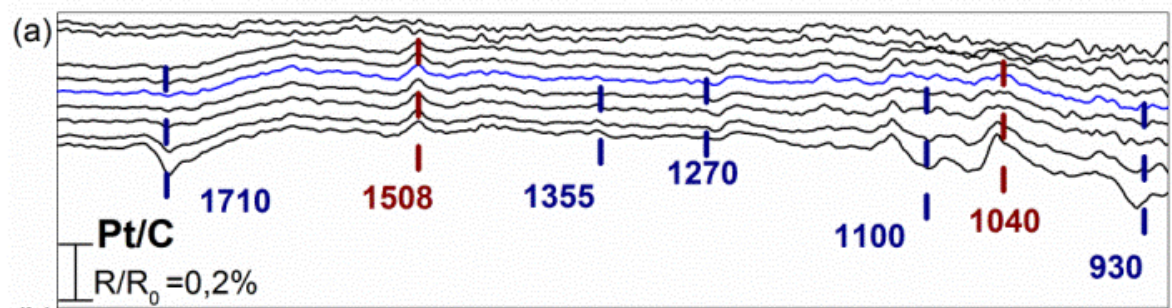

(b)

(c)

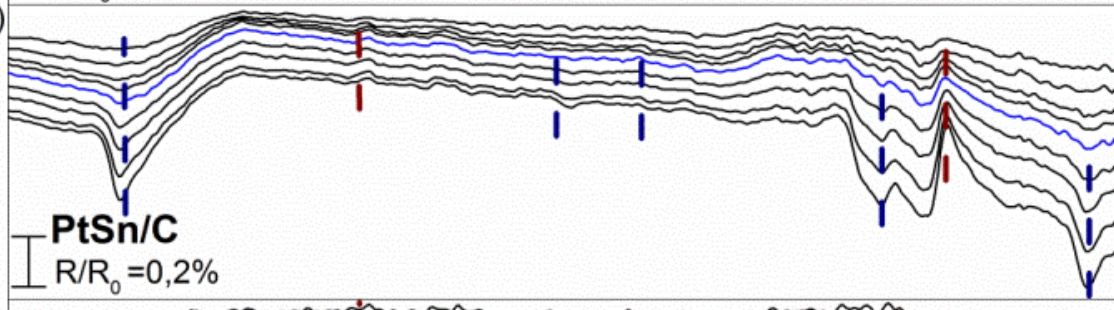

(d)
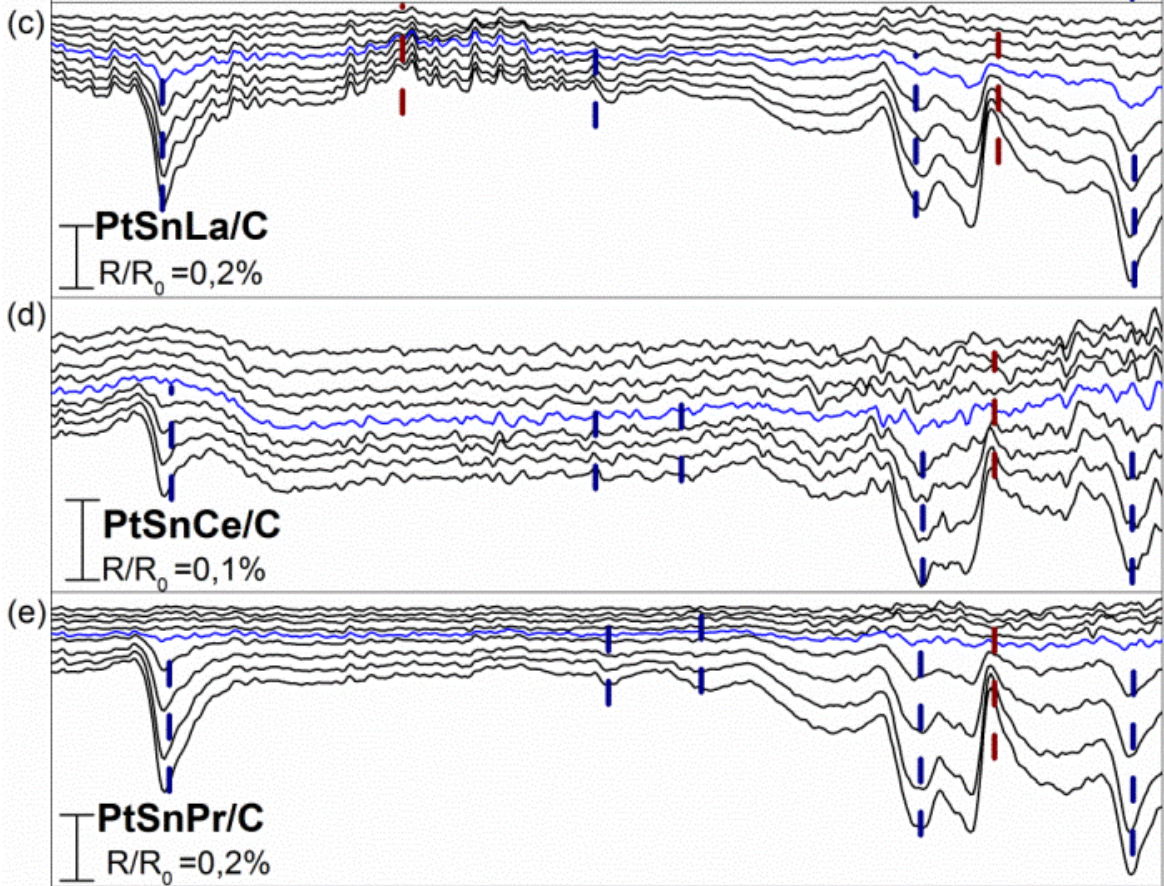

(f)
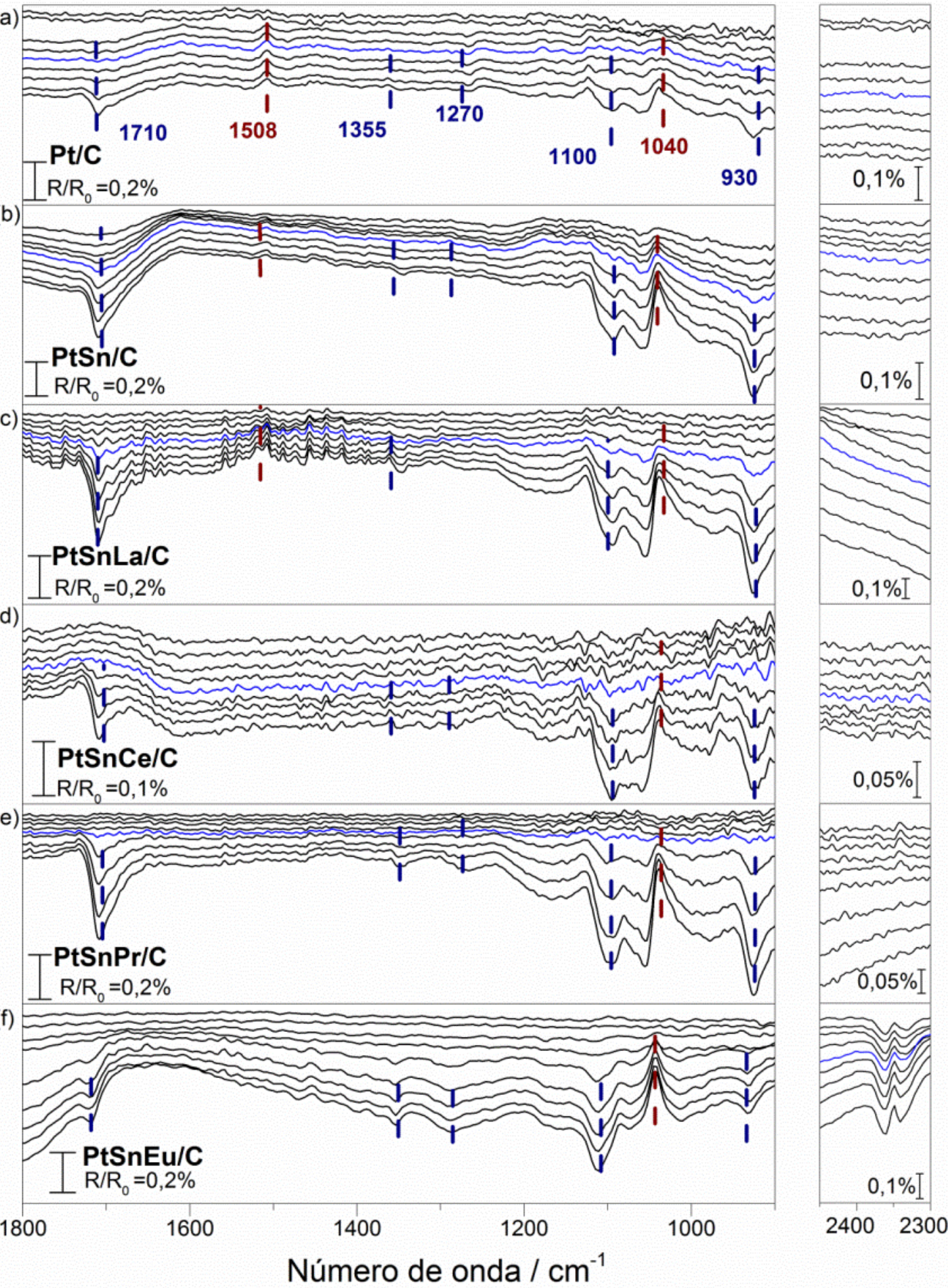

Fonte: Autoria própria. 
Ao comparar com os subprodutos observados para os catalisadores $\mathrm{Pt} / \mathrm{C} \mathrm{e}$ PtSn/C (Fig. 6.20), observa-se que poucas mudanças são observadas; apenas relacionadas ao potencial de início de aparecimento. Qualitativamente, a adição de terras raras auxiliou a ROE, mas sem alterar o mecanismo. A melhora da atividade catalítica se deve primariamente pela facilitação do mecanismo bifuncional, descrito na equação 5.17 já apresentada: ${ }^{54}$

$$
\mathrm{MO}_{\mathrm{x}}+\mathrm{H}_{2} \mathrm{O} \rightarrow \mathrm{MO}_{\mathrm{x}}-(\mathrm{OH})_{\mathrm{ad}}+\mathrm{e}^{-}+\mathrm{H}^{+}
$$

Para avaliar de forma mais quantitativa o efeito da adição do lantânio, cério e praseodímio, testes na configuração de célula unitária e a caracterização dos subprodutos por cromatografia líquida foram realizados.

\subsubsection{Testes em célula}

A caracterização eletroquímica dos catalisadores PtSnTR/C (TR: La, Ce e Pr) 75:20:05 também contemplou estudos em célula unitária, de forma a avaliar os materiais obtidos em uma configuração mais próxima das condições de operação de uma célula tipo DEFC. Para comparação, os dados obtidos para Pt/C, PtSn/C 60:40 e PtSnEu/C 75:20:05 foram reapresentados. Assim como para os catalisadores

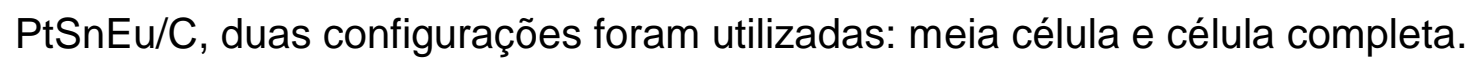

\subsubsection{Configuração de meia célula}

Nesta configuração, o cátodo de Pt/C (ETEK, 30\%) era abastecido de gás hidrogênio, agindo como um eletrodo reversível a hidrogênio; enquanto no ânodo, etanol $1,0 \mathrm{~mol} \mathrm{~L}^{-1}$ era recirculado. As voltametrias lineares para $\mathrm{ROE}$ a $90^{\circ} \mathrm{C}$ para os catalisadores PtSnTR/C (TR: La, Ce e Pr) 75:20:05 estão apresentadas na Figura 6.21a. Todos os catalisadores trimetálicos PtSnTR/C apresentaram menores potencial de onset e valores maiores de densidade de corrente que a $\mathrm{Pt} / \mathrm{C}$ no intervalo estudado. Ao comparar com os catalisadores $\mathrm{PtSn} / \mathrm{C} 60: 40$, observa-se que apenas os catalisadores PtSnEu/C 75:20:05 e PtSnLa/C 75:20:05 apresentaram densidades de correntes iguais ou superiores. As medidas de cronoamperometrias a 0,6 V estão apresentadas na Figura 6.21b. A mesma tendência da voltametria linear foi observada: aos 3600 segundos, os catalisadores PtSnEu/C $\left(41 \mathrm{~mA} \mathrm{~cm}{ }^{-2}\right)$ e 


\section{Resultados e Discussão: Catalisadores PtSnTR/C}

$\mathrm{PtSnLa} / \mathrm{C}\left(31 \mathrm{~mA} \mathrm{~cm}^{-2}\right.$ ) apresentaram maior densidade de corrente que $\mathrm{PtSn} / \mathrm{C}$ $\left(27 \mathrm{~mA} \mathrm{~cm}^{-2}\right)$. Logo em seguida, PtSnCe/C $\left(18 \mathrm{~mA} \mathrm{~cm}^{-2}\right)$ e PtSnPr/C $\left(14 \mathrm{~mA} \mathrm{~cm}{ }^{-2}\right)$ apresentaram densidades semelhantes, mas superiores a $\mathrm{Pt} / \mathrm{C}\left(8 \mathrm{~mA} \mathrm{~cm}{ }^{-2}\right)$.

Figura 6.21 - (a) Voltamogramas a $1 \mathrm{mV} \mathrm{s}^{-1} \mathrm{e}$ (b) cronoamperogramas em 0,600V para ROE dos catalisadores Pt/C, PtSn/C 60:40 e PtSnTR/C (TR:La, Ce, Pr e Eu) 75:20:05 a $90{ }^{\circ} \mathrm{C}$, solução de etanol $1 \mathrm{~mol} \mathrm{~L}^{-1}$. Densidades de corrente normalizadas pela área geométrica. Ânodo: $1 \mathrm{mg}_{\mathrm{Pt}} \mathrm{cm}^{-2}$. Cátodo: $30 \% \mathrm{Pt} / \mathrm{C}$, $1 \mathrm{mg}_{\mathrm{Pt}} \mathrm{cm}^{-2}$.

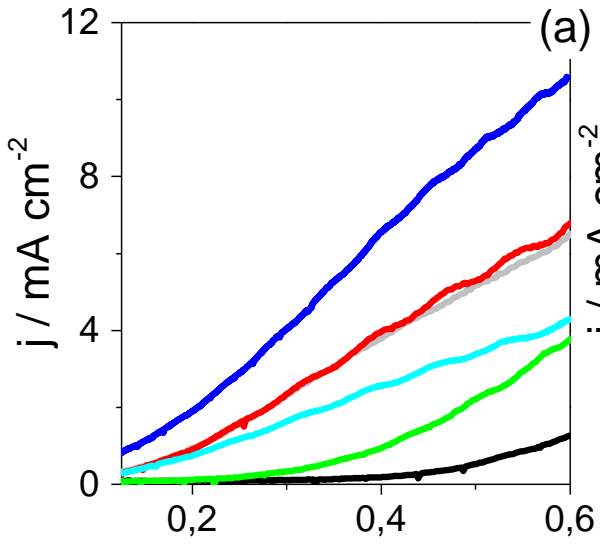

$\mathrm{E} / \mathrm{V}$

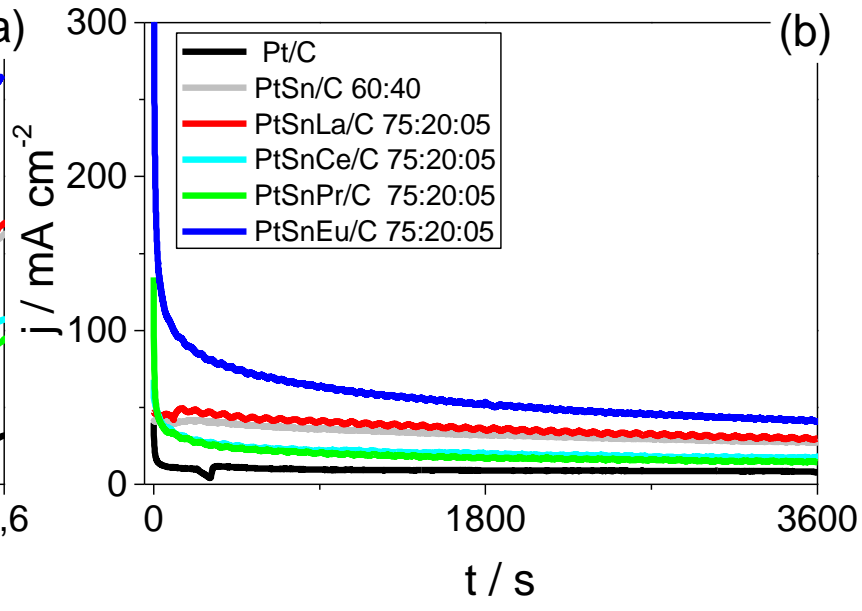

Fonte: Autoria própria.

\subsubsection{Configuração de célula completa}

Na configuração completa, o cátodo de Pt/C (ETEK, 30\%) era abastecido de gás oxigênio e o ânodo de etanol $1,0 \mathrm{~mol} \mathrm{~L}^{-1}$. As curvas de polarizações lineares para os catalisadores PtSnTR/C (TR: La, Ce, Pr e Eu) estão apresentadas na Figura 6.22. Os catalisadores ternários apresentaram densidades de corrente superiores a Pt/C no intervalo de potencial aplicado, confirmando que a adição de estanho e terras raras é benéfica para a oxidação de etanol. Ao comparar o catalisador binário $\mathrm{PtSn} / \mathrm{C}$ 60:40, apenas o catalisador PtSnPr/C 70:20:05 apresentou menores densidades de correntes no intervalo de diferença de potencial aplicado. A adição de lantânio, cério e európio, mesmo em baixas concentrações, melhoram a atividade catalítica do catalisador $\mathrm{PtSn} / \mathrm{C}$. Dentre os demais catalisadores trimetálicos, PtSnEu/C 75:20:05 apresentou maior densidade de corrente nas condições estudadas. 


\section{Resultados e Discussão: Catalisadores PtSnTR/C}

Figura 6.22 - Voltamogramas lineares em PEMFC de etanol direto para os catalisadores $\mathrm{Pt} / \mathrm{C}, \mathrm{PtSn} / \mathrm{C}$ 60:40 e PtSnTR/C (TR: La, Ce, Pr e Eu) sintetizados por poliol a $90 \stackrel{\circ}{-} \mathrm{C}$ e pressão 3 atm $\mathrm{O}_{2}$, solução de etanol $1 \mathrm{~mol} \mathrm{~L}^{-1}$. Ânodo: $1 \mathrm{mg}_{\mathrm{Pt}} \mathrm{cm}^{-2}$. Cátodo: $30 \% \mathrm{Pt} / \mathrm{C}, 1 \mathrm{mg}_{\mathrm{Pt}} \mathrm{cm}^{-2}$.

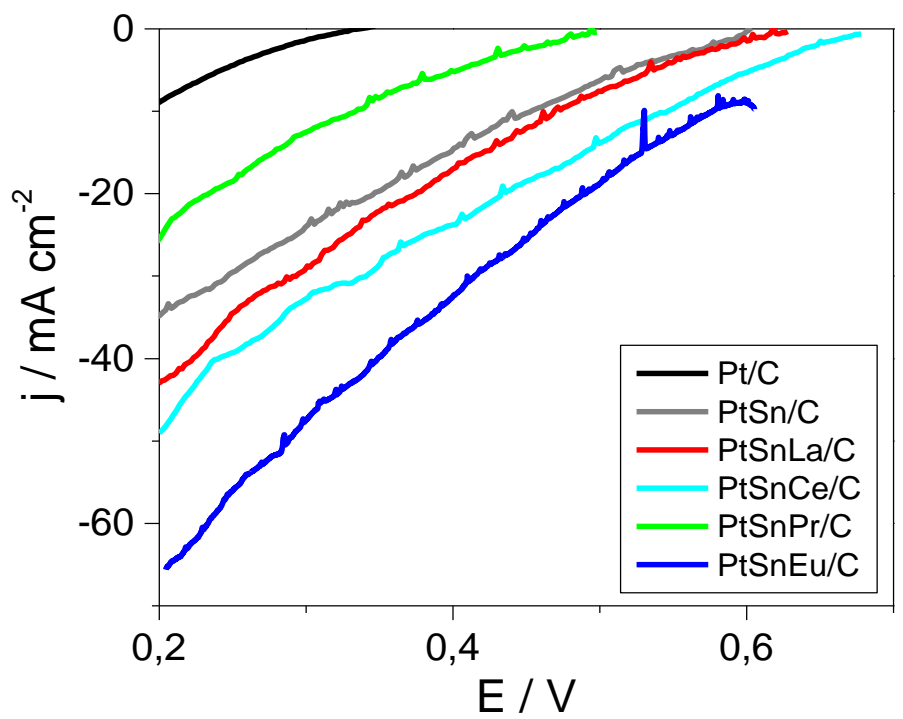

Fonte: Autoria própria.

A Figura 6.23 apresenta as curvas de densidade de potência e potencial em função da densidade de corrente dos catalisadores Pt/C, PtSn/C e PtSnTR/C (TR: $\mathrm{La}, \mathrm{Ce}, \operatorname{Pr}$ e Eu). Os catalisadores de PtSn/C, PtSnLa/C, PtSnCe/C e PtSnEu/C apresentam potencial de circuito aberto próximos a $0,65 \mathrm{~V}$, enquanto para os catalisadores $\mathrm{PtSnPr} / \mathrm{C}$ e $\mathrm{Pt} / \mathrm{C}$, o valor foi próximo de 0,5 V e 0,35 V, respectivamente. As densidades máximas de potências para os catalisadores

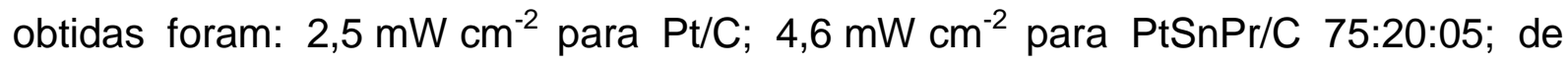
8,3 $\mathrm{mW} \mathrm{cm}^{-2}$ para $\mathrm{PtSn} / \mathrm{C}$; de 8,5 $\mathrm{mW} \mathrm{cm}^{-2}$ para PtSnCe/C 75:20:05; de $10 \mathrm{~mW} \mathrm{~cm}^{-2}$ para PtSnLa/C 75:20:05; e de $12 \mathrm{~mW} \mathrm{~cm}^{-2}$ para PtSnEu/C 75:20:05. 


\section{Resultados e Discussão: Catalisadores PtSnTR/C}

Figura 6.23 - Curvas de densidade de potência e potencial em função da densidade de corrente em PEMFC de etanol direto dos catalisadores Pt/C, PtSn/C 60:40 e $\mathrm{PtSnTR/C} \mathrm{(TR:} \mathrm{La,} \mathrm{Ce,} \mathrm{Pr} \mathrm{e} \mathrm{Eu)} \mathrm{75:20:05} \mathrm{a} 90 \stackrel{\circ}{ } \mathrm{C}$ e pressão $3 \mathrm{~atm} \mathrm{O}_{2}$, solução de etanol $1 \mathrm{~mol} \mathrm{~L}^{-1}$. Ânodo: $1 \mathrm{mg}_{\mathrm{Pt}} \mathrm{cm}^{-2}$. Cátodo: $30 \% \mathrm{Pt} / \mathrm{C}, 1 \mathrm{mg}_{\mathrm{Pt}} \mathrm{cm}^{-2}$.

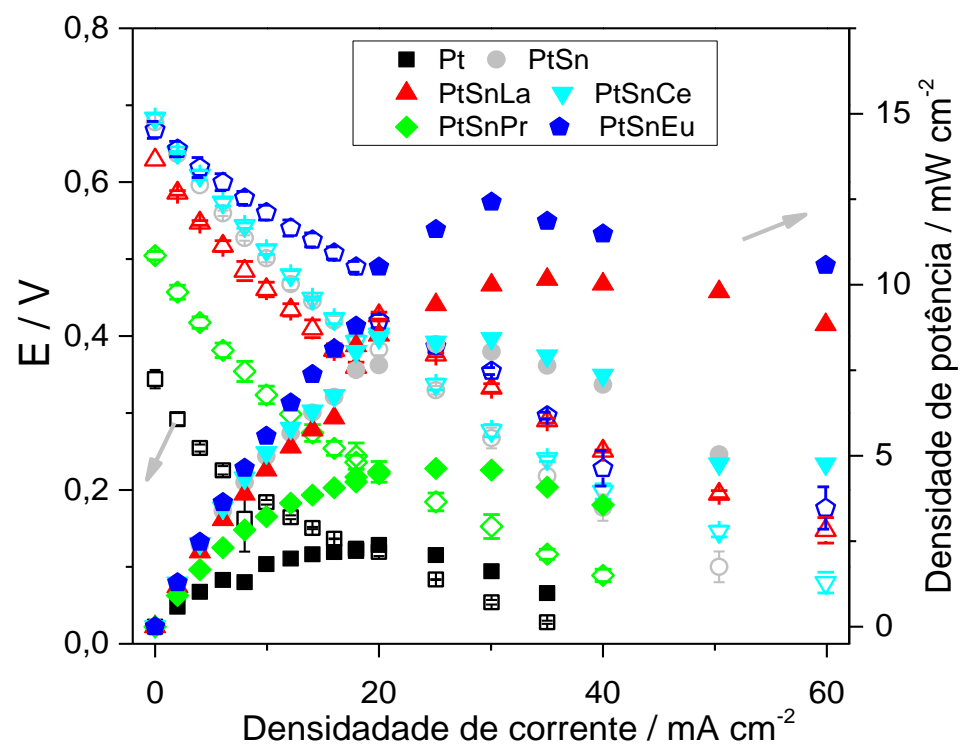

Fonte: Autoria própria.

Poucos estudos na literatura reportam a densidade de potência para materiais trimetálicos Pt-Sn-Terras Raras, mas Jacob et al. (2015) obtiveram valores de $14 \mathrm{~mW} \mathrm{~cm}^{-2}$, para ânodo de PtSnCe/C 60:20:20, obtidos pelo método do ácido fórmico e com carga metálica de $20 \%{ }^{54}$ Corradini obteve valores de $10 \mathrm{~mW} \mathrm{~cm}{ }^{-2}$ para catalisadores $\mathrm{PtSnPr} / \mathrm{C}$ 70:10:20, sintetizados pelo método do ácido fórmico. ${ }^{50}$ Os valores de densidade de potência obtidos foram neste trabalho foram menores ao reportado na literatura, mas comparando aos catalisadores $\mathrm{Pt} / \mathrm{C}$ e $\mathrm{PtSn} / \mathrm{C}$ obtidos pela mesmo método de síntese, observa-se o efeito benéfico dos terras raras.

\subsubsection{Caracterização dos subprodutos de etanol por cromatografia líquida de alta eficiência}

Os subprodutos da reação de oxidação de etanol dos catalisadores $\mathrm{PtSnLa} / \mathrm{C}$, $\mathrm{PtSnCe} / \mathrm{C}$ e PtSnPr/C foram avaliados por medidas de HPLC, acopladas a configuração de célula unitária. As coletas foram realizadas a $90^{\circ} \mathrm{C}$. Assim como para o conjunto de catalisadores $\mathrm{PtSnEu} / \mathrm{C}$, apenas detectou-se espécies de acetaldeído (AL), ácido acético (AA) e $\mathrm{CO}_{2}$. As curvas de calibração para cada produto estão no Apêndice II, Figura A1. 
A Tabela 6.7 reporta os resultados obtidos para as diferentes configurações utilizadas nas coletas, conforme descrito na seção 4.4.2. Os números de elétrons teóricos e experimentais foram calculados conforme o trabalho de Rousseau et al.

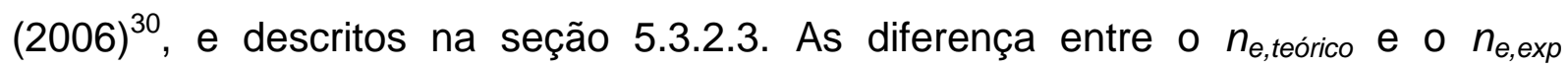
justificam-se principalmente por perdas nas coletas. Mas, considerando que a coleta foi semelhante para todos os materiais, determinou-se as concentrações dos produtos em forma relativa, para comparação dos catalisadores. Ao observar a concentração das espécies identificadas, observa-se que a conversão de etanol foi inferior a $20 \%$, visto que em todas as condições estudadas, a concentração de etanol ficou próxima ou superior a $0,85 \mathrm{~mol} \mathrm{~L}^{-1}$. A produção de ácido acético (AA) foram superiores a de acetaldeído (AL) para os catalisadores PtSnLa/C e PtSnCe/C, alcançando valores de $30 \mathrm{mmol} \mathrm{L}^{-1} \mathrm{em} 30 \mathrm{~mA} \mathrm{~cm}^{-2}$. Para $\mathrm{PtSnPr} / \mathrm{C}$, a formação de $A L$ superou a de $A A$, o que pode justificar as baixas densidades de corrente observadas para esse material. A produção de $\mathrm{CO}_{2}$ foi baixa para todos os catalisadores, indicando que a oxidação total do etanol não foi favorecida.

Para visualizar melhor a distribuição dos produtos obtidos para ROE, a Figura 6.24 apresenta a porcentagem de acetaldeído (AL), ácido acético $(\mathrm{AA})$ e $\mathrm{CO}_{2}$ para cada catalisador PtSnTR/C (TR: La, Ce, Pr) 75:20:05 nas diferentes configurações estudadas. Os dados de Pt/C, PtSn/C 60:40 e PtSnEu/C 75:20:05 foram reapresentados para comparação. Os catalisadores $\mathrm{PtSnLa} / \mathrm{C}$ (Fig. 6.24c) e PtSnCe/C (Fig. 6.24d) apresentaram maior formação de $A A$ do que $A L$ na configuração de célula completa, mas em meia célula a distribuição dos produtos majoritários inverteu. Esses materiais apresentaram o mesmo comportamento dos catalisadores Pt/C (Fig.6.24 a) e PtSn/C 60:40 (Fig. 6.24 b). Apesar de produzir $\mathrm{CO}_{2}$, principalmente em $16 \mathrm{~mA} \mathrm{~cm}^{-2}$, o produto majoritário do catalisador $\mathrm{PtSnPr} / \mathrm{C}$ 75:20:05 foi AL (Fig. 6.24 e) em todas as configurações, seguindo o comportamento do catalisador PtSnEu/C 75:20:05 (Fig. 6.24 e). 
Capíníulo_lv

Resultados e Discussão: Catalisadores PtSnTR/C

Tabela 6.7 - Características elétricas e as concentrações de acetaldeído (AL), ácido acético (AA) e $\mathrm{CO}_{2}$ formado durante a aplicação de 20 minutos em diferentes densidades de corrente, ou aplicação de um potencial fixo por 1 hora, em uma célula de $5 \mathrm{~cm}^{2}$, com cátodo de Pt/C Etek 30\% e ânodo PtSnTR (TR: La, Ce e Pr) com $1 \mathrm{mg}_{\mathrm{Pt}} \mathrm{cm}^{-2}$.

\begin{tabular}{|c|c|c|c|c|c|c|c|c|c|c|c|c|}
\hline \multirow[t]{2}{*}{ Catalisador } & \multirow[t]{2}{*}{$\mathrm{j}\left(\mathrm{mA} \mathrm{cm} \mathrm{cm}^{-2}\right)$} & \multirow[t]{2}{*}{$E_{\text {cel }}(V)$} & \multirow{2}{*}{$\begin{array}{l}n_{e, \text { teórico }} \\
\text { (mmol) }\end{array}$} & \multicolumn{4}{|c|}{ Concentração (mmol L $\left.{ }^{-1}\right)$} & \multirow{2}{*}{$\begin{array}{c}n_{e, \exp } \\
(\mathrm{mmol})\end{array}$} & \multirow{2}{*}{$\begin{array}{c}V_{\text {ânodo }} \\
\text { (mL) }\end{array}$} & \multicolumn{3}{|c|}{$\begin{array}{c}\text { Distribuição dos } \\
\text { produtos (\%) }\end{array}$} \\
\hline & & & & $\mathbf{A L}$ & $\mathbf{A A}$ & $\mathrm{CO}_{2}$ & EtOH & & & $A L$ & AA & $\mathrm{CO}_{2}$ \\
\hline \multirow{5}{*}{$\begin{array}{c}\text { PtSnLa } \\
75: 20: 05\end{array}$} & 8 & $0,489-0,532$ & 0,46 & 8 & 17 & 0,5 & 912 & 0,86 & \multirow{3}{*}{10} & 33 & 66 & 1 \\
\hline & 16 & $0,390-0,477$ & 0,92 & 10 & 23 & 0,7 & 872 & 1,15 & & 29 & 70 & 1 \\
\hline & 30 & $0,245-0,420$ & 1,73 & 13 & 30 & 1,0 & 855 & 1,48 & & 30 & 69 & 1 \\
\hline & \multirow{2}{*}{ Meia célula } & 0,500 & 6,28 & 14 & 16 & 0,6 & 876 & 2,35 & \multirow{2}{*}{25} & 49 & 51 & 0 \\
\hline & & 0,600 & 6,36 & 22 & 19 & 0,5 & 839 & 3,01 & & 53 & 46 & 0 \\
\hline \multirow{5}{*}{$\begin{array}{c}\text { PtSnCe } \\
75: 20: 05\end{array}$} & 8 & $0,490-0,552$ & 0,46 & 8 & 20 & 0,8 & 888 & 0,97 & \multirow{3}{*}{10} & 29 & 70 & 1 \\
\hline & 16 & $0,365-0,485$ & 0,92 & 10 & 24 & 0,8 & 862 & 1,19 & & 30 & 69 & 1 \\
\hline & 30 & $0,196-0,420$ & 1,73 & 16 & 30 & 0,8 & 834 & 1,56 & & 34 & 65 & 1 \\
\hline & \multirow{2}{*}{ Meia célula } & 0,500 & 4,04 & 14 & 10 & 2,1 & 883 & 1,79 & \multirow{2}{*}{25} & 57 & 42 & 2 \\
\hline & & 0,600 & 3,66 & 21 & 14 & 4,2 & 843 & 2,56 & & 58 & 39 & 2 \\
\hline \multirow{5}{*}{$\begin{array}{c}\text { PtSnPr } \\
75: 20: 05\end{array}$} & 8 & $0,288-0,366$ & 0,46 & 10 & 8 & 1,0 & 894 & 0,57 & \multirow{3}{*}{10} & 54 & 43 & 3 \\
\hline & 16 & $0,199-0,258$ & 0,92 & 13 & 10 & 1,4 & 845 & 0,72 & & 55 & 42 & 3 \\
\hline & 30 & $0,090-0,190$ & 1,73 & 20 & 14 & 1,4 & 823 & 0,99 & & 58 & 40 & 2 \\
\hline & \multirow{2}{*}{ Meia célula } & 0,500 & 1,97 & 15 & 2 & 5,0 & 893 & 1,10 & \multirow{2}{*}{25} & 84 & 10 & 5 \\
\hline & & 0,600 & 3,28 & 15 & 4 & 4,2 & 857 & 1,25 & & 78 & 18 & 4 \\
\hline
\end{tabular}




\section{Resultados e Discussão: Catalisadores PtSnTR/C}

Figura 6.24 - Distribuição dos produtos quantificados por HPLC dos catalisadores de (a) Pt/C; (b) PtSn/C 60:40; (c) PtSnLa/C 75:20:05; (d) PtSnCe/C 75:20:05; (e) $\mathrm{PtSnPr} / \mathrm{C}$ 75:20:05 (e) PtSnEu/C 75:20:05 em $8 \mathrm{~mA} \mathrm{~cm}{ }^{-2}, 16 \mathrm{~mA} \mathrm{~cm}^{-2} \mathrm{e}$ $30 \mathrm{~mA} \mathrm{~cm}^{-2}$ na configuração de célula completa; e em $0,5 \mathrm{~V}$ e $0,6 \mathrm{~V}$ na configuração de meia célula.

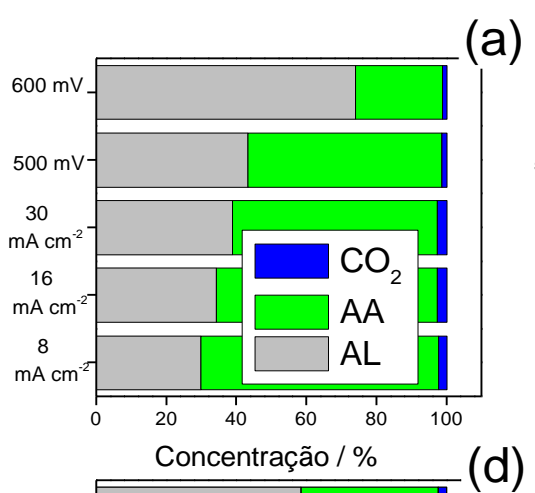

(a)

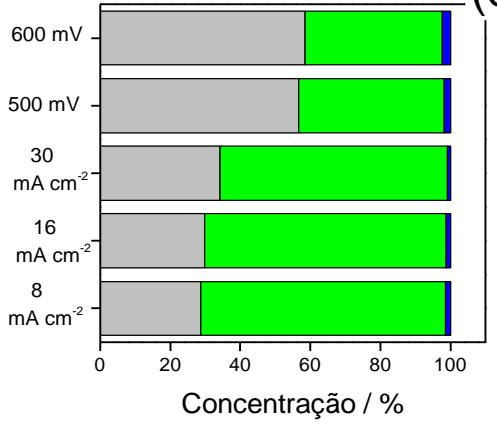

(d)

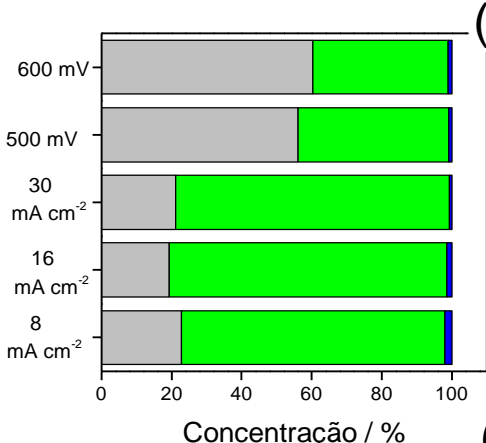

(b)
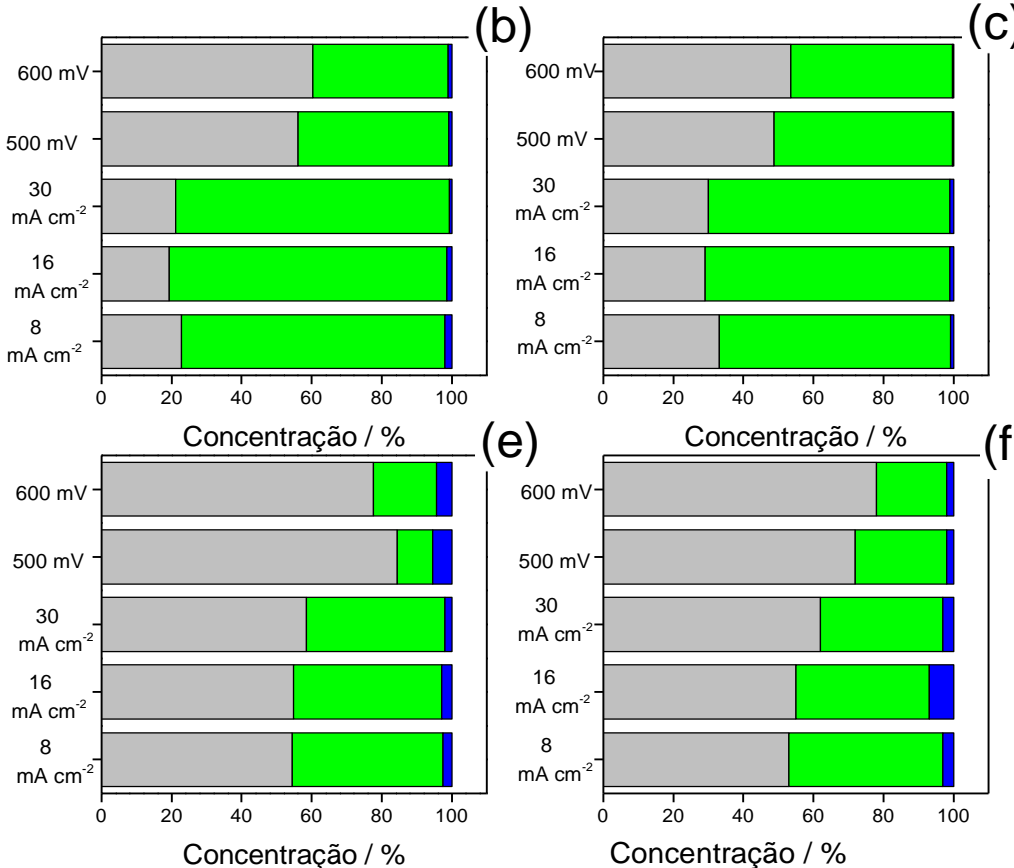

(e)

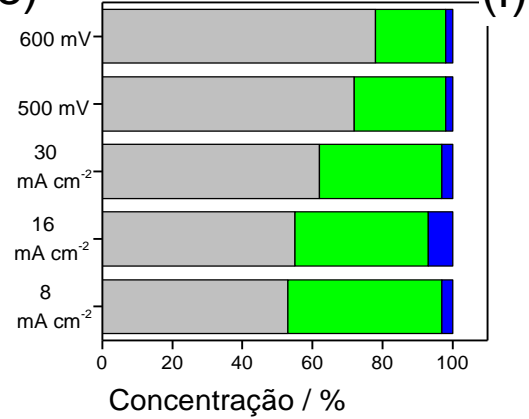

Fonte: Autoria própria.

A Figura 6.25 apresenta as concentrações dos produtos obtidos pelos diferentes catalisadores para uma mesma configuração experimental. Em $8 \mathrm{~mA} \mathrm{~cm}{ }^{-2}$ (Fig. $6.25 \mathrm{a}$ ), o catalisador que apresentou maior produção de $\mathrm{CO}_{2}$ foi $\mathrm{PtSnEu} / \mathrm{C}$ 75:20:05, enquanto PtSnCe 75:20:05 apresentou maior produção de AA. Para a densidade de corrente de $16 \mathrm{~mA} \mathrm{~cm}^{-2}$ (Fig. $6.25 \mathrm{~b}$ ), valor no qual a maioria dos catalisadores apresentou maior densidade de potência, os catalisadores apresentaram maior produção de AA, e o catalisador PtSnEu 75:20:05, apresentou maior produção de $\mathrm{CO}_{2}$. Em $30 \mathrm{~mA} \mathrm{~cm}^{-2}$, é possível observar a maior produção de $\mathrm{AL}$ para os catalisadores de $\mathrm{PtSnEu} / \mathrm{C}$ e $\mathrm{PtSnPr} / \mathrm{C}$, enquanto $\mathrm{PtSn} / \mathrm{C}, \mathrm{PtSnLa} / \mathrm{C}$ e $\mathrm{PtSnCe} / \mathrm{C}$ produzem majoritariamente AA (Fig. 6.25 c). Em meia célula, apesar de se observar a formação de $\mathrm{CO}_{2}$, a maior concentração de produto obtido para todos os catalisadores foi $\mathrm{AL}$, tanto em 0,5 V quanto em 0,6 V (Fig. $6.25 \mathrm{~d}$ e 6.25 e). 


\section{Resultados e Discussão: Catalisadores PtSnTR/C}

Figura 6.25 - Distribuição dos produtos quantificados por HPLC dos catalisadores de Pt/C, $\mathrm{PtSn} / \mathrm{C}$ 60:40 e PtSnTR/C (TR: La, Ce, Pr e Eu) na configuração de célula completa em (a) $8 \mathrm{~mA} \mathrm{~cm}^{-2}$, (b) $16 \mathrm{~mA} \mathrm{~cm}^{-2}$, (c) $30 \mathrm{~mA} \mathrm{~cm}^{-2}$ e em meia célula a (d) 0,5 V e (e) 0,6 V.

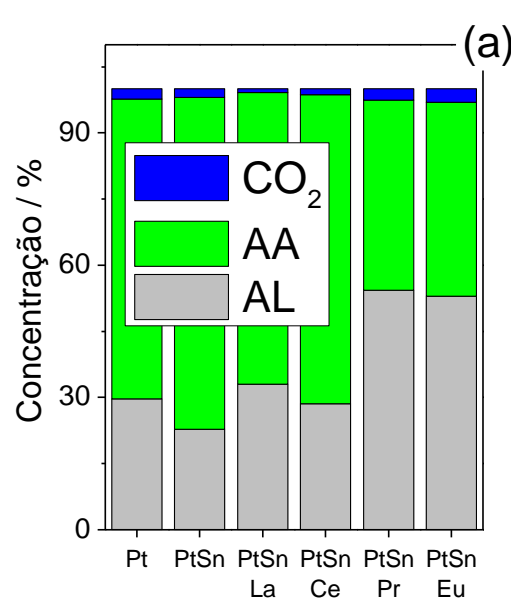

(a)

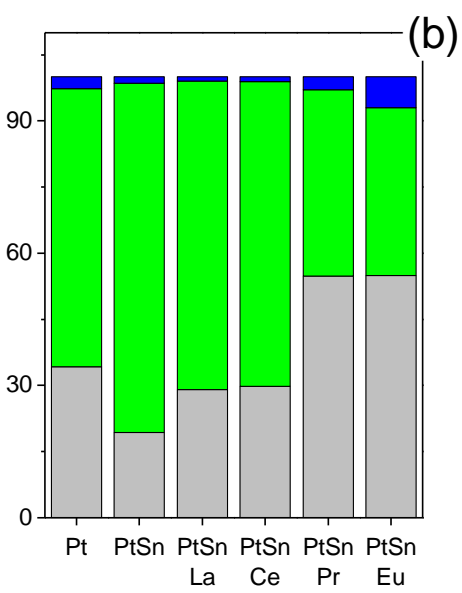

(b)
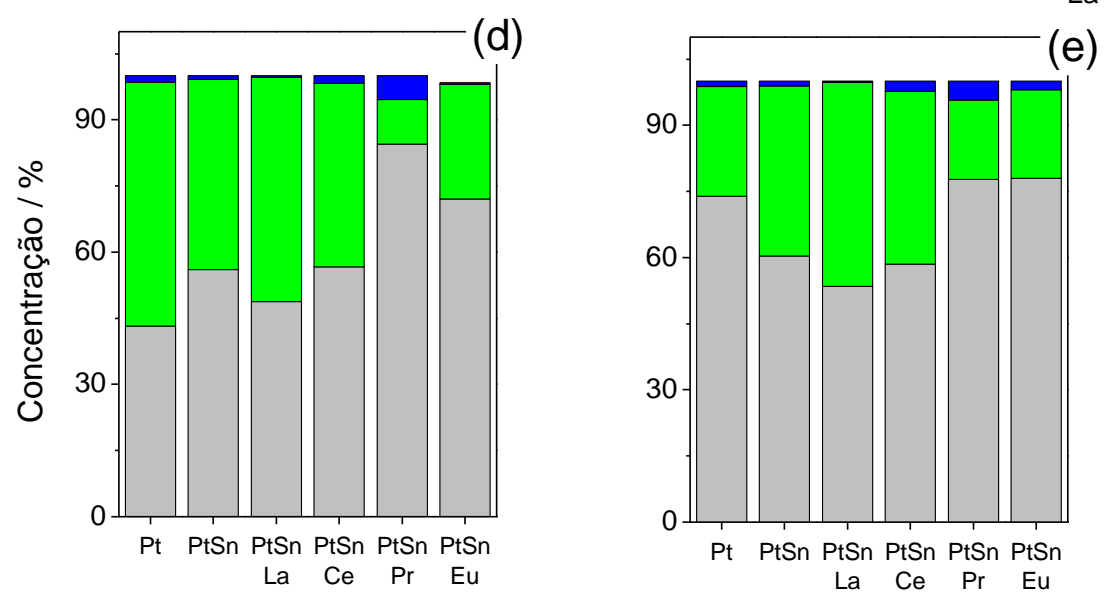

Fonte: Autoria própria.

A conversão de etanol a $\mathrm{CO}_{2}$ é bem baixa em DEFCs. Muitos trabalhos demonstram que $A L$ e $A A$ são os principais produtos de oxidação. ${ }^{24}$ As concentrações dos produtos individuais são um indício das vias de reação mais favorecidas e a eficácia dos catalisadores a promover a oxidação total do etanol. A energia correspondente a 2 elétrons é convertida durante a geração de moléculas simples $A L$, enquanto que 4 elétrons são convertidos na geração de moléculas $A A$. ${ }^{24}$ Os dados obtidos por HPLC confirmaram as medidas eletroquímicas, visto que a maior densidade de corrente observadas foi para o catalisador PtSnEu/C, com maior formação de $\mathrm{CO}_{2}$. Os catalisadores PtSn/C, PtSnLa/C, PtSnCe/C forneceram mais ácido acético, o que contribuiu para obtenção de maiores densidades de corrente que o catalisador $\mathrm{PtSnPr} / \mathrm{C}$, que produziu mais acetaldeído. Apesar da Pt/C ter 
Resultados e Discussão: Catalisadores PtSnTR/C

produzido mais $A A$, a baixa densidade de corrente observada foi a menor taxa de conversão do etanol, e não necessariamente pela distribuição de produtos formados.

Ao analisar as medidas de FTIR e os dados de HPLC, observou-se que as reações obtidas nos catalisadores trimetálicos $\mathrm{PtSnTR/C}$ podem ser resumidas pela Figura 6.26, proposto por Simões et al. (2007), para catalisadores de $\mathrm{PtSn} / \mathrm{C}^{124}$. A primeira reação assume que o etanol se adsorve na superfície de Pt (Passo 1) e pela dissociação de C-H, produz acetaldeído (Passo 2), que pode ir para a solução. Essa é aparentemente a via mais simples, e que talvez possa justificar os sinais mais intensos (e provavelmente maiores quantidades) de acetaldeído encontrado nas medidas. O acetaldeído pode ser readsorvido (Passo 3) e o intermediário adsorvido formado pode interagir com o OH adsorvido, tanto de espécies $\mathrm{Sn}-\mathrm{OH}_{\mathrm{ad}}$, como TR-OH $\mathrm{ad}_{\mathrm{ad}}$ e gerar ácido acético (Passo 4). ${ }^{124}$ Estas observações estão de acordo com o resultado do FTIR e HPLC, em que o ácido acético também é detectado. O ácido acético pode ser formado também seguindo os passos 5 e 6 , mas é aparentemente menos provável, visto que não foi detectados esses intermediários por FTIR.

Figura 6.26 - Esquema geral da oxidação do etanol em eletrocatalisadores Pt/C, PtSn/C e PtSnTR/C (TR: La, Ce, Pr e Eu)

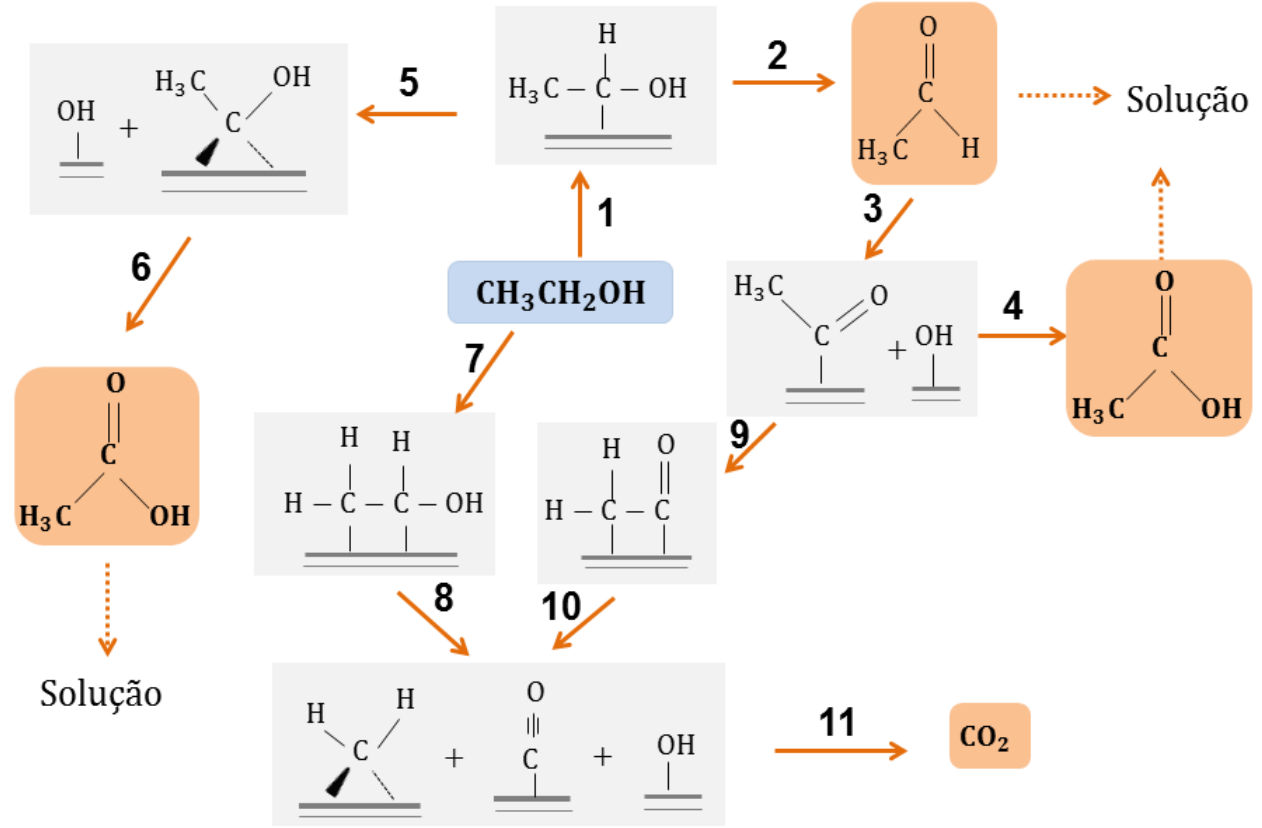

Fonte: Adaptado de SIMÕES F. C.; DOS ANJOS, D. M.; VIGIER, F.; LEGER, J. M.; HAHN, F.; COUTANCEAU, C.; GONZALEZ, E. R.; TREMILIOSI, G.; DE ANDRADE, A. R.; OLIVI; KOKOH, K. B. Journal of Power Sources. 167, 2007, p. $8 .{ }^{124}$ 


\section{Resultados e Discussão: Catalisadores PtSnTR/C}

A obtenção de $\mathrm{CO}_{2}$ pode ser explicada por duas sequências distintas, isto é, pelos passos 7 e 8 ou os passos 9 e 10, na Fig. 6. 26. A primeira hipótese implica que o etanol deve ser adsorvido pela ruptura da ligação $\mathrm{C}-\mathrm{H}$ em ambos os átomos de carbono, com seguido pela ruptura da ligação C-C. ${ }^{124}$ Não houve indícios que esta via seja tão favorecida, devido aos poucos sinais observados por FTIR de subprodutos $C_{1}$. A segunda hipótese, representados nos passos 9 e 10, implica na ruptura da ligação $\mathrm{C}-\mathrm{H}$ do intermediário formado após a adsorção de acetaldeído. As espécies de $\mathrm{CO}_{\text {ads }}$ podem reagir com $\mathrm{OH}$ adsorvido para formar $\mathrm{CO}_{2}$. Esta via é a mais aceita para catalisadores bimetálicos de $\mathrm{Pt}$, pois descreve o mecanismo de reação bifuncional. Apesar de não ter uma expressiva formação de $\mathrm{CO}_{2}$, como demonstrado pelas medidas de FTIR e HPLC, a sequência 9 e 10 descreve melhor como este produto pôde ser obtido. O principal papel dos terras raras na atividade eletrocatalítica seria fornecer espécies oxigenadas a baixos potenciais, e favorecer a permanência do estanho no catalisador, o que contribuiria para a estabilidades dos materiais bimetálicos. 


\section{CAPÍTULO V}

\section{CONCLUSÃO}

Pela síntese de poliol, foi possível obter catalisadores Pt/C, PtSn/C e PtSnTR/C (La, Ce, Pr e Eu) em forma de nanopartículas sobre o suporte de carbono. O método de síntese promoveu tamanhos médios de partícula entre 3,0 a 4,5 nm para catalisadores trimetálicos com terras raras, um dos menores valores reportados para esse tipo de material.

Os dados DRX indicaram deslocamentos aos picos característicos da estrutura cfc da Pt, devido provavelmente à formação de grau de liga entre PtSn, e quanto maior a concentração de estanho, maior a porcentagem ligada. Por XPS, foi possível confirmar a presença de Pt e Sn metálicos, óxidos de estanho e de platina e a presença de lantânio, cério, praseodímio e európio nos estados oxidados. Nas medidas de XAS, observou-se que a adição conjunta de estanho e os metais terras raras promoveu um preenchimento da banda $d$ da $\mathrm{Pt}$, comparado ao catalisador $\mathrm{Pt} / \mathrm{C}$ comercial.

Ao avaliar o efeito da adição de európio, observar-se que esse terra rara aumentou a atividade eletrocatalítica na eletro-oxidação do etanol da Pt/C e PtSn/C, quando adicionado em baixas concentrações (menor que 10\%). A caracterização eletroquímica indicou maior densidade de corrente de oxidação e menor potencial de início de oxidação para os materiais ternários comparado aos catalisadores $\mathrm{Pt} / \mathrm{C}$ e PtSn/C 60:40, tanto nos testes em célula de três eletrodos, como em célula unitária. Assim como o európio, a adição de lantânio e de cério também foi benéfica para o aumento da atividade eletrocatalítica de oxidação de etanol dos catalisadores $\mathrm{PtSn} / \mathrm{C}$.

Os testes de envelhecimento acelerado indicaram que, mesmo com a alteração dos perfis voltamétricos, os catalisadores ternários apresentaram maiores densidades de corrente após envelhecimento que os catalisadores $\mathrm{Pt} / \mathrm{C}$ e $\mathrm{PtSn} / \mathrm{C}$ sintetizados. Mesmo com a dissolução dos metais terras raras, observada pelos testes de EDX antes e após o envelhecimento dos catalisadores PtSnCe e PtSnPr 


\section{Capítulo V}

\section{Conclusão}

em meio ácido, a atividade frente a ROE após estabilidade é maior que a inicial. A adição destes metais promoveu a permanência do estanho no material, e contribuíram para a estabilidade do catalisador bimetálico.

Os produtos da oxidação dos catalisadores ternários foram avaliados qualitativamente por FTIR e HPLC, e os produtos majoritários foram acetaldeído e ácido acético, e apenas pequenas concentrações de $\mathrm{CO}_{2}$ foram detectadas. $\mathrm{A}$ melhora da eficiência na oxidação de etanol para os catalisadores PtSnTR/C pode ser justificada pelo efeito eletrônico, por enfraquecer a adsorção dos produtos intermediários na $\mathrm{Pt}$, e por favorecer o mecanismo bifuncional, visto que os óxidos de terras raras podem disponibilizar espécies oxigenadas em menores potenciais. 


\section{Perspectivas do Trabalho}

\section{PERSPECTIVAS DO TRABALHO}

Nesse trabalho foi possível observar que os catalisadores PtSnTR/C sintetizados por poliol apresentaram atividade eletrocatalítica para reação de oxidação de etanol em meio ácido. Mas, conforme as propriedades previstas pelos diagramas de Pourbaix dos metais terra raras estudados, talvez em meio básico os materiais sintetizados apresentassem melhores eficiências e estabilidade durante a ciclagem.

Alguns testes preliminares foram realizados durante o estágio no exterior, no Institut de Chimie des Milieux et Matériaux de Poitiers na Universidade de Poitiers (França). Catalisadores PtSnTR/C (TR: La, Ce, Pr e Eu) foram obtidos por outro método de síntese, conhecido como BAE (Bromide Anion Exchange) ${ }^{125}$ e testados para ROE em meio básico. Para o catalisador que apresentou maior atividade catalítica, PtSnCe/C, medidas de EDX antes e depois do envelhecimento acelerado foram realizados. A Figura 8.1 apresenta a variação da composição dos catalisadores $\mathrm{PtSnCe} / \mathrm{C}$ em meio básico, sem aplicação de potencial, e após ciclagem entre 0,3-0,8 vs $\mathrm{ERH}$, em $0,1 \mathrm{~mol} \mathrm{~L}^{-1}$ de $\mathrm{NaOH}$. Apesar de se observar algumas variações nas concentrações de estanho e platina durante os testes, observa-se que a concentração de cério se mantém constante.

Figura 8.1 - Comparação das composições atômicas determinadas por EDX do catalisador $\mathrm{PtSnCe} / \mathrm{C}$ obtido pelo método $\mathrm{BAE}$, antes e após envelhecimento eletroquímico até $0,8 \mathrm{~V}$.

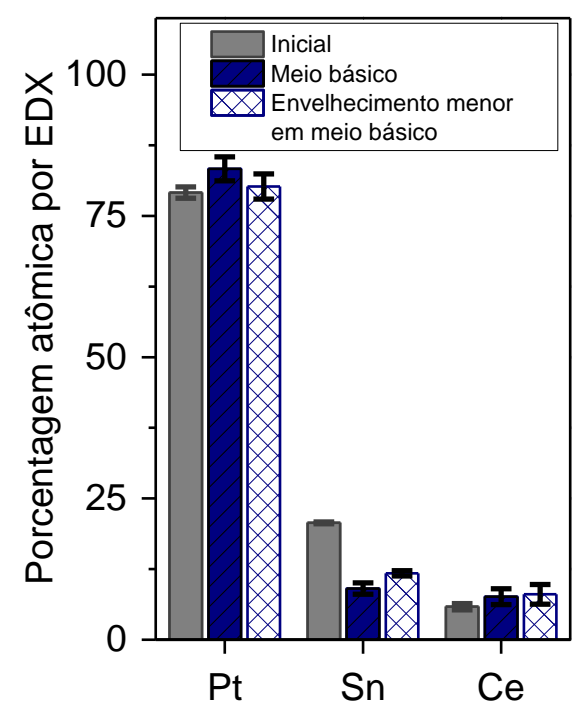

Fonte: Autoria própria. 


\section{Capítulo V}

\section{Perspectivas do Trabalho}

Outra proposta é estudar novas rotas de obtenção de catalisadores trimetálicos, que permitam incorporação do metal terra rara na rede cristalina da platina e estanho, e possibilitem avaliar como essas características influenciam a reação de oxidação de etanol. 


\section{REFERÊNCIAS BIBLIOGRÁFICAS}

1 ELMER, T.; WORALL, M.; WU, S. Y.; RIFFAT, S. B. Fuel cell technology for domestic built environment applications: State of-the-art review. Renewable \& Sustainable Energy Reviews, v. 42, p. 913-931, 2015.

2 BADWAL, S. P. S.; GIDDEY, S.; KULKARNI, A.; GOEL, J.; BASU, S. Direct ethanol fuel cells for transport and stationary applications - A comprehensive review. Applied Energy, v. 145, p. 80-103, 2015.

3 SHARAF, O. Z.; ORHAN, M. F. An overview of fuel cell technology: Fundamentals and applications. Renewable \& Sustainable Energy Reviews, v. 32, p. 810-853, 2014.

4 ABDULLAH, S.; KAMARUDIN, S. K.; HASRAN, U. A.; MASDAR, M. S.; DAUD, W. R. W. Modeling and simulation of a direct ethanol fuel cell: An overview. Journal of Power Sources, v. 262, p. 401-406, 2014.

5 YOSHIDA, T.; KOJIMA, K. Toyota MIRAI fuel cell vehicle and progress toward a future hydrogen society. Electrochemical Society Interface, v. 24, p. 45-49, 2015.

6 COLMATI, F.; ANTOLINI, E.; GONALEZ, E. R. Ethanol oxidation on carbon supported Pt-Sn electrocatalysts prepared by reduction with formic acid. Journal of the Electrochemical Society, v. 154, p. B39-B47, 2007.

7 ANTOLINI, E. Catalysts for direct ethanol fuel cells. Journal of Power Sources, v. 170, p. 1-12, 2007.

8 GODOI, D. R. M.; PEREZ, J.; VILLULLAS, H. M. Alloys and oxides on carbonsupported Pt-Sn electrocatalysts for ethanol oxidation. Journal of Power Sources, v. 195, p. 3394-3401, 2010.

9 ANTOLINI, E.; COLMATI, F.; GONZALEZ, E. R. Effect of Ru addition on the structural characteristics and the electrochemical activity for ethanol oxidation of carbon supported Pt-Sn alloy catalysts. Electrochemistry Communications, v. 9, p. 398-404, 2007. 
10 ANTOLINI, E.; ZIGNANI, S. C.; SANTOS, S. F.; GONZALEZ, E. R. Palladiumbased electrodes: A way to reduce platinum content in polymer electrolyte membrane fuel cells. Electrochimica Acta, v. 56, p. 2299-2305, 2011.

11 ANTOLINI, E.; PEREZ, J. The use of rare earth-based materials in lowtemperature fuel cells. International Journal of Hydrogen Energy, v. 36, p. 1575215765, 2011.

12 OLIVEIRA NETO, A.; WATANABE, A. Y.; RODRIGUES, R. M. D.; LINARDI, M.; FORBICINI, C. A. L. G. O.; SPINACE, E. V. Electrooxidation of ethanol using Pt rare earth-C electrocatalysts prepared by an alcohol reduction process. Ionics, v. 14, p. 577-581, 2008.

13 HE, Q.; MUKERJEE, S.; PARRES-ESCLAPEZ, S.; BUENO-LOPEZ, A. Effect of praseodymium oxide and cerium-praseodymium mixed oxide in the Pt electrocatalyst performance for the oxygen reduction reaction in PAFCs. Journal of Applied Electrochemistry, v. 41, p. 891-899, 2011.

14 LARMINIE, J.; DICKS, A. Fuel Cell Systems Explained. Chichester: Wiley, 2003. $428 \mathrm{p}$.

15 ZHANG, H.; SHEN, P. K. Recent development of polymer electrolyte membranes for fuel cells. Chemical Reviews, v. 112, p. 2780-2832, 2012.

16 ROWSHANZAMIR, S.; PEIGHAMBARDOUST, S. J.; AMJADI, M. Review of the proton exchange membranes for fuel cell applications. International Journal of Hydrogen Energy, v. 35, p. 9349-9384, 2010.

17 BUONOMENNA, M. G.; BAE, J. Membrane processes and renewable energies. Renewable \& Sustainable Energy Reviews, v. 43, p. 1343-1398, 2015.

18 MORENO, N. G.; MOLINA, M. C.; GERVASIO, D.; ROBLES, J. F. P. Approaches to polymer electrolyte membrane fuel cells (PEMFCs) and their cost. Renewable \& Sustainable Energy Reviews, v. 52, p. 897-906, 2015.

19 WANG, J. Y. Barriers of scaling-up fuel cells: Cost, durability and reliability. Energy, v. 80, p. 509-521, 2015.

20 ARICO, A. S.; SRINIVASAN, S.; ANTONUCCI, V. DMFCs: From Fundamental Aspects to Technology Development. Fuel Cells, v. 1, p. 133-161, 2001. 
21 WANG, Y.; ZOU, S. Z.; CAI, W. B. Recent advances on electro-oxidation of ethanol on Pt- and Pd-based catalysts: from reaction mechanisms to catalytic materials. Catalysts, v. 5, p. 1507-1534, 2015.

22 HITMI, H.; BELGSIR, E. M.; LÉGER, J. M.; LAMY, C.; LEZNA, R. O. A kinetic analysis of the electro-oxidation of ethanol at a platinum electrode in acid medium. Electrochimica Acta, v. 39, p. 407-415, 1994.

23 IWASITA, T.; PASTOR, E. A DEMS and FTIR spectroscopic investigation of adsorbed ethanol on polycrystalline platinum. Electrochimica Acta, v. 39, p. 531537, 1994.

24 KIM, I.; HAN, O. H.; CHAE, S. A.; PAIK, Y.; KWON, S.-H.; LEE, K.-S.; SUNG, Y.$\mathrm{E}$.; $\mathrm{KIM}, \mathrm{H}$. Catalytic reactions in direct ethanol fuel cells. Angewandte Chemie, v. 123, p. 2318-2322, 2011.

25 LAI, S. C. S.; KLEIJN, S. E. F.; OZTURK, F. T. Z.; VELLINGA, V. C. V.; KONING, J.; RODRIGUEZ, P.; KOPER, M. T. M. Effects of electrolyte $\mathrm{pH}$ and composition on the ethanol electro-oxidation reaction. Catalysis Today, v. 154, p. 92-104, 2010.

26 WANG, H. F.; LIU, Z. P. Comprehensive mechanism and structure-sensitivity of ethanol oxidation on platinum: New transition-state searching method for resolving the complex reaction network. Journal of the American Chemical Society, v. 130, p. 10996-11004, 2008.

27 TARNOWSKI, D. J.; KORZENIEWSKI, C. Effects of surface step density on the electrochemical oxidation of ethanol to acetic acid. Journal of Physical Chemistry B, v. 101, p. 253-258, 1997.

28 COLMATI, F.; TREMILIOSI-FILHO, G.; GONZALEZ, E. R.; BERNA, A.; HERRERO, E.; FELIU, J. M. Surface structure effects on the electrochemical oxidation of ethanol on platinum single crystal electrodes. Faraday Discussions, v. 140, p. 379-397, 2009.

29 FIGUEIREDO, M. C.; SOLLA-GULLON, J.; VIDAL-IGLESIAS, F. J.; NISULA, M.; FELIU, J. M.; KALLIO, T. Carbon-supported shape-controlled Pt nanoparticle electrocatalysts for direct alcohol fuel cells. Electrochemistry Communications, v. 55, p. 47-50, 2015.

30 ROUSSEAU, S.; COUTANCEAU, C.; LAMY, C.; LEGER, J. M. Direct ethanol fuel cell (DEFC): Electrical performances and reaction products distribution under operating conditions with different platinum-based anodes. Journal of Power Sources, v. 158, p. 18-24, 2006. 
31 WANG, Y. X.; MI, Y. J.; REDMON, N.; HOLIDAY, J. Understanding electrocatalytic activity enhancement of bimetallic particles to ethanol electrooxidation: water adsorption and decomposition on $\mathrm{Pt}_{n} \mathrm{M}(\mathrm{n}=2,3$, and 9; $\mathrm{M}=\mathrm{Pt}, \mathrm{Ru}$, and Sn). Journal of Physical Chemistry C, v. 114, p. 317-326, 2010.

32 HAMMER, B.; NORSKOV, J. K. Theoretical surface science and catalysiscalculations and concepts. In GATES, B.; KNOEZINGER, H. (Ed.). Advances in catalysis. San Diego: Academic Press, 2000. v. 45, p. 71-129.

33 NORSKOV, J. K.; BLIGAARD, T.; ROSSMEISL, J.; CHRISTENSEN, C. H. Towards the computational design of solid catalysts. Nature Chemistry, v. 1, p. 3746, 2009.

34 HERRERO, E.; LI, J.; ABRUNA, H. D. Electrochemical, in-situ surface EXAFS and CTR studies of Co monolayers irreversibly adsorbed onto $\mathrm{Pt}(111)$. Electrochimica Acta, v. 44, p. 2385-2396, 1999.

35 VILLULLAS, H. M.; GODOI, D. R. M.; PEREZ, J. Effects of alloyed and oxide phases on methanol oxidation of Pt-Ru/C nanocatalysts of the same particle size. Journal of Physical Chemistry C, v. 113, p. 8518-8525, 2009.

36 ZHOU, W. J.; ZHOU, Z. H.; SONG, S. Q.; LI, W. Z.; SUN, G. Q.; TSIAKARAS, P.; XIN, Q. Pt based anode catalysts for direct ethanol fuel cells. Applied Catalysis B, v. 46, p. 273-285, 2003.

37 JIANG, L.; SUN, G.; SUN, S.; LIU, J.; TANG, S.; LI, H.; ZHOU, B.; XIN, Q. Structure and chemical composition of supported Pt-Sn electrocatalysts for ethanol oxidation. Electrochimica Acta, v. 50, p. 5384-5389, 2005.

38 JIANG, L.; COLMENARES, L.; JUSYS, Z.; SUN, G. Q.; BEHM, R. J. Ethanol electrooxidation on novel carbon supported $\mathrm{Pt} / \mathrm{SnOx} / \mathrm{C}$ catalysts with varied $\mathrm{Pt}: \mathrm{Sn}$ ratio. Electrochimica Acta, v. 53, p. 377-389, 2007.

39 ALONSO, E.; SHERMAN, A. M.; WALLINGTON, T. J.; EVERSON, M. P.; FIELD, F. R.; ROTH, R.; KIRCHAIN, R. E. Evaluating rare earth element availability: A case with revolutionary demand from clean technologies. Environmental Science \& Technology, v. 46, p. 3406-3414, 2012.

$40 \mathrm{CHEN}, \mathrm{Z}$. H. Global rare earth resources and scenarios of future rare earth industry. Journal of Rare Earths, v. 29, p. 1-6, 2011. 
41 DUTTA, T.; KIM, K. H.; UCHIMIYA, M.; KWON, E. E.; JEON, B. H.; DEEP, A.; YUN, S. T. Global demand for rare earth resources and strategies for green mining. Environmental Research, v. 150, p. 182-190, 2016.

42 TAKEHARA, L.; SILVEIRA, F. V.; SANTOS, R. V. Potentiality of rare earth elements in Brazil. In LEAL FILHO, W. (Ed.). Rare earths industry. Boston: Elsevier, 2016. p. 57-72.

43 ZHAN, W. C.; GUO, Y.; GONG, X. Q.; GUO, Y. L.; WANG, Y. Q.; LU, G. Z. Current status and perspectives of rare earth catalytic materials and catalysis. Chinese Journal of Catalysis, v. 35, p. 1238-1250, 2014.

44 WANG, Y.; NGUYEN, T. S.; WANG, C.; WANG, X. Ethanol electrooxidation on $\mathrm{Pt} / \mathrm{C}$ catalysts promoted with praseodymium oxide nanorods. Dalton Transactions, v. 37, p. 7606-7609, 2009.

45 DE SOUZA, R. F. B.; FLAUSINO, A. E. A.; RASCIO, D. C.; OLIVEIRA, R. T. S.; NETO, E. T.; CALEGARO, M. L.; SANTOS, M. C. Ethanol oxidation reaction on $\mathrm{PtCeO}_{2} / \mathrm{C}$ electrocatalysts prepared by the polymeric precursor method. Applied Catalysis B, v. 91, p. 516-523, 2009.

46 RODRIGUES, R. M. S.; TUSI, M. M.; CHIKASAWA, M. H.; FORBICINI, C. A. L. G. O.; LINARDI, M.; SPINACE, E. V.; OLIVEIRA NETO, A. Preparation and characterization of $\mathrm{PtRu} / \mathrm{C}$-rare earth using an alcohol-reduction process for ethanol electro-oxidation. Ionics, v. 17, p. 189-193, 2011.

47 OLIVEIRA NETO, A.; FARIAS, L. A.; DIAS, R. R.; BRANDALISE, M.; LINARDI, M.; SPINACE, E. V. Enhanced electro-oxidation of ethanol using $\mathrm{PtSn} / \mathrm{CeO}_{2}-\mathrm{C}$ electrocatalyst prepared by an alcohol-reduction process. Electrochemistry Communications, v. 10, p. 1315-1317, 2008.

48 CORRADINI, P. G.; SANTOS, N. A.; SILVA, G. C.; PEREZ, J. Pt-rare earth catalysts for ethanol electrooxidation: modification of polyol synthesis. Journal of Solid State Electrochemistry, v. 20, p. 2581-2587, 2016.

49 WANG, F.; ZHENG, Y.; GUO, Y. The promoting effect of europium on PtSn/C catalyst for ethanol oxidation. Fuel Cells, v. 10, p. 1100-1107, 2010.

50 CORRADINI, P. G. Efeito da adição de praseodímio em catalisadores de Pt e PtSn/C para eletro-oxidação de etanol. 2012. 117 f. Dissertação (Mestrado em Físico-Química) -Instituto de Química de São Carlos, Universidade de São Paulo, São Carlos, 2012. 
51 CORRADINI, P. G.; ANTOLINI, E.; PEREZ, J. Activity, short-term stability (poisoning tolerance) and durability of carbon supported Pt-Pr catalysts for ethanol oxidation. Journal of Power Sources, v. 251, p. 402-410, 2014.

52 CORRADINI, P. G.; ANTOLINI, E.; PEREZ, J. Electro-oxidation of ethanol on ternary non-alloyed Pt-Sn-Pr/C catalysts. Journal of Power Sources, v. 275, p. 377383, 2015.

53 JACOB, J. M. Efeito da adição de cério em catalisadores $\mathbf{P t} / \mathbf{C}$ e $\mathbf{P t S n} / \mathbf{C}$ para eletro-oxidação de etanol. 2014. 80 f. Dissertação (Mestrado em Físico-Química) Instituto de Química de São Carlos, Universidade de São Paulo, São Carlos, 2014.

54 JACOB, J. M.; CORRADINI, P. G.; ANTOLINI, E.; SANTOS, N. A.; PEREZ, J. Electro-oxidation of ethanol on ternary Pt-Sn-Ce/C catalysts. Applied Catalysis B, v. 165, p. 176-184, 2015.

55 FIEVET, F.; LAGIER, J. P.; FIGLARZ, M. Preparing monodisperse metal powders in micrometer and submicrometer sizes by polyol process. MRS Bulletin, v. 1, p. 2934, 1989.

56 SUN, S.; MURRAY, C. B.; WELLER, D.; FOLKS, L.; MOSER, A. Monodisperse FePt nanoparticles and ferromagnetic FePt nanocrystal superlattices. Science, v. 287, p. 1989-1992, 2000.

57 DONIACH, S.; SUNJIC, M. Many-Electron Singularity in X-Ray Photoemission and X-Ray Line Spectra from Metals. Journal of Physics Part C Solid State Physics, v. 3, p. 285-\&, 1970.

58 MOULDER, J. F.; CHASTAIN, J. Handbook of X-ray photoelectron spectroscopy: A reference book of standard spectra for identification and interpretation of XPS data. Minnesota: Perkin-Elmer Corporation, 1992. 254 p.

59 SARMA, D. D.; RAO, C. N. R. XPES studies of oxides of $2^{\text {nd }}$ row and $3^{\text {rd }}$ row transition-metals including rare-earths. Journal of Electron Spectroscopy and Related Phenomena, v. 20, p. 25-45, 1980.

60 TOlentinO, H. C. N.; RAMOS, A. Y.; ALVES, M. C. M.; BARREA, R. A.; TAMURA, E.; CEZAR, J. C.; WATANABE, N. A 2.3 to $25 \mathrm{keV}$ XAS beamline at LNLS. Journal of Synchrotron Radiation, v. 8, p. 1040-1046, 2001. 
61 O'GRADY, W. E.; HAGANS, P. L.; PANDYA, K. I.; MARICLE, D. L. Structure of $\mathrm{Pt} / \mathrm{Ru}$ catalysts using X-ray absorption near edge structure studies. Langmuir, v. 17, p. 3047-3050, 2001.

62 RAVEL, B.; NEWVILLE, M. ATHENA,ARTEMIS,HEPHAESTUS: data analysis for $X$-ray absorption spectroscopy using IFEFFIT. Journal of Synchrotron Radiation, v. 12, p. 537, 2005.

63 CIAPINA, E. G.; TICIANELLI, E. A. The effect of electrochemical CO annealing on platinum-cobalt nanoparticles in acid medium and their correlation to the oxygen reduction reaction. Electrochimica Acta, v. 58, p. 172-178, 2011.

64 MALHEIRO, A. R.; PEREZ, J.; VILLULLAS, H. M. Surface structure and electronic properties of $\mathrm{Pt}-\mathrm{Fe} / \mathrm{C}$ nanocatalysts and their relation with catalytic activity for oxygen reduction. Journal of Power Sources, v. 195, p. 3111-3118, 2010.

65 PAGANIN, V. A.; TICIANELLI, E. A.; GONZALEZ, E. R. Development and electrochemical studies of gas diffusion electrodes for polymer electrolyte fuel cells. Journal of Applied Electrochemistry, v. 26, p. 297-304, 1996.

66 IWASITA, T.; NART, F. C. In situ infrared spectroscopy at electrochemical interfaces. Progress in Surface Science, v. 55, p. 271-340, 1997.

67 SUN, S. Recent advances in chemical synthesis, self-assembly, and applications of FePt nanoparticles. Advanced Materials, v. 18, p. 393-403, 2006.

68 CORRADINI, P. G.; ANTOLINI, E.; PEREZ, J. Structural and electrochemical characterization of carbon supported Pt-Pr catalysts for direct ethanol fuel cells prepared using a modified formic acid method in a $\mathrm{CO}$ atmosphere. Physical Chemistry Chemical Physics, v. 15, p. 11730-11739, 2013.

69 HOLADE, Y.; MORAIS, C.; ARRII-CLACENS, S.; SERVAT, K.; NAPPORN, T. W.; $\mathrm{KOKOH}, \mathrm{K}$. B. New preparation of $\mathrm{PdNi} / \mathrm{C}$ and $\mathrm{PdAg} / \mathrm{C}$ nanocatalysts for glycerol electrooxidation in alkaline medium. Electrocatalysis, v. 4, p. 167-178, 2013.

70 LIM, D. H.; CHOI, D. H.; LEE, W. D.; LEE, H. I. A new synthesis of a highly dispersed and $\mathrm{CO}$ tolerant $\mathrm{PtSn} / \mathrm{C}$ electrocatalyst for low-temperature fuel cell; its electrocatalytic activity and long-term durability. Applied Catalysis B, v. 89, p. 484493, 2009. 
71 ZHU, M. Y.; SUN, G. Q.; XIN, Q. Effect of alloying degree in PtSn catalyst on the catalytic behavior for ethanol electro-oxidation. Electrochimica Acta, v. 54, p. 15111518, 2009.

72 TAYAL, J.; RAWAT, B.; BASU, S. Bi-metallic and tri-metallic Pt-Sn/C, Pt-Ir/C, PtIr-Sn/C catalysts for electro-oxidation of ethanol in direct ethanol fuel cell.

International Journal of Hydrogen Energy, v. 36, p. 14884-14897, 2011.

73 WARREN, B. E. X-ray diffraction methods. Journal of Applied Physics, v. 12, p. 375-384, 1941.

74 KIM, J. H.; CHOI, S. M.; NAM, S. H.; SEO, M. H.; CHOI, S. H.; KIM, W. B. Influence of $\mathrm{Sn}$ content on PtSn/C catalysts for electrooxidation of $\mathrm{C}_{1}-\mathrm{C}_{3}$ alcohols: Synthesis, characterization, and electrocatalytic activity. Applied Catalysis B, v. 82, p. 89-102, 2008.

75 ZHENG, X. J.; LI, J. Y.; ZHOU, Y. C. X-ray diffraction measurement of residual stress in PZT thin films prepared by pulsed laser deposition. Acta Materialia, v. 52, p. 3313-3322, 2004.

76 IANDELLI, A.; PALENZONA, A. The phase-diagram of the Eu-Pt system and the valency behavior of europium and ytterbium intermetallics with platinum. Journal of the Less-Common Metals, v. 80, p. 71-82, 1981.

77 LIU, L.; LI, C.; WANG, F.; DU, Z.; ZHANG, W. Thermodynamic assessment of the Eu-Sn system. Journal of Alloys and Compounds, v. 379, p. 148-153, 2004.

78 DE SOUZA, R. F. B.; PARREIRA, L. S.; RASCIO, D. C.; SILVA, J. C. M.; TEIXEIRA-NETO, E.; CALEGARO, M. L.; SPINACE, E. V.; NETO, A. O.; SANTOS, M. C. Study of ethanol electro-oxidation in acid environment on $\mathrm{Pt}_{3} \mathrm{Sn} / \mathrm{C}$ anode catalysts prepared by a modified polymeric precursor method under controlled synthesis conditions. Journal of Power Sources, v. 195, p. 1589-1593, 2010.

79 DURUSSEL, P.; MASSARA, R.; FESCHOTTE, P. The binary-system Pt-Sn. Journal of Alloys and Compounds, v. 215, p. 175-179, 1994.

80 HOHEISEL, M.; SPELLER, S.; KUNTZE, J.; ATREI, A.; BARDI, U.; HEILAND, W. Structure of $\mathrm{Pt}_{3} \mathrm{Sn}(110)$ studied by scanning tunneling microscopy. Physical Review B, v. 63, p. 245403, 2001. 
81 CORCORAN, C. J.; TAVASSOL, H.; RIGSBY, M. A.; BAGUS, P. S.; WIECKOWSKI, A. Application of XPS to study electrocatalysts for fuel cells. Journal of Power Sources, v. 195, p. 7856-7879, 2010.

82 GODOI, D. R. M.; PEREZ, J.; VILLULLAS, H. M. Effects of alloyed and oxide phases on methanol oxidation of $\mathrm{Pt}-\mathrm{Ru} / \mathrm{C}$ nanocatalysts of the same particle size. The Journal of Physical Chemistry C, v. 113, p. 8518-8525, 2009.

83 MERCIER, F.; ALLIOT, C.; BION, L.; THROMAT, N.; TOULHOAT, P. XPS study of Eu(III) coordination compounds: Core levels binding energies in solid mixed-oxocompounds $\mathrm{Eu}_{\mathrm{m}} \mathrm{X}_{\mathrm{x}} \mathrm{O}_{\mathrm{y}}$. Journal of Electron Spectroscopy and Related Phenomena, v. 150, p. 21-26, 2006.

84 HASSAN, A.; PAGANIN, V. A.; CARRERAS, A.; TICIANELLI, E. A. Molybdenum carbide-based electrocatalysts for $\mathrm{CO}$ tolerance in proton exchange membrane fuel cell anodes. Electrochimica Acta, v. 142, p. 307-316, 2014.

85 BEYHAN, S.; COUTANCEAU, C.; LEGER, J. M.; NAPPORN, T. W.; KADIRGAN, F. Promising anode candidates for direct ethanol fuel cell: Carbon supported PtSnbased trimetallic catalysts prepared by Bonnemann method. International Journal of Hydrogen Energy, v. 38, p. 6830-6841, 2013.

86 PARREIRA, L. S.; DA SILVA, J. C. M.; D'VILLA -SILVA, M.; SIMOES, F. C.; GARCIA, S.; GAUBEUR, I.; CORDEIRO, M. A. L.; LEITE, E. R.; DOS SANTOS, M. C. PtSnNi/C nanoparticle electrocatalysts for the ethanol oxidation reaction: $\mathrm{Ni}$ stability study. Electrochimica Acta, v. 96, p. 243-252, 2013.

87 FRELINK, T.; VISSCHER, W.; VANVEEN, J. A. R. On the role of Ru and Sn as promoters of methanol electrooxidation over Pt. Surface Science, v. 335, p. 353360, 1995.

88 GALLAGHER, M. E.; LUCAS, C. A.; STAMENKOVIC, V.; MARKOVIC, N. M.; ROSS, P. N. Surface structure and relaxation at the $\mathrm{Pt}_{3} \mathrm{Sn}(111) /$ electrolyte interface. Surface Science, v. 544, p. 729-734, 2003.

89 LIU, Y.; LI, D. G.; STAMENKOVIC, V. R.; SOLED, S.; HENAO, J. D.; SUN, S. H. Synthesis of $\mathrm{Pt}_{3} \mathrm{Sn}$ alloy nanoparticles and their catalysis for electro-oxidation of $\mathrm{CO}$ and methanol. Acs Catalysis, v. 1, p. 1719-1723, 2011.

90 MURTHY, A.; MANTHIRAM, A. Application of derivative voltammetry in the analysis of methanol oxidation reaction. The Journal of Physical Chemistry C, $\mathrm{V}$. 116, p. 3827-3832, 2012. 
$91 \mathrm{LI}$, Y. S.; ZHAO, T. S. Understanding the performance degradation of anionexchange membrane direct ethanol fuel cells. International Journal of Hydrogen Energy, v. 37, p. 4413-4421, 2012.

92 SPEDER, J.; ZANA, A.; SPANOS, I.; KIRKENSGAARD, J. J. K.; MORTENSEN, K.; HANZLIK, M.; ARENZ, M. Comparative degradation study of carbon supported proton exchange membrane fuel cell electrocatalysts - The influence of the platinum to carbon ratio on the degradation rate. Journal of Power Sources, v. 261, p. 14-22, 2014.

93 LINSE, N.; SCHERER, G. G.; WOKAUN, A.; GUBLER, L. Quantitative analysis of carbon corrosion during fuel cell start-up and shut-down by anode purging. Journal of Power Sources, v. 219, p. 240-248, 2012.

94 PARK, Y. C.; KAKINUMA, K.; UCHIDA, M.; TRYK, D. A.; KAMINO, T.; UCHIDA, $\mathrm{H}$.; WATANABE, M. Investigation of the corrosion of carbon supports in polymer electrolyte fuel cells using simulated start-up/shutdown cycling. Electrochimica Acta, v. 91, p. 195-207, 2013.

95 ZHANG, S. S.; YUAN, X. Z.; HIN, J. N. C.; WANG, H. J.; FRIEDRICH, K. A.; SCHULZE, M. A review of platinum-based catalyst layer degradation in proton exchange membrane fuel cells. Journal of Power Sources, v. 194, p. 588-600, 2009.

96 CHEREVKO, S.; KULYK, N.; MAYRHOFER, K. J. J. Durability of platinum-based fuel cell electrocatalysts: Dissolution of bulk and nanoscale platinum. Nano Energy, v. 29, p. 275-298, 2016.

97 JUNG, D. H.; BAE, S. J.; KIM, S. J.; NAHM, K. S.; KIM, P. Effect of the Pt precursor On the morphology and catalytic performance of Pt-impregnated on $\mathrm{Pd} / \mathrm{C}$ for the oxygen reduction reaction in polymer electrolyte fuel cells. International Journal of Hydrogen Energy, v. 36, p. 9115-9122, 2011.

98 LYON, S. B. Corrosion of Tin and its Alloys. In BRITTON, C. S. (Ed.). Shreir's Corrosion. Oxford: Elsevier, 2010. v. 1, p. 2068-2077.

99 ZIGNANI, S. C.; BAGLIO, V.; LINARES, J. J.; MONFORTE, G.; GONZALEZ, E. R.; ARICO, A. S. Endurance study of a solid polymer electrolyte direct ethanol fuel cell based on a Pt-Sn anode catalyst. International Journal of Hydrogen Energy, v. 38, p. 11576-11582, 2013.

100 HSIEH, C. T.; LIU, Y. Y.; CHEN, W. Y.; HSIEH, Y. H. Electrochemical activity and durability of Pt-Sn alloys on carbon-based electrodes prepared by microwave- 
assisted synthesis. International Journal of Hydrogen Energy, v. 36, p. 1576615774, 2011.

101 BROOKINS, D. G. Eh-pH diagrams for the rare earth elements at $25{ }^{\circ} \mathrm{C}$ and one Bar pressure. Geochemical Journal, v. 17, p. 223-229, 1983.

102 SHAO, M. H.; ADZIC, R. R. Electrooxidation of ethanol on a Pt electrode in acid solutions: in situ ATR-SEIRAS study. Electrochimica Acta, v. 50, p. 2415-2422, 2005.

103 WANG, Q.; SUN, G. Q.; JIANG, L. H.; XIN, Q.; SUN, S. G.; JIANG, Y. X.; CHEN, S. P.; JUSYS, Z.; BEHM, R. J. Adsorption and oxidation of ethanol on colloid-based $\mathrm{Pt} / \mathrm{C}, \mathrm{PtRu} / \mathrm{C}$ and $\mathrm{Pt}_{3} \mathrm{Sn} / \mathrm{C}$ catalysts: In situ FTIR spectroscopy and on-line DEMS studies. Physical Chemistry Chemical Physics, v. 9, p. 2686-2696, 2007.

104 DELPEUCH, A. B.; MAILLARD, F.; CHATENET, M.; SOUDANT, P.; CREMERS, C. Ethanol oxidation reaction (EOR) investigation on $\mathrm{Pt} / \mathrm{C}, \mathrm{Rh} / \mathrm{C}$, and $\mathrm{Pt}$-based biand tri-metallic electrocatalysts: A DEMS and in situ FTIR study. Applied Catalysis B, v. 181, p. 672-680, 2016.

105 NART, F. C.; DE SOUZA, J. P. I.; QUEIROZ, S. L.; BERGAMASKI, K.; GONZALEZ, E. R. Electro-oxidation of ethanol on Pt, Rh, and PtRh electrodes. A study using DEMS and in-situ FTIR techniques. Journal of Physical Chemistry B, v. 106, p. 9825-9830, 2002.

106 WANG, Q.; SUN, G. Q.; CAO, L.; JIANG, L. H.; WANG, G. X.; WANG, S. L.; YANG, S. H.; XIN, Q. High performance direct ethanol fuel cell with double-layered anode catalyst layer. Journal of Power Sources, v. 177, p. 142-147, 2008.

107 ANTOLINI, E.; PEREZ, J.; PAGANIN, V. A. Particle size effect for ethanol electro-oxidation on $\mathrm{Pt} / \mathrm{C}$ catalysts in half-cell and in a single direct ethanol fuel cell. Journal of Electroanalytical Chemistry, v. 654, p. 108-115, 2011.

108 COLMATI, F.; ANTOLINI, E.; GONZALEZ, E. R. Ethanol oxidation on a carbonsupported $\mathrm{Pt}_{75} \mathrm{Sn}_{25}$ electrocatalyst prepared by reduction with formic acid: Effect of thermal treatment. Applied Catalysis B, v. 73, p. 106-115, 2007.

109 ANTOLINI, E.; COLMATI, F.; GONZALEZ, E. R. Ethanol oxidation on carbon supported (PtSn)alloy/SnO 2 and ( $\mathrm{PtSnPd}$ )alloy/SnO $\mathrm{Sn}_{2}$ catalysts with a fixed $\mathrm{Pt} / \mathrm{SnO}_{2}$ atomic ratio: Effect of the alloy phase characteristics. Journal of Power Sources, v. 193, p. 555-561, 2009. 
110 TANEDA, K.; YAMAZAKI, Y. Study of direct type ethanol fuel cells: Analysis of anode products and effect of acetaldehyde. Electrochimica Acta, v. 52, p. 16271631, 2006.

111 OLIVEIRA NETO, A.; WATANABE, A. Y.; BRANDALISE, M.; TUSI, M. M.; RODRIGUES, R. M. D. S.; LINARDI, M.; SPINACE, E. V.; FORBICINI, C. A. L. G. O. Preparation and characterization of Pt-rare earth/C electrocatalysts using an alcohol reduction process for methanol electro-oxidation. Journal of Alloys and Compounds, v. 476, p. 288-291, 2009.

112 COTTON, S. Lanthanide and actinide chemistry. New York: John Wiley 2006. $280 \mathrm{p}$.

113 FERRO, R.; SACCONE, A. Thermal analysis and alloy phase diagrams. Thermochimica Acta, v. 418, p. 23-32, 2004.

114 REIMANN, S.; SCHALLER, H. J. Constitution and thermodynamics of Pt-La alloys. Journal of Alloys and Compounds, v. 419, p. 133-139, 2006.

115 JANGHORBAN, A.; LOMELLO-TAFIN, M.; MOREAU, J. M.; GALEZ, P. The phase diagram of the Ce-Pt system. Intermetallics, v. 18, p. 2208-2218, 2010.

116 SCHNEIDER, W. D.; LAUBSCHAT, C.; NOWIK, I.; KAINDL, G. Shake-up excitations and core-hole screening in Eu systems. Physical Review B, v. 24, p. 5422-5425, 1981.

117 MULLICA, D. F.; LOK, C. K. C.; PERKINS, H. O.; YOUNG, V. X-Ray Photoelectron final-state screening in $\mathrm{La}(\mathrm{OH})_{3}$ - a multiplet structural-analysis.

Physical Review B, v. 31, p. 4039-4042, 1985.

118 SUNDING, M. F.; HADIDI, K.; DIPLAS, S.; LOVVIK, O. M.; NORBY, T. E.; GUNNAES, A. E. XPS characterisation of in situ treated lanthanum oxide and hydroxide using tailored charge referencing and peak fitting procedures. Journal of Electron Spectroscopy and Related Phenomena, v. 184, p. 399-409, 2011.

119 GURGUL, J.; RINKE, M. T.; SCHELLENBERG, I.; POTTGEN, R. The antimonide oxides REZnSbO and REMnSbO (RE = Ce, Pr) - An XPS study. Solid State Sciences, v. 17, p. 122-127, 2013.

120 BURROUGHS, P.; HAMNETT, A.; ORCHARD, A. F.; THORNTON, G. Satellite structure in X-Ray photoelectron-spectra of some binary and mixed oxides of 
lanthanum and cerium. Journal of the Chemical Society-Dalton Transactions, v. 17, p. 1686-1698, 1976.

121 SLEBARSKI, A.; NEUMANN, M.; MAHL, S. Electronic-structure of Pr in $\operatorname{PdPr}_{0.014}$. Physical Review B, v. 51, p. 11113-11116, 1995.

122 LOPEZ-CUDERO, A.; SOLLA-GULLON, J.; HERRERO, E.; ALDAZ, A.; FELIU, J. M. CO electrooxidation on carbon supported platinum nanoparticles: Effect of aggregation. Journal of Electroanalytical Chemistry, v. 644, p. 117-126, 2010.

123 WU, K.; SUN, L. D.; YAN, C. H. Recent progress in well-controlled synthesis of ceria-based nanocatalysts towards enhanced catalytic performance. Advanced Energy Materials, v. 6, p. 1-46, 2016.

124 SIMOES, F. C.; DOS ANJOS, D. M.; VIGIER, F.; LEGER, J. M.; HAHN, F.; COUTANCEAU, C.; GONZALEZ, E. R.; TREMILIOSI, G.; DE ANDRADE, A. R.; OLIVI, P.; KOKOH, K. B. Electroactivity of tin modified platinum electrodes for ethanol electrooxidation. Journal of Power Sources, v. 167, p. 1-10, 2007.

125 HOLADE, Y.; SERVAT, K.; NAPPORN, T. W.; KOKOH, K. B. Electrocatalytic properties of nanomaterials synthesized from "Bromide Anion Exchange" method Investigations of glucose and glycerol oxidation. Electrochimica Acta, v. 162, p. 205-214, 2015. 


\section{APÊNDICE I}

\section{RESUMO DE ATIVIDADES DURANTE O ESTÁGIO NO EXTERIOR}

O Institut de Chimie des Milieux et Matériaux de Poitiers é conhecido pelo seu conhecimento e experiência na síntese de nanomateriais e por isso foi escolhido para o estágio. O projeto intitulado "New routes for Pt-Sn-Eu/C catalysts for ethanol oxidation reaction" foi proposto para avaliar diferentes rotas sintéticas para obtenção de catalisadores trimetálicos Pt-Sn-Eu, para aplicação em reação de oxidação de etanol (ROE) em meio alcalino. PtSn/C e PtSnEu/C foram obtidos de duas rotas diferentes: o método do Bromide Anion Exchange (BAE) e por poliol assistido por micro-ondas (PMW). Catalisadores trimetálicos Pt-Sn-TR/C (TR: La, Ce e Pr) também foram obtidos, apenas rota BAE.

Por medidas de ICP, verificou-se a presença de platina, estanho e terras raras nos catalisadores obtidos por ambos os métodos. Pela análise de DRX, não foi possível observar a formação de liga Pt-Sn ou Pt-Terras Raras sintetizados por PMW e BAE. Provavelmente, estanho e os metais terras raras são encontrados na forma de óxidos e oxi-hidróxidos amorfos. A área ativa dos catalisadores, determinado por stripping de $\mathrm{CO}$, e as densidades de corrente para ROE são maiores para catalisadores obtidos por BAE, comparados aos obtidos por PMW. Por FTIR, foi possível confirmar que os catalisadores obtidos por PMW não são favoráveis à oxidação completa do etanol, enquanto para os catalisadores obtidos por BAE promoveram formação de $\mathrm{CO}_{2}$. As diferenças das atividades observadas por diferentes rotas sintéticas provavelmente estão correlacionadas com mudanças eletrônicas e geométricas, que afetaram ROE em meio alcalino. 


\section{APÊNDICE II}

Figura A1. Curva de calibração para os compostos na coluna HPX87H (BIO-RAD, modelo Aminex de $300 \mathrm{~mm}$ de comprimento e $7,8 \mathrm{~mm}$ de diâmetro). (a) Ácido acético e (b) acetaldeído foram identificados pelo detector UV, com comprimento de onda de $240 \mathrm{~nm}$. Para (c) etanol e (d) carbonato $\left(\mathrm{CO}_{3}{ }^{2-}\right)$, o detector utilizado foi o índice de refração.
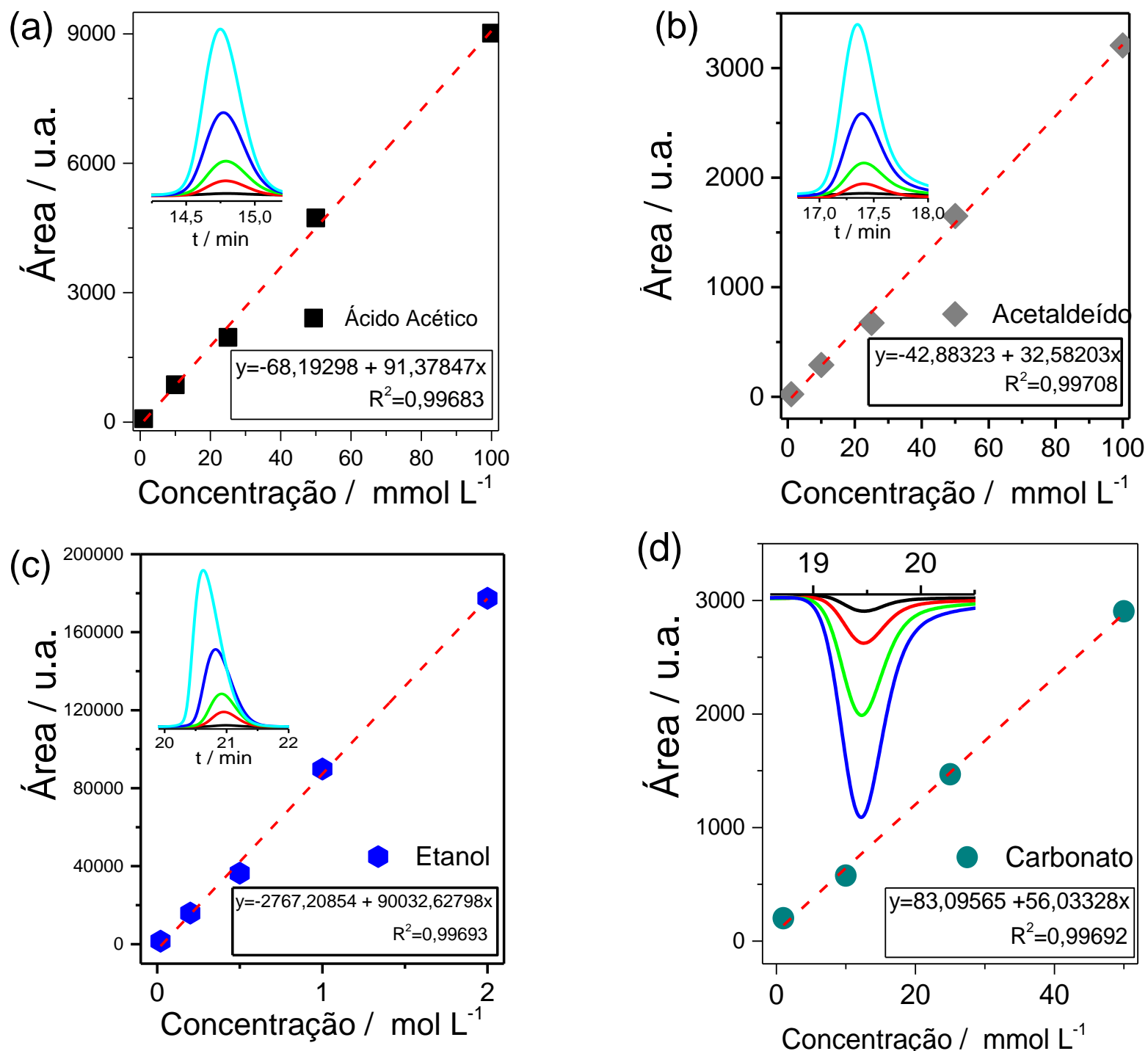

Concentração / $\mathrm{mmol} \mathrm{L}^{-1}$ 